\title{
The effect of enteral nutrition in colorectal surgery
}

Citation for published version (APA):

Smeets, B. JJ. (2019). The effect of enteral nutrition in colorectal surgery. [Doctoral Thesis, Maastricht University]. GVO drukkers \& vormgevers B.V. https://doi.org/10.26481/dis.20191218bs

Document status and date:

Published: 01/01/2019

DOI:

10.26481/dis.20191218bs

Document Version:

Publisher's PDF, also known as Version of record

\section{Please check the document version of this publication:}

- A submitted manuscript is the version of the article upon submission and before peer-review. There can be important differences between the submitted version and the official published version of record.

People interested in the research are advised to contact the author for the final version of the publication, or visit the DOI to the publisher's website.

- The final author version and the galley proof are versions of the publication after peer review.

- The final published version features the final layout of the paper including the volume, issue and page numbers.

Link to publication

\footnotetext{
General rights rights.

- You may freely distribute the URL identifying the publication in the public portal. please follow below link for the End User Agreement:

www.umlib.nl/taverne-license

Take down policy

If you believe that this document breaches copyright please contact us at:

repository@maastrichtuniversity.nl

providing details and we will investigate your claim.
}

Copyright and moral rights for the publications made accessible in the public portal are retained by the authors and/or other copyright owners and it is a condition of accessing publications that users recognise and abide by the legal requirements associated with these

- Users may download and print one copy of any publication from the public portal for the purpose of private study or research.

- You may not further distribute the material or use it for any profit-making activity or commercial gain

If the publication is distributed under the terms of Article $25 \mathrm{fa}$ of the Dutch Copyright Act, indicated by the "Taverne" license above, 


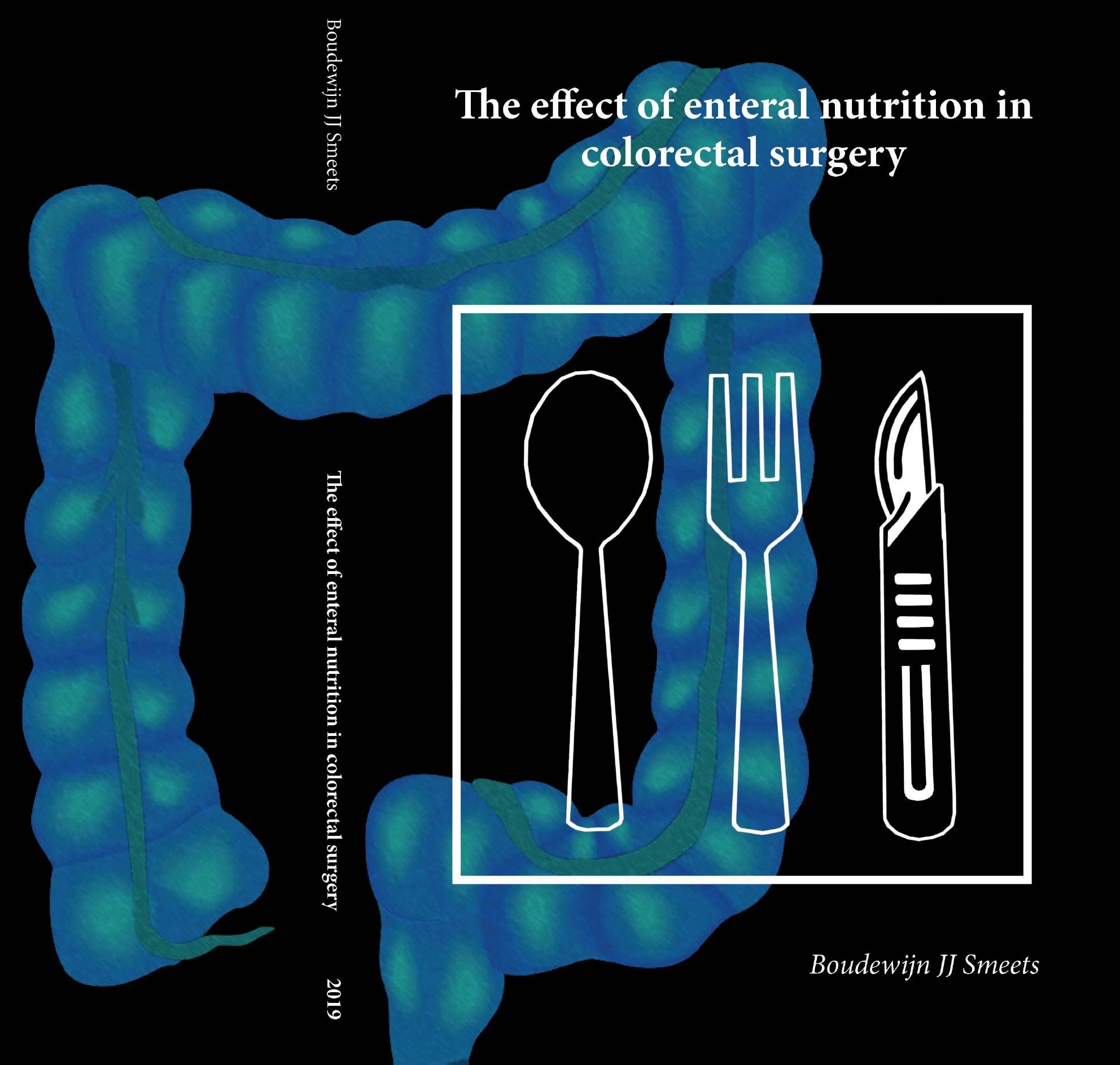




\section{The effect of enteral nutrition in colorectal surgery}




\section{Colofon}

(C) Copyright Boudewijn J.J. Smeets, Maastricht, 2019.

All rights reserved. No part of this book may be reproduced or transmitted in any form or by any means, without prior permission in writing by the author, or when appropriate, by the publishers of the publications.

ISBN 978-94-6332-580-6

Cover: Harry Kengen

Layout: Tiny Wouters

Production: GVO Drukkers en Vormgevers BV 
I gratefully acknowledge that the creation of this thesis was supported by Maastricht University, Catharina Hospital Eindhoven, Máxima Medical Centre Veldhoven, ZonMW, the Nederlandse Vereniging voor Endoscopische Chirurgie (NVEC), ChipSoft, Nutricia, Fonds Nuts Ohra, Fresenius Kabi, Rabobank Regio Eindhoven.

\section{Doastricht \\ University}

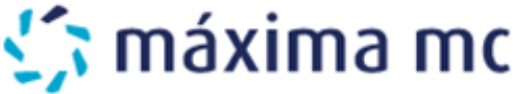

\section{NUTRICIA Advanced Medical Nutrition}

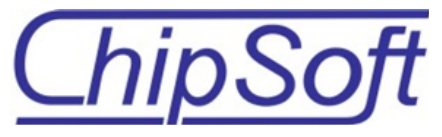

\section{Rabobank}

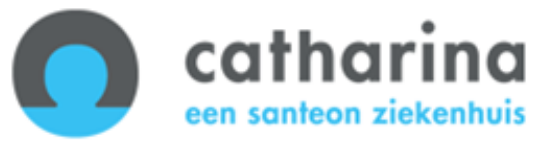

\section{ZonMw}

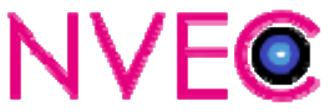

MS FRESENIUS

1 KABI

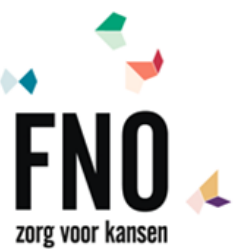





\section{The effect of enteral nutrition in colorectal surgery}

PROEFSCHRIFT

ter verkrijging van de graad van doctor aan de Universiteit Maastricht, op gezag van de Rector Magnificus, Prof.dr. Rianne M. Letschert volgens het besluit van het College van Decanen, in het openbaar te verdedigen

op woensdag 18 december 2019 om 12.00 uur

door

Boudewijn Jacobus Joseph Smeets 


\section{Promotor}

Prof. dr. H.J.T. Rutten

\section{Copromotores}

Dr. M.D.P. Luyer, Catharina Ziekenhuis, Eindhoven

Dr. P.G. Boelens, Rijndam Revalidatie, Rotterdam

\section{Beoordelingscommissie}

Prof. dr. L.P.S. Stassen (voorzitter)

Prof. dr. G.L. Beets

Dr. J.W.T. Dekker, Reinier de Graaf Gasthuis, Delft

Prof. dr. A. Masclee

Prof. dr. J.H.W. de Wilt, Radboud Universitair Medisch Centrum, Nijmegen 


\section{Contents}

Chapter 1 Introduction 9

Chapter 2 Effect of early vs late start of oral intake on anastomotic 23 leakage following elective lower intestinal surgery: a systematic review

Chapter 3 Beneficial effects of early enteral nutrition after major rectal surgery: A possible role for conditionally essential amino acids? Results of a randomized clinical trial

Chapter 4 Anti-oxidative amino acids in early enteral versus parenteral nutrition following major rectal surgery patients randomized to early enteral versus parenteral nutrition following major rectal surgery

Chapter 6 The effect of myopenia on the inflammatory response early after colorectal surgery

Chapter 7 The effects of stimulation of the autonomic nervous system via perioperative nutrition on postoperative ileus and anastomotic leakage following colorectal surgery (SANICS II trial): a study protocol for a double-blind randomized controlled trial

Chapter 8 Perioperative lipid-enriched enteral nutrition versus standard 117 care in patients undergoing elective colorectal surgery (SANICS II): a multicentre, double-blind, randomised controlled trial

Chapter 9 Nutritional interventions to improve recovery from postoperative ileus

Chapter 10 Summary, general discussion, and future perspectives

Valorisation

Nederlandse samenvatting

Publications

Curriculum vitae

Dankwoord 



\section{Chapter 1}

General introduction 



\section{Introduction}

The incidence of colorectal cancer has risen in the Netherlands over the last decade. Currently over 13,000 people are diagnosed with colorectal cancer each year. ${ }^{1}$ The introduction of a nationwide screening program for colorectal cancer in 2014 has resulted in an increased number of patients diagnosed with colorectal cancer, and will have a subsequent effect on treatment and disease-associated mortality in the next years. ${ }^{2,3}$ The growing number of patients with an early, curable stage of colorectal cancer is likely to increase the number of patients undergoing colorectal surgery. Since colorectal surgery is associated with a risk of postoperative complications ranging from 24 to $57 \%$, it is crucial to minimize these complications as much as possible.4,5 Furthermore, the effects of complications following colorectal surgery are not limited to the short-term, but may also have a detrimental effect on long-term outcomes and societal outcomes. For example, postoperative complications are associated with increased healthcare costs and negatively affect quality of life several months after colorectal surgery.4,6-8 In addition, the occurrence of postoperative complications has been shown to affect cancer survival rates up to 5 years after surgery. ${ }^{9-11}$ As such, efforts to reduce postoperative complications are needed to improve both short- and long-term outcomes following colorectal surgery.

\section{The surgical stress response}

The inflammatory stress response is an essential part of surgery and is an important determinant of postoperative recovery.12,13 From an evolutionary point of view, this stress response protects the host from injury and infection-related morbidity by maintaining plasma volume, mobilizing energy reserves, and providing substrates required for the immune response. However, the stress response may also be counterproductive and can impair postoperative recovery by inducing hyperglycemia, catabolism, and immunosuppression. ${ }^{13}$

The stress response upon surgery is initiated and modulated via a complex cascade of multiple inflammatory mediators following tissue damage. ${ }^{13-17}$ While these components all act simultaneously and interactively, they may be categorized in a neuro-endocrinological, immunological, and metabolic response. In the neuroendocrinological response, neuropeptides are released from affected body regions that activate the hypothalamic-pituitary-adrenal axis. Subsequent release of hormones such as corticotrophin and cortisol mobilize energy stores and set the body in the flight-or-fight mode. ${ }^{18,19}$ The immunological response involves a cascade of pro-inflammatory mediators including tumor necrosis factor (TNF)- $\alpha$ and interleukins that modify immune function after being released by principal and secondary inflammatory cells such as mast cells, macrophages, and neutrophilic 
granulocytes. ${ }^{14}$ The metabolic response is mainly characterized by hyperglycemia that develops via cortisol-induced hepatic gluconeogenesis and peripheral insulin resistance following reduced activation of the glucose transporter-4 (GLUT-4) protein. The reduced effect of intracellular insulin mediates the catabolic breakdown of muscle proteins into amino acids, which in turn are used for hepatic gluconeogenesis. ${ }^{18,20-22}$

An uncontrolled stress response may have adverse effects and it has been shown that an excessive early inflammatory response is associated with a greater risk of postoperative complications. ${ }^{17,23-28}$ Moreover, an uncontrolled metabolic response can result in a net catabolic state with uncorrected hyperglycemia, which is associated with an increased risk of infectious complications, prolonged hospital stay, and increased mortality. ${ }^{29-33}$ In cells that have no active glucose transport mechanisms, the hyperglycaemic state leads to higher intracellular glucose concentrations, resulting in the production of harmful oxygen radicals and inflammation. ${ }^{18,34}$

\section{Modulation of the surgical stress response - development of Enhanced Recovery Protocols}

Several perioperative elements contribute to the magnitude of the surgical stress response, including degree of surgical trauma, fasting, and bed rest. ${ }^{18,35-42}$ To improve outcomes and minimize surgical stress, the multimodal Enhanced Recovery After Surgery (ERAS) protocols were introduced.43-46 These protocols include for example carbohydrate loading, minimally invasive surgical techniques, early postoperative mobilization, and early oral feeding. ${ }^{47}$ The combined implementation of all ERAS components is thought to have the optimal effect on postoperative recovery. ${ }^{5,43,46-50}$ In addition, some components of the program have been shown to be individually effective in improving postoperative outcomes and attenuating surgical stress, such as minimally invasive surgery. ${ }^{51-64}$

In spite of ERAS protocols, the overall incidence of complications following colorectal surgery remains high. ${ }^{5}$ To further improve perioperative protocols, other factors may be identified that affect the surgical stress response. For example, decreased skeletal muscle mass (termed sarcopenia or myopenia) may increase the risk of complications by affecting the systemic inflammation. ${ }^{65-67}$ However, the effect of myopenia on the early postoperative inflammatory response is unclear and needs to be further elucidated. In addition, it may be beneficial to preserve skeletal muscle mass by enrolling surgical patients in a prehabilitation program with physiotherapy and nutritional counseling. ${ }^{68-70}$ 


\section{Modulating the surgical stress response by vagus nerve stimulation}

While ERAS protocols are considered as a means to reduce surgical stress by minimizing the inciting inflammatory events, additional strategies may be employed to actively dampen early inflammation. Experimental studies have explored the potential benefits of dampening the inflammatory response by means of vagus nerve stimulation (VNS). Specifically, VNS can mitigate inflammation via release of acetylcholine from efferent vagus nerve fibers. Acetylcholine then binds to alpha-7-nicotinic receptors that are located on mast cells and macrophages in the gut wall, limiting the release of pro-inflammatory mediators (i.e. the cholinergic anti-inflammatory pathway).71-76 In addition, vagus nerve efferents are hypothesized to activate adrenergic neurons projecting to the spleen via the celiac ganglion. These adrenergic neurons then release norepinephrine which in turn binds to splenic acetylcholine-synthesizing T-cells. Subsequent release of acetylcholine may then reduce the production of cytokines by splenic macrophages, ultimately mitigating systemic inflammation. ${ }^{74,77}$

\section{Inflammation and postoperative ileus}

The inflammatory response plays a pivotal role in the development of postoperative ileus (POI) (Figure 1.1). POI is a common complication in colorectal surgery and a major contributor to postoperative morbidity, prolonged hospital stay, and healthcare costs..$^{78-82}$ The etiology of POI consists of an initial neurogenic phase lasting several hours, and a second, more clinically relevant inflammatory phase that may last up to days or weeks. ${ }^{83,84}$ The inflammatory phase is initiated by intestinal manipulation by the surgeon, which results in activation of resident macrophages in the myenteric plexus and peritoneal mast cell degranulation. 85,86 The subsequent production of pro-inflammatory cytokines (e.g. TNF- $\alpha$, interleukin (IL)-1 $\beta$, IL-6) induces chemotaxis by upregulation of adhesion molecules (ICAM-1) in the endothelium. The intestinal muscularis is then invaded by leukocytes that release nitric oxide and prostaglandins, resulting in impaired smooth muscle cell contractility. In addition, T-helper 1 memory cells are activated that migrate away from the manipulated gut segments. These cells are then recirculated to the whole gastrointestinal tract, contributing to panenteric inflammation and a general paralysis of the entire gastrointestinal tract, which is an important clinical aspect of POI. 86

Given the pivotal role of inflammation in the development of POI, experimental and pre-clinical trials further investigated the anti-inflammatory effect of VNS in relation to POI. In experimental studies, electrical VNS has been shown to reduce cytokine production in mice and recently also in human subjects. ${ }^{76,87}$ However, a concomitant reduction of POI has thus far only been demonstrated in mice. ${ }^{87}$ While electrical VNS is currently being investigated in a clinical setting (NCT 02524626), 
it remains an invasive intervention and may not always be feasible in a clinical setting.

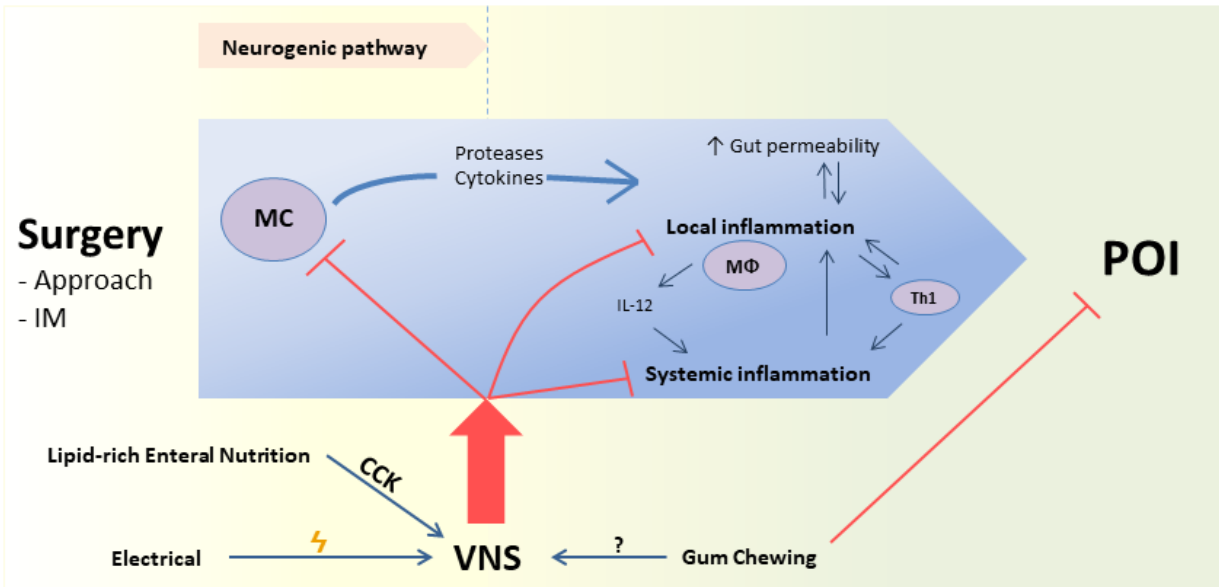

Figure 1.1: Neuro-immunological processes in postoperative ileus (POI). Surgical components trigger a neurogenic and inflammatory response in the gut wall. This includes, but is not limited to, activation of mast cells, which via degranulation and secretion of pro-inflammatory substances contribute to local and systemic inflammation. Next to increased gut permeability, this eventually leads to generalized hypomotility of the enteric system. Vagus nerve stimulation is proposed to dampen this response, either via nutrition, cephalic activation, or direct electrical impulses. CCK, cholecystokinin; IL, interleukin; IM, intestinal manipulation; MC, mast cell; MФ, macrophage; POI, postoperative ileus; Th1, T-helper 1 cell; VNS, vagus nerve stimulation. Adapted with permission from ${ }^{86}$.

\section{Enteral nutrition to reduce postoperative complications?}

Enteral nutrition may be a more physiological means to stimulate the vagus nerve and thereby reduce postoperative complications. Several studies have demonstrated that enteral nutrition triggers release of cholecystokinin (CCK) that binds to CCK-1 receptors on vagal afferents, subsequently limiting the inflammatory response. ${ }^{73,88-90}$ Attenuation of the inflammatory response by administrating high-fat enteral nutrition has been shown to improve gastrointestinal transit in a murine model of POI. ${ }^{91}$ The anti-inflammatory effects of enteral nutrition were substantiated in a human endotoxemia model, in which continuous administration of lipid-enriched enteral nutrition reduced production of pro-inflammatory cytokines following a bolus LPS-injection after an overnight fast. ${ }^{92}$ Timing and composition were essential for the magnitude of the effect; lipidenriched nutrition given just before, during, and directly after the inciting inflammatory event provided the optimal effect. 
In contrast to these experimental findings, in a clinical setting the exact effect of enteral nutrition on inflammation or specific complications is unclear. Immunonutrition has been suggested to reduce infectious complications by enhancing the immune response to surgery. However, the pooled results of different randomized trials are not generalizable given the heterogeneous compositions of the included formulas. ${ }^{93-97}$ Next, early postoperative enteral feeding is an essential part of ERAS protocols and is independently associated with improved recovery. ${ }^{98}$ In several meta-analyses, early enteral nutrition was associated with a significant reduction of overall complications, length of hospital stay, and even mortality. ${ }^{99-102}$ However, these studies are heterogeneous and of limited methodological quality. For POI, existing trials show inconsistent effects on surrogate markers of gastrointestinal motility.

As stated before, timing (i.e. directly before, during, and after surgery) was essential for the beneficial effect of enteral nutrition in experimental studies. ${ }^{92}$ However, current anesthesia guidelines strictly prohibit enteral feeding just before and during surgery to minimize risk of aspiration. To safely investigate the potentially beneficial effect of perioperative enteral nutrition in a clinical setting, our group previously performed a randomized controlled trial in patients undergoing open colorectal surgery using chewing gum (sham feeding). In this single-blind study, patients were randomized to gum chewing or placebo just before and directly after surgery. Remarkably, it was found that gum chewing reduced not only POI and postoperative inflammatory markers, but also anastomotic leakage (AL) when compared to the placebo control group. ${ }^{103}$ Similar results were found in a second study performed in patients undergoing major surgery for locally advanced or recurrent rectal cancer. In this study, the incidence of POI and AL was lower in patients who were randomized to receive early enteral nutrition compared to patients who received early parenteral nutrition. ${ }^{104}$

Although a beneficial effect of enteral nutrition on AL was previously demonstrated in some animal studies ${ }^{105-111}$, the finding that both POI and AL were reduced by means of a nutritional intervention in two independent clinical studies was new. Generally, therapeutic strategies to reduce AL are lacking, and in spite of scientific efforts AL remains a major contributor to overall morbidity and mortality following colorectal surgery. ${ }^{112-115}$ A post-hoc analysis demonstrated that POI and AL were significantly associated with one another, which may suggest similarities in their respective pathogeneses. ${ }^{116}$ However, while an uncontrolled inflammatory response may indeed play a role in the development of $\mathrm{AL}^{117,118}$, the exact pathophysiology is yet to be fully understood. 


\section{Aims of this thesis}

Based on the beneficial effects of enteral nutrition demonstrated in experimental and preclinical studies, we aimed to investigate the effects of enteral nutrition on markers of the surgical stress response and postoperative complications (in particular POI and AL) in a clinical setting. To this end, we first performed a critical appraisal of existing literature on the effects of enteral nutrition on postoperative complications (Chapter 2). Next, the physiological mechanisms underlying the observed beneficial effects of enteral nutrition on POI and AL following major rectal surgery were further investigated in Chapters 3-5. To identify other factors that may hinder recovery by affecting the surgical stress response, the effect of myopenia on early postoperative inflammatory markers was investigated in Chapter 6. In Chapters 7-8, a randomized controlled trial is described in which the beneficial effects of perioperative lipid-enriched nutrition in a clinical setting was investigated. Finally, in Chapter 9 a comprehensive review was performed to describe current insights in nutritional interventions to reduce POI. 


\section{References}

1. Integraal Kankercentrum Nederland (IKNL). Cijfers over kanker. Available at: https://www.cijfersoverkanker.nl/. Accessed 08 Mar 2018.

2. Elferink MA, van der Vlugt M, Meijer GA, Lemmens VE, Dekker E. Colorectal carcinoma in the Netherlands: the situation before and after population surveillance. Ned Tijdschr Geneeskd. 2014;158:A7699.

3. Elferink MAG, Toes-Zoutendijk E, Vink GR, Lansdorp-Vogelaar I, Meijer GA, Dekker E, et al. [National population screening for colorectal carcinoma in the Netherlands: results of the first years since the implementation in 2014]. Ned Tijdschr Geneeskd. 2018;162(0):D2283.

4. Govaert JA, Fiocco M, van Dijk WA, Scheffer AC, de Graaf EJ, Tollenaar RA, et al. Costs of complications after colorectal cancer surgery in the Netherlands: Building the business case for hospitals. Eur J Surg Oncol. 2015;41(8):1059-67.

5. Spanjersberg WR, Reurings J, Keus F, van Laarhoven CJ. Fast track surgery versus conventional recovery strategies for colorectal surgery. The Cochrane database of systematic reviews. 2011(2):CD007635.

6. Bloemen JG, Visschers RG, Truin W, Beets GL, Konsten JL. Long-term quality of life in patients with rectal cancer: association with severe postoperative complications and presence of a stoma. Dis Colon Rectum. 2009;52(7):1251-8.

7. Bosma E, Pullens MJ, de Vries J, Roukema JA. The impact of complications on quality of life following colorectal surgery: a prospective cohort study to evaluate the Clavien-Dindo classification system. Colorectal Dis. 2016;18(6):594-602.

8. Regenbogen SE, Veenstra CM, Hawley ST, Banerjee M, Ward KC, Kato I, et al. The personal financial burden of complications after colorectal cancer surgery. Cancer. 2014;120(19):3074-81.

9. Breugom AJ, van Dongen DT, Bastiaannet E, Dekker FW, van der Geest LG, Liefers GJ, et al. Association between the most frequent complications after surgery for stage I-III colon cancer and short-term survival, long-term survival, and recurrences. Ann Surg Oncol. 2016;23(9): 2858-65.

10. Dekker JW, Gooiker GA, Bastiaannet E, van den Broek CB, van der Geest LG, van de Velde CJ, et al. Cause of death the first year after curative colorectal cancer surgery; a prolonged impact of the surgery in elderly colorectal cancer patients. Eur J Surg Oncol. 2014;40(11):1481-7.

11. Gooiker GA, Dekker JW, Bastiaannet E, van der Geest LG, Merkus JW, van de Velde CJ, et al. Risk factors for excess mortality in the first year after curative surgery for colorectal cancer. Ann Surg Oncol. 2012;19(8):2428-34.

12. Wilmore DW. Metabolic response to severe surgical illness: overview. World J Surg. 2000;24(6): 705-11.

13. Gillis C, Carli F. Promoting Perioperative Metabolic and Nutritional Care. Anesthesiology. 2015;123(6):1455-72.

14. Nathan C. Points of control in inflammation. Nature. 2002;420(6917):846-52.

15. Burton D, Nicholson G, Hall G. Endocrine and metabolic response to surgery. Continuing Education in Anaesthesia Critical Care \& Pain. 2004;4(5):144-7.

16. Desborough JP. The stress response to trauma and surgery. Br J Anaesth. 2000;85(1):109-17.

17. Alazawi W, Pirmadjid N, Lahiri R, Bhattacharya S. Inflammatory and immune responses to surgery and their clinical impact. Ann Surg. 2016;264(1):73-80.

18. Carli F. Physiologic considerations of Enhanced Recovery After Surgery (ERAS) programs: implications of the stress response. Can J Anaesth. 2015;62(2):110-9.

19. Finnerty CC, Mabvuure NT, Ali A, Kozar RA, Herndon DN. The surgically induced stress response. JPEN J Parenter Enteral Nutr. 2013;37(5 Suppl):21S-9S.

20. Thorell A, Nygren J, Hirshman MF, Hayashi T, Nair KS, Horton ES, et al. Surgery-induced insulin resistance in human patients: relation to glucose transport and utilization. Am J Physiol. 1999; 276(4 Pt 1):E754-61.

21. Ljungqvist O, Nygren J, Thorell A. Insulin resistance and elective surgery. Surgery. 2000;128(5): 757-60. 
22. Brownlee M. The pathobiology of diabetic complications: a unifying mechanism. Diabetes. 2005; 54(6):1615-25.

23. Podgoreanu MV, Michelotti GA, Sato Y, Smith MP, Lin S, Morris RW, et al. Differential cardiac gene expression during cardiopulmonary bypass: ischemia-independent upregulation of proinflammatory genes. J Thorac Cardiovasc Surg. 2005;130(2):330-9.

24. Rettig TC, Verwijmeren L, Dijkstra IM, Boerma D, van de Garde EM, Noordzij PG. Postoperative interleukin-6 level and early detection of complications after elective major abdominal surgery. Ann Surg. 2016;263(6):1207-12.

25. Chuang D, Paddison JS, Booth RJ, Hill AG. Differential production of cytokines following colorectal surgery. ANZ J Surg. 2006;76(9):821-4.

26. McSorley ST, Horgan PG, McMillan DC. The impact of preoperative corticosteroids on the systemic inflammatory response and postoperative complications following surgery for gastrointestinal cancer: A systematic review and meta-analysis. Crit Rev Oncol Hematol. 2016; 101:139-50.

27. Marik PE, Flemmer M. The immune response to surgery and trauma: Implications for treatment. J Trauma Acute Care Surg. 2012;73(4):801-8.

28. Szczepanik AM, Scislo L, Scully T, Walewska E, Siedlar M, Kolodziejczyk P, et al. IL-6 serum levels predict postoperative morbidity in gastric cancer patients. Gastric cancer. 2011;14(3):266-73.

29. Thorell A, Nygren J, Ljungqvist O. Insulin resistance: a marker of surgical stress. Curr Opin Clin Nutr Metab Care. 1999;2(1):69-78.

30. Sato H, Carvalho G, Sato T, Lattermann R, Matsukawa T, Schricker T. The association of preoperative glycemic control, intraoperative insulin sensitivity, and outcomes after cardiac surgery. J Clin Endocrinol Metab. 2010;95(9):4338-44.

31. Krinsley JS. Association between hyperglycemia and increased hospital mortality in a heterogeneous population of critically ill patients. Mayo Clin Proc. 2003;78(12):1471-8.

32. Scott MJ, Baldini G, Fearon KC, Feldheiser A, Feldman LS, Gan T], et al. Enhanced Recovery After Surgery (ERAS) for gastrointestinal surgery, part 1: pathophysiological considerations. Acta Anaesthesiol Scand. 2015;59(10):1212-31.

33. Kwon S, Thompson R, Dellinger P, Yanez D, Farrohki E, Flum D. Importance of perioperative glycemic control in general surgery: a report from the Surgical Care and Outcomes Assessment Program. Ann Surg. 2013;257(1):8-14.

34. Ljungqvist 0 , Nygren J, Soop M, Thorell A. Metabolic perioperative management: novel concepts. Curr Opin Crit Care. 2005;11(4):295-9.

35. Thorell A, Efendic S, Gutniak M, Haggmark T, Ljungqvist O. Development of postoperative insulin resistance is associated with the magnitude of operation. Eur J Surg. 1993;159(11-12):593-9.

36. Prete A, Yan Q, Al-Tarrah K, Akturk HK, Prokop LJ, Alahdab F, et al. The cortisol stress response induced by surgery: a systematic review and meta-analysis. Clin Endocrinol. 2018;89(5):554-67.

37. Awad S, Constantin-Teodosiu D, Macdonald IA, Lobo DN. Short-term starvation and mitochondrial dysfunction - a possible mechanism leading to postoperative insulin resistance. Clin Nutr. 2009;28(5):497-509.

38. Ljungqvist $\mathrm{O}$, Boija PO, Esahili $\mathrm{H}$, Larsson $\mathrm{M}$, Ware J. Food deprivation alters liver glycogen metabolism and endocrine responses to hemorrhage. Am J Physiol. 1990;259(5 Pt 1):E692-8.

39. Nygren J. The metabolic effects of fasting and surgery. Best Pract Res Clin Anaesth. 2006;20(3): 429-38.

40. Svanfeldt M, Thorell A, Brismar K, Nygren J, Ljungqvist O. Effects of 3 days of "postoperative" low caloric feeding with or without bed rest on insulin sensitivity in healthy subjects. Clin Nutr. 2003;22(1):31-8.

41. Greisen J, Juhl CB, Grofte T, Vilstrup H, Jensen TS, Schmitz O. Acute pain induces insulin resistance in humans. Anesthesiology. 2001;95(3):578-84.

42. Brower RG. Consequences of bed rest. Crit Care Med. 2009;37(10 Suppl):S422-8.

43. Lassen K, Soop M, Nygren J, Cox PB, Hendry PO, Spies C, et al. Consensus review of optimal perioperative care in colorectal surgery: Enhanced Recovery After Surgery (ERAS) Group recommendations. Arch Surg. 2009;144(10):961-9. 
44. Ljungqvist O. Jonathan E. Rhoads lecture 2011: Insulin resistance and enhanced recovery after surgery. JPEN J Parenter Enteral Nutr. 2012;36(4):389-98.

45. Venara A, Duchalais E, Dariel A, Aubert P, Durand T, Meurette G, et al. Anti-inflammatory effects of enhanced recovery programs on early-stage colorectal cancer surgery. World J Surg. 2018; 42(4):953-64.

46. Ren L, Zhu D, Wei Y, Pan X, Liang L, Xu J, et al. Enhanced Recovery After Surgery (ERAS) program attenuates stress and accelerates recovery in patients after radical resection for colorectal cancer: a prospective randomized controlled trial. World J Surg. 2012;36(2):407-14.

47. Ljungqvist O, Scott M, Fearon KC. Enhanced recovery after surgery: a review. JAMA Surg. 2017; 152(3):292-8.

48. Varadhan KK, Neal KR, Dejong CH, Fearon KC, Ljungqvist O, Lobo DN. The enhanced recovery after surgery (ERAS) pathway for patients undergoing major elective open colorectal surgery: a metaanalysis of randomized controlled trials. Clin Nutr. 2010;29(4):434-40.

49. Greco M, Capretti G, Beretta L, Gemma M, Pecorelli N, Braga M. Enhanced recovery program in colorectal surgery: a meta-analysis of randomized controlled trials. World J Surg. 2014;38(6): 1531-41.

50. Barbieux J, Hamy A, Talbot MF, Casa C, Mucci S, Lermite E, et al. Does enhanced recovery reduce postoperative ileus after colorectal surgery? J Visc Surg. 2017;154(2):79-85.

51. Pascual M, Alonso S, Pares D, Courtier R, Gil MJ, Grande L, et al. Randomized clinical trial comparing inflammatory and angiogenic response after open versus laparoscopic curative resection for colonic cancer. Br J Surg. 2011;98(1):50-9.

52. Sammour T, Kahokehr A, Chan S, Booth RJ, Hill AG. The humoral response after laparoscopic versus open colorectal surgery: a meta-analysis. J Surg Res. 2010;164(1):28-37.

53. Huang C, Huang R, Jiang T, Huang K, Cao J, Qiu Z. Laparoscopic and open resection for colorectal cancer: an evaluation of cellular immunity. BMC Gastroenterol. 2010;10:127.

54. Veenhof AA, Sietses C, von Blomberg BM, van Hoogstraten IM, vd Pas MH, Meijerink WJ, et al. The surgical stress response and postoperative immune function after laparoscopic or conventional total mesorectal excision in rectal cancer: a randomized trial. Int J Colorectal Dis. 2011;26(1): 53-9.

55. Veenhof AA, Vlug MS, van der Pas MH, Sietses C, van der Peet DL, de Lange-de Klerk ES, et al. Surgical stress response and postoperative immune function after laparoscopy or open surgery with fast track or standard perioperative care: a randomized trial. Ann Surg. 2012;255(2): 216-21.

56. van Bree SH, Vlug MS, Bemelman WA, Hollmann MW, Ubbink DT, Zwinderman AH, et al. Faster recovery of gastrointestinal transit after laparoscopy and fast-track care in patients undergoing colonic surgery. Gastroenterology. 2011;141(3):872-80 e1-4.

57. Schricker T, Meterissian S, Wykes L, Eberhart L, Lattermann R, Carli F. Postoperative protein sparing with epidural analgesia and hypocaloric dextrose. Ann Surg. 2004;240(5):916-21.

58. Barr J, Boulind C, Foster JD, Ewings P, Reid J, Jenkins JT, et al. Impact of analgesic modality on stress response following laparoscopic colorectal surgery: a post-hoc analysis of a randomised controlled trial. Tech Coloproctol. 2015;19(4):231-9.

59. Day AR, Smith RV, Scott MJ, Fawcett WJ, Rockall TA. Randomized clinical trial investigating the stress response from two different methods of analgesia after laparoscopic colorectal surgery. Br J Surg. 2015;102(12):1473-9.

60. Awad S, Varadhan KK, Ljungqvist O, Lobo DN. A meta-analysis of randomised controlled trials on preoperative oral carbohydrate treatment in elective surgery. Clin Nutr. 2013;32(1):34-44.

61. Smith MD, McCall J, Plank L, Herbison GP, Soop M, Nygren J. Preoperative carbohydrate treatment for enhancing recovery after elective surgery. The Cochrane database of systematic reviews. 2014(8):CD009161.

62. Ljungqvist 0 . Randomized clinical trial to compare the effects of preoperative oral carbohydrate versus placebo on insulin resistance after colorectal surgery (Br J Surg 2010; 97: 317-327). Br J Surg. 2010;97(3):327.

63. Nygren J, Soop M, Thorell A, Efendic S, Nair KS, Ljungqvist O. Preoperative oral carbohydrate administration reduces postoperative insulin resistance. Clin Nutr. 1998;17(2):65-71. 
64. Watt DG, McSorley ST, Horgan PG, McMillan DC. Enhanced recovery after surgery: which components, if any, impact on the systemic inflammatory response following colorectal surgery?: a systematic review. Medicine. 2015;94(36):e1286.

65. Simonsen C, de Heer P, Bjerre ED, Suetta C, Hojman P, Pedersen BK, et al. Sarcopenia and postoperative complication risk in gastrointestinal surgical oncology: a meta-analysis. Ann Surg. 2018;268(1):58-69.

66. Reisinger KW, Derikx JP, van Vugt JL, Von Meyenfeldt MF, Hulsewe KW, Olde Damink SW, et al. Sarcopenia is associated with an increased inflammatory response to surgery in colorectal cancer. Clin Nutr. 2016;35(4):924-7.

67. Malietzis G, Johns N, Al-Hassi HO, Knight SC, Kennedy RH, Fearon KC, et al. Low muscularity and myosteatosis is related to the host systemic inflammatory response in patients undergoing surgery for colorectal cancer. Ann Surg. 2016;263(2):320-5.

68. Gillis C, Buhler K, Bresee L, Carli F, Gramlich L, Culos-Reed N, et al. Effects of nutritional prehabilitation, with and without exercise, on outcomes of patients who undergo colorectal surgery: a systematic review and meta-analysis. Gastroenterology. 2018;155(2):391-410 e4.

69. Merki-Kunzli C, Kerstan-Huber M, Switalla D, Gisi D, Raptis DA, Greco N, et al. Assessing the value of prehabilitation in patients undergoing colorectal surgery according to the Enhanced Recovery After Surgery (ERAS) Pathway for the improvement of postoperative outcomes: protocol for a randomized controlled trial. JMIR Res Protoc. 2017;6(10):e199.

70. Berkel AEM, Bongers BC, van Kamp MS, Kotte H, Weltevreden P, de Jongh FHC, et al. The effects of prehabilitation versus usual care to reduce postoperative complications in high-risk patients with colorectal cancer or dysplasia scheduled for elective colorectal resection: study protocol of a randomized controlled trial. BMC Gastroenterol. 2018;18(1):29.

71. de Jonge WJ, van der Zanden EP, The FO, Bijlsma MF, van Westerloo DJ, Bennink RJ, et al. Stimulation of the vagus nerve attenuates macrophage activation by activating the Jak2-STAT3 signaling pathway. Nat Immunol. 2005;6(8):844-51.

72. Wang H, Yu M, Ochani M, Amella CA, Tanovic M, Susarla S, et al. Nicotinic acetylcholine receptor alpha7 subunit is an essential regulator of inflammation. Nature. 2003;421(6921):384-8.

73. Tracey KJ. Physiology and immunology of the cholinergic antiinflammatory pathway. J Clin Invest. 2007;117(2):289-96.

74. Matteoli G, Boeckxstaens GE. The vagal innervation of the gut and immune homeostasis. Gut. 2013;62(8):1214-22.

75. Van Der Zanden EP, Boeckxstaens GE, de Jonge WJ. The vagus nerve as a modulator of intestinal inflammation. Neurogastroenterol Motil. 2009;21(1):6-17.

76. Tracey KJ. The inflammatory reflex. Nature. 2002;420(6917):853-9.

77. Pavlov VA, Chavan SS, Tracey KJ. Molecular and functional neuroscience in immunity. Ann Rev Immunol. 2018;36:783-812.

78. Wolthuis AM, Bislenghi G, Fieuws S, de Buck van Overstraeten A, Boeckxstaens G, D'Hoore A. Incidence of prolonged postoperative ileus after colorectal surgery: a systematic review and metaanalysis. Colorectal Dis. 2016;18(1):01-9.

79. Asgeirsson T, El-Badawi KI, Mahmood A, Barletta J, Luchtefeld M, Senagore AJ. Postoperative ileus: it costs more than you expect. J Am Coll Surg. 2010;210(2):228-31.

80. Iyer S, Saunders WB, Stemkowski S. Economic burden of postoperative ileus associated with colectomy in the United States. J Manag Care Pharm : JMCP. 2009;15(6):485-94.

81. Senagore AJ. Pathogenesis and clinical and economic consequences of postoperative ileus. Am J Health Syst Pharm. 2007;64(20 Suppl 13):S3-7.

82. Bragg D, El-Sharkawy AM, Psaltis E, Maxwell-Armstrong CA, Lobo DN. Postoperative ileus: Recent developments in pathophysiology and management. Clin Nutr. 2015;34(3):367-76.

83. Stakenborg N, Gomez-Pinilla PJ, Boeckxstaens GE. Postoperative Ileus: Pathophysiology, Current Therapeutic Approaches. Handbook of experimental pharmacology. 2017;239:39-57.

84. Doorly MG, Senagore AJ. Pathogenesis and clinical and economic consequences of postoperative ileus. Surg Clin North Am. 2012;92(2):259-72, viii. 
85. Berdun S, Bombuy E, Estrada O, Mans E, Rychter J, Clave P, et al. Peritoneal mast cell degranulation and gastrointestinal recovery in patients undergoing colorectal surgery. Neurogastroenterol Motil. 2015;27(6):764-74.

86. Peters EG, De Jonge WJ, Smeets BJ, Luyer MD. The contribution of mast cells to postoperative ileus in experimental and clinical studies. Neurogastroenterol Motil. 2015;27(6):743-9.

87. Stakenborg N, Wolthuis AM, Gomez-Pinilla PJ, Farro G, Di Giovangiulio M, Bosmans G, et al. Abdominal vagus nerve stimulation as a new therapeutic approach to prevent postoperative ileus. Neurogastroenterol Motil. 2017;29(9).

88. Lubbers T, de Haan JJ, Luyer MD, Verbaeys I, Hadfoune M, Dejong $\mathrm{CH}$, et al. Cholecystokinin/Cholecystokinin-1 receptor-mediated peripheral activation of the afferent vagus by enteral nutrients attenuates inflammation in rats. Ann Surg. 2010;252(2):376-82.

89. Luyer MD, Buurman WA, Hadfoune M, Jacobs JA, Dejong CH, Greve JW. High-fat enteral nutrition reduces endotoxin, tumor necrosis factor-alpha and gut permeability in bile duct-ligated rats subjected to hemorrhagic shock. J Hepatol. 2004;41(3):377-83.

90. Luyer MD, Greve JW, Hadfoune M, Jacobs JA, Dejong CH, Buurman WA. Nutritional stimulation of cholecystokinin receptors inhibits inflammation via the vagus nerve. J Exp Med. 2005;202(8):1023-9.

91. Lubbers T, Luyer MD, de Haan JJ, Hadfoune M, Buurman WA, Greve JW. Lipid-rich enteral nutrition reduces postoperative ileus in rats via activation of cholecystokinin-receptors. Ann Surg. 2009;249(3):481-7.

92. Lubbers T, Kox M, de Haan JJ, Greve JW, Pompe JC, Ramakers BP, et al. Continuous administration of enteral lipid- and protein-rich nutrition limits inflammation in a human endotoxemia model. Crit Care Med. 2013;41(5):1258-65.

93. Moya P, Soriano-Irigaray L, Ramirez JM, Garcea A, Blasco O, Blanco FJ, et al. Perioperative standard oral nutrition supplements versus immunonutrition in patients undergoing colorectal resection in an enhanced recovery (ERAS) protocol: a multicenter randomized clinical trial (SONVI Study). Medicine. 2016;95(21):e3704.

94. Cerantola Y, Hubner M, Grass F, Demartines N, Schafer M. Immunonutrition in gastrointestinal surgery. Br J Surg. 2011;98(1):37-48.

95. Xu J, Sun X, Xin Q, Cheng Y, Zhan Z, Zhang J, et al. Effect of immunonutrition on colorectal cancer patients undergoing surgery: a meta-analysis. Int J Colorectal Dis. 2018;33(3):273-83.

96. Hegazi RA, Hustead DS, Evans DC. Preoperative standard oral nutrition supplements vs immunonutrition: results of a systematic review and meta-analysis. J Am Coll Surg. 2014;219(5): 1078-87.

97. Probst P, Ohmann S, Klaiber U, Huttner FJ, Billeter AT, Ulrich A, et al. Meta-analysis of immunonutrition in major abdominal surgery. Br J Surg. 2017;104(12):1594-608.

98. Vlug MS, Bartels SA, Wind J, Ubbink DT, Hollmann MW, Bemelman WA, et al. Which fast track elements predict early recovery after colon cancer surgery? Colorectal Dis. 2012;14(8):1001-8.

99. Andersen HK, Lewis SJ, Thomas S. Early enteral nutrition within $24 \mathrm{~h}$ of colorectal surgery versus later commencement of feeding for postoperative complications. The Cochrane database of systematic reviews. 2006(4):CD004080.

100. Lewis SJ, Andersen HK, Thomas S. Early enteral nutrition within $24 \mathrm{~h}$ of intestinal surgery versus later commencement of feeding: a systematic review and meta-analysis. J Gastrointest Surg. 2009;13(3):569-75.

101. Osland E, Yunus R, Khan S, Memon MA. Early enteral nutrition within $24 \mathrm{~h}$ of intestinal surgery versus later commencement of feeding: a systematic review and meta-analysis. J Gastrointest Surg. 2009;13(6):1163-5; author reply 6-7.

102. Zhuang CL, Ye XZ, Zhang CJ, Dong QT, Chen BC, Yu Z. Early versus traditional postoperative oral feeding in patients undergoing elective colorectal surgery: a meta-analysis of randomized clinical trials. Dig Surg. 2013;30(3):225-32.

103. van den Heijkant TC, Costes LM, van der Lee DG, Aerts B, Osinga-de Jong M, Rutten HR, et al. Randomized clinical trial of the effect of gum chewing on postoperative ileus and inflammation in colorectal surgery. Br J Surg. 2015;102(3):202-11. 
104. Boelens PG, Heesakkers FF, Luyer MD, van Barneveld KW, de Hingh IH, Nieuwenhuijzen GA, et al. Reduction of postoperative ileus by early enteral nutrition in patients undergoing major rectal surgery: prospective, randomized, controlled trial. Ann Surg. 2014;259(4):649-55.

105. Demetriades H, Botsios D, Kazantzidou D, Sakkas L, Tsalis K, Manos K, et al. Effect of early postoperative enteral feeding on the healing of colonic anastomoses in rats. Comparison of three different enteral diets. European surgical research Eur Surg Res. 1999;31(1):57-63.

106. Guven A, Pehlivan M, Gokpinar I, Gurleyik E, Cam M. Early glutamine-enriched enteral feeding facilitates colonic anastomosis healing: light microscopic and immunohistochemical evaluation. Acta Histochem. 2007;109(2):122-9.

107. Khalili TM, Navarro RA, Middleton Y, Margulies DR. Early postoperative enteral feeding increases anastomotic strength in a peritonitis model. Am J Surg. 2001;182(6):621-4.

108. Fukuzawa J, Terashima H, Ohkohchi N. Early postoperative oral feeding accelerates upper gastrointestinal anastomotic healing in the rat model. World J Surg. 2007;31(6):1234-9.

109. Tadano S, Terashima H, Fukuzawa J, Matsuo R, Ikeda O, Ohkohchi N. Early postoperative oral intake accelerates upper gastrointestinal anastomotic healing in the rat model. J Surg Res. 2011; 169(2):202-8.

110. Kiyama T, Efron DT, Tantry U, Barbul A. Effect of nutritional route on colonic anastomotic healing in the rat. J Gastrointest Surg. 1999;3(4):441-6.

111. Kiyama T, Onda M, Tokunaga A, Yoshiyuki T, Barbul A. Effect of early postoperative feeding on the healing of colonic anastomoses in the presence of intra-abdominal sepsis in rats. Dis Colon Rectum. 2000;43(10 Suppl):S54-8.

112. Daams F, Luyer M, Lange JF. Colorectal anastomotic leakage: aspects of prevention, detection and treatment. World J Gastroenterol. 2013;19(15):2293-7.

113. Krarup PM, Nordholm-Carstensen A, Jorgensen LN, Harling H. Anastomotic leak increases distant recurrence and long-term mortality after curative resection for colonic cancer: a nationwide cohort study. Ann Surg. 2014;259(5):930-8.

114. Nachiappan S, Askari A, Malietzis G, Giacometti M, White I, Jenkins JT, et al. The impact of anastomotic leak and its treatment on cancer recurrence and survival following elective colorectal cancer resection. World J Surg. 2015;39(4):1052-8.

115. Nachiappan S, Faiz O. Anastomotic Leak Increases Distant Recurrence and Long-term Mortality After Curative Resection for Colonic Cancer. Ann Surg. 2015;262(6):e111.

116. Peters EG, Dekkers M, van Leeuwen-Hilbers FW, Daams F, Hulsewe KWE, de Jonge WJ, et al. Relation between postoperative ileus and anastomotic leakage after colorectal resection: a post hoc analysis of a prospective randomized controlled trial. Colorectal Dis. 2017;19(7):667-74.

117. Ishimura K, Moroguchi A, Okano K, Maeba T, Maeta H. Local expression of tumor necrosis factoralpha and interleukin-10 on wound healing of intestinal anastomosis during endotoxemia in mice. J Surg Res. 2002;108(1):91-7.

118. Ishimura K, Tsubouchi T, Okano K, Maeba T, Maeta H. Wound healing of intestinal anastomosis after digestive surgery under septic conditions: participation of local interleukin-6 expression. World J Surg. 1998;22(10):1069-75; discussion 76. 


\section{Chapter}

\section{Effect of early vs late start of oral intake on anastomotic leakage following elective lower intestinal surgery: a systematic review}




\section{Abstract}

Background

Experimental and clinical studies have demonstrated a beneficial effect of early enteral nutrition on anastomotic leakage following colorectal surgery. Early oral intake is a common form of early enteral nutrition with various clinical benefits, but the effect on anastomotic leakage is unclear. This systematic review investigates the effect of early versus late start of oral intake on anastomotic leakage following lower intestinal surgery.

\section{Methods}

A systematic literature search was performed using the PubMed, Embase, Medline and Cochrane databases. Randomized controlled trials were included that compared early (within 24 hours) versus late start of oral intake following elective surgery of the small bowel, colon or rectum. Meta-analysis was performed for anastomotic leakage, overall complications, length of stay, and mortality. Sensitivity analysis was performed in which studies of inferior methodological quality were excluded.

Results

Nine studies including 879 patients met eligibility criteria. Early start of oral intake significantly reduced overall complications (OR 0.65; 95\% CI 0.46-0.93; $\mathrm{p}=0.02$ ), length of stay (MD $-0.89 ; 95 \%$ CI -1.22 to $-0.57 ; \mathrm{p}<0.001$ ) and anastomotic leakage (OR $0.40 ; 95 \%$ CI $0.17-0.95 ; \mathrm{p}=0.04$ ), when compared to late start of oral intake. However, in the sensitivity analysis only the overall reduction of length of stay remained significant.

\section{Conclusion}

The effect of early oral intake on anastomotic leakage is unclear as existing studies are heterogeneous and at risk of bias. High-quality studies are needed to study the potential benefit of enteral nutrition on anastomotic healing. 


\section{Introduction}

Anastomotic leakage (AL) is a severe complication following colorectal surgery as it is associated with increased morbidity, mortality, and cancer recurrence rates. ${ }^{1-4}$ In spite of ongoing efforts, strategies that effectively reduce AL are lacking and the incidence has remained stable over the years. ${ }^{5}$

Several experimental studies have demonstrated that enteral nutrition may improve anastomotic healing. ${ }^{6-12}$ Moreover, in two recent randomized controlled trials, AL following colorectal surgery was significantly reduced by means of early postoperative enteral nutrition ${ }^{13}$, and direct perioperative sham feeding. ${ }^{14}$ Taken together, these results suggest that enteral nutrition administered close to surgery may provide new therapeutic opportunities to reduce AL.

A common method to provide enteral nutrition close to surgery is the early postoperative start of oral intake. Systematic reviews on the effects of direct start of oral intake following gastro-intestinal surgery have demonstrated clear benefits, including a reduction in length of stay, overall complications, and mortality. ${ }^{15-18}$ However, in these reviews early oral intake did not affect AL. ${ }^{15-18}$ Importantly, these systematic reviews included various types of gastro-intestinal surgery or included studies that combined other elements of fast-track protocols in the intervention group whilst not in the control group. ${ }^{15-18}$ To further investigate the potential beneficial effects of enteral nutrition on anastomotic healing, this systematic review compares the effect of early versus late start of oral intake on AL following elective lower intestinal surgery.

\section{Methods}

This systematic review was performed according to the Cochrane Handbook for Systematic Reviews for Interventions ${ }^{19}$ and the PRISMA statement guidelines. ${ }^{20}$ The entire review process (i.e. article search, critical appraisal, data extraction and analysis) was conducted by three independent researchers (BS, EP and EH). Any disagreements were resolved through discussion.

\section{Eligibility criteria}

We included only randomized controlled clinical trials that reported on the effects of early versus late start of oral intake on AL following elective surgery of the small bowel, colon, or rectum in patients $\geq 18$ years old. We defined early start of oral intake as any caloric intake started within 24 hours after surgery. Late start of oral intake was defined as nil-by-mouth until resolution of postoperative ileus (i.e. passage of flatus or stool without presence of nausea or vomiting). In order to 
assess the true effect of early oral intake alone, we excluded studies that combined early oral intake with other elements of fast-track protocols in the intervention group but not in the control group.

\section{Information sources and search strategy}

The Pubmed, Medline, Embase and Cochrane databases were systematically searched. The search strategy combined all synonyms regarding the intervention 'early oral intake', and the domain 'lower intestinal surgery' with the Boolean operator 'AND'. All synonyms were combined with the Boolean operator 'OR'. An example set of search terms is provided in Supplemental Table S2.1. We tested the sensitivity of the search strategy by screening all references of included articles for relevant publications that were not retrieved in the initial search. Furthermore, we screened all citing articles and related articles using Web of Science version 5.15.1. Identification of additional eligible articles led to evaluation and improvement of the search strategy until it retrieved all eligible articles. We contacted authors by email if articles were not available in full text. The search was updated until September 28th, 2016.

\section{Study selection}

Three authors screened all records on title and abstract. Records were excluded if they clearly did not address the domain and intervention under investigation. The remaining articles were screened in full text. Only articles fulfilling all eligibility criteria were included.

\section{Data extraction and outcomes}

The relevant published data was collected in pilot-tested tables. Extracted information from each study included: (A) study information including name of first author, year of publication, number of participants in each group, reported outcomes; (B) patient information including type of surgery, disease, sex, age, and perioperative protocols used affecting $\mathrm{AL}^{21}$; and (C) postoperative feeding protocols. Furthermore, we extracted data on the incidence and definition of AL, overall complications, mortality, and length of stay.

\section{Risk of bias in individual studies}

All studies included in the review were investigated for risk of bias with the Cochrane collaboration's tool for assessing risk of bias. ${ }^{19}$ Risk of bias was assessed on the following items: randomization method, allocation concealment, blinding of 
participants and personnel, blinding of outcome assessment, incomplete outcome data, selective reporting, and any other item in study design.

\section{Data analysis}

Meta-analysis was performed for AL, overall complications, length of stay, and mortality. We performed data analysis using Review Manager Software version 5.3 as recommended by the Cochrane Handbook for Systematic Reviews for Interventions. ${ }^{19,22}$ Dichotomous results were analyzed using the random effects model in the Mantel-Haenszel method and are presented as odds ratio (OR) with corresponding 95\% confidence intervals (CI). Continuous results were analyzed using the inverse variance method and are presented as mean difference (MD) with corresponding $95 \%$ CI. A p-value $<0.05$ was considered to be statistically significant. We assessed presence and amount of statistical heterogeneity using the $\mathrm{I}^{2}$ statistic. Furthermore, a sensitivity analysis was performed in which studies of inferior methodological quality were excluded.

\section{Results}

\section{Description of studies}

Figure 2.1 presents the search results and study selection process. The search revealed 80 potentially relevant studies of which 9 randomized controlled trials fitted inclusion criteria. Study characteristics are shown in Table 2.1. Types of surgical procedures were evenly matched between groups in all studies. Laparoscopic surgery was performed only in one study ${ }^{23}$; in other studies open surgery was performed. ${ }^{24-31}$ When reported, there was substantial heterogeneity between studies in the use of perioperative protocols, including use of epidural anesthesia, preoperative bowel lavage, non-steroid anti-inflammatory drugs and opioids. Postoperative feeding protocols are described in Table 2.2.

Anastomotic leakage was a rare event in most studies and rarely a primary outcome. Four studies provided definitions for AL (Table 2.3). ${ }^{25,26,28,31}$ 


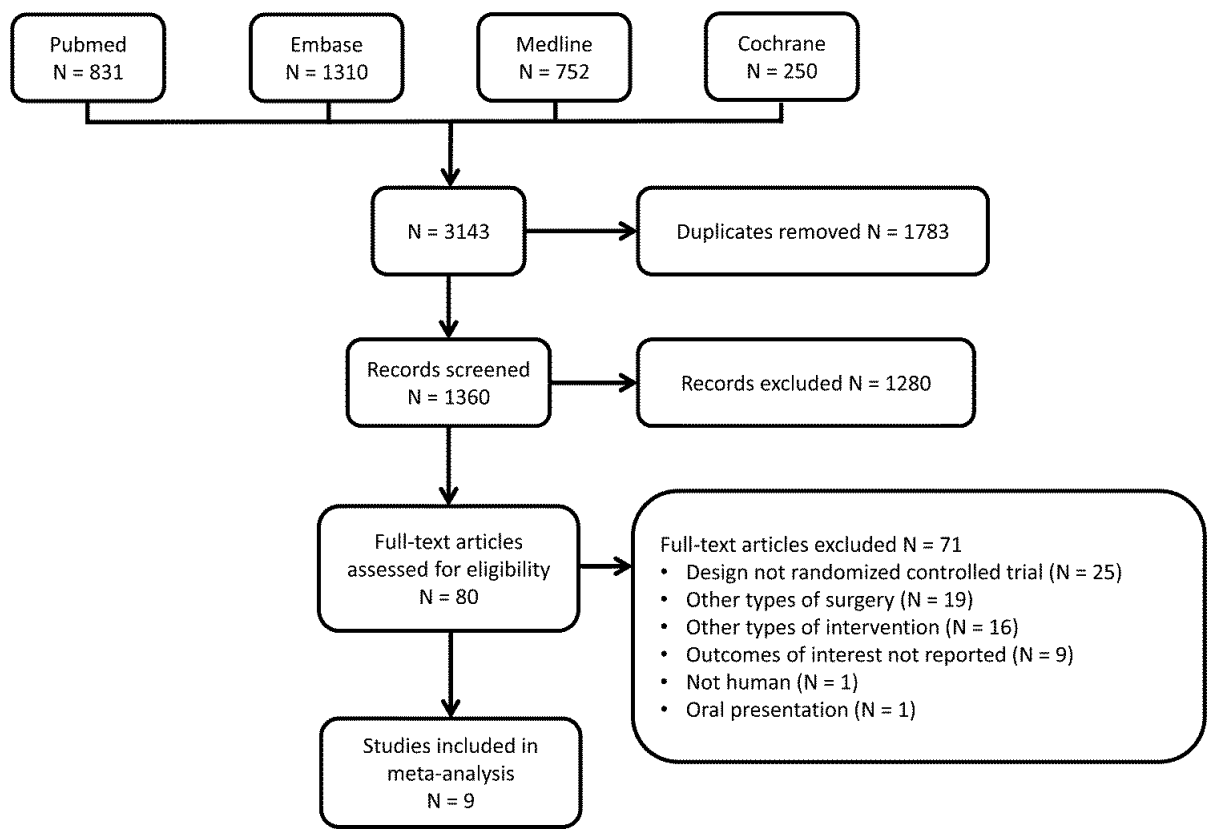

Figure 2.1 PRISMA Flowchart for search results and study selection process.

\section{Methodological quality of included studies}

Due to the nature of the intervention, blinding could not be applied in any study. Three studies gave no explicit description of the randomization-method, resulting in an unclear risk of bias. ${ }^{26,27,30}$ One open-label study used blocked randomization with a fixed block size of 6; hence risk of selection bias was present. ${ }^{29}$ In the same study, it was unclear whether the nasogastric tube was postoperatively removed in both groups at similar time-points. In one study ${ }^{28}$, patients allocated to delayed start of oral intake had a significantly greater amount of intraoperative blood loss (early oral intake median $300 \mathrm{ml}$ versus delayed oral intake median $800 \mathrm{ml}$, $\mathrm{p}=0.002$ ), which is a known risk factor for AL. ${ }^{21}$ The summary of risk of bias assessment is shown in Table 2.4. Overall, three studies were identified to have the best available methodological quality and were entered in the sensitivity analysis. ${ }^{23,24,31}$ 


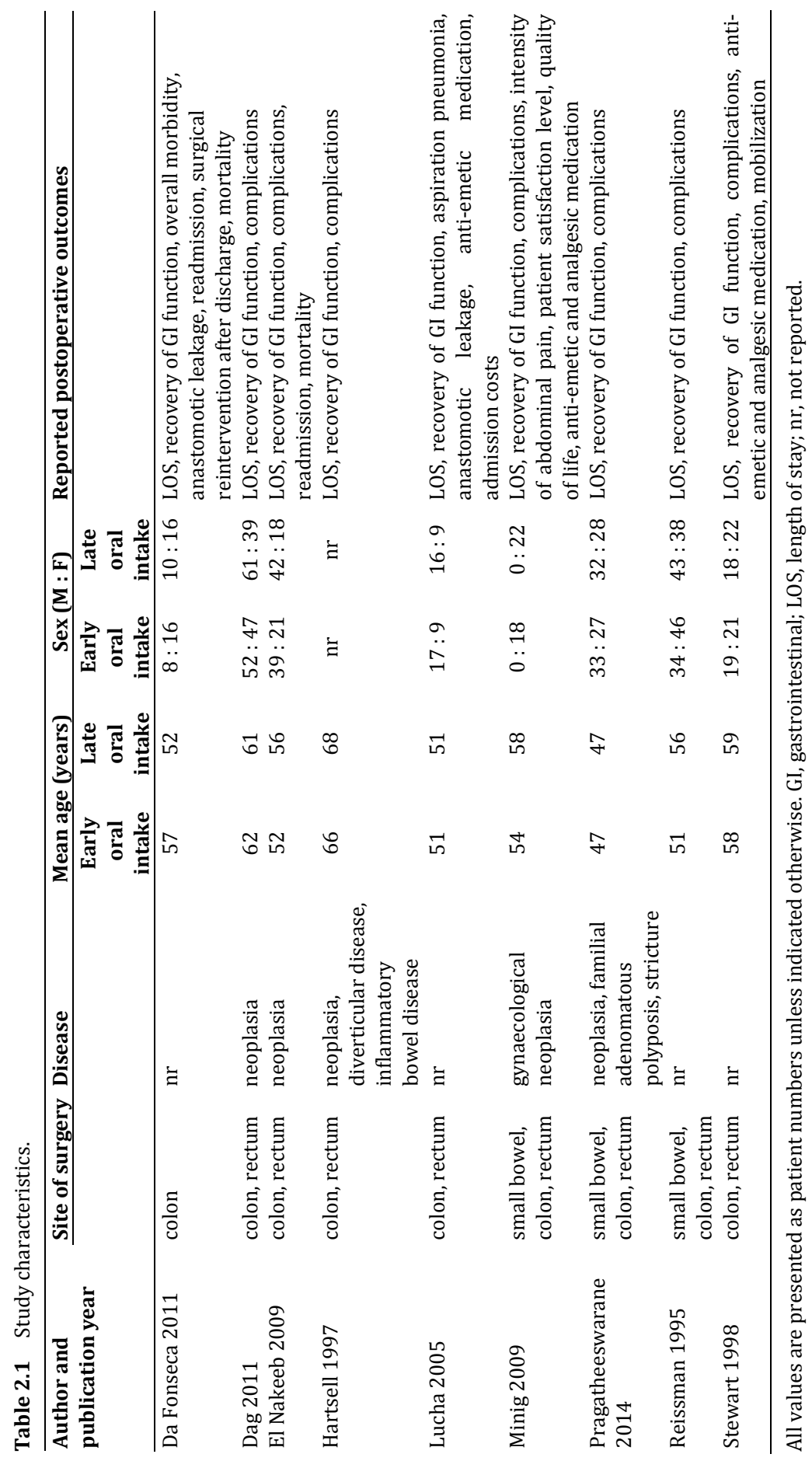


Table 2.2: Postoperative feeding protocols.

\begin{tabular}{|c|c|c|}
\hline $\begin{array}{l}\text { Author and publication } \\
\text { year }\end{array}$ & Early oral intake & $\begin{array}{l}\text { Late oral } \\
\text { intake }\end{array}$ \\
\hline Da Fonseca 2011 & $\begin{array}{l}\text { POD1 oral liquid diet, advance to regular diet within } \\
24 \text { hrs as tolerated }\end{array}$ & SC \\
\hline Dag 2011 & $\begin{array}{l}12 \text { hrs postop start fluids, advance to solid diet as } \\
\text { tolerated }\end{array}$ & SC \\
\hline El Nakeeb 2009 & $\begin{array}{l}\text { POD1 fluids, advance to regular diet within } 24-48 \text { hrs as } \\
\text { tolerated }\end{array}$ & SC \\
\hline Hartsell 1997 & $\begin{array}{l}\text { POD1 full liquid diet, advance to regular diet if }>1000 \mathrm{ml} \\
\text { was consumed within } 24 \mathrm{hrs}\end{array}$ & SC \\
\hline Lucha 2005 & 8 hrs after surgery start regular diet & SC \\
\hline Minig 2009 & POD0 CL, advance to regular diet on POD1 as tolerated & SC \\
\hline Pragatheeswarane 2014 & $\begin{array}{l}\text { POD1 CL, advance to full fluid diet within } 48 \mathrm{hrs} \text {, start } \\
\text { solid diet over next } 24 \mathrm{hrs}\end{array}$ & SC \\
\hline Reissman 1995 & P0D1 CL, advance to regular diet as tolerated & SC \\
\hline Stewart 1998 & $\begin{array}{l}4 \text { hrs postop start free fluids, advance to solid diet as } \\
\text { tolerated on POD1 }\end{array}$ & SC \\
\hline
\end{tabular}

CL, clear liquids; POD, postoperative day; SC, standard care (nil by mouth until resolution of ileus).

Table 2.3: Definitions for anastomotic leakage.

\begin{tabular}{ll}
\hline Author and publication year & Definition \\
\hline El Nakeeb 2009 & Symptoms such as fever and leakage of intestinal contents \\
Hartsell 1999 & Resulting in sepsis and eventual death \\
Minig 2009 & Requiring surgical re-exploration \\
Stewart 1998 & Fecal discharge from drain tube which settled without intervention \\
\hline
\end{tabular}

Table 2.4: Critical appraisal of included studies.

\begin{tabular}{|c|c|c|c|c|c|c|c|c|c|}
\hline Item & 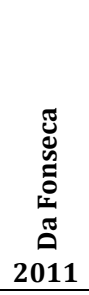 & $\stackrel{200}{\stackrel{0}{0}} 2011$ & 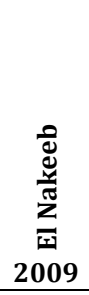 & 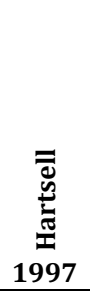 & 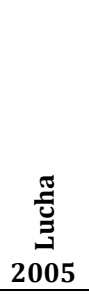 & 2009 & 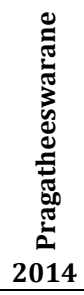 & 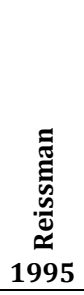 & 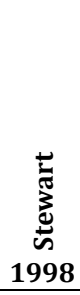 \\
\hline Randomisation? & + & + & + & $?$ & $?$ & + & + & $?$ & + \\
\hline Allocation concealment? & + & + & $?$ & $?$ & $?$ & + & - & $?$ & + \\
\hline Blinding of participants and personnel? & - & - & - & - & - & - & - & - & - \\
\hline Blinding of outcome assessment? & - & - & - & - & - & - & - & - & - \\
\hline Complete outcome data? & + & + & + & + & + & + & + & + & + \\
\hline No selective reporting? & + & + & + & + & + & + & + & + & + \\
\hline No other bias? & + & + & + & + & + & - & $?$ & + & + \\
\hline
\end{tabular}

+, yes; -, no; ?, unclear 


\section{Anastomotic leakage}

First, all studies were entered in meta-analysis regardless of methodological quality. As shown in Figure 2.2A, early start of oral intake significantly reduced AL when compared to late start of oral intake (OR 0.40; 95\% CI 0.17-0.95; p=0.04). However, when trials with risk of bias were excluded in the sensitivity analysis, the overall effect on AL was no longer significant (OR 0.39; 95\% CI 0.09-1.76; p=0.22) (Figure 2.2B).

\section{Overall complications}

All studies provided data on overall complications. As shown in Figure 2.3A, early start of oral intake significantly reduced overall complications when compared to late start of oral intake (OR 0.65; 95\% CI 0.46-0.93; p=0.02). However, when trials with risk of bias were excluded in the sensitivity analysis, the overall effect on overall complications was no longer significant (OR 0.74; 95\% CI 0.42-1.31; $\mathrm{p}=0.30$ ) (Figure 2.3B).

\section{Length of stay}

Seven studies provided data on length of stay as mean \pm standard deviation and were entered in meta-analysis. ${ }^{23-26,28-30}$ As shown in Figure 2.4A, early start of oral intake significantly reduced length of stay when compared to late start of oral intake (MD $-0.89 ; 95 \%$ CI -1.22 to -0.57 ; p<0.001). Excluding studies with risk of bias increased the overall effect of on length of stay (MD $-3.47 ; 95 \%$ CI -4.73 to 2.21; $\mathrm{p}<0.001$ ) (Figure 2.4B).

\section{Mortality}

Seven studies provided data on mortality and were entered in metaanalysis. $^{23,25,26,28-31}$ As shown in Figure 2.5A, early start of oral intake did not affect mortality when compared to late start of oral intake (OR $0.61 ; 95 \%$ CI $0.17-2.22$; $\mathrm{p}=0.45$ ). Excluding studies with risk of bias did not alter the overall effect of direct start of oral intake on mortality (OR 1.04; 95\% CI 0.10-10.35; p=0.97) (Figure 2.5B). 


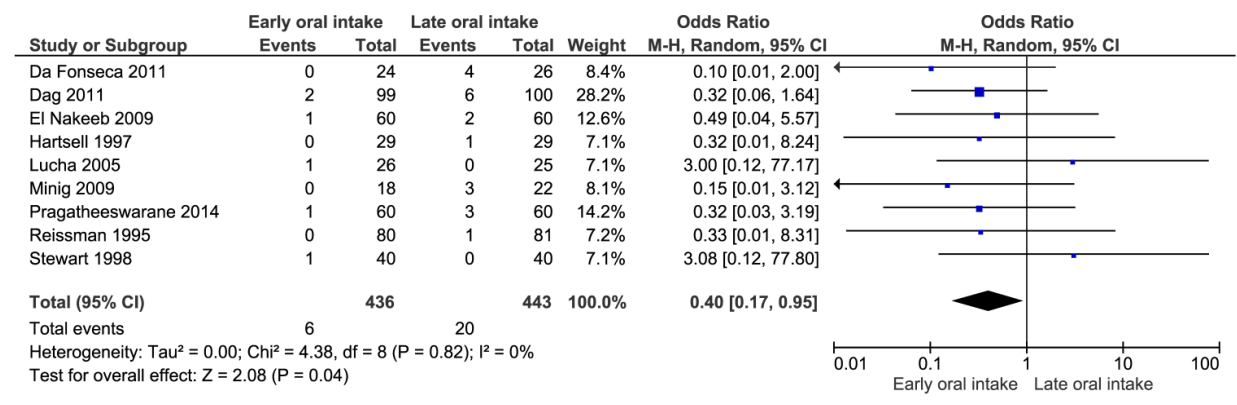

Figure 2.2A: Forest plot for studies that examined the effect of early versus late start of oral intake for anastomotic leakage.

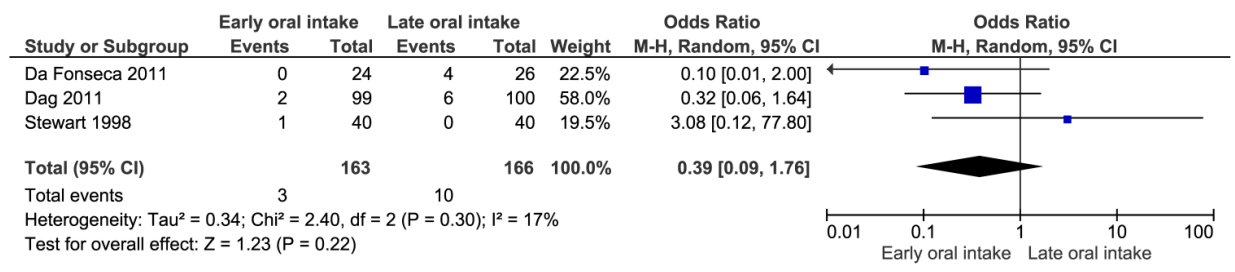

Figure 2.2B: Sensitivity analysis for studies that examined the effect of early versus late start of oral intake for anastomotic leakage.

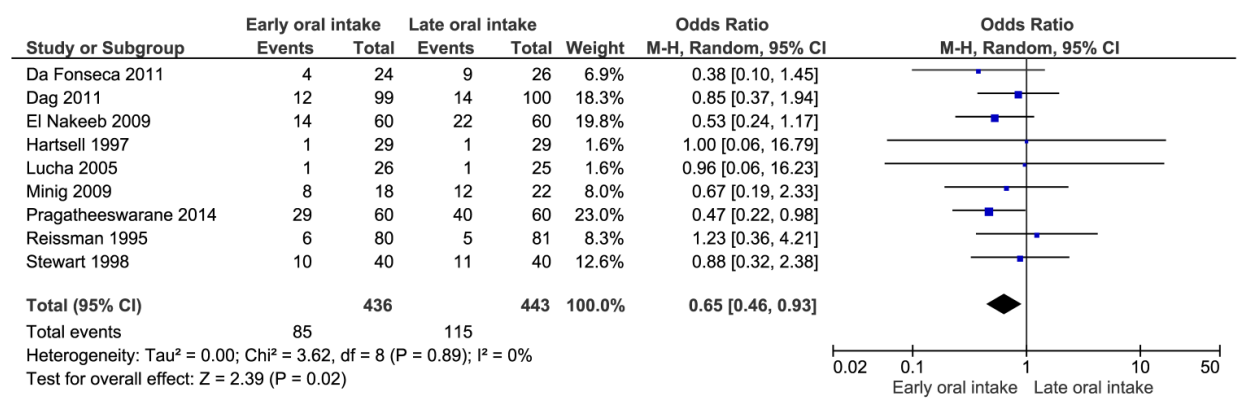

Figure 2.3A: Forest plot for studies that examined the effect of early versus late start of oral intake for overall complications.

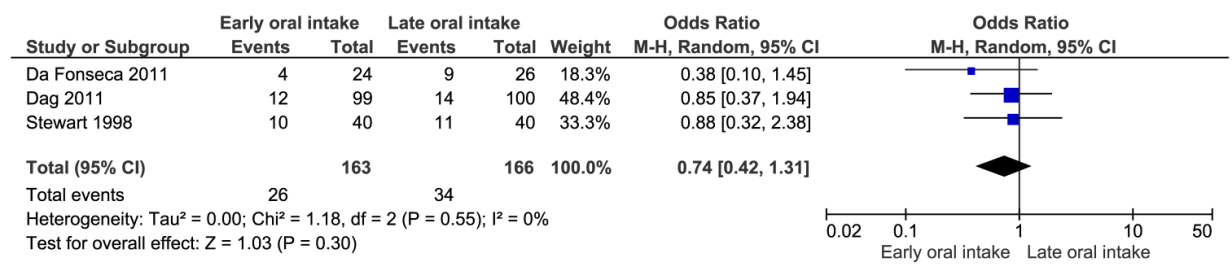

Figure 2.3B: Sensitivity analysis for studies that examined the effect of early versus late start of oral intake for overall complications. 


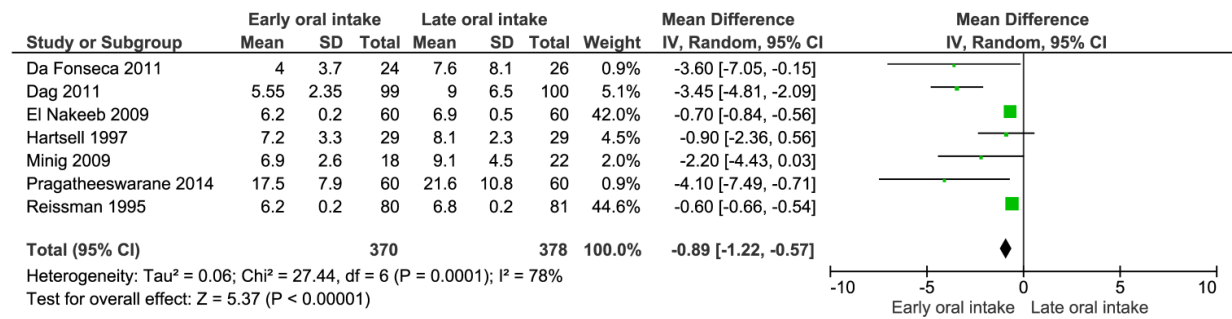

Figure 2.4A: Forest plot for studies that examined the effect of early versus late start of oral intake for length of stay.

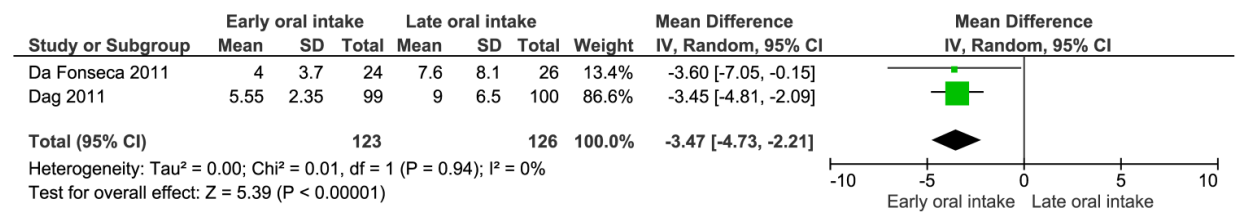

Figure 2.4B: Sensitivity analysis for studies that examined the effect of early versus late start of oral intake for length of stay.

\begin{tabular}{|c|c|c|c|c|c|c|c|c|c|c|}
\hline \multirow[b]{2}{*}{ Study or Subgroup } & \multicolumn{2}{|c|}{ Early oral intake } & \multicolumn{2}{|c|}{ Late oral intake } & \multirow[b]{2}{*}{ Weight } & \multirow{2}{*}{\multicolumn{2}{|c|}{$\begin{array}{l}\text { Odds Ratio } \\
\text { M-H, Random, } 95 \% \text { Cl }\end{array}$}} & \multirow{2}{*}{\multicolumn{2}{|c|}{$\begin{array}{c}\text { Odds Ratio } \\
\text { M-H, Random, } 95 \% \text { Cl }\end{array}$}} & \\
\hline & Events & Total & Events & Total & & & & & & \\
\hline Da Fonseca 2011 & 1 & 24 & 0 & 26 & $15.7 \%$ & $3.38[0.13,87.11]$ & & & & \\
\hline EI Nakeeb 2009 & 0 & 60 & 1 & 60 & $16.0 \%$ & $0.33[0.01,8.21]$ & & & & \\
\hline Hartsell 1997 & 0 & 29 & 1 & 29 & $15.7 \%$ & $0.32[0.01,8.24]$ & & & & \\
\hline Minig 2009 & 0 & 18 & 1 & 22 & $15.6 \%$ & $0.39[0.01,10.10]$ & & & & \\
\hline Pragatheeswarane 2014 & 1 & 60 & 1 & 60 & $21.2 \%$ & $1.00[0.06,16.37]$ & & & & \\
\hline Reissman 1995 & 0 & 80 & 0 & 81 & & Not estimable & & & & \\
\hline Stewart 1998 & 0 & 40 & 1 & 40 & $15.9 \%$ & $0.33[0.01,8.22]$ & & - & & \\
\hline Total $(95 \% \mathrm{CI})$ & & 311 & & 318 & $100.0 \%$ & $0.61[0.17,2.22]$ & & & & \\
\hline Total events & 2 & & 5 & & & & & & & \\
\hline $\begin{array}{l}\text { Heterogeneity: } \mathrm{Tau}^{2}=0.0 \\
\text { Test for overall effect: } Z=\end{array}$ & $\begin{array}{l}\mathrm{Chi}^{2}=1.7 \\
.75(\mathrm{P}=0 .\end{array}$ & $\mathrm{df}=5(\mathrm{~F}$ & $=0.89) ; l^{2}$ & $0 \%$ & & & 0.01 & 0.1 & $\begin{array}{ll}10 & 10\end{array}$ & 0 \\
\hline
\end{tabular}

Figure 2.5A: Forest plot for studies that examined the effect of early versus late start of oral intake for mortality.

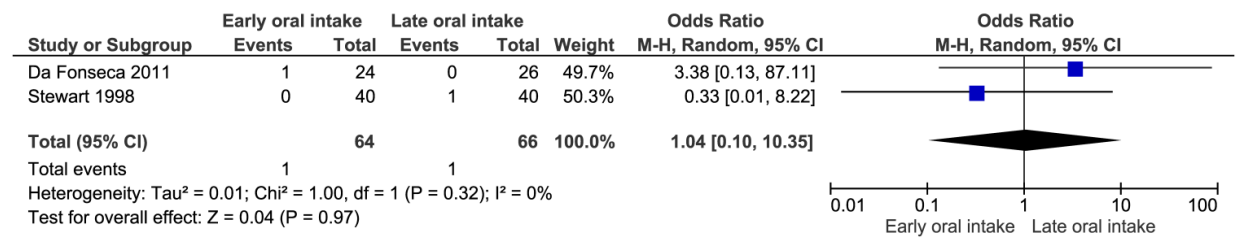

Figure 2.5B: Sensitivity analysis for studies that examined the effect of early versus late start of oral intake for mortality. 


\section{Discussion}

The current review demonstrates that the effect of early oral intake on anastomotic leakage is unclear in a clinical setting. This is mainly due to a lack of high-quality evidence, since existing randomized trials are clinically heterogeneous and at risk of bias.

Experimental studies have suggested that enteral nutrition can improve anastomotic healing via several mechanisms. ${ }^{6-12}$ These experimental findings may be corroborated by two randomized clinical trials of good methodological quality that demonstrated a reduction of AL by means of perioperative sham feeding ${ }^{14}$ (i.e. gum-chewing) and early postoperative enteral tube feeding. ${ }^{13}$ Early start of oral intake is a more common form of early enteral nutrition, and has been extensively described as part of fast-track protocols in colorectal surgery. Individual randomized trials have described no effect of early oral intake on $A L$, however most studies had a relatively small sample size and were therefore inadequately powered to detect a potential effect on AL. ${ }^{23-31}$ Previous systematic reviews on early enteral nutrition also did not support an effect on AL. ${ }^{15-18}$ However, these reviews may have been inadequate to assess the true effect of enteral nutrition, since they included studies with patients undergoing upper gastro-intestinal surgery $^{32}$, studies that applied immunonutrition ${ }^{33}$, or studies that applied other aspects of fast-track protocols only in the treatment group whilst not in the control group (e.g. early nasogastric tube removal). ${ }^{34}$ Furthermore, no review performed a sensitivity analysis to minimize the risk of bias. ${ }^{15-18}$ This study therefore aimed to provide an update of the available literature, and to perform a rigorous critical appraisal and sensitivity analysis to examine the true effect of enteral nutrition on anastomotic healing in a clinical setting. In the current meta-analysis, the pooling of all 9 randomized trials regardless of methodological quality resulted in several beneficial effects in favor of early oral intake. However, the strict exclusion of 6 studies with a modest to high risk of bias ${ }^{25-30}$ in the sensitivity analysis significantly reduced overall sample size and made the effect on AL and overall complications no longer significant. As such, the results from our study suggest that early start of oral intake is only associated with a reduction of LOS.

The overall reduction of LOS following early oral intake ranges from almost 1 day in the general meta-analysis to approximately 3 days in the sensitivity analysis. This may be explained by a faster return of bowel function in the early feeding group, as demonstrated by various indicators of GI motility (e.g. time to first flatus or defecation) in multiple studies. ${ }^{23-25,29}$ However, differences in discharge criteria between the included studies may have confounded the effect of early oral intake on LOS, as suggested by the high statistical heterogeneity.

In spite of the attempt to minimize risk of bias by means of a sensitivity analysis, several other limitations remain present in the current systematic review. First, 
perioperative protocols varied greatly between studies, including the use of nonsteroid anti-inflammatory drugs and preoperative bowel lavage. However, while differences in these protocols can affect various clinical outcomes, the specific effect on AL may be limited except for non-steroid anti-inflammatory drugs. ${ }^{21}$ Second, no study was blinded; however blinding is difficult to apply due to the nature of the intervention. Third, the included studies involved various sites of lower intestinal surgery; it is well known that the a priori risks of AL vary in the small bowel, colon and rectum. However, in the sensitivity analysis only studies including colorectal surgery were included. Lastly, a clear definition for AL lacked in most studies, and varied between studies when provided. While this review attempts to summarize best available evidence, the generalizability remains limited by the heterogeneity of the included studies.

In conclusion, the effect of early oral intake on anastomotic healing is unclear in a clinical setting, as existing literature is clinically heterogeneous and at risk of bias. More well-designed, high-quality randomized studies are needed to further study the potential benefit of enteral nutrition, since alternative strategies that reduce anastomotic leakage are lacking. 


\section{References}

1. Jannasch $\mathrm{O}$, Klinge $\mathrm{T}$, Otto $\mathrm{R}$, et al. Risk factors, short and long term outcome of anastomotic leaks in rectal cancer. Oncotarget. 2015;6(34):36884-93.

2. Kang CY, Halabi WJ, Chaudhry 00, et al. Risk factors for anastomotic leakage after anterior resection for rectal cancer. JAMA Surg. 2013;148(1):65-71.

3. Krarup PM, Nordholm-Carstensen A, Jorgensen LN, Harling H. Anastomotic leak increases distant recurrence and long-term mortality after curative resection for colonic cancer: a nationwide cohort study. Ann Surg. 2014;259(5):930-8.

4. Mirnezami A, Mirnezami R, Chandrakumaran K, Sasapu K, Sagar P, Finan P. Increased local recurrence and reduced survival from colorectal cancer following anastomotic leak: systematic review and meta-analysis. Ann Surg. 2011;253(5):890-9.

5. Daams F, Luyer M, Lange JF. Colorectal anastomotic leakage: aspects of prevention, detection and treatment. World J Gastroenterol: 2013;19(15):2293-7.

6. Demetriades H, Botsios D, Kazantzidou D, et al. Effect of early postoperative enteral feeding on the healing of colonic anastomoses in rats. Comparison of three different enteral diets. Eur Surg Res. 1999;31(1):57-63.

7. Guven A, Pehlivan M, Gokpinar I, Gurleyik E, Cam M. Early glutamine-enriched enteral feeding facilitates colonic anastomosis healing: light microscopic and immunohistochemical evaluation. Acta Histochem. 2007;109(2):122-9.

8. Khalili TM, Navarro RA, Middleton Y, Margulies DR. Early postoperative enteral feeding increases anastomotic strength in a peritonitis model. Am J Surg. 2001;182(6):621-4.

9. Fukuzawa J, Terashima H, Ohkohchi N. Early postoperative oral feeding accelerates upper gastrointestinal anastomotic healing in the rat model. World J Surg. 2007;31(6):1234-9.

10. Tadano S, Terashima H, Fukuzawa J, Matsuo R, Ikeda O, Ohkohchi N. Early postoperative oral intake accelerates upper gastrointestinal anastomotic healing in the rat model. J Surg Res. 2011;169(2):202-8.

11. Kiyama T, Efron DT, Tantry U, Barbul A. Effect of nutritional route on colonic anastomotic healing in the rat. J Gastrointest Surg. 1999;3(4):441-6.

12. Kiyama T, Onda M, Tokunaga A, Yoshiyuki T, Barbul A. Effect of early postoperative feeding on the healing of colonic anastomoses in the presence of intra-abdominal sepsis in rats. Dis Colon Rectum. 2000;43(10 Suppl):S54-8.

13. Boelens PG, Heesakkers FF, Luyer MD, et al. Reduction of postoperative ileus by early enteral nutrition in patients undergoing major rectal surgery: prospective, randomized, controlled trial. Ann Surg. 2014;259(4):649-55.

14. van den Heijkant TC, Costes LM, van der Lee DG, et al. Randomized clinical trial of the effect of gum chewing on postoperative ileus and inflammation in colorectal surgery. Br J Surg. 2015;102(3): 202-11.

15. Andersen HK, Lewis SJ, Thomas S. Early enteral nutrition within $24 \mathrm{~h}$ of colorectal surgery versus later commencement of feeding for postoperative complications. The Cochrane database of systematic reviews. 2006(4):CD004080.

16. Lewis SJ, Andersen HK, Thomas S. Early enteral nutrition within $24 \mathrm{~h}$ of intestinal surgery versus later commencement of feeding: a systematic review and meta-analysis. J Gastrointest Surg. 2009; 13(3):569-75.

17. Osland E, Yunus R, Khan S, Memon MA. Early enteral nutrition within $24 \mathrm{~h}$ of intestinal surgery versus later commencement of feeding: a systematic review and meta-analysis. J Gastrointest Surg. 2009;13(6):1163-5; author reply 1166-7.

18. Zhuang CL, Ye XZ, Zhang CJ, Dong QT, Chen BC, Yu Z. Early versus traditional postoperative oral feeding in patients undergoing elective colorectal surgery: a meta-analysis of randomized clinical trials. Dig Surg. 2013;30(3):225-32. 
19. Higgins JPT GS. Cochrane Handbook for Systematic Reviews of Interventions Version 5.1.0 [updated March 2011]. The Cochrane Collaboration, 2011. Available from www.cochranehandbook.org. 2011.

20. Moher D, Liberati A, Tetzlaff J, Altman DG, Group P. Preferred reporting items for systematic reviews and meta-analyses: the PRISMA statement. J Clin Epidemiol. 2009;62(10):1006-12.

21. McDermott FD, Heeney A, Kelly ME, Steele RJ, Carlson GL, Winter DC. Systematic review of preoperative, intraoperative and postoperative risk factors for colorectal anastomotic leaks. Br J Surg. 2015;102(5):462-79.

22. Bastin AJ, Davies N, Lim E, Quinlan GJ, Griffiths MJ. Systemic inflammation and oxidative stress post-lung resection: Effect of pretreatment with N-acetylcysteine. Respirology. 2016;21(1):180-7.

23. da Fonseca LM, Profeta da Luz MM, Lacerda-Filho A, Correia MI, Gomes da Silva R. A simplified rehabilitation program for patients undergoing elective colonic surgery--randomized controlled clinical trial. Int J Colorectal Dis. 2011;26(5):609-16.

24. Dag A, Colak T, Turkmenoglu 0, Gundogdu R, Aydin S. A randomized controlled trial evaluating early versus traditional oral feeding after colorectal surgery. Clinics. 2011;66(12):2001-5.

25. El Nakeeb A, Fikry A, El Metwally T, et al. Early oral feeding in patients undergoing elective colonic anastomosis. Int J Surg. 2009;7(3):206-9.

26. Hartsell PA, Frazee RC, Harrison JB, Smith RW. Early postoperative feeding after elective colorectal surgery. Arch Surg. 1997;132(5):518-20; discussion 520-1.

27. Lucha PA, Jr., Butler R, Plichta J, Francis M. The economic impact of early enteral feeding in gastrointestinal surgery: a prospective survey of 51 consecutive patients. Am Surg. 2005;71(3):187-90.

28. Minig L, Biffi R, Zanagnolo V, et al. Early oral versus "traditional" postoperative feeding in gynecologic oncology patients undergoing intestinal resection: a randomized controlled trial. Ann Surg Oncol. 2009;16(6):1660-8.

29. Pragatheeswarane M, Muthukumarassamy R, Kadambari D, Kate V. Early oral feeding vs. traditional feeding in patients undergoing elective open bowel surgery-a randomized controlled trial. J Gastrointest Surg. 2014;18(5):1017-23.

30. Reissman P, Teoh TA, Cohen SM, Weiss EG, Nogueras JJ, Wexner SD. Is early oral feeding safe after elective colorectal surgery? A prospective randomized trial. Ann Surg. 1995;222(1):73-7.

31. Stewart BT, Woods RJ, Collopy BT, Fink RJ, Mackay JR, Keck JO. Early feeding after elective open colorectal resections: a prospective randomized trial. Aust N Z J Surg. 1998;68(2):125-8.

32. Beier-Holgersen R, Boesby S. Influence of postoperative enteral nutrition on postsurgical infections. Gut. 1996;39(6):833-5.

33. Heslin MJ, Latkany L, Leung D, et al. A prospective, randomized trial of early enteral feeding after resection of upper gastrointestinal malignancy. Ann Surg. 1997;226(4):567-77; discussion 577-80.

34. Ortiz H, Armendariz P, Yarnoz C. Is early postoperative feeding feasible in elective colon and rectal surgery? Int J Colorectal Dis. 1996;11(3):119-21. 


\section{Supplemental material}

Supplemental Table S2.1

\begin{tabular}{|c|c|}
\hline \#1 & 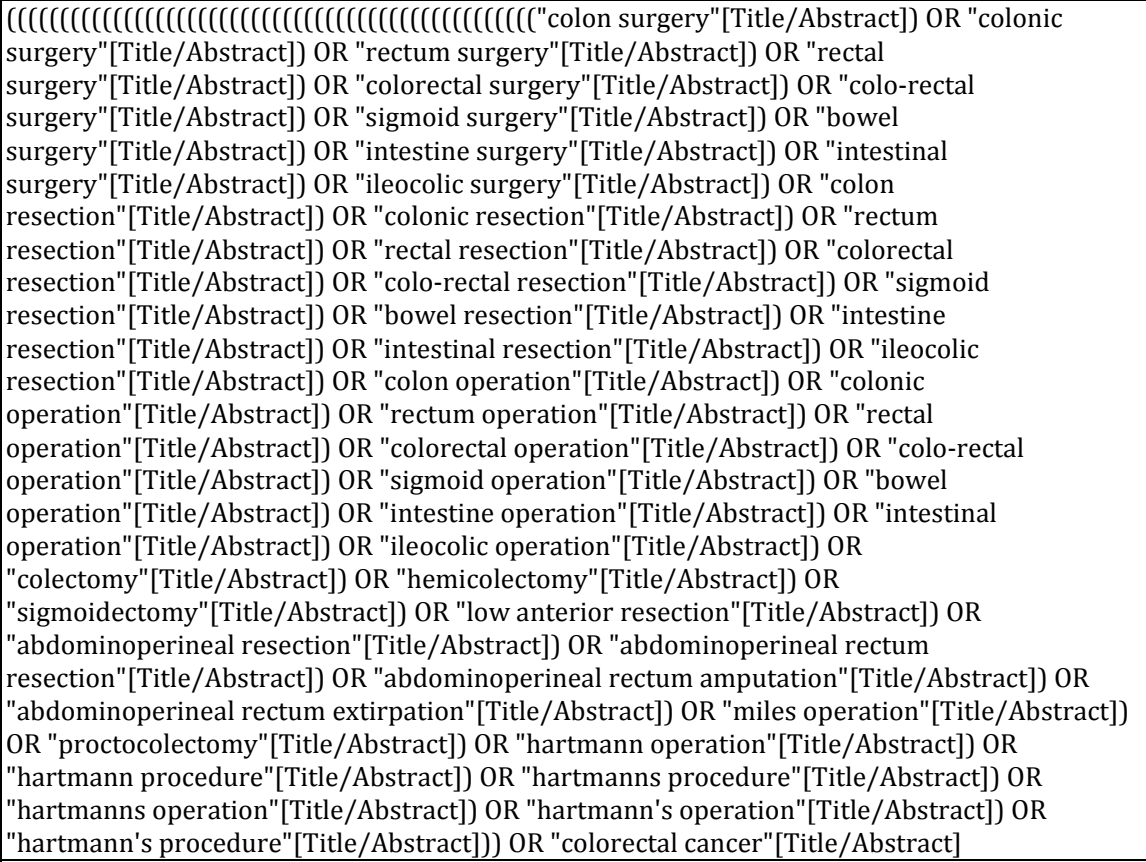 \\
\hline$\# 2$ & 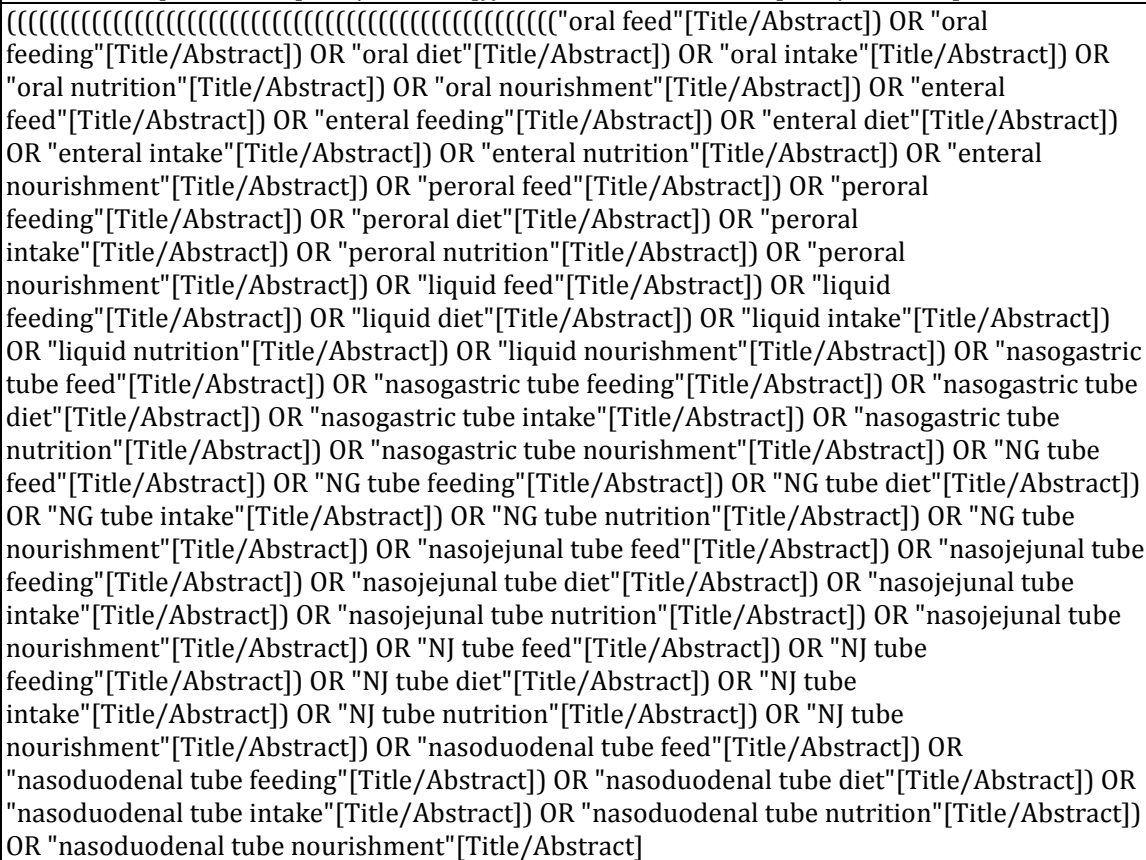 \\
\hline
\end{tabular}




\begin{tabular}{|c|c|}
\hline \#3 & 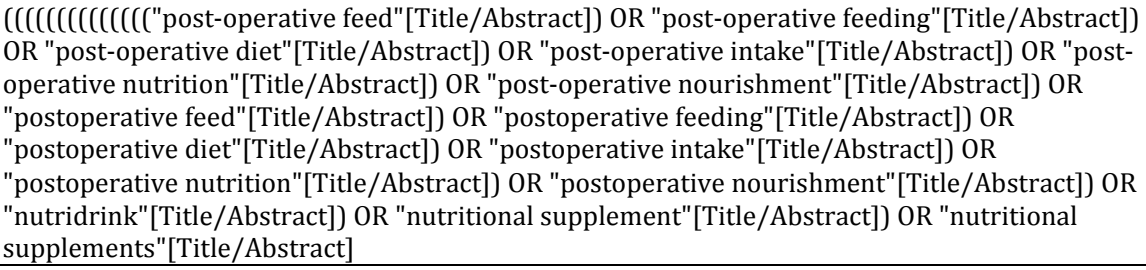 \\
\hline \#4 & \#2 OR \#3 \\
\hline \#5 & $\# 1$ AND \#4 \\
\hline
\end{tabular}





\section{Chapter}

\section{Beneficial effects of early enteral nutrition after major rectal surgery: a possible role for conditionally essential amino acids? Results of a randomized clinical trial}

van Barneveld KWY, Smeets BJJ, Heesakkers FFBM, Bosmans JWAM, Luyer MDP, Wasowicz D, Bakker JA, Roos AN, Rutten HJT, Bouvy ND, Boelens PG 


\section{Abstract}

Objective

To investigate direct postoperative outcome and plasma amino acid concentrations in a study comparing early enteral nutrition (EEN) versus early parenteral nutrition (EPN) after major rectal surgery. Previously, it was shown that a low plasma glutamine concentration represents poor prognosis in ICU patients.

Methods

A preplanned substudy of a previous prospective, randomized, open-label, single centre study, comparing EEN versus EPN in patients at high risk of postoperative ileus after surgery for locally advanced or locally recurrent rectal cancer. Early enteral nutrition reduced postoperative ileus, anastomotic leakage and hospital stay.

Setting

Tertiary referral centre for locally advanced and recurrent rectal cancer.

Patients

A total of 123 patients with locally advanced or recurrent rectal carcinoma

Interventions

Patients were randomized (ALEA web-based external randomization) preoperatively into two groups: early enteral nutrition (EEN, intervention) by nasojejunal tube $(n=61)$ or early parenteral nutrition (EPN, control) by jugular vein catheter $(n=62)$. Eight hours after the surgical procedure artificial nutrition was started in hemodynamically stable patients, stimulating oral intake in both groups. Blood samples were collected to measure plasma glutamine, citrulline and arginine concentrations using a validated UPLC-tandem mass spectrometric method.

Measurements \& Main Results

Baseline concentrations were comparable for both groups. Directly after rectal surgery, a decrease in plasma amino acids was observed. Plasma glutamine concentrations were higher in the parenteral group than in the enteral group on postoperative day $1(\mathrm{p}=0.027)$ and day $5(\mathrm{p}=0.008)$. Arginine concentrations were also significantly increased in the parenteral group at day $1(\mathrm{p}<0.001)$ and day 5 $(\mathrm{p}=0.001)$.

\section{Conclusions}

Lower plasma glutamine and arginine concentrations were measured in the enteral group, while a better clinical outcome was observed. We conclude that plasma amino acids do not provide a causal explanation for the observed beneficial effects of early enteral feeding after major rectal surgery. 


\section{Introduction}

Patients with primary or recurrent rectal cancer, requiring major rectal surgery beyond total mesorectal excision planes form a challenging and complex group. ${ }^{1}$ Distinct from 'simple' primary cancer, most patients in this group with locally advanced tumours require extended, multivisceral, exenterative surgery. ${ }^{1}$ In this population at high risk of postoperative ileus, we have previously studied the effect of supplemental early enteral versus early parenteral nutrition in a randomized controlled trial. ${ }^{2}$ Early enteral nutrition in this specific patient group was associated with clear advantages, including less postoperative ileus and less anastomotic leakage. ${ }^{2}$

The role of plasma amino acids in catabolic state has been subjected to extensive research in previous years. In particular, low plasma glutamine, arginine and citrulline levels have been related to poor outcomes in various patient groups. . $^{3-9}$ More recently, Hol et al. investigated the effect of surgical invasiveness on plasma amino acid levels. In this study, it was clearly shown that more invasive surgery is associated with lower postoperative plasma amino acid levels, such as citrulline and ornithine. ${ }^{10}$

Based on these observations, it is assumed that adequate supply of amino acids is advantageous in optimizing recovery from severe surgical trauma. Similarly, parenteral glutamine supplementation has been shown to improve outcome in the critically ill ${ }^{11}$, although serious adverse effects have also been described. ${ }^{12,13}$

We postulated that the anticipated postoperative low plasma levels of amino acids could be replenished by providing supplemental amino acids via artificial nutrition in patients undergoing major rectal surgery. Therefore, the aim of our present preplanned substudy was to investigate the beneficial effect of early enteral nutrition in comparison to early parenteral nutrition in relation to plasma glutamine, citrulline and arginine concentrations in patients with locally advanced or recurrent rectal cancer requiring aggressive surgery.

\section{Materials and methods}

This study was performed as a preplanned substudy of a single centre, open-label, randomized clinical trial comparing early enteral nutrition to early parenteral nutrition in patients undergoing major rectal surgery in a large tertiary referral hospital for locally advanced or recurrent rectal cancer. ${ }^{2}$ 


\section{Patient population}

Adult patients (age $\geq 18$ years) scheduled for elective major rectal surgery for malignancy were eligible for inclusion in the study. Patients were included after neoadjuvant (chemo-)radiation with or without intra-operative radiotherapy for locally advanced disease or locally recurrent rectal cancer. Written informed consent was obtained before randomization and surgery.

Patients were excluded in case of emergency rectal operations, simultaneous partial liver resection, pulmonary resection or hyperthermic intraperitoneal chemotherapy (HIPEC) treatment, the presence of oesophageal varices or known history of gastric or oesophageal bleeding.

The study protocol was approved by the medical ethical committee of the Catharina Hospital Eindhoven, the Netherlands (METC no. M06-1682) and was conducted by the Department of Surgery and the Department of Intensive Care. This trial was registered at www.trialregister.nl (no. NTR1523).

\section{Study objective}

The objective of this preplanned substudy was to investigate the influence of the route of administration of early supplemental artificial nutrition after rectal surgery on plasma glutamine, citrulline and arginine concentrations. Moreover, plasma amino acid concentrations were studied in relation to the impact of major rectal cancer surgery and the effect of artificial nutrition on clinical outcome. All study endpoints were predefined in the study protocol.

\section{Randomization and blinding}

A total of 123 patients were randomly assigned to one of both study groups by an independent, computer generated, online, external randomization programme (ALEA, NKI/AvL, the Netherlands Cancer Institute, Biometrics Department, Amsterdam, the Netherlands). To obtain similar groups, stratification was implemented for age, sex and neoadjuvant radiotherapy scheme (long/short). Patients were informed about their assignment to one of both treatment groups before surgery. Neither the physician nor the patient was blinded to treatment assignment. Laboratory workers were blinded for treatment allocation, patient or outcome data. In the original study, data of all randomized patients was used for final analysis, according to the intention-to-treat principle. ${ }^{2}$ No blood samples were included from patients who withdrew from this study; these patients were excluded from all analyses in this substudy. 


\section{Trial interventions}

Patients in the treatment arm received supplemental early enteral nutrition (EEN) postoperatively. In the control arm patients received early parenteral nutrition (EPN) to ensure caloric equivalence. Both groups were stimulated to progress to oral nutrition.

Patients randomized to early enteral nutrition (EEN) received a selfmigrating nasojejunal tube (Flocare Bengmark®, Nutricia, Advanced Medical Nutrition, Zoetermeer, the Netherlands) and enteral nutrition (Nutrison Protein Plus Multi Fibre ${ }^{\circledR}$, Nutricia, Advanced Medical Nutrition, Zoetermeer, the Netherlands). The nasojejunal tubes were inserted preoperatively at the ward, except in case of insertion problems. In this case the tube was placed during the surgical procedure. The surgeon confirmed its postpyloric position manually during the operation or postoperatively by means of an abdominal X-ray.

After induction of anaesthesia, patients randomized to early parenteral nutrition (EPN) received a jugular vein catheter as part of the standard procedure, followed by parenteral nutrition (Kabiven ${ }^{\circledR}$ Central, enriched with $200 \mathrm{ml}$ Dipeptiven® per day to ensure a higher supply of amino acids, Fresenius Kabi Nederland BV, 's Hertogenbosch, the Netherlands). Exact nutritional values of both formulas are shown in Table 3.1.

Table 3.1: Nutritional values of enteral versus parenteral intervention per $1000 \mathrm{ml}$.

\begin{tabular}{lcc}
\hline & Early enteral nutrition & Early parenteral nutrition \\
\hline Energy (kcal) & 1280 & 843.3 \\
Carbohydrates (g) & 141 & 88.8 \\
Fat (g) & 49 & 35.5 \\
Total amino acids (g), of which & 68.5 & 31.6 \\
Arginine (g) & 3.25 & 3.16 \\
Citrulline (g) & 0 & 0 \\
Glutamic acid / Glutamine (g) & 12.95 & 1.58 \\
Supplementary Glutamine (Dipeptiven) (g) & - & 11.9 \\
\hline
\end{tabular}

Nutritional values of enteral versus parenteral intervention. Enteral nutrition consisted of Nutrison Protein Plus Multi Fibre (Nutricia, Advanced Medical Nutrition, Zoetermeer, The Netherlands). Parenteral nutrition consisted of Kabiven Central enriched with Dipeptiven (Fresenius Kabi Nederland BV, 's Hertogenbosch, The Netherlands).

Artificial supplemental nutrition was provided for a minimum of 5 days postoperatively, with the exception of patients returning to a normal oral diet within 3 days. The postoperative nutritional protocol was standardized for both routes: 8 hours after ending the surgical procedure, nutrition was started at $500 \mathrm{ml} / 24$ hours at the day of surgery (day 0 ). The next day (postoperative day 1) at $8 \mathrm{~h} 00$ a.m., continuous infusion was increased to $1 \mathrm{l} / 24$ hours. On postoperative day 2, infusion was further increased to $21 / 24$ hours. Deviation of the artificial 
feeding protocol could occur due to medical reasons, adverse events, or patients' wish. All deviations were prospectively recorded.

The postoperative feeding regimen was determined by the patient's ability and willingness to consume food and was not dependent on intestinal function, such as passage of flatus or bowel movements. Oral magnesium and macrogol were available for both groups.

\section{Surgical technique and perioperative care}

After enrolment, the same protocol of perioperative management was applied to all patients. At the time of induction of anaesthesia, a single dose of intravenous antibiotic prophylaxis was administered. Furthermore, prophylactic low molecular weight heparin was administered subcutaneously. Participants in both study arms received a thoracic epidural catheter (TEC), unless the patient refused. This TEC was removed on postoperative day 3 or later. The catheters were infused with $0.25 \%$ bupivacaine hydrochloride plus $0.25-0.5 \mu \mathrm{g} / \mathrm{ml}$ sufentanil, administered at a rate of $8-10 \mathrm{ml} / \mathrm{h}$, with the rate reduced as quickly as possible. All patients received a jugular vein catheter, a nasogastric tube and a Bair-Hugger for temperature control. A cell saver was stand-by for all procedures. All patients underwent elective rectal surgery, such as low anterior resection (LAR) with primary anastomosis; abdominoperineal (sacral) excision (APE); or anterior, posterior or total pelvic exenteration with a Bricker urinary diversion if necessary. In case of possible non-radical resection, intra-operative radiotherapy (IORT) was performed. All operations were performed by, or under the close supervision of an experienced consultant surgeon. Access to the abdominal cavity was gained by an open approach via a midline laparotomy and/or a perineal incision, if necessary. A double-layer stapled side-to-end colorectal anastomosis was constructed when possible. In case of urinary anastomosis, a hand-sewn anastomosis was created.

If possible, nasogastric tubes were removed during extubation. However, in case of excessive blood loss and concomitant fluid resuscitation nasogastric tubes were not removed.

Anti-emetic drugs were standardized available for both groups. After the TEC had been removed, paracetamol and non-steroidal analgesics were combined with opioids intramuscularly if necessary to provide sufficient pain relief. The postoperative mobilization schedule was standardized according to in-house protocols and was comparable for both study groups. Predefined criteria for hospital discharge included stable vital signs with no febrile morbidity for at least $24 \mathrm{~h}$, passage of stool, toleration of a regular diet, and the absence of other complications. 


\section{Amino acid analysis}

At the day of surgery (day 0) prior to the surgical intervention, the first day after surgery (day 1), and the fifth day after surgery (day 5) before $10 \mathrm{~h} 00$ a.m., blood was collected in heparin tubes, which were directly put on ice. Within 15 minutes after collection, samples were centrifuged for 10 minutes at $2000 \mathrm{~g}$ in a $4^{\circ}$ Celsius cooled centrifuge. Two portions of $500 \mu \mathrm{l}$ plasma of each sample consecutively were put in two cryovials with $20 \mathrm{mg}$ dry sulfosalicylic acid for deproteinisation, vortexed, frozen in liquid nitrogen, and kept at $-80^{\circ} \mathrm{C}$ until analysis.

The concentrations of free amino acids were determined using UPLC-tandem mass spectrometry. Extracts $(10 \mu \mathrm{l})$ were diluted with $1500 \mu \mathrm{l}$ elution buffer, and mixed with $10 \mu \mathrm{l}$ stable isotope labelled internal standards solution. The injection volume was $5 \mu \mathrm{l}$, and run time 30 minutes, using an Acquity UPLC-unit coupled to a Micromass Quattro Premier XE tandem mass spectrometer (Waters, Milford VA). Chromatographic and mass spectrometric parameters were used according to a method published by Waterval et al.. ${ }^{14}$

\section{Statistical analysis and power calculation}

Continuous data are presented as a mean (s.d.), or as median (IQR). Other continuous data were compared using the Mann-Whitney U test, and categorical data with the $\chi^{2}$ test. Ninety-five per cent confidence intervals of proportions were calculated by the Wilson score method. Clinical endpoints were analysed on an intention-to-treat (ITT) basis. A Pearson's two-tailed correlation test was used to determine whether there was a statistically significant relationship between the amount of amino acids administered via artificial route and their respective plasma concentrations. In additional analyses, multiple linear regression models were used to identify the effects of type of nutrition on postoperative outcome. Statistical analyses were performed using SPSS $®$ version 21.0 (SPSS, Chicago, Illinois, USA). A two-sided $\mathrm{p}<0.050$ was considered statistically significant.

Amino acid concentrations were not taken into account in the power calculation of the original randomized controlled trial, as they were considered surrogate endpoints. ${ }^{2}$ Therefore, in the present substudy, a post hoc power analysis was performed for glutamine, arginine and citrulline concentrations on day 1 and 5 , using an $\alpha$ equal to 0.05 . In this way, it could be made clear whether our dataset was sufficiently powered to detect true significant differences in plasma amino acid concentrations between groups. 


\section{Results}

\section{Patient enrollment}

Between January 2009 and October 2011, patients were randomized in either the intervention group (EEN, $n=61)$, or the control arm (EPN, n=62). In the enteral nutrition group, five patients withdrew before nutritional intervention; of these patients no blood samples for amino acid analysis were obtained. In the control arm, no blood samples were collected from one patient due to technical reasons. See Figure 3.1 for the flow chart of patient enrolment. Furthermore, due to peritoneal metastases two patients did not receive rectal resection in the enteral group. Of these two patients, only baseline measurements were performed. All baseline patient characteristics are described in Table 3.2.

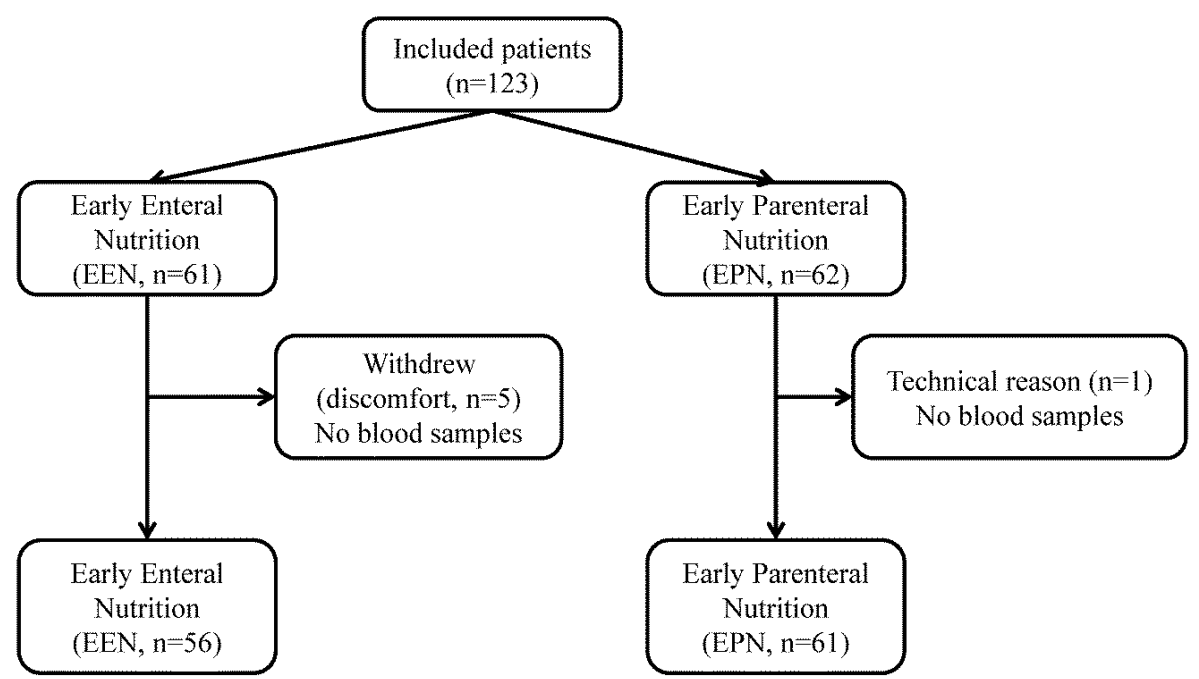

Figure 3.1: Flow diagram of patient inclusion and randomization outcomes. Five patients were excluded after randomization into the enteral group, because of withdrawal due to discomfort. From two patients in the enteral group only baseline samples were included, since rectal resection was not performed due to intraperitoneal metastases found perioperative. One patient from the parenteral group was excluded because no blood samples were obtained due to technical reasons. 
Table 3.2: Baseline characteristics of patients participating in amino acid analyses.

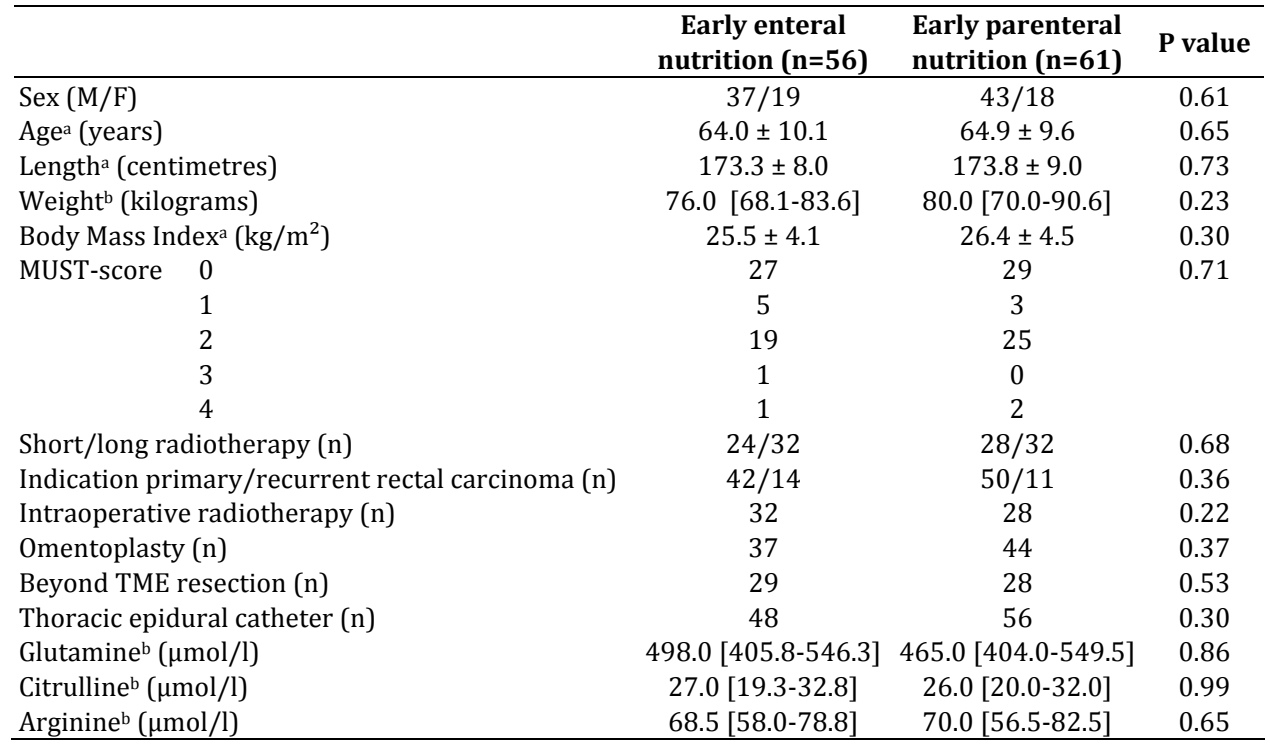

All values are numbers unless indicated otherwise. $\mathrm{a}=$ mean \pm standard deviation; $\mathrm{b}=$ median [interquartile range]. MUST = Malnutrition Universal Screening Tool.

\section{Nutritional intake}

All patients were stimulated to progress to oral intake. Advancement in oral intake did not show any differences between groups (Figure 3.2). As the exact nutritional values of oral intake were unknown, no estimates can be made regarding the total intake of calories or amino acids.

Over the first 5 postoperative days, cumulative caloric intake via artificial route was lower in the enteral group (Table 3.3). Similarly, cumulative intake of all amino acids via artificial route was significantly lower in the enteral group (Table 3.3).

\section{Clinical outcomes}

Clinical outcomes of the 123 patients are described in the original paper. ${ }^{2}$ Here, all endpoints were compared for the 117 patients included in the current substudy. Postoperative ileus during the first 5 days occurred in 10 patients in the enteral group versus 22 in the parenteral group ( $\mathrm{p}=0.027)$. Anastomotic leakage occurred in 1 patient in the enteral group versus 9 patients in the parenteral group $(\mathrm{p}=0.017)$; all underwent surgical repair. Total length of stay was not significantly shorter in the EEN group (EEN 12.00 [8.25-18.75] days versus EPN 14.00 [10.00-20.00] days, $\mathrm{p}=0.153$ ). 


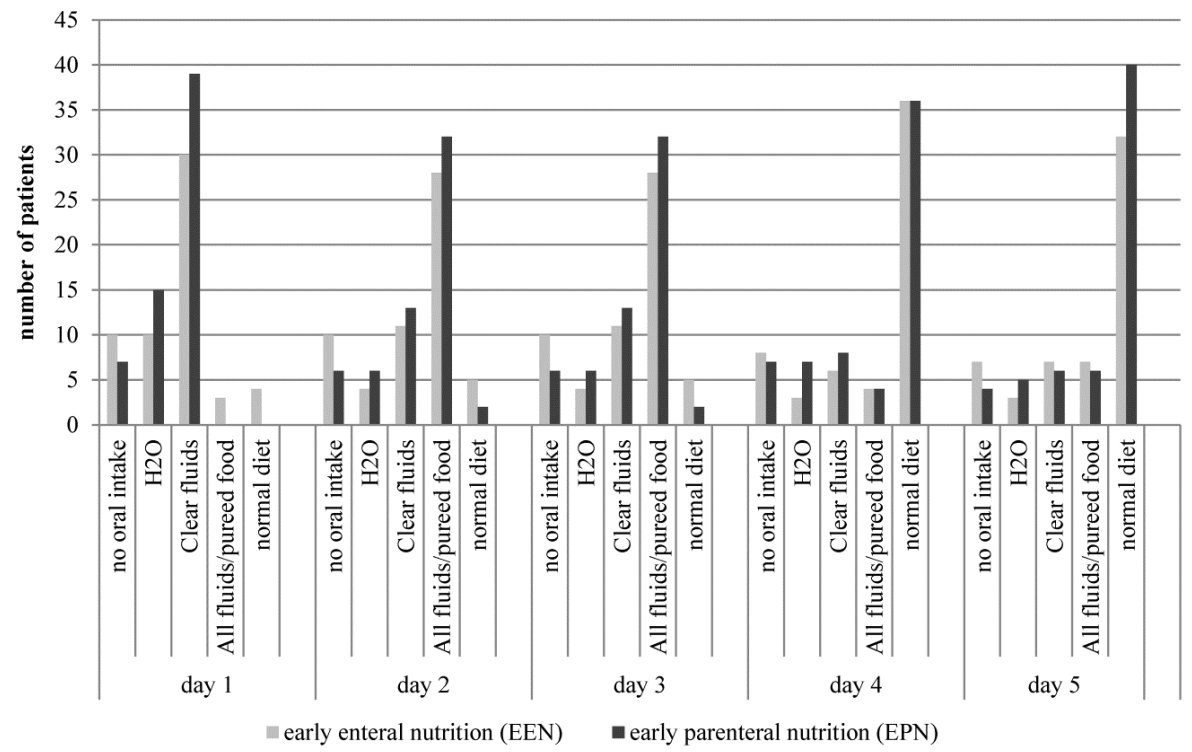

Figure 3.2: Oral intake classified in groups in the first 5 postoperative days (adapted with permission from Boelens et al.(2) Prospectively oral intake was recorded each consecutive day postoperatively. No oral intake, just water, clear fluids (mainly lemonade and tea), all drinks and pureed food, or normal diet are indicated per day and per group. Statistical analyses were performed using the Pearson chi-square test.

Table 3.3: Nutritional intake via artificial route.

\begin{tabular}{lccc}
\hline & $\begin{array}{c}\text { Early enteral } \\
\text { nutrition } \\
\text { (n=56) }\end{array}$ & $\begin{array}{c}\text { Early parenteral } \\
\text { nutrition } \\
\text { (n=61) }\end{array}$ & P value \\
\hline Cumulative caloric intake (kilocalories/5 days) & $5226.7[3049.7-7905.7]$ & $6976.5[5703.5-8243.0]$ & 0.007 \\
Cumulative total amino acids intake (g/5 days) & $286.9[159.5-405.5]$ & $349.6[279.8-409.7]$ & 0.037 \\
Cumulative arginine intake (g/5 days) & $14.3[7.7-20.1]$ & $25.4[19.9-29.8]$ & $<0.001$ \\
Cumulative citrulline intake & - & - & - \\
Cumulative glutamine intake (g/5 days) & $58.5[30.9-80.1]$ & $108.7[85.1-127.4]$ & $<0.001$ \\
\hline
\end{tabular}

Nutritional intake in the first 5 postoperative days via artificial route. All values are represented as median [interquartile range].

\section{Plasma amino acid concentrations}

Figure 3.3 shows the plasma amino acid concentrations at baseline, and on postoperative day 1 and 5 . At baseline, glutamine, citrulline and arginine were comparable for both groups (see Table 3.2). Directly after rectal surgery, a strong decrease in all amino acid concentrations was observed. 
In the parenteral group plasma glutamine concentrations were significantly higher on postoperative day 1 (EEN 354.0 [296.8-409.8] vs. EPN 383.0 [325.5-477.5], $\mathrm{p}=0.027$ ) and on postoperative day 5 (EEN 406.5 [339.8-457.3] vs. EPN 454.5 [401.0-516.8], $\mathrm{p}=0.008$ ).

Plasma citrulline concentrations did not show any significant differences between groups or within time (day 1: EEN 16.0 [14.0-22.0] $\mu$ mol/l vs. EPN 17.0 [13.0-20.0] $\mu \mathrm{mol} / \mathrm{l}$, n.s.; day 5: EEN 20.0 [14.0-25.3] $\mu \mathrm{mol} / \mathrm{l}$ vs. EPN 19.0 [15.0-24.0] $\mu \mathrm{mol} / \mathrm{l}$, n.s.).

In the parenteral group, significantly elevated plasma arginine concentrations were measured compared to the enteral group at both day 1 (EEN 38.0 [32.0-48.5] $\mu \mathrm{mol} / \mathrm{l}$ vs. EPN 52.0 [39.0-62.5] $\mu \mathrm{mol} / \mathrm{l}, \mathrm{p}<0.001$ ) and day 5 (EEN 60.5 [45.0-74.5] $\mu \mathrm{mol} / \mathrm{l}$ vs. EPN 81.5 [56.5-97.5] $\mu \mathrm{mol} / \mathrm{l}, \mathrm{p}=0.001$ ).

A post hoc power analysis was performed for amino acid concentrations on postoperative day 1 and day 5. The power of the sample analysis for glutamine, citrulline and arginine on day 1 was $0.52,0.28$ and 0.98 , respectively. The power for glutamine, citrulline and arginine on day 5 was $0.61,0.11$ and 0.94 , respectively. Thus, although our study was sufficiently powered only for arginine, significant differences between groups were seen also for glutamine.

\section{Correlations}

\section{Administration of amino acids and plasma concentrations}

Cumulative amount of glutamine administered via artificial route correlated with day 1 glutamine concentrations in the enteral group $(\mathrm{p}=0.032)$. Cumulative amount of arginine administered via artificial route correlated with day 5 arginine concentrations in the parenteral group $(\mathrm{p}=0.024)$.

No other significant correlations were found between cumulative amount of administered amino acids via artificial route, and plasma concentrations. Notably, oral intake was not registered and is thus not taken into account.

\section{Extent of surgery}

More extensive surgery (i.e. extra-mesorectal resection and concomitant organ resections) correlated with a longer duration of the operation $(p<0.001)$, a higher estimated blood loss $(p<0.001)$, less anastomotic leakage $(p=0.01)$, and lower concentrations of arginine on postoperative day $1(\mathrm{p}=0.003)$ and lower plasma glutamine on day $5(\mathrm{p}=0.013)$. In contrast, more extensive surgery did not correlate with plasma citrulline concentrations. 

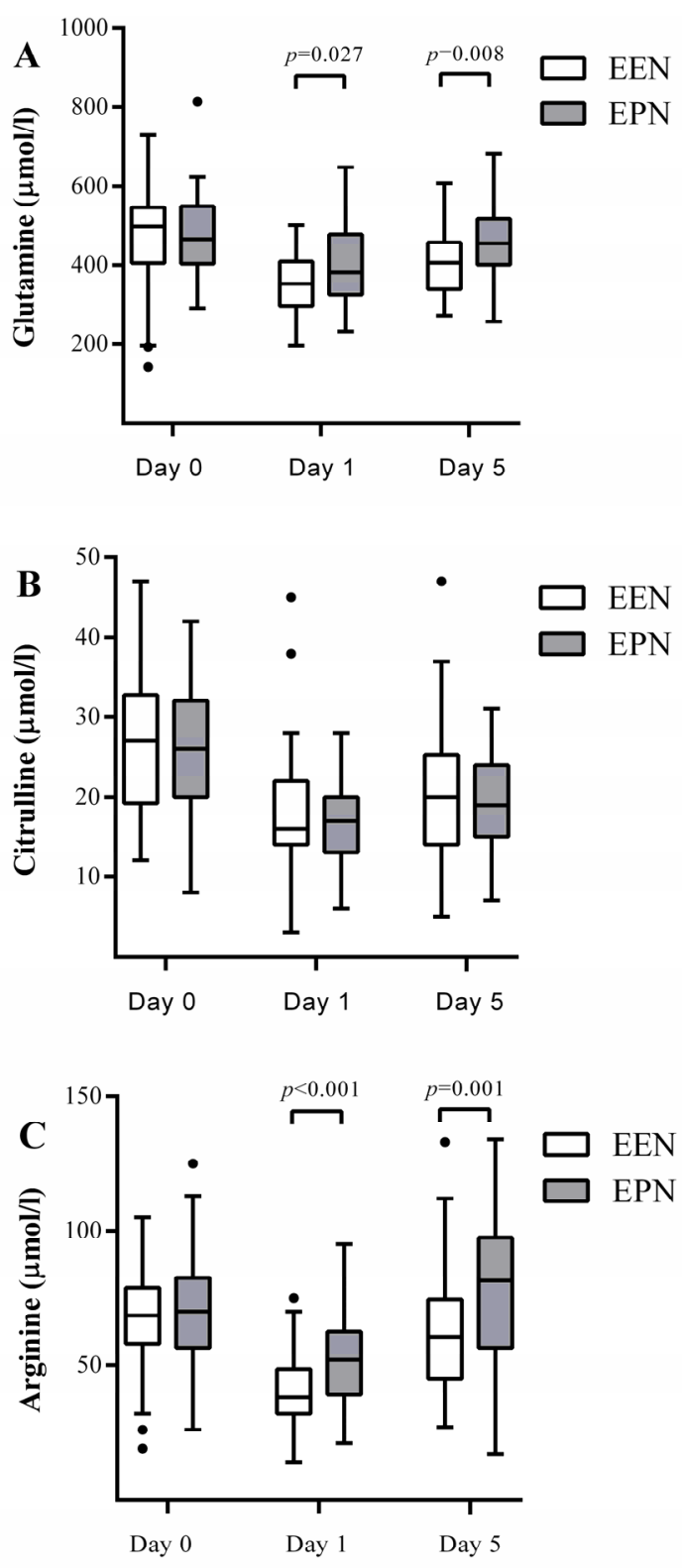

Figure 3A-C: Plasma concentrations of glutamine, citrulline and arginine. Boxplots representing the plasma concentrations of glutamine $(\mathbf{A})$, citrulline $(\mathbf{B})$ and arginine $(\mathbf{C})$ on day 0,1 and 5 . EEN = early enteral nutrition, EPN $=$ early parenteral nutrition. ${ }^{*} \mathrm{p}<0.05$ between groups. 


\section{Anastomotic leakage}

The occurrence of anastomotic leakage was associated with early parenteral feeding $(\mathrm{p}=0.012)$, a longer hospital admission $(\mathrm{p}<0.001)$, and more infectious complications $(\mathrm{p}<0.001)$. In contrast, it did not correlate with the duration of surgery, the amount of blood loss or plasma amino acid concentrations.

\section{Other factors}

Plasma amino acid concentrations did not correlate with the occurrence of infectious complications. Furthermore, it was observed that a longer duration of the operation was associated with a higher estimated blood loss $(\mathrm{p}<0.001)$, and lower plasma concentrations of both citrulline and arginine.

\section{Linear regression analysis}

Multiple linear regression analysis showed positive correlation between the occurrence of anastomotic leakage and parenteral nutrition $(\mathrm{r}=0.24, \mathrm{p}=0.006)$, length of stay $(r=0.53, p<0.001)$, absence of extra organ resections $(r=0.24$, $\mathrm{p}=0.005)$ and infectious complications $(\mathrm{r}=0.65, \mathrm{p}<0.001)$. Furthermore, it showed a positive correlation between parenteral nutrition and glutamine concentrations at day $5(\mathrm{r}=0.19, \mathrm{p}=0.021)$, arginine concentrations at day $5(\mathrm{r}=0.30, \mathrm{p}=0.001)$ and infectious complications ( $\mathrm{r}=0.17, \mathrm{p}=0.038$ ).

\section{Discussion and conclusions}

The present preplanned substudy investigated the effect of the route of artificial nutrition on plasma amino acid concentrations in patients undergoing major rectal surgery. All patients undergoing extensive rectal surgery showed a direct postoperative strong decrease of plasma amino acids. Partial recovery of plasma concentrations was found on the fifth postoperative day, but these did not reach baseline values in both groups. Remarkably, significantly lower concentrations of plasma glutamine and arginine were measured in the enteral nutrition group on both postoperative day 1 and 5, while less anastomotic leakage and less postoperative ileus was observed in this group. ${ }^{2}$

Because our patient population underwent extreme surgical trauma, this metabolic disturbance could be considered to resemble a model of severe sepsis or trauma. Preoperative treatments including radiotherapy or chemoradiation schemes were followed by extensive rectal resections for locally advanced or recurrent rectal cancer, and during surgery quite some patients underwent intraoperative radiation therapy (IORT). It is known that the extent of the surgery and the application of 
IORT both increase the duration of the operation, concomitant blood loss, and the intensity of fluid resuscitation. As observed by Luiking et al. ${ }^{5}$, patients in a catabolic state can show lowered plasma amino acid concentrations, which are amongst others associated with a decrease of nitric oxide (NO) production. ${ }^{5}$ Our patient population showed even lower plasma glutamine, arginine and citrulline concentrations, compared to the severely septic patients at the ICU department described by Luiking. ${ }^{5}$

Under normal physiological circumstances, amino acids like glutamine and arginine are known to be available in sufficient amounts. Amino acids are crucial for maintaining body homeostasis, for example they provide substrate for glutathione synthesis, gluconeogenesis, serve as an important metabolic fuel for enterocytes, hepatocytes and immune cells, and preserve cell membranes by enhancing heat shock protein generation. ${ }^{4,6,9,15-17}$

Amino acids play a major role in patients suffering from a catabolic state: critical illness, major trauma, sepsis, or even after major surgery. ${ }^{18}$ In these states, it is believed that the body's requirements for glutamine and arginine are strongly increased, whereas synthesis and uptake are decreased. ${ }^{9,18}$ This imbalance may lead to a reduced tissue availability of amino acids.

Several studies have demonstrated that glutamine in particular is an important and possibly conditional essential amino acid during metabolic stress. ${ }^{18-20}$ Glutamine is considered to play an important role as a substrate for enterocytes and in NO homeostasis. ${ }^{15,21}$ Glutamine can be metabolized via different pathways, leading to increased levels of arginine. Arginine is the precursor for NO and as such is important for vasodilatation (organ perfusion), neoangiogenesis (wound healing) and immune function. ${ }^{15,21}$ In addition, arginine can be metabolized by arginase to ornithine (and urea), which is important for the synthesis of collagen and polyamines, which are important in adequate wound and intestinal anastomotic healing. ${ }^{22,23}$

In a previous study, it was demonstrated that intestinal glutamine metabolism is highly dependent of the amount of glutamine supply. ${ }^{21}$ Furthermore, it was shown that glutamine is an important precursor for the synthesis of arginine, after intestinal conversion to citrulline. ${ }^{21}$ In the intervention group of the present study, we used protein rich enteral feeding. This type of nutrition first needs to be hydrolyzed in the gut to enable intestinal uptake and metabolism of glutamine. In contrast, parenteral supplementation of dipeptides results in a direct, rapid steady state increase in plasma glutamine (and alanine) concentrations. ${ }^{24,25}$ Also, the effect on plasma arginine concentrations is higher when dipeptides are administered intravenously. ${ }^{24}$ Our findings in the current substudy, in which plasma concentrations were higher in patients fed parenterally, are in line with this study. ${ }^{24}$ 
In the search for answers, we postulated the hypotheses described hereafter. After undergoing major surgical trauma, the drop in plasma glutamine and arginine levels could be a result of luminal fasting (decreased intake of amino acids), loss of amino acids by blood loss and hemodilution due to resuscitation, increased uptake by enterocytes for healing of anastomosis and damaged enterocytes healing, and increased energy expenditure by gut-associated lymphoid tissue, hepatocytes and gluconeogenesis. Furthermore, extensive surgery or severe blood loss can induce splanchnic hypoperfusion, which could cause mucosal acidosis and may interfere with $\mathrm{pH}$ dependent amino acid uptake by the intestinal mucosa. ${ }^{26}$

In literature, there is an ongoing discussion about the body's need for having an adequate amount of plasma arginine available, and the importance of maintaining or restoring this concentration under various (patho)physiological circumstances. ${ }^{15,17,25,27}$ In stress situations comparable to our study population, in our view, it would be beneficial to have a sufficient amount of glutamine and arginine available since arginine is the main precursor for NO and therefore regulates vasodilatation, neoangiogenesis and immune function. ${ }^{15,21} \mathrm{In}$ addition, it is an important precursor for ornithine, which regulates collagen synthesis. ${ }^{22,23}$ In contrast to this, we found a lower concentration of plasma glutamine and arginine in the enteral group, which was the group with less anastomotic leakage and less postoperative ileus.

In catabolic patients, exogenous amino acid administration via enteral and parenteral formulas seems a promising solution to overcome the increased demands. ${ }^{17,18,24,28}$ Exogenous amino acid supplementation in theory improves NO homeostasis, preserves normal body water distribution, and protects the host from gut-derived endotoxemic complications. Several studies have been conducted on exogenous amino acid supplementation, with divergent effects observed.12,13,18 The benefits of supplementation of arginine are not uniformly proven and accepted. Many side effects of this therapy have been observed. During critical illness extra arginine may even deteriorate the patients' situation, possibly with a higher mortality rate. ${ }^{15,17,29}$ Glutamine has shown to be an effective precursor for arginine and ornithine, and likely restores the optimal balance between arginine production and metabolism as well as improving NO homeostasis and related functions. ${ }^{15}$ However, recent randomized controlled trials have challenged the safety of supplementation of glutamine in critically ill patients. ${ }^{12,13}$ In these studies, higher mortality rates were seen after 6 months in groups receiving supplementary glutamine. Excess amounts of glutamine are postulated to induce an increased inflammatory response and in this way deteriorate clinical outcome. ${ }^{30}$ Notably, in these trials glutamine was administered in higher doses to mechanically ventilated ICU patients, in contrast to our study in which a lower dose was administered in a supplementary fashion to a different patient population. 
It has been established in various experimental models that the route, either intravenously or enterally, of amino acid administration has implications on the metabolism and availability of amino acids. ${ }^{17,18,20,24,25,28,31,32}$ After infusion with dipeptides, both routes showed an increase in plasma concentrations of both glutamine and citrulline, with the parenteral route causing the highest increase. ${ }^{24}$ In studies using stable isotopes, it has been shown that enteral supplementation of glutamine results in higher amounts of de novo synthesis of citrulline and arginine. ${ }^{24,25}$ In rats, it was shown that enteral supplementation of glutamine stimulates glutaminase activity and therefore enhances intestinal glutamine metabolism, but the exact mechanism still has to be unraveled. ${ }^{25}$

In conclusion, lower plasma glutamine and arginine concentrations were measured in the enteral group, while a better clinical outcome was observed in comparison to patients fed parenterally. In contrast to the study in ICU patients showing the relation between low plasma glutamine concentrations and outcome, based on our measurements we conclude that plasma amino acid concentrations do not provide a causal explanation for the observed beneficial effects of early enteral feeding after major rectal surgery. However, as the power calculations of amino acid concentrations were not as robust as those of the primary endpoints in the original trial, the findings in the present substudy may be coincidental and warrant further research. 


\section{References}

1. Beyond TMEC. Consensus statement on the multidisciplinary management of patients with recurrent and primary rectal cancer beyond total mesorectal excision planes. Br J Surg. 2013; 100(8):E1-33.

2. Boelens PG, Heesakkers FF, Luyer MD, van Barneveld KW, de Hingh IH, Nieuwenhuijzen GA, Roos AN, Rutten HJ. Reduction of postoperative ileus by early enteral nutrition in patients undergoing major rectal surgery: prospective, randomized, controlled trial. Ann Surg. 2014;259(4):649-55.

3. Freund H, Atamian S, Holroyde J, Fischer JE. Plasma amino acids as predictors of the severity and outcome of sepsis. Ann Surg. 1979;190(5):571-6.

4. Visser M, Vermeulen MA, Richir MC, Teerlink T, Houdijk AP, Kostense PJ, Wisselink W, de Mol BA, van Leeuwen PA, Oudemans-van Straaten HM. Imbalance of arginine and asymmetric dimethylarginine is associated with markers of circulatory failure, organ failure and mortality in shock patients. Br J Nutr. 2012;107(10):1458-65.

5. Luiking YC, Poeze M, Ramsay G, Deutz NE. Reduced citrulline production in sepsis is related to diminished de novo arginine and nitric oxide production. Am J Clin Nutr. 2009;89(1):142-52.

6. Wischmeyer PE: Glutamine: mode of action in critical illness. Crit Care Med. 2007;35(9 Suppl):S541-4.

7. Wijnands KA, Castermans TM, Hommen MP, Meesters DM, Poeze M. Arginine and citrulline and the immune response in sepsis. Nutrients. 2015;7(3):1426-63.

8. Rodas PC, Rooyackers O, Hebert C, Norberg A, Wernerman J. Glutamine and glutathione at ICU admission in relation to outcome. Clin Sci. 2012;122(12):591-7.

9. Oudemans-van Straaten HM, Bosman RJ, Treskes M, van der Spoel HJ, Zandstra DF. Plasma glutamine depletion and patient outcome in acute ICU admissions. Intensive Care Med. 2001; 27(1):84-90.

10. Hol JW, van Lier F, Valk M, Klimek M, Stolker RJ, Fekkes D. Effect of major and minor surgery on plasma levels of arginine, citrulline, nitric oxide metabolites, and ornithine in humans. Ann Surg. 2013;258(6):1072-1078.

11. Wischmeyer PE, Dhaliwal R, McCall M, Ziegler TR, Heyland DK. Parenteral glutamine supplementation in critical illness: a systematic review. Crit Care. 2014;18(2):R76.

12. van Zanten AR, Sztark F, Kaisers UX, Zielmann S, Felbinger TW, Sablotzki AR, De Waele JJ, Timsit JF, Honing ML, Keh D, et al. High-protein enteral nutrition enriched with immune-modulating nutrients vs standard high-protein enteral nutrition and nosocomial infections in the ICU: a randomized clinical trial. JAMA. 2014;312(5):514-24.

13. Heyland D, Muscedere J, Wischmeyer PE, Cook D, Jones G, Albert M, Elke G, Berger MM, Day AG, Canadian Critical Care Trials G. A randomized trial of glutamine and antioxidants in critically ill patients. N Engl J Med. 2013;368(16):1489-97.

14. Waterval WA, Scheijen JL, Ortmans-Ploemen MM, Habets-van der Poel CD, Bierau J. Quantitative UPLC-MS/MS analysis of underivatised amino acids in body fluids is a reliable tool for the diagnosis and follow-up of patients with inborn errors of metabolism. Clin Chim Acta. 2009;407(12):36-42.

15. Luiking YC, Ten Have GA, Wolfe RR, Deutz NE. Arginine de novo and nitric oxide production in disease states. Am J Physiol: Endocrinol Metab. 2012;303(10):E1177-89.

16. van Stijn MF, Ligthart-Melis GC, Boelens PG, Scheffer PG, Teerlink T, Twisk JW, Houdijk AP, van Leeuwen PA. Antioxidant enriched enteral nutrition and oxidative stress after major gastrointestinal tract surgery. World J Gastroenterol. 2008;14(45):6960-9.

17. Vermeulen MA, van de Poll MC, Ligthart-Melis GC, Dejong CH, van den Tol MP, Boelens PG, van Leeuwen PA. Specific amino acids in the critically ill patient--exogenous glutamine/arginine: a common denominator? Crit Care Med. 2007;35(9 Suppl):S568-76.

18. Boelens PG, Nijveldt RJ, Houdijk AP, Meijer S, van Leeuwen PA. Glutamine alimentation in catabolic state. J Nutr. 2001;131(9 Suppl):2569S-77S; discussion 2590S. 
19. Le Bacquer O, Nazih H, Blottiere H, Meynial-Denis D, Laboisse C, Darmaun D. Effects of glutamine deprivation on protein synthesis in a model of human enterocytes in culture. Am J Physiol Gastrointest Liver Physiol. 2001;281(6):G1340-7.

20. Le Bacquer O, Laboisse C, Darmaun D. Glutamine preserves protein synthesis and paracellular permeability in Caco-2 cells submitted to "luminal fasting". Am J Physiol Gastrointest Liver Physiol. 2003;285(1):G128-36.

21. van de Poll MC, Ligthart-Melis GC, Boelens PG, Deutz NE, van Leeuwen PA, Dejong CH. Intestinal and hepatic metabolism of glutamine and citrulline in humans. J Physiol. 2007;581(Pt 2):819-27.

22. Debats IB, Wolfs TG, Gotoh T, Cleutjens JP, Peutz-Kootstra CJ, van der Hulst RR. Role of arginine in superficial wound healing in man. Nitric Oxide. 2009;21(3-4):175-83.

23. Morris SM, Jr. Regulation of enzymes of urea and arginine synthesis. Annu Rev Nutr. 1992;12: 81-101.

24. Melis GC, Boelens PG, van der Sijp JR, Popovici T, De Bandt JP, Cynober L, van Leeuwen PA. The feeding route (enteral or parenteral) affects the plasma response of the dipetide Ala-Gln and the amino acids glutamine, citrulline and arginine, with the administration of Ala-Gln in preoperative patients. Br J Nutr. 2005;94(1):19-26.

25. Boelens PG, Melis GC, van Leeuwen PA, ten Have GA, Deutz NE. Route of administration (enteral or parenteral) affects the contribution of L-glutamine to de novo L-arginine synthesis in mice: a stable-isotope study. Am J Physiol Endocrinol Metab. 2006;291(4):E683-90.

26. van Wijck K, Lenaerts K, Grootjans J, Wijnands KA, Poeze M, van Loon LJ, Dejong CH, Buurman WA. Physiology and pathophysiology of splanchnic hypoperfusion and intestinal injury during exercise: strategies for evaluation and prevention. Am J Physiol Gastrointest Liver Physiol. 2012; 303(2):G155-68.

27. Luiking YC, Poeze M, Ramsay G, Deutz NE. The role of arginine in infection and sepsis. JPEN J Parent Enteral Nutr. 2005;29(1 Suppl):S70-4.

28. Rouge C, Des Robert C, Robins A, Le Bacquer O, Volteau C, De La Cochetiere MF, Darmaun D. Manipulation of citrulline availability in humans. Am J Physiol Gastrointest Liver Physiol. 2007; 293(5):G1061-7.

29. Bertolini G, Iapichino G, Radrizzani D, Facchini R, Simini B, Bruzzone P, Zanforlin G, Tognoni G. Early enteral immunonutrition in patients with severe sepsis: results of an interim analysis of a randomized multicentre clinical trial. Intensive Care Med. 2003;29(5):834-40.

30. Oudemans-van Straaten HM, van Zanten AR. Glutamine supplementation in the critically ill: friend or foe? Crit Care. 2014, 18(3):143.

31. Boelens PG, van Leeuwen PA, Dejong CH, Deutz NE. Intestinal renal metabolism of L-citrulline and L-arginine following enteral or parenteral infusion of L-alanyl-L-[2,15N]glutamine or L[2,15N]glutamine in mice. Am J Physiol Gastrointest Liver Physiol. 2005;289(4):G679-85.

32. Harvey SE, Parrott F, Harrison DA, Bear DE, Segaran E, Beale R, Bellingan G, Leonard R, Mythen MG, Rowan KM, et al. Trial of the route of early nutritional support in critically ill adults. N Engl J Med. 2014;371(18):1673-84. 


\section{Chapter}

\section{Anti-oxidative amino acids in early enteral versus parenteral nutrition following major rectal surgery}

Smeets BJJ, Heesakkers FFBM, Huijbregts CP, Luyer MDP, Bakker JA, Roos AN, Rutten HJT, Bouvy ND, Boelens PG 


\section{Abstract}

Background

Early enteral nutrition (EEN) reduced complications when compared to early parenteral nutrition (EPN) following major rectal surgery. Changes in antioxidative amino acids may play a role.

Methods

This is a preplanned substudy of a previous trial in which 123 patients were randomized to EEN versus EPN after surgery for locally advanced or recurrent rectal cancer. Plasma concentrations of glycine, taurine, $\mathrm{N}$-acetylcysteine, glutamic acid, and hydroxyproline were measured preoperatively and on postoperative day (POD) 1 and 5, and compared between groups. Furthermore, multivariable linear regression analysis was used to study the relation between plasma amino acid concentrations and clinical outcomes.

Results

Glycine concentrations were lower in the EEN-group than in the EPN-group on POD1 ( $\mathrm{p}=0.003)$ and on POD5 ( $\mathrm{p}=0.005)$. Plasma concentrations of other amino acids were similar between groups. No significant associations were found between clinical outcomes and any plasma amino acid concentration.

Conclusion

Plasma amino acid concentrations were similar or lower in the EEN-group when compared to the EPN-group, while a better clinical outcome was observed. Plasma concentrations of anti-oxidative amino acids do not explain the differences in clinical outcomes between patients randomized to EEN versus EPN. 


\section{Introduction}

Patients with locally advanced or recurrent rectal cancer require major multivisceral resections and are at high risk of complications. ${ }^{1}$ In the early postoperative period, these patients often require vasopressors, do not tolerate an early oral diet, and have a high incidence of postoperative ileus. ${ }^{2}$ Supplementary artificial nutrition may help achieve adequate nutritional intake and improve postoperative recovery. In a previous randomized study, early enteral nutrition (EEN) reduced postoperative ileus and anastomotic leakage when compared to early parenteral nutrition (EPN) after major rectal surgery. However, the underlying mechanisms are unclear and other recent studies show contrasting results regarding the optimal route of nutritional support in critically ill patients. ${ }^{3-5}$ Delineating the mechanisms underlying the effects of nutrition on clinical outcomes may provide more insight in this matter.

In patients undergoing major surgical trauma, the release of reactive oxygen species (ROS) induces oxidative stress which can impair anastomotic wound healing and contribute to the development of postoperative ileus. ${ }^{6-10}$ Anti-oxidative amino acids (AAs) such as glutathione, taurine, and hydroxyproline can scavenge ROS and reduce oxidative stress. ${ }^{11-16}$ In addition, glycine and hydroxyproline are essential for collagen-synthesis in wound healing. ${ }^{16-18}$ However, surgery induces a significant drop in AA concentrations. ${ }^{19,20}$ This may impair postoperative recovery by limiting the host's ability to cope with the excessive release of ROS following major surgical trauma. ${ }^{21,22}$

To explain the differences in clinical outcomes, we hypothesized that postoperative AA concentrations may differ between patients receiving EEN versus EPN. In this preplanned substudy, plasma concentrations of anti-oxidative AAs were studied in patients randomized to EEN versus EPN following major rectal surgery. Furthermore, the relation between AA concentrations and clinical outcomes was investigated.

\section{Materials and methods}

\section{Aim}

This was a substudy of a prospective, single-center, randomized controlled trial. ${ }^{23}$ The aim was to investigate whether the route of supplementary nutrition early after major rectal surgery affected plasma concentrations of anti-oxidative AAs. Furthermore, anti-oxidative AAs were studied in relation to occurrence of anastomotic leakage, postoperative ileus, and length of stay. The local medical ethical committee approved the original study protocol. 


\section{Patient population}

A total of 123 patients (age $\geq 18$ years) undergoing surgical resection of primary locally advanced (cT3 or cT4) or recurrent rectal carcinoma were included after providing written informed consent. Exclusion criteria were emergency rectal operations, simultaneous partial liver resection, pulmonary resection, hyperthermic intraperitoneal chemotherapy treatment, esophageal varices, or history of gastric or esophageal bleeding.

\section{Randomization and blinding}

Patients were randomized to an intervention group by an independent, computergenerated, online, external randomization program. Stratification was implemented for age, sex, and duration of neoadjuvant radiotherapy. Laboratory workers were blinded for treatment allocation, and for patient and outcome data. No blood samples were obtained from patients who withdrew informed consent.

\section{Surgical technique and perioperative care}

All patients underwent elective, open rectal surgery, including low anterior resection, abdominoperineal excision, or pelvic exenteration. A colorectal anastomosis was constructed when possible. In case of a possible non-radical resection, intra-operative radiotherapy was performed. All patients received mechanical bowel preparation (low-volume polyethylene glycol) the night before surgery. All patients were given prophylactic low molecular weight heparin subcutaneously, and antibiotic prophylaxis was administered during induction of anesthesia. A thoracic epidural catheter was placed and infused with $0.25 \%$ bupivacaine-hydrochloride plus $0.25-0.5 \mu \mathrm{g} / \mathrm{ml}$ sufentanil at $8-10 \mathrm{ml} / \mathrm{h}$, except when patients refused. The rate was reduced postoperatively as quickly as possible. All patients received a nasogastric tube, jugular vein catheter, and Bair Hugger (3M, St. Paul, MN). Nasogastric tubes were routinely removed during extubation, unless in case of excessive blood loss and concomitant fluid resuscitation. The epidural catheter was removed on postoperative day (POD) 3 or later; paracetamol and nonsteroidal analgesics were combined with opioids intramuscularly for pain relief if necessary. Oral magnesium, macrogol and anti-emetic drugs were available for both groups. Discharge criteria were stable vital signs with no febrile morbidity for 24 hours, passage of stool, toleration of a regular diet, and absence of complications. 


\section{Trial interventions}

After surgery, all patients were stimulated to progress to an oral intake. Furthermore, before surgery patients in the EEN-group received a self-migrating nasojejunal tube (Flocare Bengmark $\AA$, Nutricia, Advanced Medical Nutrition, Zoetermeer, the Netherlands) through which enteral nutrition (Nutrison Protein Plus Multi Fibre ${ }^{\circledR}$, Nutricia, Advanced Medical Nutrition, Zoetermeer, the Netherlands) was administered postoperatively. In the EPN-group, patients received parenteral nutrition (Kabiven Central®, Fresenius Kabi Nederland BV, 's Hertogenbosch, the Netherlands) through a jugular vein catheter. The parenteral feed was enriched with Dipeptiven ${ }^{\circledR}$ (Fresenius Kabi Nederland BV, 's Hertogenbosch, the Netherlands) to ensure similar AA concentrations in both feeds. Supplemental Table S4.1 demonstrates exact nutritional values of both formulas. The artificial feeding protocol was similar for both routes: 8 hours after ending the surgical procedure, nutrition was started at $500 \mathrm{ml} / 24$ hours. The next day (POD1) at $8 \mathrm{AM}$, the continuous infusion was increased to 1l/24 hours; on POD2, the infusion was increased to 2l/24 hours. Artificial nutrition was continued for the first 5 postoperative days, except in patients who had a more rapid return to normal oral diet within 3 days. The feeding regimen was determined by the patient's ability and willingness to consume food; it was not dependent on intestinal function such as passage of flatus or stool. Progression of oral intake was prospectively registered in patient diaries on a daily basis. Patients undergoing major rectal surgery are often unable to tolerate a full oral diet during the first postoperative days (e.g. due to nausea and/or vomiting). As such, exact nutritional value of oral intake was impossible to measure. Protocol violations could occur due to medical reasons, adverse events or patient's wishes and were recorded.

\section{Clinical outcomes}

All postoperative complications were recorded prospectively on a daily basis. Patients were followed for at least 30 days after surgery or until discharge. Anastomotic leakage was defined as clinical suspicion of leakage of the anastomosis, confirmed by computed tomography scanning showing free abdominal air and fluids in close proximity to the anastomosis or a visually dehiscent anastomosis during reoperation. Postoperative ileus was defined as having symptoms of failing gastrointestinal transit (nausea and vomiting, intolerance of normal diet, absence of defecation, nasogastric tube reinsertion), and was categorized in early ileus (occurring within the first 5 postoperative days), prolonged ileus (lasting longer than POD5), and late ileus (symptoms occurring first after POD5). 


\section{Amino acid analysis}

Plasma concentrations of taurine and hydroxyproline were determined before surgery (day 0), and on POD1 and POD5. The tripeptide glutathione is rapidly removed from plasma and primarily stored intracellularly by tissues rich in $\gamma$-glutamyl transpeptidase, making accurate measuring in plasma difficult. Therefore, plasma concentrations of its precursors glutamic acid, glycine and $\mathrm{N}$-acetylcysteine were analyzed as surrogate markers for glutathione. ${ }^{24}$

Blood samples were collected in heparin tubes and put directly on ice. Within 15 minutes after collection, samples were centrifuged for 10 minutes at $2000 \mathrm{~g}$ in a $4{ }^{\circ} \mathrm{C}$ cooled centrifuge. Two portions of $500 \mu \mathrm{l}$ plasma of each sample were consecutively put in two cryovials with $20 \mathrm{mg}$ dry sulfosalicylic acid for deproteinisation, vortexed, frozen in liquid nitrogen, and stored at $-80^{\circ} \mathrm{C}$. Concentrations of free AAs were determined using UPLC-tandem mass spectrometry. Extracts $(10 \mu \mathrm{l})$ were diluted with $1500 \mu \mathrm{l}$ elution buffer, and mixed with $10 \mu \mathrm{l}$ stable isotope labeled internal standards solution. The injection volume was $5 \mu \mathrm{l}$, and run time 30 minutes, using an Acquity UPLC-unit coupled to a Micromass Quattro Premier XE tandem mass spectrometer (Waters, Milford, VA). Chromatographic and mass spectrometric parameters were used as previously described. ${ }^{25}$

\section{Statistical analysis}

Continuous variables were presented as means \pm standard deviation or median [interquartile range]. The $\chi^{2}$ test or Fisher's Exact test was used for comparison of categorical variables while the independent-samples t-test or Mann-Whitney U test was used for comparison of continuous data as appropriate. Plasma AA concentrations were not primary outcomes in the original trial. Hence, to demonstrate the statistical power of these outcomes, effect sizes with $95 \%$ confidence intervals (CI) were presented as recommended by Colegraves et al. ${ }^{26}$

A Pearson two-tailed correlation test and multivariable linear regression analysis was used to identify statistically significant associations between plasma AA concentrations and clinical outcomes. All analyses were performed according to the intention-to-treat principle. All data were analyzed using statistical package for social sciences (SPSS) version 22.0 (IBM, Armonk, New York, USA). P-values <0.05 were considered significant. 


\section{Results}

\section{Patient inclusion}

A total of 123 patients were included and randomized to the intervention (EEN, $n=61$ ) or control (EPN, n=62). No blood samples were obtained from five patients in the EEN-group who withdrew from the study before administration of artificial nutrition. Furthermore, peritoneal metastases were peroperatively identified in two patients in the EEN-group and no resection was performed; only baseline measurements were performed in these patients. In the EPN-group, no blood samples were obtained from one patient due to technical reasons. Subsequently, in the current study 117 patients were included. Baseline characteristics were similar between groups (Table 4.1).

Table 4.1: Baseline characteristics

\begin{tabular}{lccc}
\hline & $\begin{array}{c}\text { Early enteral } \\
\text { nutrition (n=56) }\end{array}$ & $\begin{array}{c}\text { Early parenteral } \\
\text { nutrition (n=61) }\end{array}$ & p \\
\hline Sex (M/F) & $37 / 19$ & $43 / 18$ & 0.61 \\
Age (years) & $64.0 \pm 10.1$ & $64.9 \pm 9.6$ & 0.65 \\
Body Mass Index $\left(\mathrm{kg} / \mathrm{m}^{2}\right)$ & $25.5 \pm 4.1$ & $26.4 \pm 4.5$ & 0.30 \\
MUST-score & $0[0-2]$ & $1[0-2]$ & 0.66 \\
Short/long radiotherapy & $24 / 32$ & $28 / 32$ & 0.68 \\
Preoperative chemotherapy & 48 & 47 & 0.25 \\
Primary/recurrent rectal carcinoma & $42 / 14$ & $50 / 11$ & 0.36 \\
Intraoperative radiotherapy & 32 & 28 & 0.22 \\
Operating time (min) & $225[171-290]$ & $219[184-288]$ & 0.71 \\
Bloodloss (ml) & $1498[815-4375]$ & $1150[600-2500]$ & 0.17 \\
Omentoplasty & 37 & 44 & 0.37 \\
Beyond TME resection & 29 & 28 & 0.53 \\
Anastomosis & 23 & 27 & 0.73 \\
Stoma creation & & & 0.28 \\
Loop colostoma & 20 & 16 & 7 \\
Loop ileostoma & 1 & 1 & \\
End ileostoma & 1 & 35 & 0.30 \\
Permanent colostoma & 31 & 2 & \\
No stoma & 1 & 56 & \\
Thoracic epidural catheter & 48 & & \\
\hline
\end{tabular}

Values are patient numbers, or mean \pm standard deviation or median [interquartile range]. MUST, Malnutrition Universal Screening Tool.

\section{Nutritional intake via artificial route}

No differences were seen between groups in rate of advancement in oral diet. Since exact nutritional value of oral intake could not be registered, only cumulative intake of calories and AA via artificial route was calculated over the first 5 postoperative days. 
Cumulative intake of calories ( $\mathrm{p}=0.007)$, total AAs $(\mathrm{p}=0.037)$, glycine $(\mathrm{p}<0.001)$, and glutamine $(\mathrm{p}<0.001)$ was higher in the EPN-group, while cumulative intake of cysteine was higher in the EEN-group $(\mathrm{p}<0.001)$ (Table 4.2). Cumulative intake of proline was similar between groups.

Table 4.2: Cumulative nutritional intake via artificial route in first 5 postoperative days.

\begin{tabular}{lccc}
\hline & $\begin{array}{c}\text { Early enteral nutrition } \\
(\mathbf{n = 5 6 )}\end{array}$ & $\begin{array}{c}\text { Early parenteral } \\
\text { nutrition (n=61) }\end{array}$ & p \\
\hline Energy (kcal) & $5226.7[3049.7-7905.7]$ & $6976.5[5703.5-8243.0]$ & $\mathbf{0 . 0 0 7}$ \\
Total amino acids (g), of which & $286.9[159.5-405.5]$ & $349.6[279.8-409.7]$ & $\mathbf{0 . 0 3 7}$ \\
$\quad$ Taurine (g) & - & - & - \\
Glycine (g) & $8.3[4.3-11.3]$ & $16.8[13.1-19.7]$ & $<\mathbf{0 . 0 0 1}$ \\
Cysteine (g) & $2.8[1.1-4.9]$ & $0[0-0]$ & $<\mathbf{0 . 0 0 1}$ \\
Proline (g) & $14.6[9.4-22.4]$ & $15.1[11.7-17.1]$ & 0.278 \\
Glutamine (g) & $58.5[30.9-80.1]$ & $108.7[85.1-127.4]$ & $<\mathbf{0 . 0 0 1}$ \\
\hline
\end{tabular}

Values are median [interquartile range].

\section{Clinical outcomes}

Clinical outcomes of all 123 patients are described in the original paper. Here, outcomes were compared for the 117 patients included in this study.

Anastomotic leakage requiring surgical repair occurred in 1 patient in the EENgroup versus 9 patients in the EPN-group ( $p=0.017)$. Early ileus occurred in 10 patients in the EEN-group versus 22 patients in the EPN-group $(p=0.027)$. Length of stay was similar between groups (EEN 12.00 (8.25-18.75) versus EPN $14.00(10.00-20.00)$ days, $\mathrm{p}=0.153)$.

\section{Plasma amino acid concentrations}

$\mathrm{N}$-acetylcysteine was not detectable in any blood sample. At baseline, plasma concentrations of all AAs were comparable between groups (Figures 4.1-4). Plasma concentrations of taurine, glutamic acid, and hydroxyproline dropped in all patients after surgery and no differences between groups were observed. However, a drop in postoperative plasma glycine concentrations was observed only in the EEN-group, while in the EPN-group plasma concentrations remained similar to baseline and were higher when compared to the EEN-group on POD1 ( $p=0.003$ ) and POD5 ( $\mathrm{p}=0.005)$. No other differences between groups were observed. Exact plasma concentrations plus effect sizes are presented in Supplemental Table S4.2.

\section{Relation between anti-oxidative amino acids and clinical outcomes}

Taurine concentrations on POD1 correlated with occurrence of anastomotic leakage $(r=0.211, p=0.024)$. Proline concentrations on POD1 $(r=-0.246, p=0.008)$ 
correlated with occurrence of early ileus. No other significant correlations were found.

Multivariable regression analysis revealed no significant correlations between any plasma AA concentration and early ileus, anastomotic leakage, or length of stay.

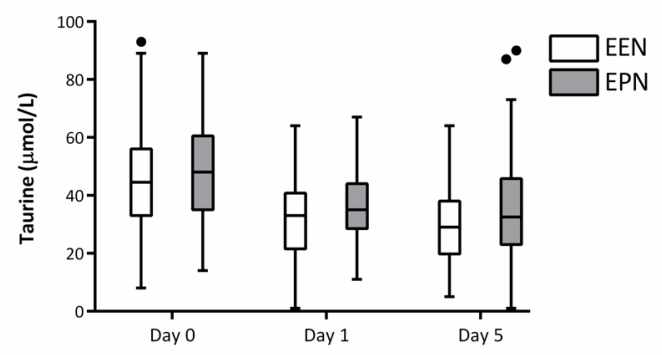

Figure 4.1: Plasma taurine concentrations in patients randomized to early enteral nutrition (EEN) versus early parenteral nutrition (EPN).

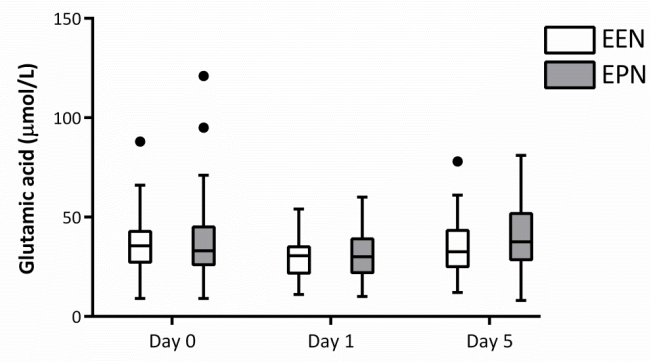

Figure 4.2: Plasma glutamic acid concentrations in patients randomized to early enteral nutrition (EEN) versus early parenteral nutrition (EPN).

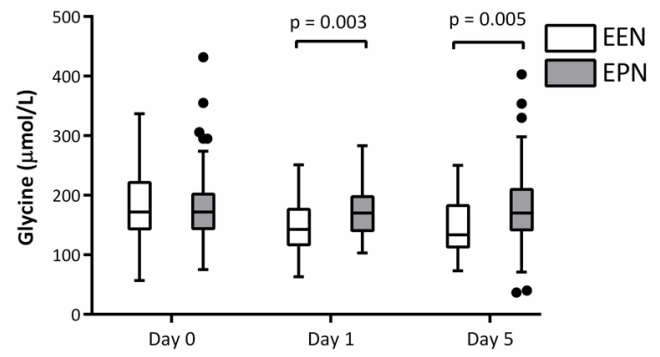

Figure 4.3: Plasma glycine concentrations in patients randomized to early enteral nutrition (EEN) versus early parenteral nutrition (EPN). 


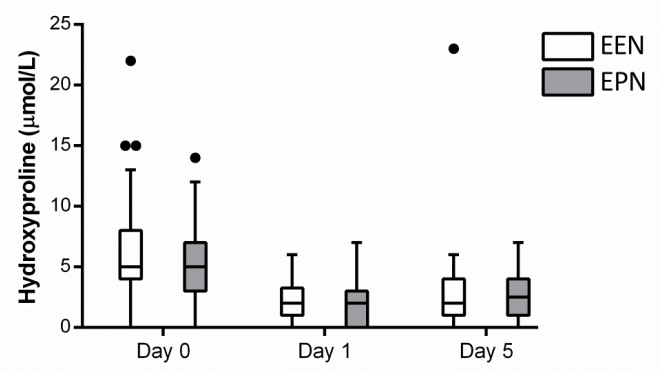

Figure 4.4: Plasma hydroxyproline concentrations in patients randomized to early enteral nutrition (EEN) versus early parenteral nutrition (EPN).

\section{Discussion}

This preplanned substudy of a randomized controlled trial investigated changes in plasma concentrations of taurine, glutamic acid, glycine, $\mathrm{N}$-acetylcysteine, and hydroxyproline in patients receiving early enteral versus parenteral nutrition following major surgery for rectal cancer. Postoperative plasma concentrations of most AAs were significantly reduced in all patients when compared to preoperative values, which is in line with results from other studies. ${ }^{19,20}$ However, no drop was seen in postoperative glycine concentrations in patients receiving EPN, as opposed to patients receiving EEN. Experimental and pre-clinical studies have suggested an important role of several AAs in wound healing, reducing oxidative damage, and other neurophysiologic processes. ${ }^{11-18,27-31}$ In addition, glycine has been shown to reduce postoperative ileus in rats. ${ }^{32}$ However, in a clinical setting, it is unclear whether reduced plasma AA concentrations can simply be considered as a manifestation of disease, or as an actual contributor to impaired postoperative recovery. In case of the latter, we hypothesized that preserving postoperative plasma AA concentrations would induce a positive effect on postoperative recovery. In contrast, our results demonstrate that parenteral nutrition was associated with similar or even more "physiological" postoperative AA concentrations, while a better clinical outcome was observed in the enteral group. In addition, linear regression analysis revealed no association between clinical outcomes and plasma concentrations of any AA.

Results from other trials may corroborate our findings. While parenteral nutrition may alleviate oxidative stress in surgical patients ${ }^{33}$, two randomized studies found no effect of supplementary taurine or glutamine on clinical outcomes. ${ }^{34,35}$ Similarly, in critically ill patients there is no strong evidence that supports the use of 
supplementary taurine or other amino acids. ${ }^{36}$ Moreover, two high quality randomized controlled trials found that supplementation of glutamine in critically ill patients increased not only plasma glutamine concentrations but also mortality rates. ${ }^{37,38}$ While the exact underlying mechanism behind this detrimental effect of glutamine is unclear, the high doses that were used may have invoked an augmented inflammatory response that negatively affected clinical outcomes. ${ }^{37-39}$ In contrast, in the present study lower doses of AAs were administered in a supplementary fashion to an oral diet. Taken together, plasma AA concentrations appear to provide no explanation for the different clinical outcomes observed in the original trial. ${ }^{23}$

While it remains unclear which nutritional route is superior in critically ill patients in general ${ }^{3,40}$, in patients undergoing gastrointestinal surgery the benefits of enteral nutrition over parenteral nutrition have been previously described. ${ }^{41,42}$ Several other mechanisms may help explain these effects, and include both harmful effects of parenteral nutrition and favorable effects of enteral nutrition. In patients receiving parenteral nutrition, caloric overfeeding can occur and is known to increase the risk of hyperglycemia which is associated with the development of infectious complications.41,43,44 Furthermore, long-chain triglycerides in the intravenous fat emulsion may induce immunosuppression. ${ }^{45}$ On the other hand, enteral nutrition has been suggested to preserve barrier integrity of the intestinal epithelium, increase splanchnic blood flow and gut associated lymphoid tissue (GALT)-mass, and "educate" naïve CD4 helper lymphocytes that subsequently proliferate and migrate to distant sites to produce IgA. ${ }^{46,47}$ In addition, enteral nutrition has been shown to reduce the postoperative inflammatory response, which is pivotal in the development of postoperative ileus. ${ }^{48}$ Lastly, AAs administered via enteral route are for a large part catabolized by the intestinal mucosa before entering the portal circulation, while arterial uptake of AAs by enterocytes is insignificant (except for glutamine). ${ }^{49}$ As such, parenteral AAs are utilized less efficiently in the gut when compared to AAs provided via enteral route. ${ }^{50,51}$ In this light, precursors for intestinal glutathione synthesis would most likely need to be administered enterally in order to optimally defend the intestinal mucosa against oxidative damage. ${ }^{49}$ However, the current study was not designed to investigate these mechanisms.

This study has several limitations. First, the original trial was not powered to demonstrate differences in AA concentrations. However, the effect sizes indicated similar significant effects when compared to p-values. Second, despite the equal progression in oral intake between groups as measured by means of patient diaries, the exact amounts of orally ingested AAs could not be estimated (e.g. due to vomiting). These factors may limit the generalizability of our findings.

In conclusion, major rectal surgery significantly reduced postoperative plasma AA concentrations. While postoperative glycine concentrations were lower in the 
enteral group when compared to the parenteral group, no correlation with clinical outcomes was found. Plasma AA concentrations do not explain the mechanisms underlying the benefits of enteral nutrition as observed in the original trial. ${ }^{23}$ 


\section{References}

1. Beyond TMEC. Consensus statement on the multidisciplinary management of patients with recurrent and primary rectal cancer beyond total mesorectal excision planes. The British journal of surgery. 2013;100:E1-33.

2. Bragg D, El-Sharkawy AM, Psaltis E, Maxwell-Armstrong CA, Lobo DN. Postoperative ileus: Recent developments in pathophysiology and management. Clinical nutrition. 2015;34:367-76.

3. Reignier J, Boisrame-Helms J, Brisard L, Lascarrou JB, Ait Hssain A, Anguel N, et al. Enteral versus parenteral early nutrition in ventilated adults with shock: a randomised, controlled, multicentre, open-label, parallel-group study (NUTRIREA-2). Lancet. 2018;391:133-43.

4. Yan X, Zhou FX, Lan T, Xu H, Yang XX, Xie CH, et al. Optimal postoperative nutrition support for patients with gastrointestinal malignancy: A systematic review and meta-analysis. Clinical nutrition. 2017;36:710-21.

5. Lewis SR, Schofield-Robinson OJ, Alderson P, Smith AF. Enteral versus parenteral nutrition and enteral versus a combination of enteral and parenteral nutrition for adults in the intensive care unit. The Cochrane database of systematic reviews. 2018;6:CD012276.

6. Bryan N, Ahswin H, Smart N, Bayon Y, Wohlert S, Hunt JA. Reactive oxygen species (ROS)--a family of fate deciding molecules pivotal in constructive inflammation and wound healing. European cells \& materials. 2012;24:249-65.

7. Garcia JG, Criado FJ, Persona MA, Alonso AG. Healing of colonic ischemic anastomoses in the rat: role of superoxide radicals. Diseases of the colon and rectum. 1998;41:892-5.

8. Shandall AA, Williams GT, Hallett MB, Young HL. Colonic healing: a role for polymorphonuclear leucocytes and oxygen radical production. The British journal of surgery. 1986;73:225-8.

9. De Backer O, Elinck E, Blanckaert B, Leybaert L, Motterlini R, Lefebvre RA. Water-soluble COreleasing molecules reduce the development of postoperative ileus via modulation of MAPK/HO-1 signalling and reduction of oxidative stress. Gut. 2009;58:347-56.

10. de Winter BY, van Nassauw L, de Man JG, de Jonge F, Bredenoord AJ, Seerden TC, et al. Role of oxidative stress in the pathogenesis of septic ileus in mice. Neurogastroenterology and motility : the official journal of the European Gastrointestinal Motility Society. 2005;17:251-61.

11. Aquilano K, Baldelli S, Ciriolo MR. Glutathione: new roles in redox signaling for an old antioxidant. Frontiers in pharmacology. 2014;5:196.

12. Buijs N, Worner EA, Brinkmann SJ, Luttikhold J, van der Meij BS, Houdijk AP, et al. Novel nutritional substrates in surgery. The Proceedings of the Nutrition Society. 2013;72:277-87.

13. Schaffer SW, Jong CJ, Ito T, Azuma J. Effect of taurine on ischemia-reperfusion injury. Amino acids. 2014;46:21-30.

14. Schaffer SW, Ito T, Azuma J. Clinical significance of taurine. Amino acids. 2014;46:1-5.

15. Huxtable RJ. Physiological actions of taurine. Physiological reviews. 1992;72:101-63.

16. Wu G, Bazer FW, Burghardt RC, Johnson GA, Kim SW, Knabe DA, et al. Proline and hydroxyproline metabolism: implications for animal and human nutrition. Amino acids. 2011;40:1053-63.

17. Srivastava AK, Khare P, Nagar HK, Raghuwanshi N, Srivastava R. Hydroxyproline: A Potential Biochemical Marker and Its Role in the Pathogenesis of Different Diseases. Current protein \& peptide science. 2016;17:596-602.

18. Albaugh VL, Mukherjee K, Barbul A. Proline Precursors and Collagen Synthesis: Biochemical Challenges of Nutrient Supplementation and Wound Healing. The Journal of nutrition. 2017;147:2011-7.

19. Hol JW, van Lier F, Valk M, Klimek M, Stolker RJ, Fekkes D. Effect of major and minor surgery on plasma levels of arginine, citrulline, nitric oxide metabolites, and ornithine in humans. Annals of surgery. 2013;258:1072-8.

20. Viggiano E, Passavanti MB, Pace MC, Sansone P, Spaziano G, Viggiano A, et al. Plasma glutamine decreases immediately after surgery and is related to incisiveness. Journal of cellular physiology. 2012;227:1988-91. 
21. Su L, Li H, Xie A, Liu D, Rao W, Lan L, et al. Dynamic changes in amino acid concentration profiles in patients with sepsis. PloS one. 2015;10:e0121933.

22. Hirose T, Shimizu K, Ogura H, Tasaki O, Hamasaki T, Yamano S, et al. Altered balance of the aminogram in patients with sepsis - the relation to mortality. Clinical nutrition. 2014;33:179-82.

23. Boelens PG, Heesakkers FF, Luyer MD, van Barneveld KW, de Hingh IH, Nieuwenhuijzen GA, et al. Reduction of postoperative ileus by early enteral nutrition in patients undergoing major rectal surgery: prospective, randomized, controlled trial. Annals of surgery. 2014;259:649-55.

24. Wu G, Fang YZ, Yang S, Lupton JR, Turner ND. Glutathione metabolism and its implications for health. The Journal of nutrition. 2004;134:489-92.

25. Waterval WA, Scheijen JL, Ortmans-Ploemen MM, Habets-van der Poel CD, Bierau J. Quantitative UPLC-MS/MS analysis of underivatised amino acids in body fluids is a reliable tool for the diagnosis and follow-up of patients with inborn errors of metabolism. Clinica chimica acta; international journal of clinical chemistry. 2009;407:36-42.

26. Colegrave N, Ruxton GD. Confidence intervals are a more useful complement to nonsignificant tests than are power calculations. Behavioral Ecology. 2003;14:446-U4.

27. Schaffer S, Takahashi K, Azuma J. Role of osmoregulation in the actions of taurine. Amino acids. 2000;19:527-46.

28. Cruzat VF, Bittencourt A, Scomazzon SP, Leite JS, de Bittencourt PI, Jr., Tirapegui J. Oral free and dipeptide forms of glutamine supplementation attenuate oxidative stress and inflammation induced by endotoxemia. Nutrition. 2014;30:602-11.

29. Kuyumcu A, Akyol A, Buyuktuncer Z, Ozmen MM, Besler HT. Improved oxidative status in major abdominal surgery patients after $\mathrm{N}$-acetyl cystein supplementation. Nutrition journal. 2015;14:4.

30. Zhang M, Izumi I, Kagamimori S, Sokejima S, Yamagami T, Liu Z, et al. Role of taurine supplementation to prevent exercise-induced oxidative stress in healthy young men. Amino acids. 2004;26:203-7.

31. Effenberger-Neidnicht K, Jagers J, Verhaegh R, de Groot H. Glycine selectively reduces intestinal injury during endotoxemia. The Journal of surgical research. 2014;192:592-8.

32. Stoffels B, Turler A, Schmidt J, Nazir A, Tsukamoto T, Moore BA, et al. Anti-inflammatory role of glycine in reducing rodent postoperative inflammatory ileus. Neurogastroenterology and motility : the official journal of the European Gastrointestinal Motility Society. 2011;23:76-87, e8.

33. Szpetnar M, Matras P, Kielczykowska M, Horecka A, Bartoszewska L, Pasternak K, et al. Antioxidants in patients receiving total parenteral nutrition after gastrointestinal cancer surgery. Cell biochemistry and function. 2012;30:211-6.

34. Van Stijn MF, Bruins AA, Vermeulen MA, Witlox J, Teerlink T, Schoorl MG, et al. Effect of oral taurine on morbidity and mortality in elderly hip fracture patients: a randomized trial. International journal of molecular sciences. 2015;16:12288-306.

35. Ziegler TR, May AK, Hebbar G, Easley KA, Griffith DP, Dave N, et al. Efficacy and Safety of Glutamine-supplemented Parenteral Nutrition in Surgical ICU Patients: An American Multicenter Randomized Controlled Trial. Annals of surgery. 2016;263:646-55.

36. Gunst J, Vanhorebeek I, Thiessen SE, Van den Berghe G. Amino acid supplements in critically ill patients. Pharmacological research. 2018;130:127-31.

37. van Zanten AR, Sztark F, Kaisers UX, Zielmann S, Felbinger TW, Sablotzki AR, et al. High-protein enteral nutrition enriched with immune-modulating nutrients vs standard high-protein enteral nutrition and nosocomial infections in the ICU: a randomized clinical trial. Jama. 2014;312:514-24.

38. Heyland D, Muscedere J, Wischmeyer PE, Cook D, Jones G, Albert M, et al. A randomized trial of glutamine and antioxidants in critically ill patients. The New England journal of medicine. 2013;368:1489-97.

39. Oudemans-van Straaten HM, van Zanten AR. Glutamine supplementation in the critically ill: friend or foe? Critical care. 2014;18:143.

40. Harvey SE, Parrott F, Harrison DA, Bear DE, Segaran E, Beale R, et al. Trial of the route of early nutritional support in critically ill adults. The New England journal of medicine. 2014;371:167384. 
41. Mazaki T, Ebisawa K. Enteral versus parenteral nutrition after gastrointestinal surgery: a systematic review and meta-analysis of randomized controlled trials in the English literature. Journal of gastrointestinal surgery : official journal of the Society for Surgery of the Alimentary Tract. 2008;12:739-55.

42. Wheble GA, Knight WR, Khan OA. Enteral vs total parenteral nutrition following major upper gastrointestinal surgery. International journal of surgery. 2012;10:194-7.

43. van den Berghe G, Wouters P, Weekers F, Verwaest C, Bruyninckx F, Schetz M, et al. Intensive insulin therapy in critically ill patients. The New England journal of medicine. 2001;345:1359-67.

44. Elke G, van Zanten AR, Lemieux M, McCall M, Jeejeebhoy KN, Kott M, et al. Enteral versus parenteral nutrition in critically ill patients: an updated systematic review and meta-analysis of randomized controlled trials. Critical care. 2016;20:117.

45. Battistella FD, Widergren JT, Anderson JT, Siepler JK, Weber JC, MacColl K. A prospective, randomized trial of intravenous fat emulsion administration in trauma victims requiring total parenteral nutrition. The Journal of trauma. 1997;43:52-8; discussion 8-60.

46. McClave SA, Heyland DK. The physiologic response and associated clinical benefits from provision of early enteral nutrition. Nutrition in clinical practice : official publication of the American Society for Parenteral and Enteral Nutrition. 2009;24:305-15.

47. Schorghuber M, Fruhwald S. Effects of enteral nutrition on gastrointestinal function in patients who are critically ill. The lancet Gastroenterology \& hepatology. 2018;3:281-7.

48. Peters EG, De Jonge WJ, Smeets BJ, Luyer MD. The contribution of mast cells to postoperative ileus in experimental and clinical studies. Neurogastroenterology and motility : the official journal of the European Gastrointestinal Motility Society. 2015;27:743-9.

49. Wu G. Intestinal mucosal amino acid catabolism. The Journal of nutrition. 1998;128:1249-52.

50. Parent BA, Seaton M, Djukovic D, Gu H, Wheelock B, Raftery D, et al. Parenteral and enteral nutrition in surgical critical-care: plasma metabolomics demonstrates divergent effects on nitrogen, fatty-acid, ribonucleotide and oxidative metabolism. The journal of trauma and acute care surgery. 2017.

51. Ligthart-Melis GC, van de Poll MC, Dejong CH, Boelens PG, Deutz NE, van Leeuwen PA. The route of administration (enteral or parenteral) affects the conversion of isotopically labeled L-[2$15 \mathrm{~N}$ ]glutamine into citrulline and arginine in humans. JPEN Journal of parenteral and enteral nutrition. 2007;31:343-48; discussion 9-50. 


\section{Supplemental tables}

TableS4.1: Nutritional values of enteral and parenteral intervention per $1000 \mathrm{ml}$.

\begin{tabular}{lcc}
\hline Nutrition variable & Early enteral nutrition & Early parenteral nutrition \\
\hline Energy (kcal) & 1280 & 843.32 \\
Carbohydrate (g) & 141 & 88.77 \\
Fat (g) & 49 & 35.50 \\
Total amino acids (g), of which & 68 & 47.94 \\
$\quad$ Glutamic acid / Glutamine (g) & 12.95 & 1.58 \\
Taurine (g) & - & - \\
$\quad$ Glycine (g) & 1.82 & 2.09 \\
Cysteine (g) & 0.90 & - \\
$\quad$ Proline (g) & 4.11 & 1.82 \\
Supplementary Glutamine (Dipeptiven) (g) & - & 11.9 \\
\hline
\end{tabular}

Enteral nutrition consisted of Nutrison Protein Plus Multi Fibre (Nutricia, Advanced Medical Nutrition, Zoetermeer, The Netherlands). Parenteral nutrition consisted of Kabiven Central enriched with Dipeptiven (Fresenius Kabi Nederland BV, 's Hertogenbosch, The Netherlands).

Table S4.2: Changes in plasma amino acid concentrations $(\mu \mathrm{mol} / \mathrm{l})$ in patients receiving early enteral versus parenteral nutrition.

\begin{tabular}{lccccc}
\hline & Day & $\begin{array}{c}\text { Early enteral } \\
\text { nutrition }(\mathbf{n = 5 6 )}\end{array}$ & $\begin{array}{c}\text { Early parenteral } \\
\text { nutrition (n=61) }\end{array}$ & $\mathbf{p}$ & $\begin{array}{c}\text { Effect size } \\
\text { (95\% CI) }\end{array}$ \\
\hline Taurine & 0 & $44.50[33.00-56.00]$ & $48.00[35.00-60.50]$ & 0.555 & $-0.09(-0.46$ to 0.27$)$ \\
& 1 & $33.00[21.50-40.75]$ & $35.00[28.50-44.00]$ & 0.138 & $-0.34(-0.70$ to 0.03$)$ \\
Glutamic acid & 5 & $29.00[19.75-38.00]$ & $32.50[23.00-45.75]$ & 0.108 & $-0.35(-0.72$ to 0.02$)$ \\
& 0 & $35.50[27.25-42.75]$ & $33.00[26.00-45.00]$ & 0.950 & $-0.08(-0.45$ to 0.28$)$ \\
Glycine & 1 & $30.50[21.75-35.00]$ & $30.00[22.00-39.00]$ & 0.913 & $0.05(-0.32$ to 0.42$)$ \\
& 5 & $32.50[25.00-43.25]$ & $37.50[28.50-51.75]$ & 0.062 & $-0.34(-0.70$ to 0.04$)$ \\
& 0 & $172.00[143.50-221.25]$ & $172.00[144.00-202.00]$ & 0.787 & $-0.10(-0.46$ to 0.26$)$ \\
Hydroxyproline & 1 & $142.50[117.00-176.25]$ & $170.00[140.50-197.50]$ & $\mathbf{0 . 0 0 3}$ & $-0.55(-0.91$ to -0.17$)$ \\
& 5 & $133.50[113.25-182.50]$ & $170.00[142.00-209.75]$ & $\mathbf{0 . 0 0 5}$ & $-0.58(-0.95$ to -0.20$)$ \\
& 0 & $5.00[4.00-8.00]$ & $5.00[3.00-7.00]$ & 0.115 & $0.37(0.00$ to 0.73$)$ \\
& 1 & $2.00[1.00-3.25]$ & $2.00[0.00-3.00]$ & 0.268 & $0.20(-0.17$ to 0.57$)$ \\
& 5 & $2.00[1.00-4.00]$ & $2.50[1.00-4.00]$ & 0.860 & $0.08(-0.28$ to 0.45$)$ \\
\hline
\end{tabular}

Values are presented as median [interquartile range]. CI, confidence interval. 


\title{
Chapter
}

\author{
Changes in the metabolic and inflammatory \\ response in patients randomized to early enteral \\ versus parenteral nutrition following major \\ rectal surgery
}

Smeets BJJ, van den Bunder F, Roos AN, Luyer MDP, Rutten HJT, Bouvy ND, Boelens PG 


\section{Abstract}

Background

This study investigated the effect of early enteral nutrition (EEN) compared to early parenteral nutrition (EPN) on markers of insulin resistance and inflammation following major surgery for locally advanced or recurrent rectal cancer.

Methods

Preplanned substudy of a previous trial in which patients were randomized to EEN versus EPN. Cumulative caloric intake via artificial route was calculated for all patients. Plasma concentrations of $\mathrm{C}$-reactive protein, albumin, glucose, and insulin were determined preoperatively and on postoperative day (POD) 1 and 5 . Homeostatic Model Assessment of Insulin Resistance (HOMA-IR) was used to assess postoperative insulin resistance.

Results

Caloric intake was less in the EEN-group when compared to the EPN-group (5625 [3343-8077] versus 6977 [5628-8230] kcal, $p=0.033)$. The EEN-group demonstrated lower albumin concentrations (25.50 [24.00-27.75] versus 29.00 [25.75-32.00], $\mathrm{p}<0.001)$ and higher CRP concentrations (135.00 [102.50-160.00] versus 110.00 [79.00-140.00] $\mathrm{mg} / \mathrm{l}, \mathrm{p}=0.014$ ) when compared to the EPN-group on POD1. Furthermore, lower insulin concentrations (14.00 [6.90-25.00] versus 21.00 [11.50-37.00] $\mu \mathrm{U} / \mathrm{ml}, \mathrm{p}=0.021$ ) and HOMA-IR scores (1.87 [1.02-3.29] versus 2.82 [1.57-4.35], $p=0.043$ ) were observed in the EEN-group when compared to the EPNgroup on POD5. These markers were not associated with clinical outcomes.

Conclusion

Patients receiving EEN had a stronger inflammatory response on POD1, while cumulative caloric intake and insulin resistance were less on POD5 when compared patients receiving EPN. The beneficial effects of EEN after major rectal surgery are not explained by the different inflammatory and metabolic effects when compared to EPN. 


\section{Introduction}

Patients with locally advanced or recurrent rectal cancer often require multivisceral exenterative surgery, leading to a substantial risk of developing severe postoperative complications. ${ }^{1}$ In these patients, early start of oral intake as recommended in fast-track protocols is not always feasible due to a high incidence of postoperative ileus. ${ }^{2}$ In a recent randomized controlled trial, supplemental early enteral nutrition (EEN) reduced postoperative complications when compared to supplemental early parenteral nutrition (EPN) after major rectal surgery. ${ }^{3}$ However, the underlying mechanism is unclear.

An effect of nutritional route on the surgical stress response may play a role. Severe surgical trauma can induce a strong inflammatory response and peripheral insulin resistance, resulting in a net catabolic state with uncorrected hyperglycemia. ${ }^{4-9}$ These metabolic derangements are associated with an increased risk of infectious complications, prolonged hospital stay, and increased mortality. ${ }_{4}^{4,8,10}$ Conversely, attenuating insulin resistance and maintaining euglycemia has been shown to improve clinical outcomes. ${ }^{11-16}$ Previous studies have demonstrated that enteral nutrition may preserve insulin sensitivity and attenuate inflammation. ${ }^{17-20}$ However, it is unclear whether this is true in patients undergoing major rectal surgery who are allowed early oral feeding.

To investigate the observed benefits of EEN as seen in the previous randomized controlled trial ${ }^{3}$, it was hypothesized that nutritional route may have affected the metabolic and inflammatory stress response. Therefore, this preplanned substudy of a randomized trial ${ }^{3}$ compares the effect of EEN versus EPN on markers of insulin resistance and the inflammatory response in relation to postoperative recovery in patients undergoing major rectal surgery.

\section{Materials and methods}

This is a preplanned substudy of a prospective, single-center, randomized controlled trial that compared EEN with EPN in patients undergoing major rectal surgery for primary or recurrent rectal carcinoma. ${ }^{3}$ The original study protocol was approved by the medical ethical committee of the Catharina Hospital Eindhoven, the Netherlands (M06-1682). This trial was registered at www.trialregister.nl (no NRT1523).

\section{Study objective}

The aim of the present substudy was to investigate the effects of EEN versus EPN on markers of the metabolic and inflammatory stress response to surgery in 
patients with locally advanced or recurrent rectal cancer. In addition, markers of the surgical stress response were studied in relation to clinical outcomes, including postoperative ileus, anastomotic leakage, number of infectious complications, and length of stay.

\section{Patient population}

Patients aged $\geq 18$, undergoing elective rectal surgery for locally advanced (cT3 or cT4) or recurrent rectal carcinoma, with or without intraoperative radiotherapy were included in the original trial after signing informed consent. Exclusion criteria were emergency rectal operations, simultaneous hyperthermic intraperitoneal chemotherapy treatment, partial liver resection or pulmonary resection, the presence of esophageal varices, or known history of gastric or esophageal bleeding. Since peripheral insulin resistance was an important endpoint in the current substudy, patients with diabetes were excluded.

\section{Randomization and blinding}

Patients were randomly assigned to the treatment group (EEN; $n=61$ ) or the control group (EPN; $n=62$ ) by an independent, online external randomization program (ALEA, NKI/AvL, The Netherlands Cancer Institute, Biometrics Department, Amsterdam, The Netherlands). Stratification was implemented for sex, age and scheme of neoadjuvant radiotherapy (long/short). No blood samples were retrieved from patients who withdrew consent to participate. Laboratory technicians were blinded for treatment allocation and clinical outcomes.

\section{Perioperative protocols and surgical technique}

All patients followed the same perioperative protocol. During induction of anesthesia, a single dose of intravenous antibiotic prophylaxis and prophylactic low-molecular-weight heparin was administered. An epidural catheter was placed and infused with $0.25 \%$ bupivacaine hydrochloride plus $0.25-0.5 \mu \mathrm{g} / \mathrm{ml}$ sufentanil at a rate of 8-10 ml/hour. The epidural catheter was removed on postoperative day (POD) 3 or later, after which paracetamol and nonsteroidal analgesics were combined with opioids intramuscularly if necessary. All patients received a Bair Hugger (3M, St. Paul, MN) for temperature control, a jugular vein catheter, and a nasogastric tube. Nasogastric tubes were routinely removed during extubation.

All patients underwent elective open rectal surgery, such as low anterior resection; abdominoperineal (sacral) excision; or anterior, posterior, or total pelvic exenteration. In case of possible non-radical resection, intraoperative radiotherapy was performed. All operations were performed by or under supervision of an experienced consultant surgeon. 
Intravenous insulin therapy to normalize postoperative glucose concentrations was available for all patients if needed; the use of insulin therapy was recorded prospectively. The postoperative mobilization schedule was standardized according to hospital protocol and was comparable for both study arms. Predefined criteria for hospital discharge included stable vital signs, no febrile temperature for at least 24 hours, passage of stool, toleration of a regular diet, and the absence of other complications.

\section{Trial interventions}

All patients were allowed to start oral intake after surgery, and were allowed to progress ad libitum. In addition, before surgery patients in the treatment arm received a self-migrating nasojejunal tube (Flocare Bengmark®, Nutricia, Advanced Medical Nutrition, Zoetermeer, The Netherlands), through which enteral nutrition (Nutrison Protein Plus Multi Fibre ${ }^{\circledR}$, Nutricia, Advanced Medical Nutrition, Zoetermeer, The Netherlands) was administered in a supplementary fashion postoperatively. The nasojejunal tube was inserted on the ward except in case of insertion problems. Alternatively, the tube was placed during the surgical procedure. The surgeon confirmed the postpyloric position of the tube either manually during surgery or by abdominal x-ray postoperatively. Patients in the control group received a jugular vein catheter for parenteral nutrition (Kabiven Central®, enriched with $200 \mathrm{ml}$ Dipeptiven ${ }^{\circledR}$ per day, Fresenius Kabi Nederland BV, 's Hertogenbosch, The Netherlands) after induction of anesthesia. Exact nutritional values of both formulas are shown in Table 5.1.

Table 5.1: Nutritional values of enteral and parenteral intervention per $1000 \mathrm{ml}$.

\begin{tabular}{lcc}
\hline Nutrition variable & Early enteral nutrition & Early parenteral nutrition \\
\hline Energy (kcal) & 1280 & 843.32 \\
Carbohydrate (g) & 141 & 88.77 \\
Fat (g) & 49 & 35.50 \\
\hline
\end{tabular}

Enteral nutrition consisted of Nutrison Protein Plus Multi Fibre (Nutricia, Advanced Medical Nutrition, Zoetermeer, The Netherlands). Parenteral nutrition consisted of Kabiven Central enriched with Dipeptiven (Fresenius Kabi Nederland BV, 's Hertogenbosch, The Netherlands).

The postoperative nutrition protocol was standardized for both groups: 8 hours after ending the surgical procedure, nutrition was started at $500 \mathrm{ml} / 24$ hours. On POD1 at $8.00 \mathrm{AM}$ the continuous infusion was increased to $11 / 24$ hours; the infusion was increased further to 2l/24 hours on POD2. Artificial supplemental nutrition was continued for a minimum of 5 days postoperatively, except for patients returning to a normal oral diet within 3 days. Postoperative oral feeding was allowed at will in all patients. Patients undergoing major rectal surgery are often unable to tolerate a full oral diet during the first postoperative days, for 
example due to nausea and/or vomiting, or fatigue. To estimate the progression in oral intake, each patient kept an oral intake prospective diary. Oral magnesium and macrogol were available for both groups. Deviation of the protocol could occur due to medical reasons, adverse events, or patients' wish. All protocol violations were recorded.

\section{Clinical outcomes}

Postoperative complications were recorded prospectively. Postoperative ileus was defined as having symptoms of impaired gastrointestinal transit (nausea and vomiting, intolerance of oral diet, absence of defecation, nasogastric tube reinsertion), and was categorized in early ileus (occurring within the first 5 postoperative days), prolonged ileus (lasting longer than POD5), and late ileus (symptoms occurring after POD5). Anastomotic leakage was defined as clinical suspicion of leakage of the anastomosis, confirmed by computed tomography scanning showing free abdominal air and fluids in close proximity to the anastomosis or a visually dehiscent anastomosis during reoperation. ${ }^{3}$ Total number of infectious complications and length of hospital stay were prospectively recorded.

\section{Markers of the surgical stress response}

Markers of the metabolic and inflammatory stress response (C-reactive protein, albumin, glucose and insulin) were determined in blood samples that were collected before surgery, on POD1 and on POD5. Blood samples were collected in heparin tubes and put directly on ice. Within 15 minutes after collection, the samples were analyzed using the Roche/Hitachi cobas 6000 system (Roche, Mannheim, Germany) and the Liason system (Diasorin, Stillwater, USA). Furthermore, the insulin resistance index was calculated using the Homeostasis Model Assessment of Insulin Resistance (HOMA-IR), as previously described. ${ }^{21}$ In short, the HOMA-IR model uses plasma glucose and plasma insulin values to calculate a score reflecting peripheral insulin sensitivity.

\section{Statistical analysis}

Continuous variables are presented as means \pm standard deviation or as median [interquartile range], and compared between groups using the independentsamples t-test or Mann-Whitney $U$ test as appropriate. Categorical variables are compared between groups using the $\chi^{2}$ test or Fisher's Exact test as appropriate. All data were analyzed using the statistical package for social sciences (SPSS) version 22.0 (IBM, Armonk, New York, USA). P-values $<0.05$ were considered significant. All analyses were performed according to the intention-to-treat principle. 
The original trial was powered to detect differences in clinical outcomes rather than in markers for the metabolic and inflammatory stress response. ${ }^{3}$ Therefore, effect sizes were calculated as estimated mean differences with $95 \%$ confidence intervals (CI) for each outcome as recommended by Colegrave et al. ${ }^{22}$ to further assess the effect of nutritional route.

A Pearson two-tailed correlation test and multivariable linear regression analysis was used to identify statistically significant associations between markers of the metabolic and inflammatory stress response, and clinical outcomes (postoperative ileus, anastomotic leakage, number of infectious complications, and length of stay). The multivariable linear regression analysis also corrected for age, sex, intraoperative blood loss, and creation of an anastomosis.

\section{Results}

\section{Patient inclusion}

A total of 123 patients were included, of which 61 were randomized to the intervention group (EEN) and 62 to the control group (EPN) (see Figure 5.1). Five patients in the EEN-group withdrew consent before artificial nutrition was started due to discomfort of the tube. Furthermore, during surgery peritoneal metastases were found in two patients in the EEN-group and no resection was performed; in these patients only baseline measurements were performed. No blood samples were obtained from one patient in the EPN-group due to technical reasons. Lastly, six patients with diabetes were excluded in both groups. Subsequently, 105 patients were included in the current intention-to-treat analysis. No significant differences in baseline characteristics were observed between groups (Table 5.2).

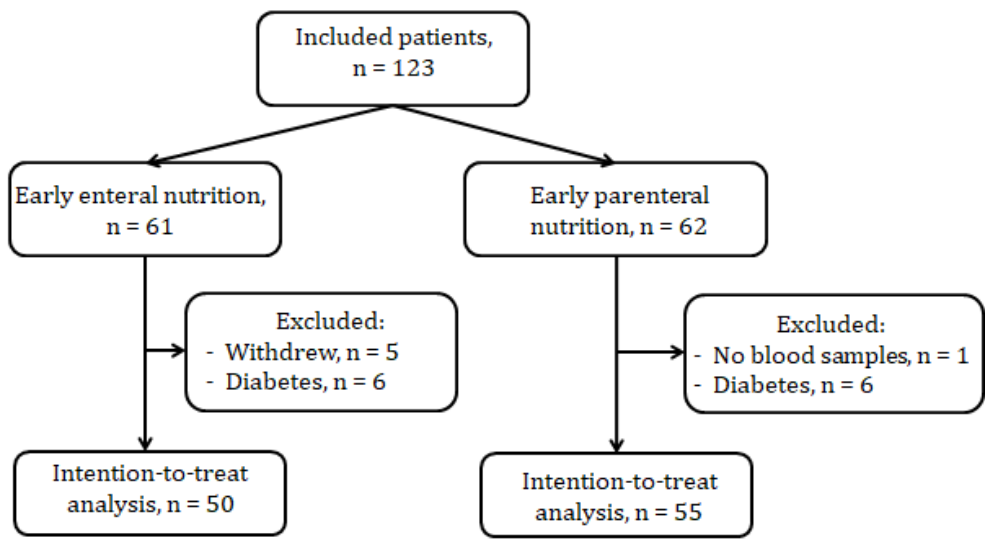

Figure 5.1: Flowchart. 
Table 5.2: Baseline characteristics.

\begin{tabular}{lcc}
\hline & $\begin{array}{c}\text { Early enteral nutrition } \\
(\mathbf{n = 5 0})\end{array}$ & $\begin{array}{c}\text { Early parenteral nutrition } \\
(\mathbf{n = 5 5})\end{array}$ \\
\hline Sex (M/F) & $32 / 18$ & $37 / 18$ \\
Age (years) & $64 \pm 9$ & $65 \pm 10$ \\
Body Mass Index $\left(\mathrm{kg} / \mathrm{m}^{2}\right)$ & $24.8[23.0-26.8]$ & $26.1[22.8-29.3]$ \\
MUST-score & $1[0-2]$ & $1[0-2]$ \\
Short/long radiotherapy & $21 / 29$ & $26 / 28$ \\
Primary/recurrent cancer & $13 / 37$ & $11 / 44$ \\
Intraoperative radiotherapy & 29 & 25 \\
Operating time (min) & $226[160-293]$ & $219[184-298]$ \\
Bloodloss (ml) & $1525[875-4500]$ & $1150[600-2650]$ \\
Omentoplasty & 32 & 40 \\
Creation of anastomosis & 21 & 24 \\
Beyond TME resection & 27 & 25 \\
Thoracic epidural catheter & 42 & 51 \\
\hline
\end{tabular}

Values are patient numbers, or mean \pm standard deviation or median [interquartile range]. MUST = malnutrition universal screening tool; TME = total mesorectal excision.

\section{Caloric intake and use of intravenous insulin therapy}

Both groups had a similar rate of advancement in oral diet. ${ }^{3}$ Cumulative intake of calories via artificial route was lower in the EEN-group when compared to the EPNgroup (5625 [3343-8077] versus 6977 [5628-8230] kcal, estimated mean difference $-1317 \mathrm{kcal}$ (95\% CI -2327 to -307$)$ ), $\mathrm{p}=0.033$ ). Postoperative intravenous insulin therapy was administered to 6 patients in the EEN-group versus 5 patients in the EPN-group $(\mathrm{p}=0.627)$.

\section{Effect of nutritional route on surgical stress response}

On POD1, albumin concentrations were lower $(\mathrm{p}<0.001)$ while C-reactive protein concentrations were higher $(\mathrm{p}=0.014)$ in the EEN-group when compared to the EPN-group (Table 5.3). However, the effect size indicated no difference between groups in C-reactive protein concentrations on POD1. On POD5 insulin concentrations were lower in the EEN-group when compared to the EPN-group $(p=0.021)$. Compared to the EPN-group, HOMA-IR scores were lower in the EENgroup on POD5 $(\mathrm{p}=0.043)$. However, the effect sizes indicated no differences between groups in insulin concentrations or HOMA-IR scores. No other differences were observed between groups.

\section{Clinical outcomes}

Clinical outcomes of all 123 patients are described in the original paper. ${ }^{3}$ In the current study, outcomes were compared for the 105 patients included. 
Anastomotic leakage requiring surgical repair occurred in 1 patient in the EENgroup versus 7 patients in the EPN-group (p=0.062).(3) Early ileus occurred in 8 patients in the EEN-group versus 20 patients in the EPN-group ( $p=0.018)$.(3) Total number of infectious complications was similar between groups (Table 5.4, $\mathrm{p}=0.684)^{3}{ }^{3}$ Length of stay was similar between groups (EEN 13.50 [8.00-19.00] versus EPN 14.00 [10.00-18.00] days, $p=0.407) .^{3}$

Table 5.3: Changes in biochemical markers in patients receiving early enteral versus parenteral nutrition.

\begin{tabular}{lccccc}
\hline & Day & $\begin{array}{c}\text { Early enteral } \\
\text { nutrition (n=50) }\end{array}$ & $\begin{array}{c}\text { Early parenteral } \\
\text { nutrition (n=55) }\end{array}$ & $\begin{array}{c}\text { Estimated mean } \\
\text { difference (95\% CI) }\end{array}$ & p \\
\hline Glucose $(\mathrm{mmol} / \mathrm{l})$ & 0 & $5.60[5.05-6.65]$ & $5.50[5.10-6.50]$ & $0.00(-0.59$ to 0.59$)$ & 0.710 \\
& 1 & $7.40[6.45-8.48]$ & $7.30[6.28-8.40]$ & $0.32(-0.30$ to 0.93$)$ & 0.481 \\
& 5 & $6.80[5.80-7.60]$ & $6.95[6.00-8.03]$ & $-0.27(-0.99$ to 0.45$)$ & 0.222 \\
Insulin $(\mu \mathrm{U} / \mathrm{ml})$ & 0 & $9.15[3.70-24.75]$ & $8.20[3.90-25.50]$ & $-3.75(-12.60$ to 5.10$)$ & 0.986 \\
& 1 & $17.00[9.50-25.00]$ & $14.50[9.95-24.00]$ & $4.88(-2.33$ to 12.09$)$ & 0.557 \\
& 5 & $14.00[6.90-25.00]$ & $21.00[11.50-37.00]$ & $-7.98(-16.01$ to 0.05$)$ & 0.021 \\
HOMA-IR & 0 & $1.63[0.94-3.40]$ & $1.13[0.58-2.70]$ & $0.23(-0.55$ to 1.00$)$ & 0.322 \\
& 1 & $2.44[1.33-3.36]$ & $2.01[1.49-3.45]$ & $0.17(-0.41$ to 0.75$)$ & 0.733 \\
Albumin $(\mathrm{g} / \mathrm{l})$ & 5 & $1.87[1.02-3.29]$ & $2.82[1.57-4.35]$ & $-0.65(-1.41$ to 0.12$)$ & 0.043 \\
& 0 & $39.00[35.00-42.50]$ & $39.00[34.00-43.00]$ & $0.74(-1.53$ to 3.01) & 0.912 \\
& 1 & $25.50[24.00-27.75]$ & $29.00[25.75-32.00]$ & $-2.90(-4.45$ to -1.34$)$ & $<0.001$ \\
C-reactive & 5 & $30.00[27.00-33.00]$ & $31.00[29.00-34.00]$ & $-1.38(-3.12$ to 0.36$)$ & 0.184 \\
Protein $(\mathrm{mg} / \mathrm{l})$ & 0 & $6.00[6.00-12.00]$ & $6.00[6.00-8.00]$ & $5.24(-1.87$ to 12.35$)$ & 0.183 \\
& 1 & $135.00[102.50-160.00]$ & $110.00[79.00-140.00]$ & $18.30(-1.34$ to 37.95$)$ & 0.014 \\
& 5 & $97.00[77.00-150.00]$ & $96.50[43.25-160.00]$ & $-1.77(-32.58$ to 29.04) & 0.517 \\
\hline
\end{tabular}

Values are median [interquartile range]. HOMA-IR = Homeostatic Model Assessment of Insulin Resistance.

Table 5.4: Infectious complications.

\begin{tabular}{lccc}
\hline & $\begin{array}{c}\text { Early enteral } \\
\text { nutrition }(\mathbf{n = 5 0 )}\end{array}$ & $\begin{array}{c}\text { Early parenteral } \\
\text { nutrition (n=55) }\end{array}$ & $\mathbf{p}$ \\
\hline Total number of infectious complications & 10 & 12 & 0.684 \\
1 & 5 & 3 \\
2 & 1 & 2 \\
3 & 1 & 3 \\
4 & 1 & 0 \\
5 & 0 & 1 \\
6 & 0 & 1 \\
\hline
\end{tabular}

Values are patient numbers.

Relation between clinical outcomes and plasma markers of the metabolic and inflammatory stress response

Glucose concentrations on POD1 correlated with occurrence of postoperative ileus $(\mathrm{r}=0.213, \mathrm{p}=0.031)$, and total number of infectious complications $(\mathrm{r}=0.231$, 
$\mathrm{p}=0.019$ ). Albumin concentrations on POD5 inversely correlated with total number of infectious complications ( $\mathrm{r}=-0.330, \mathrm{p}=0.001)$ and length of stay $(\mathrm{r}=-0.407$, $\mathrm{p}<0.001$ ). C-reactive protein concentrations on POD5 correlated with occurrence of anastomotic leakage $(\mathrm{r}=0.414, \mathrm{p}<0.001)$, total number of infectious complications $(\mathrm{r}=0.598, \mathrm{p}<0.001)$, and length of stay $(\mathrm{r}=0.474, \mathrm{p}<0.001)$. No other correlations were found.

In the multivariable linear regression analysis, C-reactive protein concentrations on POD5 were independently associated with length of stay (standardized $\beta 0.377$, $\mathrm{p}<0.001$ ), total number of infectious complications (standardized $\beta$ 0.566, $\mathrm{p}<0.001$ ), and occurrence of anastomotic leakage (standardized $\beta 0.419, \mathrm{p}<0.001$ ). No other significant associations were found.

\section{Discussion}

Patients receiving supplementary EEN had a stronger inflammatory response on POD1 and a lesser degree of insulin resistance on POD5 when compared to supplementary EPN after major surgery for locally advanced or recurrent rectal cancer. On the first day after surgery, a marked increase in C-reactive protein concentrations and drop in albumin concentrations was observed in all patients, which is in line with previous studies. ${ }^{23-25}$ Hepatic production of C-reactive protein is a well-known part of the surgical inflammatory response, while the drop in albumin concentrations is attributable to operative blood loss and cytokineinduced increase of capillary leakage. ${ }^{23,26,27}$

The EEN-group had higher C-reactive protein concentrations and lower albumin concentrations when compared to the EPN-group on POD1. These early postoperative outcomes may be explained by differences in degree of surgical trauma between groups, as illustrated by the greater amount of operative blood loss in the EEN-group (although not statistically significant), and discussed by the authors of the original trial. ${ }^{3}$ Alternatively, a direct effect of enteral or parenteral nutrition must be considered. In the current study, both nutritional interventions did not contain albumin, making a direct effect on postoperative albumin concentrations unlikely. ${ }^{28}$ Other studies on the effect of postoperative nutrition on inflammation are scarce, but suggest an attenuating effect of enteral nutrition or no effect at all.19,20,29-32 Importantly, on POD5 there were no differences between groups in C-reactive protein or albumin concentrations, and there was no correlation between inflammatory markers on POD1 and clinical outcomes. Taken together, we hypothesize that the observed differences between groups may be attributable to differences in surgical trauma rather than nutritional route. 
Regardless, the beneficial effects of EEN are likely not explained by a potential effect on inflammatory markers on POD1.

In addition to changes in plasma C-reactive protein and albumin, a marked increase in insulin concentrations, HOMA-IR scores, and to a limited extend glucose concentrations was observed after surgery in the overall study cohort when compared to preoperative values. The metabolic response to surgery has been well described and includes the development of peripheral insulin resistance, and increased glycogenolysis and gluconeogenesis, leading to hyperglycemia with compensatory hyperinsulinemia.4,7,25 For patients developing hyperglycemia, insulin therapy may be used to counter the increased risk of adverse outcomes.11,12,16 Since postoperative insulin therapy was available in this study, most postoperative glucose measurements were within normal range and no differences were observed between groups. In contrast, insulin concentrations and HOMA-IR scores were less increased (i.e. more physiological) in the EEN-group than in the EPN-group on POD5. Similarly, other studies in esophageal ${ }^{17}$ and colorectal $^{18}$ surgery showed that enteral nutrition improved glucose utilization and insulin sensitivity when compared to parenteral nutrition alone. This may be due to the release of gut peptides (incretins), including glucose-dependent insulinotropic polypeptide (GIP) and glucagon-like peptide 1 (GLP-1), which improve peripheral insulin sensitivity and potentiate the glucose stimulus for pancreatic insulin secretion. ${ }^{6,17,33-35}$ Alternatively, the differences in insulin concentrations and HOMAIR scores may be explained by the fact that the EPN-group received significantly greater amounts of calories via artificial route when compared to the EEN-group. As a result, the EPN group likely required greater quantities of insulin to maintain euglycemia. Due to the observed difference in caloric intake between groups, it is unclear whether the differences in metabolic response are due to nutritional route or amount of administered calories.

Caloric overfeeding and the subsequent metabolic derangements are a wellrecognized risk of parenteral nutrition and may explain the differences in clinical outcomes. ${ }^{36}$ However, no association was found between clinical outcomes and glucose, insulin or HOMA-IR in the linear regression analysis. As such, any differences between groups in the metabolic stress response were likely not a major determinant for clinical outcomes, or vice versa.

Several limitations were present in this study. First, it was postulated that measuring exact caloric value of oral intake would be impossible (e.g. because of nausea or vomiting) and tracking each bite and sip of calories a day would be very labour intensive. Therefore, the prospective diaries on oral intake were introduced and showed that differences in oral intake between groups were minimal, since oral intake commenced no earlier than POD4 for most patients (see Figure 2 in original trial paper). ${ }^{3}$ Second, in the HOMA-IR model it is preferred to use fastened blood glucose samples in the absence of short-acting insulin. ${ }^{37}$ As some patients received 
insulin therapy and all patients received continuous artificial nutrition, the generalizability of the observed HOMA-IR scores is limited. The hyperinsulinemic euglycemic clamp is considered the gold standard to measure insulin sensitivity, however it has inherent practical and ethical limitations with regards to its use in large surgical patient groups. Alternatively, HOMA-IR scores are known to correlate well with clamp estimates of insulin sensitivity and may be more practical to use in the postoperative setting. ${ }^{38}$ Third, the original trial was not designed nor powered to demonstrate an effect of artificial nutrition on markers of the inflammatory or metabolic response, which may explain why effect sizes and p-values yielded similar results for most, but not all, outcomes. As such, the results need to be interpreted with caution. Lastly, other factors may have affected the surgical stress response, such as the use of preoperative fasting, epidural analgesia, and postoperative mobilization. ${ }^{6,39,40}$ However, these factors were equally present in both treatment groups, limiting the risk of confounding in the overall study cohort. In conclusion, patients receiving EEN had a stronger inflammatory response on POD1, while cumulative caloric intake and insulin resistance were less on POD5 when compared to patients receiving EPN. However, these differences were not associated with clinical outcomes. The beneficial effects of EEN after major rectal surgery are not explained by the different inflammatory and metabolic effects when compared to EPN. 


\section{References}

1. Beyond TMEC. Consensus statement on the multidisciplinary management of patients with recurrent and primary rectal cancer beyond total mesorectal excision planes. Br J Surg. 2013;100(8):E1-33.

2. Klaver YL, Nienhuijs SW, Nieuwenhuijzen GA, Rutten HJ, de Hingh IH. Omentoplasty in rectal cancer surgery prolongs post-operative ileus. Int J Colorectal Dis. 2008;23(2):165-9.

3. Boelens PG, Heesakkers FF, Luyer MD, van Barneveld KW, de Hingh IH, Nieuwenhuijzen GA, Roos AN, Rutten HJ. Reduction of postoperative ileus by early enteral nutrition in patients undergoing major rectal surgery: prospective, randomized, controlled trial. Ann Surg. 2014;259(4):649-55.

4. Finnerty CC, Mabvuure NT, Ali A, Kozar RA, Herndon DN. The surgically induced stress response. JPEN J Parenter Enteral Nutr. 2013;37(5 Suppl):21S-9S.

5. Cuthbertson DP. Post-shock Metabolic Response. The Lancet. 1942;239(6189):433-7.

6. Barazzoni R, Deutz NE, Biolo G, Bischoff S, Boirie Y, Cederholm T, Cuerda C, Delzenne N, Leon Sanz M, Ljungqvist O, Muscaritoli M, Pichard C, Preiser JC, Sbraccia P, Singer P, Tappy L, Thorens B, Van Gossum A, Vettor R, Calder PC. Carbohydrates and insulin resistance in clinical nutrition: Recommendations from the ESPEN expert group. Clin Nutr. 2017;36(2):355-63.

7. Burton D, Nicholson G, Hall G. Endocrine and metabolic response to surgery. Continuing Education in Anaesthesia Critical Care \& Pain. 2004;4(5):144-7.

8. Kwon S, Thompson R, Dellinger P, Yanez D, Farrohki E, Flum D. Importance of perioperative glycemic control in general surgery: a report from the Surgical Care and Outcomes Assessment Program. Ann Surg. 2013;257(1):8-14.

9. Gillis C, Carli F. Promoting perioperative metabolic and nutritional care. Anesthesiology. 2015; 123(6):1455-72.

10. Thorell A, Nygren J, Ljungqvist O. Insulin resistance: a marker of surgical stress. Curr Opin Clin Nutr Metab Care. 1999;2(1):69-78.

11. Van den Berghe G, Wilmer A, Hermans G, Meersseman W, Wouters PJ, Milants I, Van Wijngaerden E, Bobbaers H, Bouillon R. Intensive insulin therapy in the medical ICU. N Engl J Med. 2006; 354(5):449-61.

12. van den Berghe G, Wouters P, Weekers F, Verwaest C, Bruyninckx F, Schetz M, Vlasselaers D, Ferdinande P, Lauwers P, Bouillon R. Intensive insulin therapy in critically ill patients. N Engl J Med. 2001;345(19):1359-67.

13. Lidder P, Thomas S, Fleming S, Hosie K, Shaw S, Lewis S. A randomized placebo controlled trial of preoperative carbohydrate drinks and early postoperative nutritional supplement drinks in colorectal surgery. Colorectal Dis.2013;15(6):737-45.

14. Ljungqvist O, Nygren J, Soop M, Thorell A. Metabolic perioperative management: novel concepts. Curr Opin Crit Care. 2005;11(4):295-9.

15. Smith MD, McCall J, Plank L, Herbison GP, Soop M, Nygren J. Preoperative carbohydrate treatment for enhancing recovery after elective surgery. Cochrane Database Syst Rev. 2014(8):CD009161.

16. Wiener RS, Wiener DC, Larson RJ. Benefits and risks of tight glucose control in critically ill adults: a meta-analysis. JAMA. 2008;300(8):933-44.

17. Lidder P, Flanagan D, Fleming S, Russell M, Morgan N, Wheatley T, Rahamin J, Shaw S, Lewis S. Combining enteral with parenteral nutrition to improve postoperative glucose control. Br J Nutr. 2010;103(11):1635-41.

18. Magnusson J, Tranberg KG, Jeppsson B, Lunderquist A. Enteral versus parenteral glucose as the sole nutritional support after colorectal resection. A prospective, randomized comparison. Scand J Gastroenterol. 1989;24(5):539-49.

19. Lubbers T, Kox M, de Haan JJ, Greve JW, Pompe JC, Ramakers BP, Pickkers P, Buurman WA. Continuous administration of enteral lipid- and protein-rich nutrition limits inflammation in a human endotoxemia model. Crit Care Med. 2013;41(5):1258-65. 
20. Li B, Liu HY, Guo SH, Sun P, Gong FM, Jia BQ. Impact of early enteral and parenteral nutrition on prealbumin and high-sensitivity C-reactive protein after gastric surgery. Genet Mol Res. 2015; 14(2):7130-5.

21. Levy JC, Matthews DR, Hermans MP. Correct homeostasis model assessment (HOMA) evaluation uses the computer program. Diabetes Care. 1998;21(12):2191-2.

22. Colegrave N, Ruxton GD. Confidence intervals are a more useful complement to nonsignificant tests than are power calculations. Behavioral Ecology. 2003;14(3):446-U444.

23. Watt DG, Horgan PG, McMillan DC. Routine clinical markers of the magnitude of the systemic inflammatory response after elective operation: a systematic review. Surgery. 2015;157(2): 362-80.

24. Hubner M, Mantziari S, Demartines N, Pralong F, Coti-Bertrand P, Schafer M. Postoperative Albumin Drop Is a Marker for Surgical Stress and a Predictor for Clinical Outcome: A Pilot Study. Gastroenterol Res Pract. 2016;2016:8743187.

25. Andersson B, Ansari D, Norden M, Nilsson J, Andersson R. Surgical stress response after colorectal resection. Int Surg. 2013;98(4):292-9.

26. Nicholson JP, Wolmarans MR, Park GR. The role of albumin in critical illness. Br J Anaesth. 2000; 85(4):599-610.

27. Soeters PB, Wolfe RR, Shenkin A. Hypoalbuminemia: Pathogenesis and clinical significance. JPEN J Parenter Enteral Nutr. 2019;43(2):181-93.

28. Hulshoff A, Schricker T, Elgendy H, Hatzakorzian R, Lattermann R. Albumin synthesis in surgical patients. Nutrition. 2013;29(5):703-7.

29. Aiko S, Yoshizumi Y, Sugiura Y, Matsuyama T, Naito Y, Matsuzaki J, Maehara T. Beneficial effects of immediate enteral nutrition after esophageal cancer surgery. Surg Today. 2001;31(11):971-8.

30. Seike J, Tangoku A, Yuasa Y, Okitsu H, Kawakami Y, Sumitomo M. The effect of nutritional support on the immune function in the acute postoperative period after esophageal cancer surgery: total parenteral nutrition versus enteral nutrition. J Med Invest. 2011;58(1-2):75-80.

31. Yu G, Chen G, Huang B, Shao W, Zeng G. Effect of early enteral nutrition on postoperative nutritional status and immune function in elderly patients with esophageal cancer or cardiac cancer. Chin J Cancer Res. 2013;25(3):299-305.

32. Braga M, Gianotti L, Gentilini O, Parisi V, Salis C, Di Carlo V. Early postoperative enteral nutrition improves gut oxygenation and reduces costs compared with total parenteral nutrition. Crit Care Med. 2001;29(2):242-8.

33. Baggio LL, Drucker DJ. Biology of incretins: GLP-1 and GIP. Gastroenterology. 2007;132(6): 2131-57.

34. Moore MC, Coate KC, Winnick JJ, An Z, Cherrington AD. Regulation of hepatic glucose uptake and storage in vivo. Adv Nutr. 2012;3(3):286-94.

35. Petrov MS, Zagainov VE. Influence of enteral versus parenteral nutrition on blood glucose control in acute pancreatitis: a systematic review. Clin Nutr. 2007;26(5):514-23.

36. Elke G, van Zanten AR, Lemieux M, McCall M, Jeejeebhoy KN, Kott M, Jiang X, Day AG, Heyland DK. Enteral versus parenteral nutrition in critically ill patients: an updated systematic review and meta-analysis of randomized controlled trials. Crit Care. 2016;20(1):117.

37. Wallace TM, Levy JC, Matthews DR. Use and abuse of HOMA modeling. Diabetes Care. 2004; 27(6):1487-95.

38. Borai A, Livingstone C, Ferns GA. The biochemical assessment of insulin resistance. Ann Clin Biochem. 2007;44(Pt 4):324-42.

39. Nygren J. The metabolic effects of fasting and surgery. Best Pract Res Clin Anaesthesiol. 2006; 20(3):429-38.

40. Soop M, Nygren J, Myrenfors P, Thorell A, Ljungqvist O. Preoperative oral carbohydrate treatment attenuates immediate postoperative insulin resistance. Am J Physiol Endocrinol Metab. 2001; 280(4):E576-83. 


\section{Chapter}

\section{The effect of myopenia on the inflammatory response early after colorectal surgery}

Smeets BJJ, Brinkman DJ, Horsten ECJ, Langius JAE, Rutten HJT, de Jonge WJ,

Luyer MDP 


\section{Abstract}

Background

Myopenia (low skeletal muscle mass) is associated with an increased risk of complications following colorectal surgery, however the underlying mechanism is poorly understood. This study investigates the effect of myopenia on the early postoperative systemic inflammatory response.

Materials and methods

In 78 patients undergoing colorectal surgery, the presence of myopenia was preoperatively assessed using computed tomography images of the third lumbar vertebra. Interleukin-8 (Il-8) and soluble tumor necrosis factor receptor-1 (TNFRSF1A) were measured in plasma before and 4 hours after start of surgery as part of a randomized controlled trial investigating the effect of perioperative gum chewing on the inflammatory response. Multivariable linear regression analysis was performed to assess the effect of myopenia on inflammatory markers while correcting for possible confounders.

Results

Four hours after start of surgery, IL-8 was higher in patients with myopenia than in patients without myopenia (352 \pm 268 vs. $239 \pm 211 \mathrm{pg} / \mathrm{ml}, \mathrm{p}=0.048)$, while TNFRSF1A was similar between groups. After adjusting for sex and the intervention with perioperative gum chewing, myopenia remained associated with higher postoperative IL-8 concentrations ( $\mathrm{p}=0.047)$.

Conclusion

Myopenia may affect IL-8 early after colorectal surgery. However, more studies are needed to validate these findings. 


\section{Introduction}

Myopenia indicates the clinically relevant loss of skeletal muscle mass, and is common in patients with colorectal cancer. ${ }^{1,2}$ Myopenia is considered an indicator of increased vulnerability to stressors, and is associated with higher complication rates following colorectal surgery. ${ }^{3-6}$ Although dietary- and exercise-based strategies may improve skeletal muscle mass to some extent after some time, these interventions are not always feasible in patients with colorectal cancer requiring prompt surgical treatment.7-10 Therefore, rather than by increasing skeletal muscle mass, postoperative complications in patients with myopenia may be reduced more effectively by interventions that target the underlying biological mechanisms that impair postoperative recovery. However, these biological mechanisms are poorly understood. To develop effective interventions in the surgical population, it is necessary to understand how myopenia increases the risk of postoperative complications.

Multiple studies have demonstrated that myopenia is associated with an increased inflammatory response before and several days after colorectal surgery. ${ }^{11-14}$ However, the effect of myopenia on the early (i.e. within hours) postoperative systemic inflammatory response is unclear. Recent studies suggest that the magnitude of the early systemic inflammatory response to surgery is related to the development of postoperative complications. ${ }^{15-20}$ In this light, examining the effect of myopenia on the early postoperative inflammatory response may help explain the increased risk of complications. In this study, the effects of myopenia on the early postoperative systemic inflammatory response and complications are investigated in patients undergoing colorectal surgery.

\section{Materials and methods}

\section{Study characteristics}

This study was performed with data from a previous randomized controlled clinical trial that compared perioperative gum chewing to placebo in patients undergoing major colorectal surgery in two large Dutch tertiary referral hospitals. ${ }^{21}$ All outcomes except presence of myopenia were predefined in the original study protocol 22 , which was designed in accordance with the Declaration of Helsinki and Good Clinical Practice and was approved by the Medical Ethics Committee of Catharina Hospital Eindhoven. 


\section{Patient population}

Patients were included if aged 18 or older and undergoing elective, open colorectal surgery. Patients were excluded if they suffered from peritoneal carcinomatosis, inflammatory bowel disease, a history of gastric or esophageal surgery, a disturbance of acetylcholine metabolism owing to neurological disease or depression, pre-existing ileostoma, allergy to mint, or if they used agents influencing gut motility (including opioids) or acetylcholine metabolism (e.g. parasympatheticomimetics).

A total of 120 patients were previously included and randomized to the intervention group or the control group. ${ }^{21}$ The intervention group was instructed to chew gum starting 3 hours before surgery, and again starting 3 hours after surgery until start of oral intake. Alternatively, the control group received a placebo dermal patch at the same moments as the intervention group and was instructed not to chew gum. ${ }^{21}$

In the current study, we excluded patients who did not have a preoperative computed tomography (CT) scan suitable for myopenia assessment.

\section{Analysis of skeletal muscle mass}

Presence of myopenia was determined by two trained, independent researchers (BS and EH) by means of preoperative CT image analysis, while blinded for treatment allocation and postoperative outcomes. ${ }^{23}$ A CT scan was deemed suitable for skeletal muscle analysis if it was performed within 2 months prior to surgery and if none of the following conditions were present: abnormal muscular anatomy (e.g. stoma, abdominal wall hernia), poor demarcation between different body compartments, presence of artefacts, or incomplete visualization of the abdominal wall musculature.

CT image analysis was performed using Slice-O-Matic V5.0 software (Tomovision, Montreal, Canada) as previously described. ${ }^{23}$ Briefly, total surface area of skeletal muscle was determined on a single image at the level of the third lumbar vertebra (L3) using Hounsfield Unit thresholds of -29 to 150 for skeletal muscle. Skeletal muscle surface area was normalized for height in meters squared $\left(\mathrm{m}^{2}\right)$ and reported as lumbar skeletal muscle index $\left(\mathrm{cm}^{2} / \mathrm{m}^{2}\right)$. Presence of myopenia was determined in accordance with body mass index- and sex-specific threshold values as defined by Martin et al..24

\section{Measurement of inflammatory markers and postoperative complications}

Venous blood samples were collected before surgery and 4 hours after start of surgery to measure interleukin 8 (IL-8) and soluble tumor necrosis factor receptor 
1 (TNFRSF1A) as specific markers of the innate systemic inflammatory response. TNFRSF1A is a transmembrane receptor through which tumor necrosis factor (TNF)- $\alpha$ exerts its effects, and gives a good representation of TNF- $\alpha$ plasma concentrations. ${ }^{25}$ EDTA-treated plasma was separated by centrifugation and stored at $-80^{\circ} \mathrm{C}$ within 30 minutes until further analysis. Plasma concentrations of inflammatory markers were determined in plasma samples with an enzyme-linked immunosorbent assay (Hycult Biotech, Uden, The Netherlands). Furthermore, first postoperative C-reactive protein (CRP) levels were determined in plasma by means of an immunoturbodimetric assay (Roche/Hitachi cobas c system, Roche, Mannheim, Germany) as part of routine clinical care on postoperative day 1, 2, or 3 . All postoperative complications were registered prospectively until patient discharge, and were graded according to the Clavien-Dindo classification. ${ }^{26}$

\section{Statistical analysis}

SPSS v22.0 (IBM, Armonk, New York, USA) was used for statistical analysis. Continuous parameters are presented as mean \pm standard deviation or median [interquartile range], and compared between patients with and without myopenia using the unpaired T-test or Mann-Whitney $U$ test as appropriate. Categorical variables were compared between groups using the $\chi^{2}$ test or the Fisher's Exact test. The association between myopenia and inflammatory markers was analyzed by means of univariable and multivariable linear regression analysis. In addition to perioperative gum chewing, other potential confounding factors were identified by comparing relevant baseline characteristics between patients with versus without myopenia, and between patients in whom the postoperative inflammatory response was smaller versus greater than the overall median value. To minimize risk of bias, adjustments were made for gum chewing and for other potential confounding factors significantly associated with any inflammatory marker in multivariable linear regression analysis. Statistical significance was determined as $\mathrm{p}<0.05$.

\section{Results}

\section{Patient characteristics}

Out of 120 patients included in the original trial, eight patients were excluded after randomization, due to consent withdrawal $(n=4)$ and technical reasons $(n=4)$. No preoperative CT scan was available in 24 patients, and in 10 patients the CT scan was performed more than two months prior to surgery. Subsequently, a total of 78 patients were included in the current study. Overall, patients had a mean 
skeletal muscle index of $46.6 \pm 9.0 \mathrm{~cm}^{2} / \mathrm{m}^{2}$. Myopenia was present in 31 patients $(40 \%)$. Patients with myopenia were more often female $(\mathrm{p}=0.012)$, and were more likely to have a higher American Society of Anesthesiologists (ASA) grade $(\mathrm{p}=0.035)$ when compared to patients without myopenia (Table 6.1). No other differences in patient characteristics or surgical details were observed between patients with versus without myopenia.

Table 6.1: Baseline characteristics of patients with versus without myopenia.

\begin{tabular}{|c|c|c|c|}
\hline & Myopenia (n=31) & No myopenia $(n=47)$ & $p$ value \\
\hline Age (years) & $69 \pm 12$ & $64 \pm 9$ & 0.058 \\
\hline Sex ratio $(\mathrm{M}: \mathrm{F})$ & $16: 15$ & $37: 10$ & 0.012 \\
\hline Height $(\mathrm{cm})$ & $172 \pm 11$ & $172 \pm 8$ & 0.853 \\
\hline Weight (kg) & $72[64-83]$ & $78[73-84]$ & 0.077 \\
\hline Body mass index $\left(\mathrm{kg} / \mathrm{m}^{2}\right)$ & 25 [23-28] & 25 [24-29] & 0.189 \\
\hline ASA grade & & & 0.035 \\
\hline 1 & $2(6)$ & $11(23)$ & \\
\hline 2 & $25(81)$ & $35(75)$ & \\
\hline 3 & $4(13)$ & $1(2)$ & \\
\hline Previous abdominal surgery & $7(23)$ & $10(21)$ & 0.891 \\
\hline Diabetes Mellitus & $8(27)$ & $8(17)$ & 0.625 \\
\hline Smoking & $5(27)$ & $4(50)$ & 0.233 \\
\hline Duration of surgery (min) & 123 [110-205] & $130[110-180]$ & 0.959 \\
\hline Blood loss (ml) & $500[240-1000]$ & $300[150-725]$ & 0.238 \\
\hline Colostomy required & $14(45)$ & $21(45)$ & 0.967 \\
\hline Type of operation & & & 0.245 \\
\hline Right hemicolectomy & $12(39)$ & $10(21)$ & \\
\hline Left hemicolectomy & $9(29)$ & $18(39)$ & \\
\hline Rectal resection & $10(32)$ & $19(40)$ & \\
\hline Gum chewing : Control & $16: 15$ & $20: 27$ & 0.432 \\
\hline Skeletal Muscle Index $\left(\mathrm{cm}^{2} / \mathrm{m}^{2}\right)$ & $37.7[35.3-40.8]$ & $52.2[46.0-55.9]$ & $<0.001$ \\
\hline
\end{tabular}

ASA, American Society of Anesthesiologists. Values are numbers (\%) or mean \pm s.d. or median [interquartile range].

\section{Inflammatory markers and complications in patients with versus without myopenia}

At baseline, four patients with myopenia had detectable concentrations of IL-8, while IL-8 was not detectable in patients without myopenia. This resulted in significant higher preoperative concentrations of IL-8 in patients with myopenia compared to patients without myopenia $(p=0.011)$ (Table 6.2). Baseline concentrations of TNFRSF1A were similar between groups ( $\mathrm{p}=0.176)$.

Surgery induced a marked inflammatory response in all patients regardless of presence of myopenia. However, postoperative IL-8 was significantly higher in patients with myopenia compared to patients without myopenia $(p=0.048)$. Postoperative TNFRSF1A was similar between groups $(p=0.296)$. First 
postoperative CRP concentrations were similar between patients with and without myopenia $(\mathrm{p}=0.636)$.

Myopenia was not associated with an increased risk of any postoperative complication in this patient cohort.

Table 6.2: Inflammatory parameters at baseline and 4 hours after start of surgery in myopenia versus no myopenia.

\begin{tabular}{lccc}
\hline & Myopenia (n=31) & No myopenia (n=47) & p value \\
\hline Baseline & $0[0-6.01]$ & & \\
${\text { IL-8 }(\mathrm{pg} / \mathrm{ml})^{\mathrm{a}}}$ & $0.54[0.28-1.19]$ & $0.45[0-0]$ & 0.011 \\
TNFRSF1A (ng/ml)b & & & 0.176 \\
After surgery & $352 \pm 268$ & $239 \pm 211$ & 0.048 \\
IL-8 (pg/ml)c & $0.83[0.29-2.98]$ & $0.78[0.29-1.85]$ & 0.296 \\
TNFRSF1A (ng/ml)b & $160[110-270]$ & $153[90-255]$ & 0.636 \\
CRP (mg/l)b & & & \\
\hline
\end{tabular}

CRP, first measured C-reactive protein; IL-8, interleukin-8; TNFRSF1A, soluble tumor necrosis factor receptor 1 . Values are ${ }^{a}$ median [range] or ${ }^{b}$ median [interquartile range] or ${ }^{\mathrm{c}}$ mean $\pm \mathrm{s} . \mathrm{d}$..

\section{Identification of confounders}

Sex and ASA grade were identified as potential confounders for the postoperative inflammatory response based on differences in baseline characteristics between patients with versus without myopenia. Next, patients were stratified based on the magnitude of the postoperative inflammatory response, i.e. smaller versus greater than the overall median postoperative concentration of IL-8 (259 pg/ml), TNFRSF1A (0.79 ng/ml), and CRP (156 mg/l), and relevant baseline characteristics were compared between groups (Tables 6.3A-C). There was a trend towards a longer duration of surgery in patients with a higher IL-8 response, however this was not statistically significant. Body mass index was greater in patients with a high postoperative CRP concentration $(\mathrm{p}=0.046)$. Intraoperative blood loss and type of resection (colon versus rectum) were similar all groups. Based on these findings, body mass index was evaluated as a potential confounder in linear regression analysis.

Table 6.3A: Baseline characteristics in patients with a low $(<260 \mathrm{pg} / \mathrm{ml})$ versus high $(\geq 260 \mathrm{pg} / \mathrm{ml})$ postoperative IL-8 response.

\begin{tabular}{lccc}
\hline & Low IL-8 & High IL-8 & p value \\
\hline Body mass index $\left(\mathrm{kg} / \mathrm{m}^{2}\right)$ & $25[24-28]$ & $26[24-28]$ & 0.547 \\
Duration of surgery $(\mathrm{min})$ & $120[101-178]$ & $154[117-221]$ & 0.050 \\
Blood loss $(\mathrm{ml})$ & $300[100-800]$ & $500[300-900]$ & 0.101 \\
Type of surgery & & & 0.629 \\
Colon & $23(64)$ & $21(58)$ & \\
Rectum & $13(36)$ & $15(42)$ & \\
\hline
\end{tabular}

IL-8, interleukin 8. Values are numbers (\%) or median [interquartile range]. 
Table 6.3B: Baseline characteristics in patients with a low $(<0.79 \mathrm{pg} / \mathrm{ml})$ versus high $(\geq 0.79 \mathrm{pg} / \mathrm{ml})$ postoperative TNFRSF1A response.

\begin{tabular}{lccc}
\hline & Low TNFRSF1A & High TNFRSF1A & $\boldsymbol{p}$ value \\
\hline Body mass index $\left(\mathrm{kg} / \mathrm{m}^{2}\right)$ & $25[24-28]$ & $26[24-29]$ & 0.723 \\
Duration of surgery $(\mathrm{min})$ & $128[102-190]$ & $142[111-192]$ & 0.313 \\
Blood loss (ml) & $300[175-750]$ & $500[100-900]$ & 0.665 \\
Type of surgery & & & 0.851 \\
Colon & $21(60)$ & $23(62)$ & \\
Rectum & $14(40)$ & $14(38)$ & \\
\hline
\end{tabular}

TNFRSF1A, soluble tumor necrosis factor receptor 1 . Values are numbers (\%) or median [interquartile range].

Table 6.3C: Baseline characteristics in patients with a low $(<156 \mathrm{mg} / \mathrm{l})$ versus high $(\geq 156 \mathrm{mg} / \mathrm{l})$ postoperative CRP response.

\begin{tabular}{llll}
\hline & Low CRP & High CRP & p value \\
\hline Body mass index $\left(\mathrm{kg} / \mathrm{m}^{2}\right)$ & $25[24-27]$ & $27[24-28]$ & 0.046 \\
Duration of surgery $(\mathrm{min})$ & $123[104-173]$ & $148[112-211]$ & 0.119 \\
Blood loss (ml) & $400[250-840]$ & $300[100-900]$ & 0.579 \\
Type of surgery & & & 0.929 \\
Colon & $23(62)$ & $24(63)$ & \\
Rectum & $14(38)$ & $14(37)$ & \\
\hline
\end{tabular}

CRP, first measured C-reactive protein. Values are numbers (\%) or median [interquartile range].

\section{Linear regression analysis}

In univariable linear regression analysis, myopenia was associated with increased concentrations of IL-8 at baseline $(\mathrm{p}=0.040)$ and four hours after start of surgery $(\mathrm{p}=0.048)$ (Table 6.4).

Table 6.4: Linear regression analyses between myopenia and inflammatory parameters.

\begin{tabular}{lcccccc}
\hline & B & $\begin{array}{c}\text { Crude model } \\
\mathbf{9 5 \%} \text { CI }\end{array}$ & p value & B & $\begin{array}{c}\text { Adjusted model } \\
\mathbf{9 5 \%} \text { CI }\end{array}$ & p value \\
\hline Baseline & & & & & & \\
$\quad$ IL-8 & 0.481 & $0.22-0.941$ & 0.040 & 0.503 & $0.021-0.986$ & 0.041 \\
TNFRSF1A & 0.074 & $-0.49-0.198$ & 0.233 & 0.052 & $-0.072-0.176$ & 0.406 \\
After Surgery & & & & & & \\
$\quad$ IL-8 & 113.780 & $1.070-226.490$ & 0.048 & 116.328 & $1.470-231.186$ & 0.047 \\
TNFRSF1A & 0.142 & $-0.61-0.344$ & 0.167 & 0.127 & $-0.860-0.340$ & 0.238 \\
CRP & 10.001 & $-31.132-51.135$ & 0.629 & 10.539 & $-32.386-53.464$ & 0.626 \\
\hline
\end{tabular}

CRP, first measured C-reactive protein; IL-8, interleukin-8; TNFRSF1A, soluble tumor necrosis factor receptor 1 . adjusted for perioperative gum chewing and sex.

In addition to perioperative gum chewing, sex, ASA grade, and body mass index were evaluated as potential confounding factors for the association between myopenia and inflammatory markers. Perioperative gum chewing was associated with lower concentrations of IL-8 four hours after start of surgery $(p=0.048)$. 
Female sex was associated with increased concentrations of TNFRSF1A at baseline $(\mathrm{p}=0.041)$. Body mass index and ASA grade were not significantly associated with any inflammatory marker in univariable linear regression analysis.

Due to the significant association with inflammatory markers in univariable linear regression analysis, perioperative gum chewing and sex were added as confounders in multivariable linear regression analysis. After adjusting for the effect of perioperative gum chewing and sex, myopenia remained associated with increased concentrations of IL-8 four hours after start of surgery ( $p=0.047)$.

When the four patients that demonstrated detectable IL-8 concentrations at baseline were excluded from multivariable linear regression analysis, the association between myopenia and postoperative IL-8 concentrations was no longer significant ( $\mathrm{B}=84.183,95 \%$ CI -33.673-202.039, $\mathrm{p}=0.158)$.

\section{Discussion}

The current study demonstrates no association between myopenia and postoperative concentrations of TNFRSF1A or CRP. Myopenia may be associated with increased postoperative concentrations of IL-8. However, this association is limited by the presence of confounders.

Previous studies investigating the relation between myopenia and inflammation mainly focused on the preoperative inflammatory response. Before surgery, myopenia was associated with increased markers of subclinical inflammation, including the neutrophil-to-lymphocyte ratio (NLR) and the modified Glasgow Prognostic Score (mGPS). ${ }^{12,13}$ In patients with colorectal cancer, increased NLR- and mGPS-scores before surgery are associated with higher mortality rates and more infective complications. ${ }^{27-30}$ It is hypothesized that a preoperative state of increased inflammation, as seen in patients with myopenia, impairs wound healing and alters the inflammatory response to surgery. ${ }^{31-33}$

The findings of the current study may support the hypothesis that myopenia alters the postoperative inflammatory response, as the presence of reduced skeletal muscle mass was associated with increased IL-8 concentrations early after surgery. However, no effect was observed on TNFRSF1A or CRP. IL-8 is produced early in the inflammatory cascade mainly by monocytes and macrophages following activation by TNF- $\alpha .{ }^{34}$ IL- 8 then induces chemotaxis and activation of neutrophils, that subsequently secrete other inflammatory mediators including calprotectin. ${ }^{35}$ Interestingly, Reisinger et al. found that reduced skeletal muscle mass in patients undergoing colorectal surgery was associated with higher calprotectin concentrations on postoperative days 2-5, while no effect was seen on IL-6 or CRP. ${ }^{14}$ Taken together, we hypothesize that myopenia may augment the IL-8 
response early after start of surgery, which subsequently leads to an increase of other, but not all, inflammatory markers (e.g. calprotectin) in a later stage. Postoperative measurements of IL-8 concentrations at later timepoints could provide more insight in this matter. However, in the original trial IL-8 was determined only before and four hours after surgery.

It is well established that postoperative complications induce a marked inflammatory response. Vice versa, an increased early inflammatory response to surgery is associated with the development of complications later. ${ }^{15-20}$ Specifically, an upregulated innate, systemic inflammatory response can suppress the acquired, cell-mediated immunity of the host, which increases the risk of infective complications and may also promote tumor progression. ${ }^{19,36}$ Furthermore, the early postoperative local and systemic inflammatory response is essential in the development of postoperative ileus, which is a major contributor to postoperative morbidity. ${ }^{16}$ Taken together, an augmented early postoperative inflammatory response may explain the increased risk of complications in patients with myopenia as seen in other studies. ${ }^{3-6}$

In contrast to other studies that clearly demonstrate an increase in complications in patients with reduced skeletal muscle mass ${ }^{3-6}$, in this study myopenia was not associated with an effect on postoperative complications. These differences may be explained by several limitations in the current study. First, myopenia was assessed in a retrospective manner. This reduced the number of patients suitable for analysis resulting in a relatively small patient group when compared to other studies. ${ }^{3-6}$ Second, we applied thresholds of myopenia that were adjusted for sex and body mass index as proposed by Martin et al.. ${ }^{24}$ However, specific thresholds to determine clinically relevant loss of skeletal muscle mass vary throughout the literature, which limits comparison of our results with other studies. ${ }^{3}$ Third, several confounders were identified that may have affected the effect of myopenia on inflammatory markers. However, our data and other literature ${ }^{37,38}$ do not support a strong effect of sex or ASA grade on the postoperative inflammatory response. The surgical approach (open versus laparoscopic), setting (acute versus elective), and degree of surgical trauma may also affect the magnitude of the surgical inflammatory response. ${ }^{39,40}$ However, in our study cohort only elective, open surgery was performed, and no significant differences were observed in amount of blood loss, or the duration or type of surgery between patients with versus without myopenia, or between patients with a limited versus substantiated inflammatory response. Furthermore, multivariable linear regression analysis was performed to adjust for the effects of potential confounders. Fourth, when excluding patients with detectable concentrations of IL-8 at baseline, the association between myopenia and postoperative IL-8 concentrations was no longer significant. As such, an elevated preoperative inflammatory state may be a confounder for 
postoperative IL-8 concentrations. Alternatively, the smaller cohort size may have decreased statistical power.

Several strategies have been explored to prevent or reverse skeletal muscle wasting, including physical exercise, dietary supplements, and certain pharmacological agents. ${ }^{7,8,10,41}$ However, most pharmaceutical agents are associated with limited effects on muscle mass and serious side-effects. ${ }^{7,10,42}$ Physical exercise in combination with adequate nutrition is deemed most effective in increasing skeletal muscle mass after some time, but is not always feasible in patients with colorectal cancer requiring prompt surgical treatment.7,10 Instead, a short intervention that targets the underlying biological effects of myopenia may be more effective to counter the increased risk of postoperative complications. In this light, the anti-inflammatory effect of perioperative gum chewing 21 may be interesting; however, more research is needed to validate our findings and to determine to what degree inflammation plays a role in the development of complications in patients with myopenia.

In conclusion, myopenia was not associated with postoperative concentrations of CRP of TNFRSF1A, while it may affect plasma concentrations of IL-8 early after colorectal surgery. However, larger studies are needed to determine the true effect of myopenia on the postoperative inflammatory response given the presence of possible confounders and small sample size of our study cohort. 


\section{References}

1. Broughman JR, Williams GR, Deal AM, Yu H, Nyrop KA, et al. Prevalence of sarcopenia in older patients with colorectal cancer. J Geriatr Oncol. 2015;6:442-5.

2. Fearon K, Evans WJ, Anker SD. Myopenia-a new universal term for muscle wasting. J Cachexia Sarcopenia Muscle. 2011;2:1-3.

3. Malietzis G, Aziz O, Bagnall NM, Johns N, Fearon KC, et al.: The role of body composition evaluation by computerized tomography in determining colorectal cancer treatment outcomes: a systematic review. Eur J Surg Oncol. 2015;41:186-96.

4. Lieffers JR, Bathe OF, Fassbender K, Winget M, Baracos VE. Sarcopenia is associated with postoperative infection and delayed recovery from colorectal cancer resection surgery. Br J Cancer. 2012;107:931-6.

5. Miyamoto Y, Baba Y, Sakamoto Y, Ohuchi M, Tokunaga R, et al. Sarcopenia is a Negative Prognostic Factor After Curative Resection of Colorectal Cancer. Ann Surg Oncol. 2015;22:2663-8.

6. Margadant CC, Bruns ER, Sloothaak DA, van Duijvendijk P, van Raamt AF, et al. Lower muscle density is associated with major postoperative complications in older patients after surgery for colorectal cancer. Eur J Surg Oncol. 2016;42:1654-9.

7. Rolland Y, Onder G, Morley JE, Gillette-Guyonet S, Abellan van Kan G, et al. Current and future pharmacologic treatment of sarcopenia. Clin Geriatr Med. 2011;27:423-47.

8. Beyer I, Mets T, Bautmans I. Chronic low-grade inflammation and age-related sarcopenia. Curr Opin Clin Nutr Metab Care. 2012;15:12-22.

9. Sinclair M, Gow PJ, Grossmann M, Angus PW. Review article: sarcopenia in cirrhosis--aetiology, implications and potential therapeutic interventions. Aliment Pharmacol Ther. 2016;43:765-77.

10. Wakabayashi H, Sakuma K. Comprehensive approach to sarcopenia treatment. Curr Clin Pharmacol. 2014;9:171-80.

11. Meng SJ, Yu LJ. Oxidative stress, molecular inflammation and sarcopenia. Int J Mol Sci. 2010;11: 1509-26.

12. Malietzis G, Johns N, Al-Hassi HO, Knight SC, Kennedy RH, et al. Low muscularity and myosteatosis is related to the host systemic inflammatory response in patients undergoing surgery for colorectal cancer. Ann Surg, 2016;263(2):320-5.

13. Richards $\mathrm{CH}$, Roxburgh CS, MacMillan MT, Isswiasi S, Robertson EG, et al. The relationships between body composition and the systemic inflammatory response in patients with primary operable colorectal cancer. PLoS One. 2012;7:e41883.

14. Reisinger KW, Derikx JP, van Vugt JL, Von Meyenfeldt MF, Hulsewe KW, et al. Sarcopenia is associated with an increased inflammatory response to surgery in colorectal cancer. Clin Nutr, 2016;35(4):924-7.

15. Rettig TC, Verwijmeren L, Dijkstra IM, Boerma D, van de Garde EM, et al. Postoperative interleukin6 level and early detection of complications after elective major abdominal surgery. Ann Surg, 2016;263(6):1207-12.

16. Peters EG, De Jonge WJ, Smeets BJ, Luyer MD. The contribution of mast cells to postoperative ileus in experimental and clinical studies. Neurogastroenterol Motil. 2015;27:743-9.

17. McSorley ST, Horgan PG, McMillan DC. The impact of preoperative corticosteroids on the systemic inflammatory response and postoperative complications following surgery for gastrointestinal cancer: A systematic review and meta-analysis. Crit Rev Oncol Hematol. 2016;101:139-50.

18. Chuang D, Paddison JS, Booth RJ, Hill AG. Differential production of cytokines following colorectal surgery. ANZ J Surg 2006;76:821-4.

19. Marik PE, Flemmer M. The immune response to surgery and trauma: Implications for treatment. J Trauma Acute Care Surg. 2012;73:801-8.

20. Szczepanik AM, Scislo L, Scully T, Walewska E, Siedlar M, et al. IL-6 serum levels predict postoperative morbidity in gastric cancer patients. Gastric Cancer. 2011;14:266-73. 
21. van den Heijkant TC, Costes LM, van der Lee DG, Aerts B, Osinga-de Jong M, et al. Randomized clinical trial of the effect of gum chewing on postoperative ileus and inflammation in colorectal surgery. Br J Surg. 2015;102:202-11.

22. Berghmans TM, Hulsewe KW, Buurman WA, Luyer MD. Stimulation of the autonomic nervous system in colorectal surgery: a study protocol for a randomized controlled trial. Trials. 2012;13:93.

23. Mourtzakis M, Prado CM, Lieffers JR, Reiman T, McCargar LJ, et al. A practical and precise approach to quantification of body composition in cancer patients using computed tomography images acquired during routine care. Appl Physiol Nutr Metab. 2008;33:997-1006.

24. Martin L, Birdsell L, Macdonald N, Reiman T, Clandinin MT, et al. Cancer cachexia in the age of obesity: skeletal muscle depletion is a powerful prognostic factor, independent of body mass index. J Clin Oncol. 2013;31:1539-47.

25. Lantz M, Malik S, Slevin ML, Olsson I. Infusion of tumor necrosis factor (TNF) causes an increase in circulating TNF-binding protein in humans. Cytokine. 1990;2:402-6.

26. Dindo D, Demartines N, Clavien PA. Classification of surgical complications: a new proposal with evaluation in a cohort of 6336 patients and results of a survey. Ann Surg. 2004;240:205-13.

27. Moyes LH, Leitch EF, McKee RF, Anderson JH, Horgan PG, et al. Preoperative systemic inflammation predicts postoperative infectious complications in patients undergoing curative resection for colorectal cancer. Br J Cancer. 2009;100:1236-9.

28. Ishizuka M, Nagata H, Takagi K, Horie T, Kubota K. Inflammation-based prognostic score is a novel predictor of postoperative outcome in patients with colorectal cancer. Ann Surg. 2007;246: 1047-51.

29. De Magistris L, Paquette B, Orry D, Facy O, Di Giacomo G, et al. Preoperative inflammation increases the risk of infection after elective colorectal surgery: results from a prospective cohort. Int J Colorectal Dis. 2016;31:1611-7.

30. Malietzis G, Giacometti M, Kennedy RH, Athanasiou T, Aziz O, et al. The emerging role of neutrophil to lymphocyte ratio in determining colorectal cancer treatment outcomes: a systematic review and meta-analysis. Ann Surg Oncol. 2014;21:3938-46.

31. Nozoe T, Matsumata T, Sugimachi K. Preoperative elevation of serum C-reactive protein is related to impaired immunity in patients with colorectal cancer. Am J Clin Oncol. 2000;23:263-6.

32. Canna K, McArdle PA, McMillan DC, McNicol AM, Smith GW, et al. The relationship between tumour T-lymphocyte infiltration, the systemic inflammatory response and survival in patients undergoing curative resection for colorectal cancer. Br J Cancer. 2005;92:651-4.

33. Du Clos TW, Mold C. C-reactive protein: an activator of innate immunity and a modulator of adaptive immunity. Immunol Res. 2004;30:261-77.

34. Remick DG. Interleukin-8. Crit Care Med. 2005;33:S466-7.

35. Striz I, Trebichavsky I. Calprotectin - a pleiotropic molecule in acute and chronic inflammation. Physiol Res. 2004;53:245-53.

36. Roxburgh CS, Horgan PG, McMillan DC. The perioperative immune/inflammatory insult in cancer surgery: Time for intervention? Oncoimmunology. 2013;2:e27324.

37. Lord JM, Midwinter MJ, Chen YF, Belli A, Brohi K, et al.:The systemic immune response to trauma: an overview of pathophysiology and treatment. Lancet. 2014;384:1455-65.

38. Lopez MC, Efron PA, Ozrazgat-Baslanti T, Zhang J, Cuschieri J, et al. Sex-based differences in the genomic response, innate immunity, organ dysfunction, and clinical outcomes after severe blunt traumatic injury and hemorrhagic shock. J Trauma Acute Care Surg. 2016;81:478-85.

39. Leung KL, Lai PB, Ho RL, Meng WC, Yiu RY, et al. Systemic cytokine response after laparoscopicassisted resection of rectosigmoid carcinoma: A prospective randomized trial. Ann Surg. 2000;231: 506-11.

40. Catena F, Ansaloni L, Avanzolini A, Di Saverio S, D'Alessandro L, et al. Systemic cytokine response after emergency and elective surgery for colorectal carcinoma. Int J Colorectal Dis. 2009;24:803-8.

41. Subramaniam K, Fallon K, Ruut T, Lane D, McKay R, et al. Infliximab reverses inflammatory muscle wasting (sarcopenia) in Crohn's disease. Aliment Pharmacol Ther. 2015;41:419-28.

42. Scheinfeld N. A comprehensive review and evaluation of the side effects of the tumor necrosis factor alpha blockers etanercept, infliximab and adalimumab. J Dermatolog Treat. 2004;15:280-94. 



\section{Chapter}

The effects of stimulation of the autonomic nervous system via perioperative nutrition on postoperative ileus and anastomotic leakage following colorectal surgery (SANICS II trial): a study protocol for a double-blind randomized controlled trial

Peters EG, Smeets BJJ, Dekkers M, Buise MD, de Jonge WJ, Slooter GD, de Vries Reilingh TS, Wegdam JA, Nieuwenhuijzen GAP, Rutten HJT, de Hingh IHJT, Hiligsmann M, Buurman WA, Luyer MDP 


\section{Abstract}

Background

Postoperative ileus and anastomotic leakage are important complications following colorectal surgery associated with short-term morbidity and mortality. Previous experimental and preclinical studies have shown that a short intervention with enriched enteral nutrition dampens inflammation via stimulation of the autonomic nervous system and thereby reduces postoperative ileus. Furthermore, early administration of enteral nutrition reduced anastomotic leakage. This study will investigate the effect of nutritional stimulation of the autonomic nervous system just before, during and early after colorectal surgery on inflammation, postoperative ileus and anastomotic leakage.

\section{Methods/Design}

This multicenter, prospective, double-blind, randomized controlled trial will include 280 patients undergoing colorectal surgery. All patients will receive a selfmigrating nasojejunal tube that will be connected to a specially designed blinded tubing system. Patients will be allocated either to the intervention group, receiving perioperative nutrition, or to the control group, receiving no nutrition. The primary endpoint is postoperative ileus. Secondary endpoints include anastomotic leakage, local and systemic inflammation, (aspiration) pneumonia, surgical complications classified according to Clavien-Dindo, quality of life, gut barrier integrity and length of functional recovery. Furthermore, a costeffectiveness analysis will be performed.

Discussion

Activation of the autonomic nervous system via perioperative enteral feeding is expected to dampen the local and systemic inflammatory response. Consequently, postoperative ileus will be reduced as well as anastomotic leakage. The present study is the first to investigate the effects of enriched nutrition given shortly before, during and after surgery in a clinical setting. 


\section{Background}

Postoperative ileus (POI) is considered to be an inevitable consequence of colorectal surgery by many clinicians and is associated with an increased morbidity and prolonged hospital stay. Therapeutic strategies to cure this condition of decreased gastrointestinal motility lack in our current health system and at this moment only supportive care is given to optimize the patient's condition. Although perioperative care is improved by several measures such as encouraging early mobilization, minimally invasive surgery and standard anesthetic protocols as part of the Enhanced Recovery After Surgery (ERAS) guidelines, POI cannot be completely avoided and the incidence is still substantial.1,2 POI is caused by a local and systemic inflammatory response associated with bowel manipulation..$^{3,4}$ In experimental studies, it is shown that nutritional stimulation of the autonomic nervous system reduces the inflammatory response and POI via a specific mechanism. ${ }^{5-7}$ Ingestion of dietary lipids, proteins and peptides triggers release of cholecystokinin (CCK) via chylomicron formation. ${ }^{8}$ CCK binds to CCK-1 receptors located on vagal afferents, thereby rapidly activating the autonomic nervous system and subsequently activating efferent vagal nerve fibers leading to the release of acetylcholine. Acetylcholine then binds to alpha-7-nicotinic receptors, located on inflammatory cells such as mast cells, triggering an intracellular pathway that results in a decreased release of inflammatory mediators. ${ }^{9-11}$ Via this mechanism, POI can be inhibited. ${ }^{9,10}$

Also, in previous preclinical and clinical studies, our group has shown that enteral nutrition and sham feeding via chewing gum are very effective means in the reduction of POI and inflammation. When enteral nutrition was started very early after colorectal surgery, POI was reduced from $35 \%$ to $16 \%$. In a second study, using chewing gum as means to stimulate the autonomic nervous system, a reduction of $\mathrm{POI}$ was seen from $48 \%$ in the control group to $27 \%$ in the intervention group. ${ }^{12,13}$ These studies also revealed an as yet unaccountable effect on anastomotic leakage (AL), resulting in an average reduction of $73 \%$. AL is a dreaded complication following colorectal surgery, which is associated with significant morbidity and even mortality. It is a risk factor for local recurrence of colorectal cancer and has a significant impact on overall survival and quality of life. ${ }^{14}$

Composition of the enteral nutrition and timing of administration are essential for the magnitude of this response. Administration of an enriched enteral formula that optimally stimulates release of CCK via chylomicrons just before, during and directly after the inciting event for inflammation is pivotal. ${ }^{9}$ The current study will investigate whether enriched enteral nutrition given shortly before, during and early after colorectal surgery reduces POI and AL via stimulation of the autonomic nervous system in a clinical setting. Given limited healthcare resources and the 
increasing importance of economic evaluation, we also plan to estimate the costeffectiveness of this intervention in the current medical health care system.

\section{Study objectives}

The objective is to investigate whether enriched enteral nutrition given shortly before, during and early after colorectal surgery, reduces POI and AL via stimulation of the autonomic nervous system in a clinical setting, compared with standard care. The primary outcome will be POI. Secondary outcomes will include effects of perioperative nutrition compared with standard of care on AL, aspiration pneumonia, gastric volumes preoperatively, length of functional recovery, inflammatory markers, intestinal barrier integrity, surgical complications according to Clavien-Dindo and health-related quality of life. Furthermore a cost-effectiveness analysis and a cost-utility analysis will be performed.

\section{Methods and design}

This is a multicenter, prospective, double-blind, randomized controlled superiority trial with two parallel groups. A written informed consent needs to be obtained from every patient. The trial will be conducted according to the rules of Good Clinical Practice, and a Data Safety Monitoring Board (DSMB) is installed to monitor (serious) adverse events. Ethical approval for this study was granted by the Medical Ethics Committee Catharina Hospital (Eindhoven, the Netherlands) under reference number NL45640.060.13.

\section{Study population}

Patients aged $>18$ undergoing elective segmental colorectal resection with an anastomosis are eligible for inclusion. A total of 280 patients will be included. Exclusion criteria are previous gastric or esophageal resection, peritoneal carcinomatosis, pre-existent or creation of an ileostomy, steroid use and use of medication that disrupts the acetylcholine metabolism, such as selective serotonin reuptake inhibitors and anticonvulsants. Both the investigator and the responsible surgeon will verify eligibility. If the indication for operation is established, the patient will receive written and oral information about the trial during a scheduled outpatient appointment. Patients will be offered sufficient time to enquire about details of the trial and to decide whether or not they wish to participate. Patients will have to sign the informed consent form in the physical presence of the surgeon or investigator. A participant flow diagram is shown in Figure 7.1. 

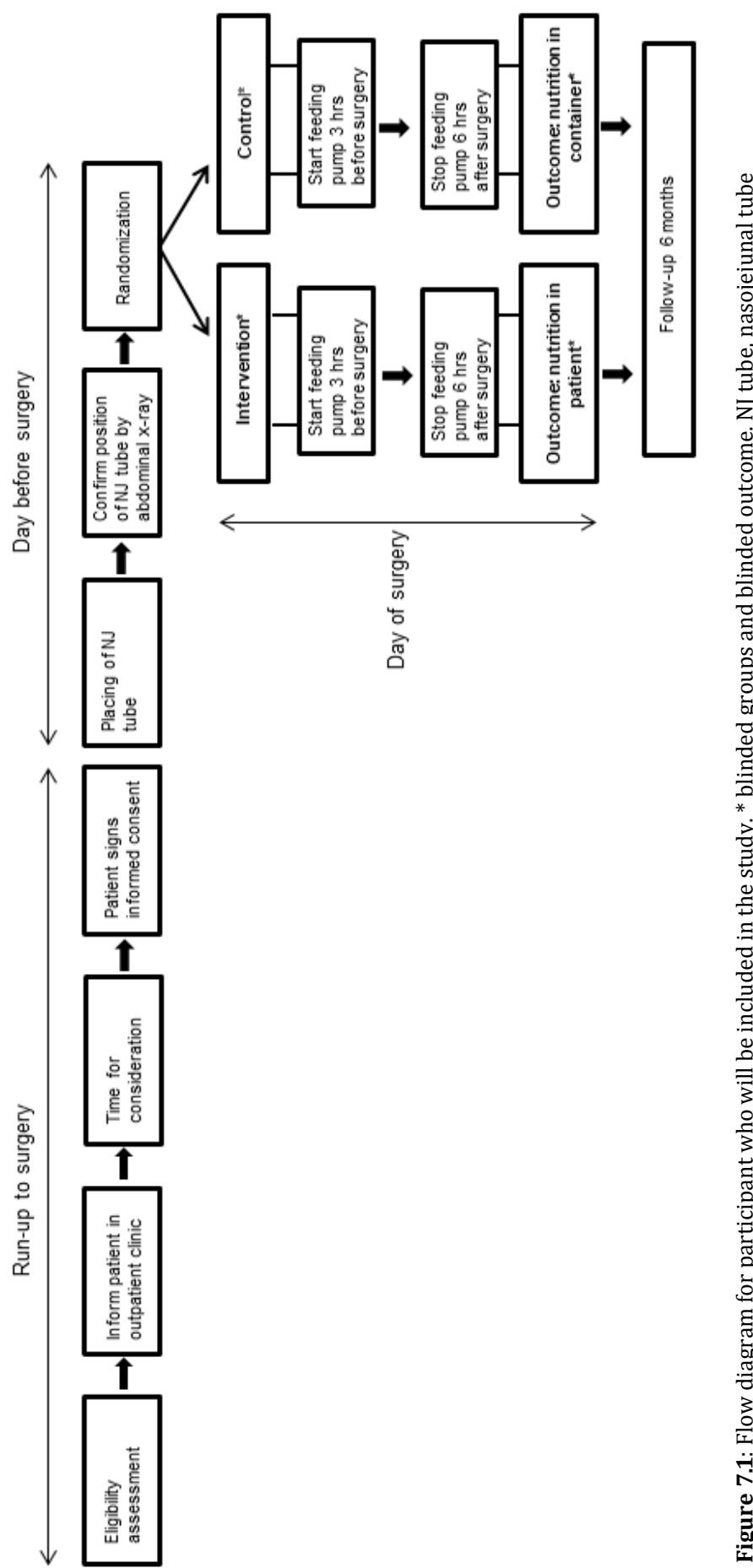


\section{Participating centers}

Patients eligible for this study will be initially included in the Catharina Hospital Eindhoven, the Netherlands. After inclusion of 40 patients, a safety analysis will be performed to assess feasibility and safety of perioperative nutrition. After this first safety analysis, this study will be conducted in a multicenter setting. Also, when 140 patients are included, an interim-analysis will be performed. The estimated duration of the recruitment period is two years.

\section{Randomization}

Patients will be randomized as block randomization with a 1:1 allocation by means of randomization software (TENALEA Clinical Trial Data Management System, Amsterdam, The Netherlands). A selfmigrating nasojejunal tube (Bengmark, Nutricia Flocare, Zoetermeer, The Netherlands) will be inserted in all included patients. To minimize aspiration, the nasojejunal tube needs to be positioned postpylorically, which will be confirmed by an abdominal X-ray. The patient will be randomized after confirmation of a correct position of the nasojejunal tube. Blinded stratification will be applied to ensure an equal distribution between colon or rectum surgery and between a laparoscopic or an open procedure.

After randomization, enriched enteral nutrition (Nutricia research, Utrecht, the Netherlands) will be started via an electronic feeding pump (Infinity, Nutricia Flocare, Zoetermeer, The Netherlands) in all patients. The nutrition and the pump will be connected to a specially designed opaque tubing system (ECMbv, Gemert, the Netherlands) that is similar to what is used in daily practice. However, the tubing has a bifurcation with two branches; one branch leads to the nasojejunal feeding tube in the patient and one branch leads to a sealed container (attached to the bed in all patients). For patients who will be allocated to the intervention group, the tubing system is open towards the patient and occluded towards the container. For patients in the control group, the tubing system is occluded towards the patient and open towards the container. In this way, the patients in the intervention group will receive enriched enteral nutrition, while the patients in the control group will not. The tubing will be labeled with a randomization number provided by TENALEA. Independent research nurses will provide the labeling of the tubing and store the allocation list.

The tubing system can easily be connected to all materials, including the standard enteral feeding system, the nasojejunal feeding tube, and the container. The containers will be sealed and weighted, to prevent differentiation between the groups by examining the containers. Neither the patient, nor the nursing staff or the researchers will be able to see which branch of the tubing system is occluded. 


\section{Study outline}

The day before surgery, all patients will receive a selfmigrating nasojejunal feeding tube at the ward. The position of the nasojejunal tube will be verified by means of abdominal X-ray. Preoperatively, all patients will be fasted for oral solid foods for a period of 6 hours, and oral liquids for a period of 2 hours. Three hours before surgery, the pump with enriched tube feeding will be started at a continuous rate of $1,5 \mathrm{ml} / \mathrm{min}$ in all patients. Subsequently, six hours after surgery, the feeding pump will be stopped and the nasojejunal tube will be removed. Depending on the randomization outcome, the nutrition will be administrated either to the patient, or into the sealed container. This setup allows a double-blind comparison between the control group and the intervention group, receiving enriched enteral nutrition. The fixed timeframe and the administration of feeding by electronic pump will support adherence to the study protocol. Anesthetic regimens will be standardized and registered per patient, as will the standardized postoperative care. Participants should continue to take medication for other conditions as usual.

Both the rate of infusion and the composition of the nutrition have been described in previous studies. ${ }^{9}$ Furthermore, the nutrition has been tested in healthy volunteers and is well tolerated. ${ }^{9}$ The enriched nutrition contains 44 energy percent (en\%) fat, $25 \mathrm{en} \%$ protein, and $31 \mathrm{en} \%$ carbohydrates. The protein fraction consists of intact casein, whey protein, and soy protein hydrolysate. The lipid fraction contains less than 5 weight percent omega- 3 fatty acids.

Perioperative nutrition is a new concept with a potential risk of aspiration pneumonia. In this trial, nutrition will be administered postpylorically, thereby reducing gastric volumes. To minimize risk of aspiration pneumonia, the stomach will be emptied by means of a gastric tube before surgery. Gastric volumes will be measured in every patient when the stomach is emptied, before surgery in the operating room. By giving the nutrition postpylorically, in a low volume and assuring an empty stomach before intubation, the risk of complications will be minimized.

A Data Safety Monitoring Board (DSMB) has been installed to evaluate all complications and monitor patient safety. If a serious event regarding safety of preoperative feeding (e.g. aspiration pneumonia) occurs, the DSMB will be informed, who will then discuss the consequences and report their advice to the investigator and Medical Ethics Committee.

POI is defined in accordance with a standardized definition, and will be measured clinically. POI is established if both of the following criteria are met: lack of passage of flatus or stool, and inability to tolerate an oral diet in the interval between surgery and postoperative day four. ${ }^{15}$

Prolonged POI is established if two or more of the following criteria are met on or after postoperative day four without prior resolution of POI: nausea or vomiting, 
inability to tolerate an oral diet over the last 24 hours, absence of flatus over the last 24 hours, abdominal distension, and/or radiologic confirmation.

In addition, gastric motility will be measured by means of ultrasound of the gastric antrum before and after a standardized meal on the second postoperative day. Previous studies have shown that ultrasonic gastric antrum measurements are representative for determining gastric emptying and gastric motility by determining the change in the gastric antral cross sectional area of the stomach before a standardized meal, and 15 and 90 minutes postprandially. ${ }^{16}$

AL is defined as clinical and radiological signs of anastomotic leakage, if confirmed by re-operation or if an enterocutaneous fistula occurs. Blood plasma, peritoneal lavage fluid and tissue samples will be collected at predefined time-points before, during and after surgery. All samples will be stored at $-80^{\circ} \mathrm{C}$ until further analysis. These samples will be analyzed for markers of the inflammatory response and gut barrier integrity using immunohistochemistry, Western Blot, Enzyme Linked Immunosorbent Assay (ELISA) and/or Polymerase Chain Reaction (PCR).

Patient characteristics, nutritional status and clinical parameters will be registered prospectively. Surgical complications will be classified using the Clavien-Dindo classification. ${ }^{17}$ Quality of life will be measured preoperatively and postoperatively at three and six months after surgery via checklists (EORTC QLQ C-30 in cancer patients and EQ-5D-5L).

The total follow-up for this study is six months. All data will be registered on a paper case report form and in an electronic database. The principal investigator and the local investigators will have access to the data set.

\section{Statistical analysis}

The sample size is calculated with a power analysis and is aimed at POI and AL, based on previous studies of our group. ${ }^{12,13}$ For POI, these previous data show a mean incidence of $40 \%$ and a reduction of almost $50 \%$ by nutrition or sham feeding. Based on a power of 0.8 and an alpha of 0.05 , a total of 91 patients are needed per group. For AL, our previous data show a mean incidence of $13 \%$ and a reduction to $3.5 \%$ by nutrition or sham feeding. Using a power of 0.8 and a dropout percentage of 5\%, a total of 140 patients are needed per group. In this way both the primary endpoint and the most important secondary endpoint AL will be adequately powered and a multi comparison correction will not be applied in the final analysis.

All analyses will be done according to the intention-to-treat approach, which includes all randomized patients, regardless of adherence to study protocol. Occurrences of the primary and secondary endpoints will be compared between the intervention group and the control group. Results will be presented as risk ratios with corresponding $95 \%$ confidence intervals. A two-tailed p-value $<0.05$ is 
considered statistically significant. To compare the groups, the data will be tested for normal distribution, and an unpaired T-test will be performed if appropriate, otherwise the Mann-Whitney $U$ test, Chi-square test or Fisher exact test will be used.

\section{Economic evaluation design}

A cost-effectiveness analysis and a cost-utility analysis will be performed to assess the economic value of perioperative nutrition compared with usual care. The incremental cost-effectiveness ratio (ICER) will be expressed as the incremental costs per point change in POI and $\mathrm{AL}$, and the incremental cost-utility ratio (ICUR) will be expressed as the incremental costs per quality-adjusted life years (QALYs) gained. Quality of life will be measured using the EORTC QLQ C-30 and EQ-5D-5L questionnaires.

A societal perspective will be used for cost evaluation. We will consider cost factors in three categories: healthcare sector costs (direct costs such as personnel, operation, or diagnostics), patient and family costs (out-of-pocket expenses, travel expenses), and costs in other sectors (mainly cost due to absenteeism in paid work and production losses in the domestic sphere). Healthcare costs, costs to patients and family, and costs occurring in other sectors will be measured at the individual (participant) level using data from registration systems of the hospitals and patient questionnaires (including adapted version of the iMTA Medical Consumption Questionnaire (iMCQ) and the iMTA Productivity Cost Questionnaire (iPCQ)). Finally, monetary values will be assigned to the relevant cost factors. The identified health services consumed by study participants will be multiplied with their corresponding unit prices. Total costs will be determined by summing up the costs of individual services. The updated Dutch manual for costing in economic evaluations in healthcare will be used in the valuation step of healthcare costs and patient cost. Costs will be indexed for the year 2014.

ICER (and ICUR) will be estimated as the difference in costs between perioperative nutrition and standard care divided by their differences in outcomes. To quantify the uncertainty around the ICER, non-parametric bootstrapping will be conducted in Excel (Microsoft, Redmond, WA, USA) (1000 simulations). The results of the bootstrapping will be plotted in the cost-effectiveness plane, where the horizontal axis reflects differences in effects and the vertical axis differences in costs, and will be represented as a cost-effective acceptability curve showing the probability that perioperative nutrition is cost-effective for a range of willingness-to-pay values. Additional sensitivity analyses will be done to test the robustness of the results. 


\section{Discussion}

Despite advances that are being made in surgical technique and improvement in postoperative care, POI and AL remain very important clinical determinants of short-term morbidity and mortality following colorectal surgery. In previous studies it was shown that $35-45 \%$ and $7-13 \%$ of patients experience POI and AL after elective colorectal surgery, respectively. ${ }^{12,13}$ Both POI and AL have proven to be significant predictors of increased hospital length of stay and hospital costs. ${ }^{2,18,19}$ Furthermore, AL is a risk factor for local recurrence of colorectal cancer and has a significant impact on disease-free and overall survival. ${ }^{14}$ It is therefore believed that improving postoperative outcome following colorectal surgery will also improve long-term oncological outcomes regarding overall survival and tumour recurrence. ${ }^{20}$

Although the mechanism underlying POI has been studied extensively in animal experiments, targeted therapeutic strategies are currently lacking in a clinical setting and only supportive measures are taken to optimize the patient's recovery. ${ }^{21}$ For POI it is believed that formation of an inflammatory infiltrate in the muscular layers of the intestine following bowel manipulation during surgery leads to a decreased gastrointestinal motility. ${ }^{4}$ In previous experimental and clinical studies our group has shown that a short intervention with enriched enteral nutrition given just before and directly after the inciting event, dampens the inflammatory response and reduces POI by stimulation of the autonomic nervous system through release of CCK. Evidence on the relation between POI and AL is scarce, but has a great impact. Early inhibition of the inflammatory response may play a role, since release of proinflammatory cytokines such as TNF- $\alpha$ modulates intestinal epithelial function and is an inhibitory factor in the wound healing process of intestinal anastomoses. ${ }^{22}$

Nutrition is usually given to provide nutrients, or to administer specific nutrients with a potential therapeutic effect (e.g. probiotics, omega- 3 fatty acids). ${ }^{23}$ However, in this study enteral nutrition is used to directly alter the immune response following colorectal surgery via a newly discovered neuro-immunological feedback mechanism. This is a new concept and changes the way of thinking about the usage of enteral nutrition in a clinical setting.

To optimally stimulate the release of CCK and thereby activating the autonomic nervous system, a specific nutritional formula will be used that is enriched in lipids and proteins. Furthermore, this nutrition is administered during surgery, which has been found to be most effective in experimental studies. We are not aware of previous, current or proposed studies with similar innovative approaches. To ensure patient safety this study is conducted according to the rules of Good Clinical Practice and a Data Safety Monitoring Board is installed. 
Improvement of postoperative care and reduction of POI and AL is a complex challenge that requires a multidisciplinary approach. This clinical study will be performed based on the hypothesis that early modulation of the immune response by enriched enteral nutrition will reduce POI and also affect AL. A reduction of postoperative morbidity by this nutritional intervention may contribute to an enhanced efficiency, resulting in measurable improvements of productivity, cost and quality.

In conclusion, this study will investigate whether nutrition can be used to reduce POI and AL following colorectal surgery. Nutrition will be administered as a means to stimulate the autonomic nervous system and to modulate the immune response directly. Furthermore, the timing is essential for the magnitude of effect. Reduction of POI and AL following colorectal surgery would not only optimize surgical care for this large patient group and thereby reduce healthcare costs, but may also open new therapeutic opportunities and changes the way of thinking about the usage of enteral nutrition in a clinical setting. 


\section{References}

1. Spanjersberg WR, Reurings J, Keus F, van Laarhoven CJ. Fast track surgery versus conventional recovery strategies for colorectal surgery. The Cochrane database of systematic reviews. 2011(2):CD007635.

2. Zhuang CL, Ye XZ, Zhang XD, Chen BC, Yu Z. Enhanced recovery after surgery programs versus traditional care for colorectal surgery: a meta-analysis of randomized controlled trials. Dis Colon Rectum. 2013;56(5):667-78.

3. Kalff JC, Schraut WH, Simmons RL, Bauer AJ. Surgical manipulation of the gut elicits an intestinal muscularis inflammatory response resulting in postsurgical ileus. Ann Surg. 1998, 228(5):652-663.

4. Boeckxstaens GE, de Jonge WJ: Neuroimmune mechanisms in postoperative ileus. Gut. 2009; 58(9):1300-11.

5. Luyer MD, Buurman WA, Hadfoune M, Jacobs JA, Konstantinov SR, Dejong CH, Greve JW. Pretreatment with high-fat enteral nutrition reduces endotoxin and tumor necrosis factor-alpha and preserves gut barrier function early after hemorrhagic shock. Shock. 2004;21(1):65-71.

6. Luyer MD, Buurman WA, Hadfoune M, Jacobs JA, Dejong CH, Greve JW. High-fat enteral nutrition reduces endotoxin, tumor necrosis factor-alpha and gut permeability in bile duct-ligated rats subjected to hemorrhagic shock. J Hepatol. 2004;41(3):377-83.

7. Lubbers T, de Haan JJ, Luyer MD, Verbaeys I, Hadfoune M, Dejong CH, Buurman WA, Greve JW. Cholecystokinin/Cholecystokinin-1 receptor-mediated peripheral activation of the afferent vagus by enteral nutrients attenuates inflammation in rats. Ann Surg. 2010;252(2):376-82.

8. Luyer MD, Greve JW, Hadfoune M, Jacobs JA, Dejong CH, Buurman WA. Nutritional stimulation of cholecystokinin receptors inhibits inflammation via the vagus nerve. J Exp Med. 2005;202(8): 1023-9.

9. Lubbers T, Kox M, de Haan JJ, Greve JW, Pompe JC, Ramakers BP, Pickkers P, Buurman WA. Continuous administration of enteral lipid- and protein-rich nutrition limits inflammation in a human endotoxemia model. Crit Care Med. 2013;41(5):1258-65.

10. de Jonge WJ, van der Zanden EP, The FO, Bijlsma MF, van Westerloo DJ, Bennink RJ, Berthoud HR, Uematsu S, Akira S, van den Wijngaard RM et al. Stimulation of the vagus nerve attenuates macrophage activation by activating the Jak2-STAT3 signaling pathway. Nat Immunol. 2005; 6(8):844-51.

11. Wang H, Yu M, Ochani M, Amella CA, Tanovic M, Susarla S, Li JH, Wang H, Yang H, Ulloa L et al. Nicotinic acetylcholine receptor alpha7 subunit is an essential regulator of inflammation. Nature. 2003;421(6921):384-8.

12. Boelens PG, Heesakkers FF, Luyer MD, van Barneveld KW, de Hingh IH, Nieuwenhuijzen GA, Roos AN, Rutten HJ. Reduction of postoperative ileus by early enteral nutrition in patients undergoing major rectal surgery: prospective, randomized, controlled trial. Ann Surg. 2014;259(4):649-55.

13. van den Heijkant TC, Costes LMM, van der Lee DGC, Aerts B, Osinga-de Jong M, Rutten HJT, Hulsewé KWE, de Jonge WJ, Buurman WA, Luyer MDP. Randomized clinical trial on the effect of gum chewing on postoperative ileus and inflammation in colorectal surgery. Br J Surg. 2015; 102(3):202-11.

14. Mirnezami A, Mirnezami R, Chandrakumaran K, Sasapu K, Sagar P, Finan P. Increased local recurrence and reduced survival from colorectal cancer following anastomotic leak: systematic review and meta-analysis. Ann Surg. 2011;253(5):890-9.

15. Vather R, Trivedi S, Bissett I. Defining postoperative ileus: results of a systematic review and global survey. J Gastrointest Surg. 2013;17(5):962-72.

16. Darwiche G, Bjorgell O, Thorsson 0, Almer LO. Correlation between simultaneous scintigraphic and ultrasonographic measurement of gastric emptying in patients with type 1 diabetes mellitus. J Ultrasound Med. 2003;22(5):459-66.

17. Dindo D, Demartines N, Clavien PA. Classification of surgical complications: a new proposal with evaluation in a cohort of 6336 patients and results of a survey. Ann Surg. 2004;240(2):205-13. 
18. Ashraf SQ, Burns EM, Jani A, Altman S, Young JD, Cunningham C, Faiz O, Mortensen NJ. The economic impact of anastomotic leakage after anterior resections in English NHS hospitals: are we adequately remunerating them? Colorectal Dis. 2013;15(4):e190-8.

19. Iyer S, Saunders WB, Stemkowski S. Economic burden of postoperative ileus associated with colectomy in the United States. J Manag Care Pharm. 2009;15(6):485-94.

20. Gooiker GA, Dekker JW, Bastiaannet E, van der Geest LG, Merkus JW, van de Velde CJ, Tollenaar RA, Liefers GJ. Risk factors for excess mortality in the first year after curative surgery for colorectal cancer. Ann Surg Oncol. 2012;19(8):2428-34.

21. Story SK, Chamberlain RS. A comprehensive review of evidence-based strategies to prevent and treat postoperative ileus. Dig Surg. 2009;26(4):265-75.

22. Ishimura K, Moroguchi A, Okano K, Maeba T, Maeta H. Local expression of tumor necrosis factoralpha and interleukin-10 on wound healing of intestinal anastomosis during endotoxemia in mice. J Surg Res. 2002;108(1):91-7.

23. Cerantola Y, Hubner M, Grass F, Demartines N, Schafer M. Immunonutrition in gastrointestinal surgery. Br J Surg. 2011;98(1):37-48. 



\section{Chapter}

\section{Perioperative lipid-enriched enteral nutrition versus standard care in patients undergoing elective colorectal surgery (SANICS II): a multicentre, double-blind, randomised controlled trial}

Peters EG*, Smeets BJJ*, Nors J, Back CM, Funder JA, Sommer T, Laurberg S, Løve US, Leclercq WKG, Slooter GD, de Vries Reilingh TS, Wegdam JA, Nieuwenhuijzen GAP, Hiligsmann M, Buise MP, Buurman WA, de Jonge WJ, Rutten HJT, Luyer MDP *authors contributed equally 


\section{Abstract}

Background

Postoperative ileus and anastomotic leakage severely impair recovery after colorectal resection. We investigated the effect of perioperative lipid-enriched enteral nutrition versus standard care on the risk of postoperative ileus, anastomotic leakage, and other clinical outcomes.

Methods

We did an international, multicentre, double-blind, randomised, controlled trial of patients ( $\geq 18$ years) undergoing elective colorectal surgery with primary anastomosis at six clinical centres in the Netherlands and Denmark. Patients were randomly assigned (1:1), stratified by location (colonic and rectal) and type of surgery (laparoscopic and open), via online randomisation software, with block sizes of six, to receive either continuous lipid-enriched enteral tube feeding from 3 $\mathrm{h}$ before until $6 \mathrm{~h}$ after surgery (intervention) or no perioperative nutrition (control). Surgeons, patients, and researchers were masked to treatment allocation for the entire study period. The primary outcome was postoperative ileus. Secondary outcomes included anastomotic leakage, pneumonia, preoperative gastric volumes, time to functional recovery, length of hospital stay, the need for additional interventions, intensive care unit admission, postoperative inflammatory response, and surgical complications. Analyses were by intention to treat. This study is registered with ClinicalTrials.gov, number NCT02175979, and trialregister.nl, number NTR4670.

Findings

Between July 28, 2014, and February 20, 2017, 280 patients were randomly assigned, 15 of whom were excluded after random allocation because they fulfilled one or more exclusion criteria. 265 patients received perioperative nutrition $(n=132)$ or standard care $(n=133)$ and were included in the analyses. A postoperative ileus occurred in 37 (28\%) patients in the intervention group versus $29(22 \%)$ in the control group (risk ratio [RR] 1.09, 95\% CI 0.95-1.25; p=0.24). Anastomotic leakage occurred in 12 (9\%) patients in the intervention group versus $11(8 \%)$ in the control group (RR 1.01, 95\% CI 0.94-1.09; $\mathrm{p}=0.81$ ). Pneumonia occurred in ten $(8 \%)$ patients in the intervention group versus three $(2 \%)$ in the control group (RR 1.06, 95\% CI 1.00-1.12; $\mathrm{p}=0.051$ ). All other secondary

outcomes were similar between groups (all $\mathrm{p}>0.05$ ).

Interpretation

Perioperative lipid-enriched enteral nutrition in patients undergoing elective colorectal surgery has no advantage over standard care in terms of postoperative complications. 


\section{Introduction}

Postoperative outcomes in colorectal surgery have improved with the introduction of enhanced recovery after surgery (ERAS) programmes. ${ }^{1}$ However, postoperative complications continue to impair recovery and increase health-care costs. In particular, postoperative ileus is a common complication and is associated with a prolonged length of hospital stay. ${ }^{2}$

Early initiation of oral intake is an independent determinant of early recovery in ERAS protocols. ${ }^{3}$ Furthermore, early enteral nutrition reduces not only postoperative ileus but also anastomotic leakage after major rectal surgery. ${ }^{4}$ Anastomotic leakage is a major determinant for postoperative recovery. However, beneficial effects of early oral intake on postoperative ileus and anastomotic leakage were not seen in other studies. ${ }^{5}$ Despite extensive research, no therapeutic options to reduce postoperative ileus and anastomotic leakage are available, and the incidence of these complications has remained stable. 6,7

The inflammatory response is essential in the development of postoperative ileus, and is likely to also play an important part in anastomotic leakage. ${ }^{8,9}$ In postoperative ileus, opening of the peritoneal cavity and intestinal manipulation induce the release of inflammatory mediators that impair gastrointestinal motility. ${ }^{9}$ In experimental studies, enteral nutrition reduced postoperative ileus by dampening the inflammatory response via a mechanism that involves activation of the autonomic nervous system. ${ }^{10}$ This activation is the result of the enhanced availability of specific lipids and proteins that stimulate the release of cholecystokinin, which binds to cholecystokinin receptors expressed on afferent vagal fibres in the small intestine. Subsequent vagal reflex activity can inhibit the inflammatory response. ${ }^{11}$ The timing and composition of nutrition are essential; optimum effects are established when lipid-enriched nutrition is given just before, during, and directly after the inciting event continuously or via a bolus in low volumes. ${ }^{12}$ In a clinical setting, the continuous administration of enteral nutrition just before, during, and directly after surgery to stimulate the autonomic nervous system is controversial and does not conform with American Society of Anaesthesiology guidelines. ${ }^{13}$ We validated that autonomic nervous system stimulation via chewing gum effectively reduced postoperative inflammation in patients undergoing colorectal surgery. ${ }^{14}$ Additionally, we showed a concomitant beneficial effect on both postoperative ileus and anastomotic leakage in the group treated with chewing gum. ${ }^{14}$

In this double-blind, randomised controlled trial, we investigated the effect of lipidenriched enteral nutrition administration just before, during, and directly after colorectal surgery on postoperative ileus and anastomotic leakage. 


\section{Methods}

\section{Study design and participants}

This international, multicentre, double-blind, parallel, randomised controlled trial was done from July 28, 2014, to March 22, 2017, in six hospitals in the Netherlands and Denmark. We followed the principles of Good Clinical Practice and the Declaration of Helsinki, and a Data Safety Monitoring Board (DSMB) monitored serious adverse events every ten consecutively enrolled and randomly assigned patients.

Patients aged at least 18 years undergoing elective segmental colorectal resection with primary anastomosis were eligible for inclusion. Exclusion criteria were a previous gastric or oesophageal resection, peritoneal carcinomatosis, a pre-existing or the creation of an ileostomy, and use of glucocorticosteroids or drugs that disrupt acetylcholine metabolism (e.g. selective serotoninreuptake inhibitors or anticonvulsants).

Patient recruitment began in the Catharina Hospital (Eindhoven, Netherlands) on July 28, 2014. After a safety analysis was done for the first 40 consecutively enrolled and randomly assigned patients, the DSMB approved expansion of the trial to the following participating centres: Máxima Medical Centre (Veldhoven, Netherlands), Elkerliek Hospital (Helmond, Netherlands), Aarhus University Hospital (Aarhus, Denmark), Randers Regional Hospital (Randers, Denmark), and Viborg Regional Hospital (Viborg, Denmark). Patients were enrolled by trained investigators at each site. After 140 patients were randomly assigned, an interim analysis of the primary and relevant secondary outcomes (postoperative ileus, anastomotic leakage, aspiration pneumonia, length of stay, and mortality) was done by the DSMB to assess the benefit or potential harm of the intervention. The results of the interim analysis did not prompt the DSMB to prematurely terminate the study, and recruitment continued.

The study protocol was approved by the Medical Ethics Committee of the Catharina Hospital under reference number NL45640.060.13 and has been published. ${ }^{15}$ The institutional review board of each participating hospital approved the protocol. All patients provided written informed consent before enrolment.

\section{Randomisation and masking}

The day before surgery, all patients received a self-migrating nasojejunal tube (Bengmark, Nutricia Flocare, Zoetermeer, Netherlands) at the surgical ward. An abdominal x-ray was done to assess whether the tube had migrated post pylorically after 7-24 h. Patients were excluded if post-pyloric tube migration was unsuccessful. Patients in whom the tube had migrated successfully were randomly 
assigned (1:1) to continuous lipid-enriched enteral tube feeding (intervention group) or no perioperative nutrition (control group) by external online randomisation software (TENALEA Clinical Trial Data Management System, Amsterdam, Netherlands), with a block size of six and stratified by site. Additionally, we used masked stratification to ensure an equal distribution between colonic and rectal surgery and between laparoscopic and open procedures. During randomisation, a number was generated that corresponded to an envelope containing a branched tubing system (ECM Europe BV, Gemert, Netherlands). These tubing systems were packed in identical, sealed envelopes labelled by independent research nurses with a randomisation number from an allocation list provided by TENALEA. The tubing system, specially designed for the double-blind nature of the study, was opaque and bifurcated into two branches. One branch was connected to the Bengmark tube in the patient, and the other branch was connected to a black container that was attached to the bed. One of the branches was occluded at the bifurcation by the manufacturer. For patients allocated to the intervention group, the tubing system was open towards the patient and closed towards the black container. Conversely, for patients allocated to the control group, the tubing system was closed towards the patient and open towards the black container. Consequently, only patients in the intervention group received lipid-enriched enteral nutrition. The containers were sealed and weighted with 4-6 l of saline; thus, any possible changes in weight from the added nutrition would be imperceptible to the patients and supporting medical and research staff.

\section{Procedures}

In all patients in the intervention group, lipid-enriched enteral nutrition (Nutricia Research, Utrecht, Netherlands) was administered via an electronic feeding pump at a rate of $1.5 \mathrm{ml} / \mathrm{min}$. The composition of the enteral formula is described in Supplemental Table S8.1. The enteral nutrition was administered perioperatively: the feeding pump was started $3 \mathrm{~h}$ before the planned onset of surgery, continued during the operation, and stopped $6 \mathrm{~h}$ after ending the surgical procedure. The time of cessation was chosen because patients generally initiated oral intake at this time and were offered enteral nutrition at about $6 \mathrm{~h}$ after surgery according to ERAS guidelines. ${ }^{1}$ After nutrition was stopped, the nasojejunal tube was flushed with $20 \mathrm{ml}$ of saline to remove any potential residue. After disconnecting from the patient, the masked tubing sets and black containers were retained until ten procedures had been done before being disposed of by independent research nurses.

All patients were treated according to the principles of the ERAS protocols. In the Danish centres, ERAS protocols had been gradually implemented since the end of the 1990s, whereas all Dutch centres received formal training when ERAS was 
introduced in 2006. The ERAS protocols of the participating hospitals were compared and were the same regarding the initiation of oral feeding and mobilisation (i.e. stimulating patients to engage in physical activity instead of remaining in bed), preoperative carbohydrate administration, use of drains or nasogastric tubes (not routine), provision of patient information, and discharge criteria. Postoperative antiemetic and analgesic drugs and use of epidural analgesia were not standardised among the participating centres, and the use of an oral bowel preparation was optional. Any confounding effect on study outcomes by these local differences was minimised by stratifying by site. Patients were not allowed to use chewing gum during the study because of possible interference with the primary endpoints. ${ }^{14}$ All patients were fasted for oral solids for $6 \mathrm{~h}$ and for oral liquids for $2 \mathrm{~h}$ before the start of surgery. All patients received $200 \mathrm{ml}$ of oral carbohydrate loading (Nutricia preOp, Nutricia Advanced Medical Nutrition, Zoetermeer, Netherlands) $2 \mathrm{~h}$ before the start of surgery. A thoracic epidural catheter was placed in cases of an open procedure unless the patient refused. For laparoscopic procedures, patients did not routinely receive a thoracic epidural catheter for analgesia. The thoracic epidural catheter was infused with an initial bolus of $0.125-0.250 \mu \mathrm{g} / \mathrm{ml}$ of bupivacaine with or without epinephrine $(5 \mu \mathrm{g} / \mathrm{ml})$ and with or without $0.50 \mu \mathrm{g} / \mathrm{ml}$ of sufentanil; the exact quantities were recorded prospectively. Patients without a thoracic epidural catheter received a patientcontrolled intravenous analgesic pump with intravenous morphine; alternatively, oral analgesia consisting of acetaminophen and morphine was provided. Continuous postoperative epidural analgesia was achieved with $0.125 \mu \mathrm{g} / \mathrm{ml}$ of bupivacaine and $0.1 \mu \mathrm{g} / \mathrm{ml}$. of sufentanil at 6-12 $\mathrm{ml} / \mathrm{h}$. The epidural catheter was removed on postoperative day 3. All patients received a Bair Hugger (3M, St Paul, MN, USA) for temperature control. In cases of expected severe blood loss, a Cell Saver (Haemonetics, Braintree, MA, USA) was readily available. Since perioperative nutrition is a novel principle with a possible risk of aspiration pneumonia, the use of rapid-sequence induction was left to the discretion of the attending anaesthesiologist. After induction of anaesthesia, all patients received a nasogastric tube through which any residual gastric contents were aspirated and quantified. The residual gastric volumes were aspirated via a nasogastric tube and quantified directly after the induction of anaesthesia. The nasogastric tube was removed at the end of the surgical procedure. All patients underwent elective colorectal surgery with creation of a primary anastomosis. Intraoperative radiotherapy was done in some patients with locally advanced rectal cancer; this decision was made by a multidisciplinary team. A deviating transverse colostomy was created in patients with a low anastomosis close to the anal verge.

Follow-up was done until 90 days after surgical resection. All exclusions, serious adverse events, and cases of postoperative ileus and anastomotic leakage were recorded before any analyses and without knowledge of the treatment allocation. 
Analyses were done after verification that the outcome measures met the definition stated in the original protocol. The randomisation code was broken on March 23, 2017. After finishing the study, all of the used tube sets were checked for possible allocation errors, by flushing the tubes to check whether the nutrition was actually led to the correct branch for each case.

\section{Outcomes}

All outcomes were registered on a daily basis. The primary endpoint was postoperative ileus. Secondary outcomes included anastomotic leakage; aspiration pneumonia; preoperative gastric volumes; time to functional recovery; length of hospital stay, calculated as days from the day of surgery; the need for additional surgical, radiological or endoscopic interventions; intensive care unit admission (and length of intensive care unit stay); postoperative inflammatory response; and surgical complications according to the Clavien-Dindo classification. ${ }^{16}$ Additional secondary outcomes were measures of intestinal barrier function and local inflammation in the gut, composition of faecal microbiome, quality of life, and costeffectiveness ratios. These outcomes will be presented in an independent report.

Postoperative ileus was defined as proposed by Vather and colleagues ${ }^{17}$ and classified as early, prolonged, or late. Briefly, early postoperative ileus was defined as absence of flatus or stool passage and inability to tolerate a regular oral diet between surgery and postoperative day 4. Prolonged postoperative ileus was defined as at least two of the following criteria on or after postoperative day 4 in patients with early postoperative ileus: nausea or vomiting, inability to tolerate a regular oral diet for the last two meals, absence of flatus and stool for the last $24 \mathrm{~h}$, or radiological confirmation. Late postoperative ileus was defined as the initial development of symptoms of postoperative ileus (absence of flatus or stool passage and inability to tolerate an oral diet) after postoperative day 4. Patients were instructed to register presence of nausea or vomiting, passage of flatus and defecation, and consumption of a regular oral diet in a diary daily. Exact times of first onset of these events were recorded, and the nursing staff or local investigators checked the completion of diary registration on a daily basis. Two researchers analysed the diaries after discharge but before unmasking to establish whether patients had developed early, prolonged, or late ileus. Anastomotic leakage was diagnosed by means of radiological examination (perianastomotic presence of an abscess, or free air or fluids) or visualised during reoperation, or both. Pneumonia was defined as presence of a pulmonary infiltrate on a radiograph combined with either fever or a rise in inflammatory parameters, corresponding to a revised Uniform Pneumonia Score of 2 or higher. ${ }^{18}$ Functional recovery was defined as postoperative patients not receiving intravenous fluid who have 
adequate pain control, restoration of independent mobility, sufficient caloric intake, and no signs of active infection. ${ }^{19}$

To further assess gastrointestinal motility, gastric emptying was measured using standardised real-time ultrasonography. ${ }^{20}$ After a period of nil-by-mouth of at least $2 \mathrm{~h}$ in the afternoon of postoperative day 2, patients were offered a standardised meal consisting of $150 \mathrm{ml}$ of liquid and one slice of toast with a topping of their choice. Ultrasound measurements of the longitudinal (D1) and anteroposterior (D2) diameters of the gastric antrum were done three times immediately before the meal and, in patients who could completely consume the standardised meal, at 15 and $90 \mathrm{~min}$ after the meal. The antral area (A) was calculated from the mean diameters using the following formula at each time point: $A=\pi \times D 1$ mean $\times$ D2mean / 4. The decrease in the gastric antral area, or the gastric emptying rate (GER), was calculated as follows: GER $=[(\mathrm{A} 15 \mathrm{~min}-\mathrm{A} 90 \mathrm{~min}) / \mathrm{A} 15 \mathrm{~min}] \times 100 \%$.

To determine the postoperative inflammatory response, we measured plasma Creactive protein concentrations using an immunoturbidimetric assay Roche/Hitachi cobas c system, Roche, Mannheim, Germany) as part of routine clinical care on postoperative days $1-4$. Surgical complications were defined as any deviation of the normal postoperative course and were graded according to the Clavien-Dindo classification of surgical complications. ${ }^{21}$

\section{Statistical analysis}

Although postoperative ileus was the primary outcome, the sample size was calculated with a power analysis to show an effect on both postoperative ileus and anastomotic leakage because of the clinical relevance of anastomotic leakage. The sample size was calculated based on previous studies by our group. ${ }^{4,14}$ For postoperative ileus, a mean incidence of $40 \%$ and a reduction of $48 \%$ through enteral nutrition or sham-feeding were previously reported. ${ }^{4,14}$ Using a power of 0.8 and an alpha of $0.05,91$ patients were needed per group. For anastomotic leakage, our previous data showed a mean incidence of $13 \%$ and a reduction of $4 \%$ through enteral nutrition or sham-feeding. ${ }^{4,14}$ Using a power of 0.8 and a dropout percentage of 5\%, 140 patients were needed per group. 140 patients per group were ultimately included to ensure that both the primary endpoint (postoperative ileus) and the most clinically important secondary endpoint (anastomotic leakage) were adequately powered.

All analyses were done according to the intention-to-treat approach regardless of adherence to the study protocol, although patients who were found to meet one or more exclusion criteria after randomisation were excluded from analyses. Subgroup analyses were done according to the stratification parameters. Categorical variables are presented as $n(\%)$ and were compared between the groups using the $\chi^{2}$ test or Fisher's exact test, as appropriate. Continuous variables 
are presented as the mean (SD) or median (IQR) and were compared between the groups using the independent Student's t test or Mann-Whitney $U$ test, as appropriate. A two-tailed p value less than 0.05 was deemed significant. Treatment effects are reported as risk ratios (RRs) or estimated mean differences with corresponding 95\% CIs. All statistical analyses were done with SPSS (version 22).

This trial is registered with ClinicalTrials.gov, number NCT02175979, and trialregister.nl, number NTR4670.

\section{Role of the funding source}

The funders of the study had no role in the study design, data collection, data analysis, data interpretation, or writing of the report. The corresponding author had full access to all data in the study and had the final responsibility for the decision to submit the report for publication.

\section{Results}

From July 28, 2014, to Feb 20, 2017, 454 patients were deemed eligible for inclusion (Figure 8.1). 66 patients were excluded before admission to the surgical wards, mainly because they withdrew consent or were not eligible for study participation (e.g. an indication for perioperative glucocorticosteroids or development of an intestinal obstruction needing prompt surgery). Another 108 patients were excluded upon admission to the ward but before randomisation, mainly because of discomfort of the nasojejunal tube or the prepyloric position of the nasojejunal tube on repeated x-ray. 280 patients were randomly assigned to receive perioperative lipid-enriched enteral tube feeding (intervention group, $n=139$ ) or standard care (control group, $n=141$ ). There were no allocation errors. Protocol violations occurred in nine patients in the intervention group, either because of technical problems (e.g. tube dislocation) or an accidental late start or premature cessation of the feeding pump. Similar problems occurred in the control group but did not result in protocol violations, because these patients were already allocated to receive no perioperative nutrition. In four patients in the control group a technical issue with the black box resulted in unmasking. No patients were excluded from the analysis because of protocol violations.

Fifteen patients were excluded after randomisation for fulfilling one or more of the exclusion criteria. In five patients, a deviating ileostomy was created for technical reasons, and intraoperative findings in eight patients prohibited colorectal resection or anastomosis (e.g. peritoneal carcinomatosis or a dubious vascular supply to the anastomotic segment). One patient in the control group received intraoperative glucocorticosteroids, and one patient in the intervention group 
deteriorated clinically because of a previously unrecognised intestinal obstruction the night before surgery and underwent surgery in a non-elective setting. Thus, 132 patients in the intervention group and 133 in the control group were included in the analyses. Table 8.1 summarises demographics and baseline characteristics, which were well matched between the two study groups. We noted slight differences between groups in distribution of ASA grades; however, correction for ASA grade revealed no effect on the outcomes (data not shown). Colorectal malignancy was the indication for surgical resection in 245 (92\%) of 265 patients; these patients were equally distributed between the groups based on the TNM (seventh edition) stage. Other indications for colorectal resection were diverticulitis $(n=14)$ endometriosis $(n=3)$, colonic stenosis $(n=1)$, familial adenomatous polyposis $(n=1)$, and irritable bowel disease $(n=1)$. Preoperative oral bowel preparation was given to $60(45 \%)$ patients in the intervention group and to $54(41 \%)$ patients in the control group.

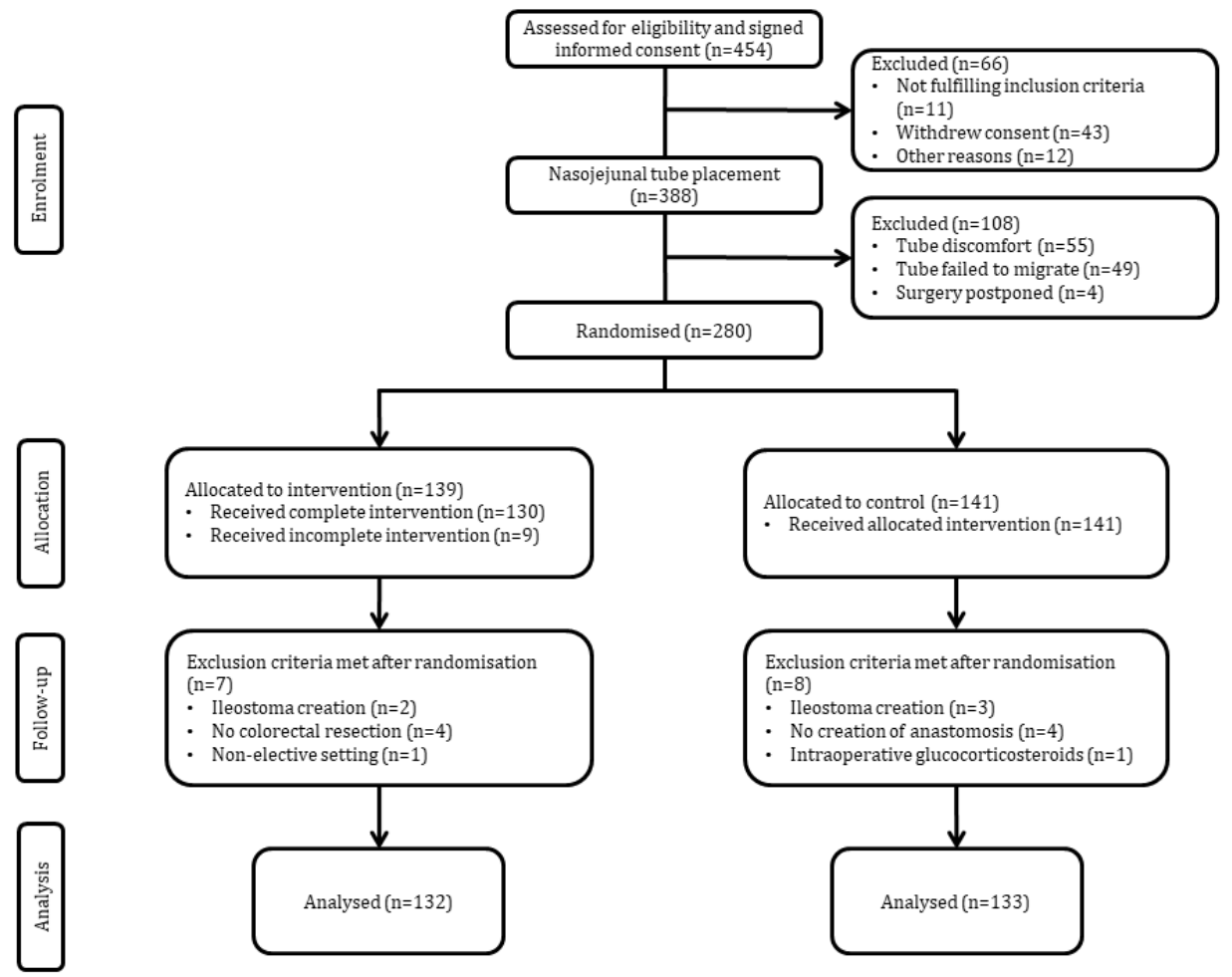

Figure 8.1: Flowchart. 
Table 8.1: Baseline characteristics.

\begin{tabular}{|c|c|c|}
\hline & Perioperative nutrition $(n=132)$ & Control (n=133) \\
\hline Male sex & $80(61 \%)$ & $78(59 \%)$ \\
\hline Age (years) & $69[62-75]$ & $68[63-74]$ \\
\hline Body Mass Index $\left(\mathrm{kg} / \mathrm{m}^{2}\right)$ & $25.8[23.2-29.0]$ & $26.0[24.0-29.3]$ \\
\hline \multicolumn{3}{|l|}{ ASA grade } \\
\hline I & $21(16 \%)$ & $24(18 \%)$ \\
\hline II & $96(73 \%)$ & $83(62 \%)$ \\
\hline III & $15(11 \%)$ & $26(20 \%)$ \\
\hline \multicolumn{3}{|l|}{ MUST score } \\
\hline 0 & $112(85 \%)$ & $113(85 \%)$ \\
\hline 1 & $14(11 \%)$ & $11(8 \%)$ \\
\hline 2 & $3(2 \%)$ & $9(7 \%)$ \\
\hline 3 & $1(1 \%)$ & $0(0 \%)$ \\
\hline 4 & $2(1 \%)$ & $0(0 \%)$ \\
\hline Smoking & $14(11 \%)$ & $17(13 \%)$ \\
\hline Diabetes Mellitus & $16(12 \%)$ & $22(17 \%)$ \\
\hline Previous abdominal surgery & $49(37 \%)$ & $45(34 \%)$ \\
\hline \multicolumn{3}{|l|}{ Neo-adjuvant treatment } \\
\hline Chemotherapy only & $0(0 \%)$ & $1(1 \%)$ \\
\hline Radiotherapy only & $5(4 \%)$ & $3(2 \%)$ \\
\hline Chemoradiotherapy & $22(17 \%)$ & $16(12 \%)$ \\
\hline \multicolumn{3}{|l|}{ Surgical approach } \\
\hline Laparoscopic & $74(56 \%)$ & $79(60 \%)$ \\
\hline Conversion & $11(8 \%)$ & $15(11 \%)$ \\
\hline Open & $47(36 \%)$ & $39(29 \%)$ \\
\hline \multicolumn{3}{|l|}{ Type of operation } \\
\hline Right hemicolectomy & $45(34 \%)$ & $49(37 \%)$ \\
\hline Left hemicolectomy & $50(38 \%)$ & $51(38 \%)$ \\
\hline Subtotal colectomy & $2(1 \%)$ & $3(2 \%)$ \\
\hline Rectal resection & $35(27 \%)$ & $30(23 \%)$ \\
\hline Deviating colostomy & $30(23 \%)$ & $24(18 \%)$ \\
\hline Duration of surgery (min) & 145 [119-185] & $150[120-185]$ \\
\hline Intraoperative blood loss (ml) & $150[50-300]$ & $100[50-200]$ \\
\hline Thoracic epidural catheter & $70(53 \%)$ & $66(50 \%)$ \\
\hline Intraoperative radiotherapy & $12(9 \%)$ & $8(6 \%)$ \\
\hline
\end{tabular}

The data are $\mathrm{n}(\%)$ or the median [interquartile range]. ASA = American Society of Anesthesiologists. MUST = Malnutrition Universal Screening Test. NSAID = non-steroid anti-inflammatory drugs.

We noted no differences between groups in postoperative ileus occurrence, time to oral intake tolerance, time to first flatus, or time to first defecation (Table 8.2). Although not a prespecified outcome, opioid use did not differ between groups (data not shown). The occurrence of anastomotic leakage and its severity as indicated by the treatment needed were similar between groups (Table 8.2). Incidence of pneumonia was higher in the intervention group than in the control group (ten [8\%] vs three [2\%], RR 1.06, 95\% CI 1.00-1.12; p=0.051). The incidences of urinary tract infection (seven [5\%] in the intervention group vs three [2\%] in the control group, RR 1.03, 95\% CI 0.98-1.08; $\mathrm{p}=0.22$ ) and wound infection (nine [7\%] vs six [5\%], 1.03, 0.97-1.09; $\mathrm{p}=0.42$ ) were similar between groups. 
Table 8.2: Recovery of bowel function and anastomotic leakage and treatment.

\begin{tabular}{lcccc}
\hline & $\begin{array}{c}\text { Perioperative } \\
\text { nutrition (n=132) }\end{array}$ & $\begin{array}{c}\text { Control } \\
\text { (n=133) }\end{array}$ & Effect size (95\% CI) & $\begin{array}{c}\text { p } \\
\text { value }\end{array}$ \\
\hline Recovery of bowel function & & & & \\
Any postoperative ileus & $37(28 \%)$ & $29(22 \%)$ & $1.09(0.95$ to 1.25$)$ & 0.24 \\
$\quad$ Early & $8(6 \%)$ & $7(5 \%)$ & $1.01(0.95$ to 1.07$)$ & 0.78 \\
$\quad$ Prolonged & $19(14 \%)$ & $14(11 \%)$ & $1.05(0.95$ to 1.15$)$ & 0.34 \\
$\quad$ Late & $10(8 \%)$ & $8(6 \%)$ & $1.02(0.95$ to 1.09$)$ & 0.61 \\
Time to tolerance of oral diet (h) & $50[41-87]$ & $47[41-71]$ & $16.13(-7.09$ to 39.35$)$ & 0.30 \\
Time to first flatus (h) & $25[17-45]$ & $23[13-45]$ & $3.31(-3.46$ to 10.09$)$ & 0.23 \\
Time to first defecation (h) & $48[24-77]$ & $53[26-77]$ & $1.12(-8.02$ to 10.26$)$ & 0.48 \\
Anastomotic Leakage & & & & \\
Total & $12(9.1 \%)$ & $11(8.3 \%)$ & $1.01(0.94$ to 1.09$)$ & 0.81 \\
$\quad$ Colon & $8 / 100(8.0 \%)$ & $8 / 108(7.4 \%)$ & $1.01(0.93$ to 1.09) & 0.87 \\
Rectum & $4 / 32(12.5 \%)$ & $3 / 25(12.0 \%)$ & $1.01(0.83$ to 1.22$)$ & 1.00 \\
Treatment needed & & & & 0.06 \\
Asymptomatic & $0(0.0 \%)$ & $3(2.3 \%)$ & & \\
Antibiotics only & $6(4.5 \%)$ & $1(0.8 \%)$ & & \\
Drainage of abscess & $2(1.5 \%)$ & $1(0.8 \%)$ & & \\
Re-laparotomy & $4(3.0 \%)$ & $6(4.5 \%)$ & & \\
\hline
\end{tabular}

The data are number (\%) or median [IQR]. The effect sizes are risk ratios for categorical outcomes or the estimated mean differences for continuous outcomes.

We noted no differences between groups in the rate of the highest Clavien-Dindo grade complication or the readmission rate after 30 or 90 days (Table 8.3). Time to functional recovery and length of hospital stay were similar between groups; however, although not significant, the estimated mean differences suggested a longer length of stay and a longer time to functional recovery in the intervention group than in the control group. We did subgroup analyses by surgical approach (open vs laparoscopic) and the type of resection (colon vs rectum), but found no differences between intervention and control (data not shown). Two patients in the control group died because of postoperative complications: one patient died on postoperative day 14 after developing septic shock after anastomotic leakage, and another patient developed fascial dehiscence after undergoing re-laparotomy for an abdominal abscess, which resulted in long-term treatment for an open abdomen and eventual death on postoperative day 54 because of pulmonary oedema. Table 8.4 summarises details of all Clavien-Dindo complications of grade IIIa or higher. Notably, complications were graded as Clavien-Dindo IIIa or higher in only one of 25 cases of postoperative ileus and two of 13 cases of pneumonia, whereas this occurred in 16 of 23 cases of anastomic leakage. 71 complications (38 intervention and 33 control) occurred at Clavien-Dindo grade I and 75 complications (50 intervention and 25 control) occurred at Clavien-Dindo grade II. 
Table 8.3: Morbidity and mortality.

\begin{tabular}{lcccc}
\hline & $\begin{array}{c}\text { Perioperative } \\
\text { nutrition (n=132) }\end{array}$ & $\begin{array}{c}\text { Control } \\
\text { (n=133) }\end{array}$ & $\begin{array}{c}\text { Effect size* (95\% } \\
\text { CI) }\end{array}$ & $\begin{array}{c}\text { p } \\
\text { value }\end{array}$ \\
\hline Highest Clavien-Dindo grade† & $72(55 \%)$ & $71(53 \%)$ & $1.03(0.79$ to 1.33$)$ & 0.85 \\
$\quad$ No complication & $16(12 \%)$ & $22(17 \%)$ & $0.95(0.86$ to 1.05$)$ & 0.31 \\
I & $29(22 \%)$ & $19(14 \%)$ & $1.10(0.98$ to 1.23$)$ & 0.10 \\
II & $5(4 \%)$ & $5(4 \%)$ & $1.00(0.95$ to 1.05$)$ & 0.99 \\
IIIa & $5(4 \%)$ & $8(6 \%)$ & $0.98(0.93$ to 1.03$)$ & 0.40 \\
IIIb & $4(3 \%)$ & $6(5 \%)$ & $0.99(0.94$ to 1.03$)$ & 0.75 \\
IVa & $1(1 \%)$ & $0(0 \%)$ & $1.01(0.99$ to 1.02$)$ & 0.50 \\
IVb & $0(0 \%)$ & $2(2 \%)$ & $0.99(0.96$ to 1.01$)$ & 0.50 \\
V & $11(8 \%)$ & $13(10 \%)$ & $0.98(0.91$ to 1.06$)$ & 0.68 \\
Readmissions within 30 days & $17(13 \%)$ & $17(13 \%)$ & $1.00(0.91$ to 1.10$)$ & 0.98 \\
Readmissions within 90 days & $5.0[3.0-9.0]$ & $5.0[3.0-7.0]$ & $1.96(0.19$ to 3.72$)$ & 0.25 \\
Time to functional recovery (days) & $6.0[4.0-10.0]$ & $6.0[4.0-7.8]$ & $2.05(0.28$ to 3.83$)$ & 0.21 \\
\hline Length of stay (days) & & &
\end{tabular}

The data are number (\%) or median [IQR]. Some percentages do not add up to 100 because of rounding. *Risk ratios for categorical outcomes and estimated mean differences for continuous outcomes. †The number of complications displayed here is lower than the total number.

Table 8.4: Details of all Clavien Dindo grade $\geq$ IIIa complications

\begin{tabular}{|c|c|c|}
\hline $\begin{array}{l}\text { Clavien- } \\
\text { Dindo grade }\end{array}$ & $\begin{array}{l}\text { Perioperative nutrition } \\
(\mathrm{n}=132)\end{array}$ & $\begin{array}{l}\text { Control } \\
(n=133)\end{array}$ \\
\hline IIIa & $\begin{array}{l}\text { AL }(\mathrm{N}=2) \text {, bleeding gastric ulcer }(\mathrm{N}=1) \text {, } \\
\text { hernia cicatricalis }(\mathrm{N}=1) \text {, hematoma on } \\
\text { hand }(\mathrm{N}=1) \text {, hematoma in liver }(\mathrm{N}=1) \text {, } \\
\text { POI }(\mathrm{N}=1)\end{array}$ & $\begin{array}{l}\text { Intraluminal anastomotic bleed }(\mathrm{N}=2) \text {, } \\
\text { perianal abces }(\mathrm{N}=1), \text { POI }(\mathrm{N}=1), \\
\text { rectushematoma }(\mathrm{N}=1)\end{array}$ \\
\hline IIIb & $\begin{array}{l}\text { Fascial dehiscence }(\mathrm{N}=1) \text {, trocardhernia } \\
(\mathrm{N}=1) \text {, internal bowel herniation }(\mathrm{N}=1) \text {, } \\
\text { adhesion ileus }(\mathrm{N}=1), \mathrm{AL}(\mathrm{N}=2)\end{array}$ & $\begin{array}{l}\text { AL }(\mathrm{N}=7) \text {, umbilical hernia }(\mathrm{N}=1) \text {, } \\
\text { anastomotic stenosis }(\mathrm{N}=1) \text {, trocardhernia } \\
(\mathrm{N}=1)\end{array}$ \\
\hline IVa & $\begin{array}{l}\text { Hypotension }(\mathrm{N}=1) \text {, AL }(\mathrm{N}=1) \text {, bleeding } \\
(\mathrm{N}=1) \text {, parastomal abces }(\mathrm{N}=1)\end{array}$ & $\begin{array}{l}\text { Bilateral pulmonary embolism }(\mathrm{N}=1) \text {, } \\
\text { bleeding with asystoly }(\mathrm{N}=1) \text {, morphine } \\
\text { intoxication }(\mathrm{N}=1) \text {, pneumonia }(\mathrm{N}=2) \text {, fluid } \\
\text { overloading }(\mathrm{N}=1) \text {, respiratory insufficiency } \\
(\mathrm{N}=1)\end{array}$ \\
\hline $\mathrm{IVb}$ & $\operatorname{AL}(\mathrm{N}=1)$ & \\
\hline V & & $\begin{array}{l}\text { AL }(N=1) \text {, fascial dehiscence with respiratory } \\
\text { failure }(N=1)\end{array}$ \\
\hline
\end{tabular}

Data are number of patients experiencing a complication at each grade. AL anastomotic leakage; POI postoperative ileus.

Ultrasonography measurements of the GER on postoperative day 2 were successfully done in 106 patients in the intervention group versus 109 patients in the control group $(p=0.73)$. The reasons the ultrasound measurements were not done (e.g. the presence of a colostomy preventing clear visualisation of the pylorus and the patient's inability to consume the standard meal) were equally distributed 
between groups (data not shown). The percentage decrease in the antral area after a standard meal was similar between groups: $31.4 \%$ (IQR 9.8-46.6) in the intervention group versus $32.7 \%(9.2-45.9)$ in the control group (estimated mean difference $-2.20 \%, 95 \%$ CI -12.61 to $8.22 ; \mathrm{p}=0.76$ ). Residual gastric volumes were greater in the intervention group than in the control group (median $0.0 \mathrm{ml}$, IQR $0.0-13.5$ vs $0.0 \mathrm{ml}, 0.0-4.0$, estimated mean difference $6.66 \mathrm{ml}, 95 \% \mathrm{CI}-0.13$ to 13.44; $\mathrm{p}=0.007)$. The aspirated gastric contents were clear and did not contain enteral nutrition in any patient. Furthermore, no aspiration was observed clinically. No differences in C-reactive protein concentrations occurred between groups on any postoperative day (Supplemental Figure S8.1).

\section{Discussion}

In this international, multicentre, double-blind, randomised controlled trial, perioperative continuous lipid-enriched enteral nutrition did not have beneficial effects on postoperative ileus or surgical complications compared with standard care in patients undergoing colorectal surgery.

Enteral feeding early after colorectal surgery has been associated with reductions in complications and length of stay. 3,5 Furthermore, immunonutrition has been suggested to enhance postoperative recovery by ameliorating the immune response. ${ }^{22,23}$ However, the available evidence is heterogeneous in terms of the definitions of the complications studied, patient populations, and timing and composition of the enteral diet, which limit the validity and generalisability of the suggested benefits. ${ }^{5,24}$ In our previous experimental and preclinical studies, ${ }^{10,12}$ the composition (lipid-rich) and timing (right before and directly after the inciting event) of the enteral diet were essential for establishing the anti-inflammatory effect. The luminal presence of dietary lipids triggers a vagal reflex via peripheral cholecystokinin-1 receptors located on vagal afferents. Via this route, dietary lipids can inhibit both local and systemic inflammation and subsequent postoperative ileus in rodent models. ${ }^{10,25}$ However, the current results show that these positive effects are not substantiated in a clinical setting, at least in this study.

Findings from this trial are comparable to those from other studies of colorectal surgery. The overall rates of postoperative ileus (25\%) and anastomotic leakage (9\%) were consistent with those reported in previous work in which the incidence varied between $2 \%$ and $61 \%$ for postoperative ileus and between $5 \%$ and $50 \%$ for anastomotic leakage.6,7 In the literature, various definitions are used for postoperative ileus, resulting in broad ranges of incidence. For this reason, we used a definition based on objective outcomes that were registered in patient diaries as accurately as possible. ${ }^{17}$ Although this process was closely monitored, it remains 
potentially subject to registration inaccuracies. However, by following a definition based on quantifiable and verifiable variables, we believe postoperative ileus is optimally represented. Most patients underwent laparoscopic procedures, which is the standard approach in modern colorectal surgery, resulting in low mean blood loss volumes. However, inclusion of patients with locally advanced or recurrent cancer diversified the study cohort and accounted for a substantial number of open resections. To minimise confounding, the surgical approach (open vs laparoscopic) and the type of resection (colon vs rectum) were evenly stratified between the groups. Additionally, all patients were treated according to ERAS protocols, including the use of preoperative carbohydrate loading, which was suggested to attenuate the degree of postoperative insulin resistance. ${ }^{26}$ Although the individual effects of preoperative carbohydrate loading or other ERAS components on clinical outcomes or postoperative inflammation are unclear, ${ }^{27,28}$ their combined use with laparoscopy seems to substantially reduce the surgical stress response. ${ }^{29,30}$ These strategies could have attenuated the surgical stress response to such an extent that the nutritional intervention did not further improve clinical outcomes. Alternatively, the current intervention might not have activated the autonomic nervous system successfully, which was the essential mechanism in our previous preclinical studies.11,25,31 Intraoperative electrical stimulation of the vagus nerve attenuates inflammation, ${ }^{32}$ but further investigations are needed to identify the effect of autonomic nervous system stimulation on postoperative ileus.

In this study, continuous perioperative enteral nutrition was tested in patients undergoing colorectal surgery, although anaesthesia guidelines advocate a period of strict nil-by-mouth to minimise the risk of perioperative aspiration. ${ }^{13}$ In a recent study in 33 patients with burns, ${ }^{33}$ intraoperative enteral feeding was safe and was not associated with an increased risk of aspiration. Similarly, we observed no aspiration of the gastric contents in the current trial. However, perioperative nutrition was associated with a higher residual gastric volume and a trend toward a higher incidence of pneumonia. Although the overall incidence of pneumonia (5\%) was comparable with the incidence reported in other recent studies, ${ }^{34,35}$ this finding was concerning and challenged the safety of perioperative enteral feeding.

The methodological strengths of this study include the multicentre, double-blind, randomised design; the adequate statistical power for assessing postoperative ileus and anastomotic leakage; and the prospective registration of clearly defined clinical outcomes. However, there are some limitations. First, our results might have been confounded by the absence of standardisation among the participating centres. ERAS protocols were compared before the start of the study, and most ERAS components were applied similarly in all hospitals. However, adherence to the ERAS protocol was not monitored continuously during the trial, leading to possible bias. In particular, the use of epidural analgesia and oral bowel preparation was not standardised for patients undergoing colonic surgery. Although ERAS protocols 
recommend the use of epidural analgesia and omits bowel preparation, findings from studies in the past few years seem to challenge these practices. ${ }^{36,37}$ Regardless, in this study, randomisation was stratified by site, resulting in an even distribution of epidural analgesia and oral bowel preparation between groups. Furthermore, correcting for the use of epidural analgesia and bowel preparation in our data did not alter the interventional effectiveness significantly. Also, the feasibility of the self-migrating nasojejunal tube was limited by the number of patients who did not tolerate tube placement or in whom the tube did not spontaneously migrate post pylorically within $24 \mathrm{~h}$ after placement.

Overall, this study represents, to our knowledge, the best available evidence for the use of perioperative lipid-rich enteral nutrition in elective colorectal surgery. Based on our findings, we conclude that perioperative lipid-rich enteral nutrition does not improve clinical outcomes further compared with modern practices in colorectal surgery, including the use of laparoscopy and ERAS protocols. 


\section{References}

1. Lassen K, Soop M, Nygren J, et al. Consensus review of optimal perioperative care in colorectal surgery: Enhanced Recovery After Surgery (ERAS) Group recommendations. Arch Surg. 2009;144: 961-69.

2. Iyer S, Saunders WB, Stemkowski S. Economic burden of postoperative ileus associated with colorectomy in the United States. J Manag Care Pharm. 2009;15:485-94.

3. Vlug MS, Bartels SA, Wind J, et al. Which fast track elements predict early recovery after colon cancer surgery? Colorectal Dis. 2012;14:1001-08.

4. Boelens PG, Heesakkers FF, Luyer MD, et al. Reduction of postoperative ileus by early enteral nutrition in patients undergoing major rectal surgery: prospective, randomized, controlled trial. Ann Surg. 2014;259:649-55.

5. Smeets BJJ, Peters EG, Horsten ECJ, et al. Effect of early vs late start of oral intake on anastomotic leakage following elective lower intestinal surgery: a systematic review. Nutr Clin Pract 2018; 33(6):803-12.

6. Daams F, Luyer M, Lange JF. Colorectal anastomotic leakage: aspects of prevention, detection and treatment. World J Gastroenterol. 2013;19:2293-97.

7. Wolthuis AM, Bislenghi G, Fieuws S, de Buck van Overstraeten A, Boeckxstaens G, D’Hoore A. Incidence of prolonged postoperative ileus after colorectal surgery: a systematic review and metaanalysis. Colorectal Dis. 2016;18:1-9.

8. Ishimura K, Moroguchi A, Okano K, Maeba T, Maeta H. Local expression of tumor necrosis factoralpha and interleukin-10 on wound healing of intestinal anastomosis during endotoxemia in mice. J Surg Res. 2002;108:91-97.

9. Boeckxstaens GE, de Jonge WJ. Neuroimmune mechanisms in postoperative ileus. Gut. 2009;58: 1300-11.

10. Lubbers T, Luyer MD, de Haan JJ, Hadfoune M, Buurman WA, Greve JW. Lipid-rich enteral nutrition reduces postoperative ileus in rats via activation of cholecystokinin-receptors. Ann Surg. 2009; 249:481-87.

11. Luyer MD, Greve JW, Hadfoune M, Jacobs JA, Dejong CH, Buurman WA. Nutritional stimulation of cholecystokinin receptors inhibits inflammation via the vagus nerve. J Exp Med. 2005;202: 1023-29.

12. Lubbers T, Kox M, de Haan JJ, et al. Continuous administration of enteral lipid- and protein-rich nutrition limits inflammation in a human endotoxemia model. Crit Care Med. 2013;41:1258-65.

13. Practice guidelines for preoperative fasting and the use of pharmacologic agents to reduce the risk of pulmonary aspiration: application to healthy patients undergoing elective procedures: an updated report by the American Society of Anesthesiologists Task Force on Preoperative Fasting and the Use of Pharmacologic Agents to Reduce the Risk of Pulmonary Aspiration. Anesthesiology 2017;126:376-93.

14. van den Heijkant TC, Costes LM, van der Lee DG, et al. Randomized clinical trial of the effect of gum chewing on postoperative ileus and inflammation in colorectal surgery. Br J Surg. 2015;102: 202-11.

15. Peters EG, Smeets BJ, Dekkers M, et al. The effects of stimulation of the autonomic nervous system via perioperative nutrition on postoperative ileus and anastomotic leakage following colorectal surgery (SANICS II trial): a study protocol for a double-blind randomized controlled trial. Trials. 2015;16:20.

16. Dindo D, Demartines N, Clavien PA. Classification of surgical complications: a new proposal with evaluation in a cohort of 6336 patients and results of a survey. Ann Surg. 2004;240:205-13.

17. Vather R, Trivedi S, Bissett I. Defining postoperative ileus: results of a systematic review and global survey. J Gastrointest Surg. 2013;17:962-72.

18. Weijs TJ, Seesing MF, van Rossum PS, et al. Internal and external validation of a multivariable model to define hospital-acquired pneumonia after esophagectomy. J Gastrointest Surg. 2016;20: 680-87. 
19. van Dam RM, Hendry PO, Coolsen MM, et al. Initial experience with a multimodal enhanced recovery programme in patients undergoing liver resection. Br J Surg. 2008;95:969-75.

20. Darwiche G, Bjorgell 0, Thorsson 0, Almer LO. Correlation between simultaneous scintigraphic and ultrasonographic measurement of gastric emptying in patients with type 1 diabetes mellitus. J Ultrasound Med. 2003;22:459-66.

21. Dindo D, Demartines N, Clavien PA. Classification of surgical complications: a new proposal with evaluation in a cohort of 6336 patients and results of a survey. Ann Surg. 2004;240:205-13.

22. Cerantola Y, Hubner M, Grass F, Demartines N, Schafer M. Immunonutrition in gastrointestinal surgery. Br J Surg. 2011;98:37-48.

23. Moya P, Soriano-Irigaray L, Ramirez JM, et al. Perioperative standard oral nutrition supplements versus immunonutrition in patients undergoing colorectal resection in an enhanced recovery (ERAS) protocol: a multicenter randomized clinical trial (SONVI Study). Medicine (Baltimore). 2016;95:e3704.

24. Osland E, Hossain MB, Khan S, Memon MA. Effect of timing of pharmaconutrition (immunonutrition) administration on outcomes of elective surgery for gastrointestinal malignancies: a systematic review and meta-analysis. JPEN J Parenter Enteral Nutr. 2014;38: 53-69.

25. Lubbers T, de Haan JJ, Luyer MD, et al. Cholecystokinin/ cholecystokinin-1 receptor-mediated peripheral activation of the afferent vagus by enteral nutrients attenuates inflammation in rats. Ann Surg. 2010;252:376-82.

26. Barazzoni R, Deutz NEP, Biolo G, et al. Carbohydrates and insulin resistance in clinical nutrition: recommendations from the ESPEN expert group. Clin Nutr. 2017;36:355-63.

27. Amer MA, Smith MD, Herbison GP, Plank LD, McCall JL. Network meta-analysis of the effect of preoperative carbohydrate loading on recovery after elective surgery. Br J Surg. 2017;104:187-97.

28. Watt DG, McSorley ST, Horgan PG, McMillan DC. Enhanced recovery after surgery: which components, if any, impact on the systemic inflammatory response following colorectal surgery?: A systematic review. Medicine (Baltimore). 2015;94:e1286.

29. Carli F. Physiologic considerations of enhanced recovery after surgery (ERAS) programs: implications of the stress response. Can J Anaesth. 2015;62:110-19.

30. van Bree SH, Vlug MS, Bemelman WA, et al. Faster recovery of gastrointestinal transit after laparoscopy and fast-track care in patients undergoing colonic surgery. Gastroenterology. 2011; 141:872-80. e1-4.

31. Luyer MD, Habes Q, van Hak R, Buurman W. Nutritional stimulation of the autonomic nervous system. World J Gastroenterol. 2011;17:3859-63.

32. Stakenborg N, Wolthuis AM, Gomez-Pinilla PJ, et al. Abdominal vagus nerve stimulation as a new therapeutic approach to prevent postoperative ileus. Neurogastroenterol Motil. 2017; published online April 21. DOI:10.1111/nmo.13075.

33. Varon DE, Freitas G, Goel N, et al. Intraoperative feeding improves calorie and protein delivery in acute burn patients. J Burn Care Res. 2017;38:299-303.

34. Liu ZH, Huang MJ, Zhang XW, et al. The effects of perioperative probiotic treatment on serum zonulin concentration and subsequent postoperative infectious complications after colorectal cancer surgery: a double-center and double-blind randomized clinical trial. Am J Clin Nutr. 2013; 97:117-26.

35. Kotzampassi K, Stavrou G, Damoraki G, et al. A four-probiotics regimen reduces postoperative complications after colorectal surgery: a randomized, double-blind, placebo-controlled study. World J Surg. 2015;39:2776-83.

36. Klinger AL, Green H, Monlezun DJ, et al. The role of bowel preparation in colorectal surgery: results of the 2012-2015 ACS-NSQIP data. Ann Surg. 2019;269(4):671-7.

37. Borzellino G, Francis NK, Chapuis O, Krastinova E, Dyevre V, Genna M. Role of epidural analgesia within an ERAS program after laparoscopic colorectal surgery: a review and meta-analysis of randomised controlled studies. Surg Res Pract. 2016;2016:7543684. 


\section{Supplemental materials}

Table S8.1: Composition of the enteral formula

\begin{tabular}{lcc}
\hline & per $\mathbf{1 0 0} \mathbf{g}$ & per $\mathbf{1 0 0} \mathbf{~ m l}$ \\
\hline Chemical analysis & & \\
Protein /Kjeldahl-n (g) & 5.72 & 5.99 \\
Fat (g) & 4.44 & 4.65 \\
Carbohydrates (g) & 7.6 & 8.0 \\
Lactose (mg) & & \\
Total Solids (g) & 18.8 & 19.7 \\
Minerals & & \\
Sodium (mg) & 94 & 98 \\
Potassium (mg) & 184 & 193 \\
Calcium (mg) & 40 & 41 \\
Phosphor (mg) & 71 & 74 \\
Magnesium (mg) & 24.3 & 25.4 \\
Iron (mg) & 1.87 & 1.95 \\
Chloride (mg) & 102 & 107 \\
Zinc (mg) & 1.34 & 1.40 \\
Vitamins & & \\
Vitamin C (mg) & 16 & 17 \\
Vitamin A (mcg) & 80 & 84 \\
\hline
\end{tabular}

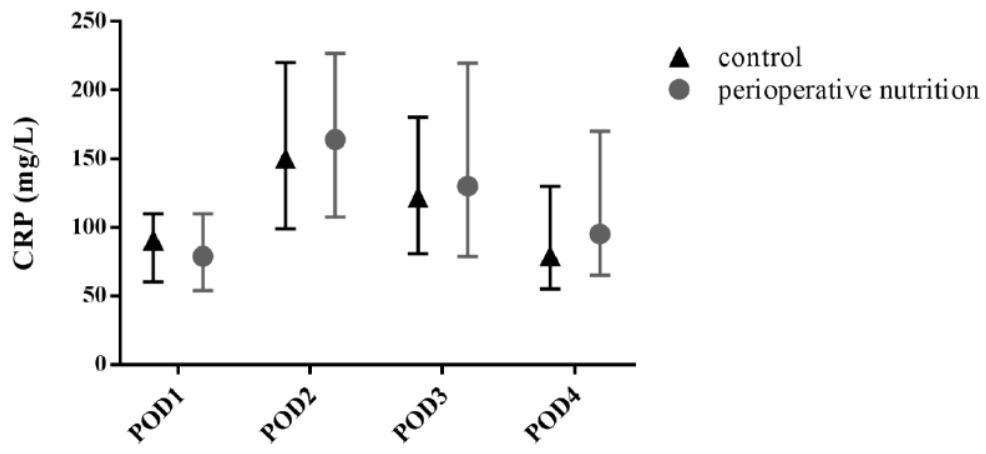

Figure S8.1: C-reactive protein concentrations. The data are the median [interquartile range]. POD: postoperative day 



\section{Chapter}

\section{Nutritional interventions to improve recovery from postoperative ileus}




\section{Abstract}

Purpose of review

Postoperative ileus (POI) is an important contributor to postoperative morbidity. However, postoperative outcomes have improved by enhanced recovery after surgery (ERAS) programs. Enteral nutrition is an essential part of ERAS and many studies suggest a therapeutic effect of nutrition on POI.

Recent findings

Early postoperative enteral nutrition has been shown to reduce various complications, including POI, although studies are heterogeneous. Experimental studies suggest that composition and timing of the enteral feed is important for the potential beneficial effects: lipid-enriched nutrition given just before, during, and directly after surgery was most effective in reducing POI in an experimental setting. In a clinical study in patients undergoing advanced rectal cancer surgery, direct start of enteral tube feeding reduced POI. Conversely, perioperative lipid-enriched enteral nutrition did not reduce POI in patients undergoing colorectal surgery with an ERAS protocol.

\section{Summary}

POI is common and remains an important determinant of postoperative recovery following colorectal surgery. Nutrition is a potential therapeutic means to reduce POI. Timing and composition of the enteral feed have been shown to be essential for the beneficial effects of enteral nutrition in an experimental setup. However perioperative lipid-enriched nutrition does not reduce POI in patients undergoing colorectal surgery with an ERAS protocol. 


\section{Introduction}

Postoperative ileus (POI) is a common complication in colorectal surgery and a major contributor to postoperative morbidity. The mean incidence of POI following colorectal surgery in literature is $\pm 10 \% .^{1}$ However, data from recent prospective studies indicate POI incidences as high as $68 \%$, suggesting that the incidence of POI may be underestimated.2,3 This may be explained by the fact that POI is often not a primary outcome in clinical studies, and definitions of POI strongly differ throughout the literature. ${ }^{4}$

POI is characterized by impaired gastrointestinal motility resulting in nausea, vomiting, and absence of flatus and defecation. It is associated with an increased risk of other complications (e.g. pneumonia or anastomotic leakage), prolonged hospital length of stay, and increased health-care costs.5-9

Introduction of the Enhanced Recovery After Surgery (ERAS) protocols in the late 1990 's has led to a significant reduction of postoperative morbidity and hospital length of stay following colorectal surgery. ${ }^{10,11}$ Early start of enteral nutrition is a key element in ERAS protocols and is believed to be an important contributor to improved recovery. ${ }^{12}$ However, the exact effect on postoperative complications remains elusive.

In this review, we summarize recent advancements and findings regarding the role of enteral nutrition on postoperative ileus in colorectal surgery.

\section{Pathogenesis of POI}

The cause of POI consists of an initial neurogenic phase lasting several hours, and an inflammatory phase that may last up to days or weeks. ${ }^{7,13}$ The initial neurogenic phase is mediated by adrenergic and non-adrenergic inhibitory reflexes. ${ }^{14,15}$ Following skin incision, spinal afferents synapse in the spinal cord and activate an inhibitory pathway through adrenergic mesenteric neurons. Activation of these spinal afferents is enhanced by disruption of the peritoneum and intestinal manipulation. Furthermore, these signals are transmitted to the brainstem, resulting in release of corticotrophin-releasing factor in the hypothalamus. Signals are then sent down through the intermedio-lateral columns of the spinal cord, activating sympathetic preganglionic neurons that further inhibit gastrointestinal motility. Moreover, the activated motor nucleus of the vagus nerve synapses to inhibitory non-adrenergic neurons throughout the enteral tract. Notably, this neurogenic phase of POI ceases shortly after ending the surgical procedure, limiting its relevance in the clinical manifestation of prolonged POI. 
The second phase of POI is based upon a local and systemic inflammatory response. ${ }^{13}$ Specifically, intestinal manipulation by the surgeon results in activation of resident macrophages in the myenteric plexus and peritoneal mast cell degranulation. ${ }^{16,17}$ The subsequent production of pro-inflammatory cytokines (e.g. tumour necrosis factor (TNF)- $\alpha$, interleukin (IL)-1 $\beta$, IL-6) induces chemotaxis by upregulation of adhesion moleculs (ICAM-1) in the endothelium. The intestinal muscularis is then invaded by leukocytes that release nitric oxide and prostaglandins, resulting in impaired smooth muscle cell contractility. In addition, T-helper 1 memory cells are activated that migrate away from the manipulated gutsegments. These cells are then recirculated to the whole gastrointestinal tract, contributing to panenteric inflammation and a general paralysis of the entire gastrointestinal tract, which is an important clinical aspect of POI.17

The duration of POI is considered physiological when symptoms of impaired gastrointestinal transit occur only in the first four postoperative days. However, when a patient is not yet able to tolerate a regular oral diet or has passed no flatus or stool on POD5, this is considered a pathologically prolonged duration of POI. ${ }^{4}$

\section{Attenuating inflammation to reduce POI}

Dampening the inflammatory response may be a potent way to reduce POI. Vagal nerve stimulation (VNS) can attenuate inflammation via release of acetylcholine from efferent vagal nerve fibers. Acetylcholine then binds to alpha-7-nicotinic receptors that are located on mast cells and macrophages in the gut wall, limiting the release of pro-inflammatory mediators (i.e. the cholinergic anti-inflammatory pathway).15,17,18 In addition, vagal nerve efferents activate adrenergic neurons in the spleen, leading to the release of norepinephrine which binds to splenic T-cells. Subsequent release of acetylcholine reduces the production of cytokines by splenic macrophages, ultimately ameliorating systemic inflammation. ${ }^{17,18}$

In experimental studies, electrical VNS has been shown to reduce cytokine production in mice and recently also in human subjects. ${ }^{19}$ More specifically, Stakenborg et al. ${ }^{19}$ recently demonstrated in a murine model that abdominal, electrical stimulation of the vagus nerve reduced the lipopolysaccharide (LPSJinduced TNF- $\alpha$ response in endotoxic shock. Furthermore, recruitment of myeloperoxidase (MPO-)positive cells in the muscularis externa 24 hours after surgery was significantly less following electrical VNS. These anti-inflammatory properties of electrical VNS resulted into improved gastrointestinal motility following intestinal manipulation. Next, the authors included 18 patients undergoing colorectal surgery to undergo electrical high $(20 \mathrm{~Hz})$ or low $(5 \mathrm{~Hz})$ frequency abdominal VNS, and compared these patients to controls (no 
stimulation). LPS-induced release of pro-inflammatory cytokines in whole blood cultures was measured before surgery, and on postoperative day (POD) 1 and POD2. It was found that high frequency electrical VNS significantly reduced concentrations of IL-6 and IL-8 on POD1 but not on POD2. No effect was seen on concentrations of TNF- $\alpha$ or monocyte chemoattractant protein-1 (MCP-1). These results are promising and suggest a potent anti-inflammatory effect of electrical VNS. However, although electrical VNS has been shown to reduce production of cytokines in both animal and human populations, a concomitant reduction of POI has thus far only been demonstrated in mice. ${ }^{19}$ This may be because electrical VNS in a clinical setting remains invasive and is not always feasible. A clinical trial on the effect of electrical VNS on gastrointestinal motility is currently ongoing (NCT 02524626).

\section{Nutritional stimulation of the vagus nerve}

A physiological way to stimulate the vagus nerve is by means of enteral nutrition, specifically lipid-enriched nutrition. ${ }^{17,18}$ The effect of lipid-enriched enteral nutition on inflammatory markers was first investigated in rats subjugated to hemorrhagic shock. It was found that administration of enteral nutrition high in fat reduced systemic concentrations of TNF- $\alpha$ and IL-6 90 minutes after induction of shock. ${ }^{15}$ Timing and composition of the enteral feed were critical to establish the antiinflammatory effect; lipid-enriched nutrition given just before, during, and directly after the inflammatory event resulted in the optimal effect. The anti-inflammatory effect of lipid-enriched enteral nutrition is established via stimulation of cholecystokinin (CCK)-receptors on vagal afferents. Acetylcholine is subsequently released from vagal efferents and then binds to $\alpha-7$ nicotinic ( $\alpha-7-n A c h)$ receptors located on intestinal macrophages, limiting the release of pro-inflammatory cytokines. Vagotomy and antagonists for CCK or nicotinic receptors abrogated this anti-inflammatory effect of lipid-enriched enteral nutrition. ${ }^{15,18}$

Additional experimental studies demonstrated that this strategy could be used to improve gastrointestinal motility. In a murine model of POI, treatment with lipidenriched enteral nutrition attenuated plasma concentrations of mast cell proteaseII and peritoneal levels of TNF- $\alpha$ and IL-6, and reduced the influx of neutrophils in jejunal tissue samples. This was accompanied by a significant improvement of gastrointestinal transit. ${ }^{20}$

Next, the anti-inflammatory effects of lipid-enriched enteral nutrition were demonstrated in a human study, using a model of endotoxemia. A total of 18 healthy male volunteers were subjected to a bolus LPS-injection after an overnight fast. Continuous postpyloric administration of lipid-enriched enteral 
nutrition increased concentrations of CCK and IL-10 (an anti-inflammatory cytokine), while reducing TNF- $\alpha$ and IL- 6 concentrations. ${ }^{21}$

\section{Enteral nutrition and POI in a clinical setting}

In clinical setting anesthesia guidelines prohibit the use of enteral nutrition just before and during surgery to reduce the risk of aspiration. However, early postoperative feeding is feasible and is started as soon as 6 hours after surgery in current ERAS guidelines.

Early start of enteral nutrition has been shown in several meta-analyses to reduce overall complications and length of hospital stay. ${ }^{12,14,22}$ However, the included trials in these studies are clinically heterogeneous and of limited methodological quality, and show inconsistent results on surrogate markers for gastrointestinal motility. ${ }^{14,22,23}$

After extensive abdominal surgery, however, early oral feeding is not always feasible whereas these patients are at a higher risk of developing POI. ${ }^{24}$ For this reason, a recent trial randomized patients undergoing multivisceral rectal resection for locally advanced or recurrent rectal cancer to receive supplemental early postoperative enteral versus parenteral nutrition. ${ }^{2}$ Interestingly, it was found that the group fed enterally experienced fewer complications, in particular less POI and anastomotic leakage. Although these results confirm the potential benefits of enteral feeding, a possible adverse effect of parenteral feeding may also have played a role. ${ }^{25,26}$

As mentioned before, timing of the enteral feed was important in an experimental setup. To further investigate the potentially beneficial effect of direct perioperative enteral nutrition in a clinical setting, a randomized controlled trial was performed in patients undergoing open colorectal surgery using sham feeding. ${ }^{27}$ Sham feeding also activates the vagus nerve and is considered a safe option when used perioperatively. In this single-blind study, patients were randomized to sham feeding by means of gum chewing just before and directly after surgery, versus a placebo dermal patch. It was found that gum chewing reduced not only POI and postoperative inflammatory markers, but also anastomotic leakage when compared to the placebo control group. ${ }^{3}$ Other trials where patients were instructed to chew gum found varying effects. In most studies chewing gum was only given after surgery (and not before). ${ }^{28-30}$ Differences in effect may also be contributed to timing.

Since timing and composition were essential in the experimental studies, the effects of high-fat enteral nutrition given just before, during, and directly after colorectal surgery was investigated in patients in a multicenter, double-blind, randomized 
controlled trial. ${ }^{31}$ In contrast to experimental findings, no effect of lipid-enriched enteral nutrition was seen on POI or other complications. ${ }^{32}$ The lack of effect was unexpected but may be explained by various differences compared with earlier studies. Most patients in this study were operated via laparoscopic approach and ERAS guidelines. While the effect of individual ERAS components on inflammation is unclear, their combined use with laparoscopy may have reduced the inflammatory response to such an extent that the effects of perioperative nutrition were not measurable. ${ }^{3-36}$ However this needs to be clarified further in additional studies.

\section{Conclusion}

Despite improvements in perioperative care, POI remains a common complication and an important contributor to postoperative morbidity following colorectal surgery. Early start of enteral nutrition is considered an essential part of ERAS protocols and has been demonstrated to improve various outcomes in patients undergoing colorectal surgery, however existing studies are heterogeneous and at risk of bias. Several experimental and pre-clinical studies suggested that timing and composition of the enteral feed is important and show beneficial effects of lipidenriched enteral nutrition on POI. However, a recent well-designed randomized trial showed no effect of lipid-enriched nutrition on postoperative complications following colorectal surgery. Further research is needed to delineate the lack of effect in this study. 


\section{References}

1. Wolthuis AM, Bislenghi G, Fieuws S, de Buck van Overstraeten A, Boeckxstaens G, D'Hoore A. Incidence of prolonged postoperative ileus after colorectal surgery: a systematic review and metaanalysis. Colorectal Dis. 2016;18(1):1-9.

2. Boelens PG, Heesakkers FF, Luyer MD, van Barneveld KW, de Hingh IH, Nieuwenhuijzen GA, et al. Reduction of postoperative ileus by early enteral nutrition in patients undergoing major rectal surgery: prospective, randomized, controlled trial. Ann Surg. 2014;259(4):649-55.

3. van den Heijkant TC, Costes LM, van der Lee DG, Aerts B, Osinga-de Jong M, Rutten HR, et al. Randomized clinical trial of the effect of gum chewing on postoperative ileus and inflammation in colorectal surgery. Br J Surg. 2015;102(3):202-11.

4. Vather R, Trivedi S, Bissett I. Defining postoperative ileus: results of a systematic review and global survey. J Gastrointest Surg. 2013;17(5):962-72.

5. Bragg D, El-Sharkawy AM, Psaltis E, Maxwell-Armstrong CA, Lobo DN. Postoperative ileus: Recent developments in pathophysiology and management. Clin Nutr. 2015;34(3):367-76.

6. Peters EG, Dekkers M, van Leeuwen-Hilbers FW, Daams F, Hulsewe KWE, de Jonge WJ, et al. Relation between postoperative ileus and anastomotic leakage after colorectal resection: a post hoc analysis of a prospective randomized controlled trial. Colorectal Dis. 2017;19(7):667-74.

7. Doorly MG, Senagore AJ. Pathogenesis and clinical and economic consequences of postoperative ileus. Surg Clin North Am. 2012;92(2):259-72, viii.

8. Gan TJ, Robinson SB, Oderda GM, Scranton R, Pepin J, Ramamoorthy S. Impact of postsurgical opioid use and ileus on economic outcomes in gastrointestinal surgeries. Curr Med Res Opin. 2015; 31(4):677-86.

9. Barletta JF, Senagore AJ. Reducing the burden of postoperative ileus: evaluating and implementing an evidence-based strategy. World J Surg. 2014;38(8):1966-77.

10. Ljungqvist 0, Scott M, Fearon KC. Enhanced Recovery After Surgery: A Review. JAMA Surg. 2017;152(3):292-8.

11. Greco M, Capretti G, Beretta L, Gemma M, Pecorelli N, Braga M. Enhanced recovery program in colorectal surgery: a meta-analysis of randomized controlled trials. World J Surg. 2014;38(6): 1531-41.

12. Vlug MS, Bartels SA, Wind J, Ubbink DT, Hollmann MW, Bemelman WA, et al. Which fast track elements predict early recovery after colon cancer surgery? Colorectal Dis. 2012;14(8):1001-8.

13. Stakenborg N, Gomez-Pinilla PJ, Boeckxstaens GE. Postoperative Ileus: Pathophysiology, Current Therapeutic Approaches. Handbook of experimental pharmacology. 2017;239:39-57.

14. Chapman SJ, Pericleous A, Downey C, Jayne DG. Postoperative ileus following major colorectal surgery. Br J Surg. 2018;105(7):797-810.

15. Lubbers T, Buurman W, Luyer M. Controlling postoperative ileus by vagal activation. World J Gastroenterol. 2010;16(14):1683-7.

16. Berdun S, Bombuy E, Estrada O, Mans E, Rychter J, Clave P, et al. Peritoneal mast cell degranulation and gastrointestinal recovery in patients undergoing colorectal surgery. Neurogastroenterol Motil. 2015;27(6):764-74.

17. Peters EG, De Jonge WJ, Smeets BJ, Luyer MD. The contribution of mast cells to postoperative ileus in experimental and clinical studies. Neurogastroenterol Motil. 2015;27(6):743-9.

18. Matteoli G, Boeckxstaens GE. The vagal innervation of the gut and immune homeostasis. Gut. 2013;62(8):1214-22.

19. Stakenborg N, Wolthuis AM, Gomez-Pinilla PJ, Farro G, Di Giovangiulio M, Bosmans G, et al. Abdominal vagus nerve stimulation as a new therapeutic approach to prevent postoperative ileus. Neurogastroenterol Motil. 2017;29(9).

20. Lubbers T, Luyer MD, de Haan JJ, Hadfoune M, Buurman WA, Greve JW. Lipid-rich enteral nutrition reduces postoperative ileus in rats via activation of cholecystokinin-receptors. Ann Surg. 2009; 249(3):481-7. 
21. Lubbers T, Kox M, de Haan JJ, Greve JW, Pompe JC, Ramakers BP, et al. Continuous administration of enteral lipid- and protein-rich nutrition limits inflammation in a human endotoxemia model. Crit Care Med. 2013;41(5):1258-65.

22. Zhuang CL, Ye XZ, Zhang CJ, Dong QT, Chen BC, Yu Z. Early versus traditional postoperative oral feeding in patients undergoing elective colorectal surgery: a meta-analysis of randomized clinical trials. Dig Surg. 2013;30(3):225-32.

23. Smeets BJJ, Peters EG, Horsten ECJ, Weijs TJ, Rutten HJT, Buurman WA, et al. Effect of early vs late start of oral intake on anastomotic leakage following elective lower intestinal surgery: A systematic review. Nutr Clin Pract. 2018;33(6):803-12.

24. Beyond TMEC. Consensus statement on the multidisciplinary management of patients with recurrent and primary rectal cancer beyond total mesorectal excision planes. Br J Surg. 2013; 100(8):1009-14.

25. van Barneveld KW, Smeets BJ, Heesakkers FF, Bosmans JW, Luyer MD, Wasowicz D, et al. Beneficial effects of early enteral nutrition after major rectal surgery: A possible role for conditionally essential amino acids? Results of a randomized clinical trial. Crit Care Med. 2016;44(6):e353-61.

26. Elke G, van Zanten AR, Lemieux M, McCall M, Jeejeebhoy KN, Kott M, et al. Enteral versus parenteral nutrition in critically ill patients: an updated systematic review and meta-analysis of randomized controlled trials. Crit Care. 2016;20(1):117.

27. Berghmans TM, Hulsewe KW, Buurman WA, Luyer MD. Stimulation of the autonomic nervous system in colorectal surgery: a study protocol for a randomized controlled trial. Trials. 2012;13:93.

28. de Leede EM, van Leersum NJ, Kroon HM, van Weel V, van der Sijp JRM, Bonsing BA, et al. Multicentre randomized clinical trial of the effect of chewing gum after abdominal surgery. Br J Surg. 2018;105(7):820-8.

29. Liu Q, Jiang H, Xu D, Jin J. Effect of gum chewing on ameliorating ileus following colorectal surgery: A meta-analysis of 18 randomized controlled trials. Int J Surg. 2017;47:107-15.

30. Short V, Herbert G, Perry R, Atkinson C, Ness AR, Penfold C, et al. Chewing gum for postoperative recovery of gastrointestinal function. The Cochrane database of systematic reviews. 2015(2):CD006506.

31. Peters EG, Smeets BJ, Dekkers M, Buise MD, de Jonge WJ, Slooter GD, et al. The effects of stimulation of the autonomic nervous system via perioperative nutrition on postoperative ileus and anastomotic leakage following colorectal surgery (SANICS II trial): a study protocol for a double-blind randomized controlled trial. Trials. 2015;16:20.

32. Peters EG, Smeets BJJ, Nors J, Back CM, Funder JA, Sommer T, et al. Perioperative lipid-enriched enteral nutrition versus standard care in patients undergoing elective colorectal surgery (SANICS II): a multicentre, double-blind, randomised controlled trial. Lancet Gastroenterol Hepatol. 2018;3(4):242-51.

33. Watt DG, McSorley ST, Horgan PG, McMillan DC. Enhanced recovery after surgery: which components, if any, impact on the systemic inflammatory response following colorectal surgery?: A systematic review. Medicine. 2015;94(36):e1286.

34. Ljungqvist O. Jonathan E. Rhoads lecture 2011: Insulin resistance and enhanced recovery after surgery. JPEN J Parenter Enteral Nutr. 2012;36(4):389-98.

35. Veenhof AA, Vlug MS, van der Pas MH, Sietses C, van der Peet DL, de Lange-de Klerk ES, et al. Surgical stress response and postoperative immune function after laparoscopy or open surgery with fast track or standard perioperative care: a randomized trial. Ann Surg. 2012;255(2):216-21.

36. Carli F. Physiologic considerations of Enhanced Recovery After Surgery (ERAS) programs: implications of the stress response. Can J Anaesth. 2015;62(2):110-9. 



\section{Chapter}

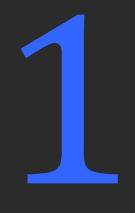

\section{Summary, general discussion, and future}

perspectives 



\section{General summary and discussion}

In spite of improvements in perioperative care, the incidence and burden of postoperative complications in colorectal surgery remains substantial. ${ }^{1,2} \mathrm{~A}$ balanced surgical stress response is crucial for optimal recovery and to reduce complications such as postoperative ileus (POI). ${ }^{3}$ Previous studies demonstrated a beneficial effect of enteral nutrition on POI and surgical stress. Specifically, vagal nerve stimulation by means of lipid-enriched enteral nutrition reduced inflammation and POI in experimental studies ${ }^{4}$, while in a clinical setting POI and anastomotic leakage (AL) were reduced by means of sham feeding ${ }^{5}$ and early postoperative enteral nutrition. ${ }^{6}$ In this thesis, we further investigated the role of enteral nutrition in the development of complications and the surgical stress response following colorectal surgery.

In Chapter 2 we performed a systematic review and meta-analysis to study existing literature on the effects of early enteral nutrition on AL. We found that most existing trials were of limited methodological quality, and definitions of AL varied greatly. Pooling of all available data demonstrated a reduction of AL by means of early start of enteral nutrition. However, after excluding trials with a risk of bias in the sensitivity analysis, this effect was no longer significant. Taken together, this study showed that high-quality studies are needed to further study the effects of enteral nutrition on AL in a clinical setting.

In a prospective, randomized controlled study, patients undergoing major surgery for locally advanced or recurrent rectal cancer were allocated to receive supplementary early enteral versus parenteral nutrition in addition to a regular oral diet. Patients in the enteral group experienced less POI and less AL as compared to the parenteral group. ${ }^{6}$ It was hypothesized that the observed effects of early enteral nutrition on clinical outcomes may be explained by an effect on plasma amino acid concentrations. Chapters 3, 4, and 5 are preplanned substudies of this trial. In Chapter 3, plasma concentrations of conditionally essential amino acids (i.e. glutamine, citrulline, and arginine) were compared between the two groups. It was found that plasma concentrations of glutamine and arginine were lower in the enteral group on postoperative day 1 and 5, whereas a better clinical outcome was observed as compared to the parenteral group. These findings suggest that plasma glutamine or arginine concentrations were not important determinants of clinical outcome, and that the benefit of enteral nutrition may have other mechanisms. Furthermore, these results are in line with other studies showing that supplementing specific amino acids may not necessarily result in improved clinical outcomes, or may even be harmful in specific patient groups. ${ }^{7-12}$

In Chapter 4, changes in anti-oxidative amino acids (taurine, glutamic acid, glycine, $\mathrm{N}$-acetylcysteine, and hydroxyproline) were compared between patients receiving supplementary enteral versus parenteral nutrition undergoing rectal surgery. ${ }^{6}$ It 
was found that postoperative glycine concentrations were significantly higher in the parenteral group, while other amino acid concentrations were similar between groups. This may be due to the higher amounts of glycine administered in the parenteral group. Multivariable regression analysis showed no association between plasma amino acid concentrations and clinical outcomes. Again, these findings are in line with results of other studies that show no benefit of supplementing amino acids in a clinical setting. ${ }^{12,13}$ As such, in accordance with the results from Chapter 3 , postoperative plasma amino acid concentrations did not provide a causal explanation for the observed benefits of enteral nutrition. It may be postulated that lower plasma amino acid concentrations are to be considered as an epiphenomenon of surgical trauma, rather than an actual contributor to impaired postoperative recovery. Of note, these studies were limited by the fact that the original trial ${ }^{6}$ was not powered to detect differences in plasma amino acid concentrations.

In Chapter 5 it was investigated whether an effect on the inflammatory or metabolic stress response could explain the beneficial effect of enteral nutrition as observed in the original trial. ${ }^{6}$ Here, markers of surgical stress (C-reactive protein and albumin) were determined as well as markers of postoperative insulin resistance (Homeostatic Model Assessment of Insulin Resistance (HOMA-IR) by means of plasma glucose and insulin concentrations). On postoperative day (POD) 1 , albumin concentrations were lower while $\mathrm{C}$-reactive protein concentrations were higher in the enteral group, suggesting a greater surgical stress response when compared to the parenteral group. These early postoperative differences may be explained by the fact that the enteral group experienced a greater degree of surgical trauma and concomitant fluid resuscitation, as reflected by the longer operating time and greater amounts of operative blood loss in this group, and discussed by the authors in the original paper. ${ }^{6}$ Patients in the parenteral group demonstrated higher insulin concentrations and HOMA-IR scores on POD5, indicating a greater magnitude of metabolic dysregulation as compared to the enteral group. Further analysis revealed that significantly more calories were cumulatively provided via the parenteral route as compared to the enteral route, which may have induced caloric overfeeding. These findings are in line with other studies that suggest an improved metabolic response by means of enteral nutrition when compared to parenteral nutrition. ${ }^{14-19}$ Caloric overfeeding and the subsequent detrimental effects on clinical outcomes (e.g. increased risk of infectious complications) is now a well-known complication of parenteral feeding. ${ }^{20}$ Interestingly, when overfeeding is prevented by maintaining normocaloric feeding goals, a recent trial showed no differences in clinical outcomes between enteral versus parenteral nutrition in critically ill patients. ${ }^{21}$ As such, changes in metabolic dysregulation may partially explain the differences in clinical outcomes between the two groups in the original trial. ${ }^{6}$ However, in this study cohort increased markers of metabolic stress were not 
associated with clinical outcomes. Taken together, patients in the parenteral group may have experienced a greater degree of caloric overfeeding and metabolic dysregulation, however this likely does not explain the beneficial effect of enteral nutrition.

Myopenia is another factor that can impair recovery following colorectal surgery by increasing the early surgical stress response. In Chapter 6, presence of myopenia in patients undergoing colorectal surgery was investigated by means of quantifying skeletal muscle mass via computed tomography images at the third lumbar vertebra. For this study, data was analyzed from patients from a previous randomized trial, in which the effect of perioperative gum chewing on specific markers of the systemic inflammatory response was studied. ${ }^{5}$ Almost $40 \%$ of the included patients in this cohort were myopenic and demonstrated significantly higher plasma concentrations of interleukin-8 (IL-8) when compared to patients without myopenia four hours after start of surgery. However, this proinflammatory effect of myopenia was no longer significant after exclusion of four patients that demonstrated increased preoperative IL-8 concentrations. No effect of myopenia was observed on concentrations of C-reactive protein or soluble tumor necrosis factor receptor 1 . Taken together, the finding that myopenia may increase some, but not all, markers of systemic inflammation was limited by the presence of confounders and small patient cohort size, underlining the need for further studies with larger sample sizes.

Experimental studies have previously demonstrated a reduction of POI and AL by means of enteral nutrition. Timing and composition were essential; lipid-enriched nutrition given just before, during, and directly after surgery provided the optimal effect. To further study this concept, an international, multicenter, double-blind, randomized controlled trial was performed to test the effects of perioperative lipidenriched enteral nutrition on POI and AL in a clinical setting (Chapter 7 and 8). Patients undergoing elective, colorectal resection with primary anastomosis were included. Via a branched, double-blind tube feeding system, lipid-enriched enteral nutrition was administered either to the patient via a nasojejunal tube, or to a blinded black box that was attached to the bed. Continuous feeding was administered from three hours before until six hours after surgery in all patients. In contrast to experimental findings, no effect of perioperative lipid-enriched enteral nutrition was seen on POI, AL or any other complication. The lack of effect was unexpected but may be explained by important differences in study design. In contrast to previous studies ${ }^{5,6}$, the combined use of laparoscopy and overall good adherence to ERAS protocols in the current trial may have attenuated the surgical stress response to such an extent that the effect of perioperative nutrition was no longer measurable. ${ }^{22-27}$ However, this needs to be clarified further in additional studies. 
In Chapter 9, current nutritional interventions to reduce POI were reviewed. Importantly, it was found that nutritional interventions from experimental studies were not effective in a clinical setting. Alternative strategies to reduce POI by mitigating inflammation, such as electrical vagal nerve stimulation ${ }^{28}$, may be promising but are yet to be tested in a clinical setting.

\section{Future perspectives}

To improve postoperative outcomes in colorectal surgery, optimizing the surgical stress response by attenuating early postoperative inflammation may be essential. In this light, the results from this thesis show that in patients who are treated by means of modern surgical protocols including laparoscopy and ERAS, perioperative lipid-enriched enteral nutrition has no additional benefit in terms of postoperative complications, in contrast to results from previous experimental studies. It may be postulated that perioperative lipid-enriched nutrition could be effective when postoperative inflammation and risk of POI is greater, for example in patients undergoing multivisceral resections with hyperthermic intraperitoneal chemotherapy (HIPEC). ${ }^{29}$ However, this is yet to be further investigated. Alternatively, methods of direct vagus nerve stimulation may be more effective in reducing early inflammation and improving outcomes. For example, electrical stimulation of the vagus nerve has been shown to significantly reduce systemic inflammation in both murine and human subjects. ${ }^{28}$ However, a concomitant reduction of POI has only been observed in mice. ${ }^{28} \mathrm{~A}$ clinical trial on the effects of electrical vagus nerve stimulation is currently ongoing (NCT 02524626), and should demonstrate whether this is a safe and effective intervention to reduce POI in the surgical population. Lastly, other strategies aimed at optimizing patient status and attenuating surgical stress may further improve postoperative outcomes. Such strategies could include preoperative prehabilitation with physiotherapy and nutritional counseling ${ }^{30}$, and are currently being investigated in various surgical groups. ${ }^{31-33}$

Another way to improve perioperative care can be to further study the role of postoperative inflammation and other potentially pathogenic factors in surgical convalescence. $^{34}$ To this end, various biological samples were obtained from patients in the SANICS II trial as secondary outcomes. These include pre- and postoperative plasma inflammatory markers, peritoneal lavage samples, fullthickness colonic tissue samples, and pre- and postoperative fecal samples. In particular, perioperative changes in the gut microbiome will be studied in fecal samples and colonic tissue samples, since cumulative evidence suggests that changes in the gut microbiome play an important role in the recovery from gastrointestinal surgery, development of postoperative complications including $\mathrm{AL}$ and POI, and even in cancer recurrence. ${ }^{35-40}$ Furthermore, there is some evidence 
suggesting that there may be genetic predispositions for impaired wound healing that can make a patient prone to develop AL or other complications. ${ }^{41,42}$ Future research will be necessary to substantiate these results. 


\section{References}

1. Govaert JA, Fiocco M, van Dijk WA, Scheffer AC, de Graaf EJ, Tollenaar RA, et al. Costs of complications after colorectal cancer surgery in the Netherlands: Building the business case for hospitals. Eur J Surg Oncol. 2015;41(8):1059-67.

2. Spanjersberg WR, Reurings J, Keus F, van Laarhoven CJ. Fast track surgery versus conventional recovery strategies for colorectal surgery. The Cochrane database of systematic reviews. 2011(2):CD007635.

3. Chapman SJ, Pericleous A, Downey C, Jayne DG. Postoperative ileus following major colorectal surgery. Br J Surg. 2018;105(7):797-810.

4. Peters EG, De Jonge WJ, Smeets BJ, Luyer MD. The contribution of mast cells to postoperative ileus in experimental and clinical studies. Neurogastroenterol Motil. 2015;27(6):743-9.

5. van den Heijkant TC, Costes LM, van der Lee DG, Aerts B, Osinga-de Jong M, Rutten HR, et al. Randomized clinical trial of the effect of gum chewing on postoperative ileus and inflammation in colorectal surgery. Br J Surg. 2015;102(3):202-11.

6. Boelens PG, Heesakkers FF, Luyer MD, van Barneveld KW, de Hingh IH, Nieuwenhuijzen GA, et al. Reduction of postoperative ileus by early enteral nutrition in patients undergoing major rectal surgery: prospective, randomized, controlled trial. Ann Surg. 2014;259(4):649-55.

7. Rosenthal MD, Carrott PW, Patel J, Kiraly L, Martindale RG. Parenteral or Enteral Arginine Supplementation Safety and Efficacy. J Nutr. 2016;146(12):2594S-600S.

8. van Zanten AR, Dhaliwal R, Garrel D, Heyland DK. Enteral glutamine supplementation in critically ill patients: a systematic review and meta-analysis. Crit Care. 2015;19:294.

9. Stehle P, Ellger B, Kojic D, Feuersenger A, Schneid C, Stover J, et al. Glutamine dipeptidesupplemented parenteral nutrition improves the clinical outcomes of critically ill patients: A systematic evaluation of randomised controlled trials. Clin Nutr ESPEN. 2017;17:75-85.

10. van Zanten AR, Sztark F, Kaisers UX, Zielmann S, Felbinger TW, Sablotzki AR, et al. High-protein enteral nutrition enriched with immune-modulating nutrients vs standard high-protein enteral nutrition and nosocomial infections in the ICU: a randomized clinical trial. JAMA. 2014;312(5): 514-24.

11. Heyland D, Muscedere J, Wischmeyer PE, Cook D, Jones G, Albert M, et al. A randomized trial of glutamine and antioxidants in critically ill patients. N Engl J Med. 2013;368(16):1489-97.

12. Gunst J, Vanhorebeek I, Thiessen SE, Van den Berghe G. Amino acid supplements in critically ill patients. Pharmacological Res. 2018;130:127-31.

13. Van Stijn MF, Bruins AA, Vermeulen MA, Witlox J, Teerlink T, Schoorl MG, et al. Effect of oral taurine on morbidity and mortality in elderly hip fracture patients: a randomized trial. Int J Mol Sci. 2015;16(6):12288-306.

14. Magnusson J, Tranberg KG, Jeppsson B, Lunderquist A. Enteral versus parenteral glucose as the sole nutritional support after colorectal resection. A prospective, randomized comparison. Scand J Gastroenterol. 1989;24(5):539-49.

15. Moore FA, Feliciano DV, Andrassy RJ, McArdle AH, Booth FV, Morgenstein-Wagner TB, et al. Early enteral feeding, compared with parenteral, reduces postoperative septic complications. The results of a meta-analysis. Ann Surg. 1992;216(2):172-83.

16. Lidder P, Flanagan D, Fleming S, Russell M, Morgan N, Wheatley T, et al. Combining enteral with parenteral nutrition to improve postoperative glucose control. Br J Nutr. 2010;103(11):1635-41.

17. O'Keefe SJ. Physiological response of the human pancreas to enteral and parenteral feeding. Curr Opin Clin Nutr Metab Care. 2006;9(5):622-8.

18. Holst JJ, Gromada J. Role of incretin hormones in the regulation of insulin secretion in diabetic and nondiabetic humans. Am J Physiol Endocrinol Metab. 2004;287(2):E199-206.

19. Gillis C, Carli F. Promoting Perioperative Metabolic and Nutritional Care. Anesthesiology. 2015;123(6):1455-72. 
20. Elke G, van Zanten AR, Lemieux M, McCall M, Jeejeebhoy KN, Kott M, et al. Enteral versus parenteral nutrition in critically ill patients: an updated systematic review and meta-analysis of randomized controlled trials. Crit Care. 2016;20(1):117.

21. Reignier J, Boisrame-Helms J, Brisard L, Lascarrou JB, Ait Hssain A, Anguel N, et al. Enteral versus parenteral early nutrition in ventilated adults with shock: a randomised, controlled, multicentre, open-label, parallel-group study (NUTRIREA-2). Lancet. 2018;391(10116):133-43.

22. Watt DG, McSorley ST, Horgan PG, McMillan DC. Enhanced recovery after surgery: Which components, if any, impact on the systemic inflammatory response following colorectal surgery?: A systematic review. Medicine. 2015;94(36):e1286.

23. Venara A, Duchalais E, Dariel A, Aubert P, Durand T, Meurette G, et al. Anti-inflammatory effects of enhanced recovery programs on early-stage colorectal cancer surgery. World J Surg. 2018; 42(4):953-64.

24. Barbieux J, Hamy A, Talbot MF, Casa C, Mucci S, Lermite E, et al. Does enhanced recovery reduce postoperative ileus after colorectal surgery? J Visc Surg. 2017;154(2):79-85.

25. Ljungqvist 0 . Jonathan E. Rhoads lecture 2011: Insulin resistance and enhanced recovery after surgery. JPEN J Parenter Enteral Nutr. 2012;36(4):389-98.

26. Veenhof AA, Vlug MS, van der Pas MH, Sietses C, van der Peet DL, de Lange-de Klerk ES, et al. Surgical stress response and postoperative immune function after laparoscopy or open surgery with fast track or standard perioperative care: a randomized trial. Ann Surg. 2012;255(2):216-21.

27. Carli F. Physiologic considerations of Enhanced Recovery After Surgery (ERAS) programs: implications of the stress response. Can J Anaesth. 2015;62(2):110-9.

28. Stakenborg N, Wolthuis AM, Gomez-Pinilla PJ, Farro G, Di Giovangiulio M, Bosmans G, et al. Abdominal vagus nerve stimulation as a new therapeutic approach to prevent postoperative ileus. Neurogastroenterol Motil. 2017;29(9).

29. Plas M, van Leeuwen BL, de Haan JJ. Enteral nutrition during major surgery: how to proceed after SANICS II. Lancet Gastroenterol Hepatol. 2018;3(7):454.

30. Gillis C, Buhler K, Bresee L, Carli F, Gramlich L, Culos-Reed N, et al. Effects of nutritional prehabilitation, with and without exercise, on outcomes of patients who undergo colorectal surgery: A systematic review and meta-analysis. Gastroenterology. 2018;155(2):391-410 e4.

31. Abdullah HR, Lien VP, Ong HK, Er PL, Hao Y, Khan SA, et al. Protocol for a single-centre, randomised controlled study of a preoperative rehabilitation bundle in the frail and elderly undergoing abdominal surgery. BMJ Open. 2017;7(8):e016815.

32. Merki-Kunzli C, Kerstan-Huber M, Switalla D, Gisi D, Raptis DA, Greco N, et al. Assessing the value of prehabilitation in patients undergoing colorectal surgery according to the enhanced recovery after surgery (ERAS) Pathway for the improvement of postoperative outcomes: Protocol for a randomized controlled trial. JMIR Res Protoc. 2017;6(10):e199.

33. Berkel AEM, Bongers BC, van Kamp MS, Kotte H, Weltevreden P, de Jongh FHC, et al. The effects of prehabilitation versus usual care to reduce postoperative complications in high-risk patients with colorectal cancer or dysplasia scheduled for elective colorectal resection: study protocol of a randomized controlled trial. BMC Gastroenterol. 2018;18(1):29.

34. Alazawi W, Pirmadjid N, Lahiri R, Bhattacharya S. Inflammatory and Immune Responses to Surgery and Their Clinical Impact. Ann Surg. 2016;264(1):73-80.

35. Alverdy JC, Hyoju SK, Weigerinck M, Gilbert JA. The gut microbiome and the mechanism of surgical infection. Br J Surg. 2017;104(2):e14-e23.

36. Gaines S, Shao C, Hyman N, Alverdy JC. Gut microbiome influences on anastomotic leak and recurrence rates following colorectal cancer surgery. Br J Surg. 2018;105(2):e131-e41.

37. Guyton K, Alverdy JC. The gut microbiota and gastrointestinal surgery. Nat Rev Gastroenterol Hepatol. 2017;14(1):43-54.

38. Stavrou G, Kotzampassi K. Gut microbiome, surgical complications and probiotics. Ann Gastroenterol. 2017;30(1):45-53.

39. van Praagh JB, de Goffau MC, Bakker IS, van Goor H, Harmsen HJM, Olinga P, et al. Mucus microbiome of anastomotic tissue during surgery has predictive value for colorectal anastomotic leakage. Ann Surg. 2019;269(5):911-6. 
40. Lederer AK, Pisarski P, Kousoulas L, Fichtner-Feigl S, Hess C, Huber R. Postoperative changes of the microbiome: are surgical complications related to the gut flora? A systematic review. BMC Surg. 2017;17(1):125.

41. Reisinger KW, Schellekens DH, Bosmans JW, Boonen B, Hulsewe KW, Sastrowijoto P, et al. Cyclooxygenase-2 Is Essential for Colorectal Anastomotic Healing. Ann Surg. 2017;265(3):547-54.

42. Matthijsen RA, Derikx JP, Steffensen R, van Dam RM, Dejong CH, Buurman WA. Mannose-binding lectin null alleles are associated with preserved epithelial cell integrity following intestinal ischemia reperfusion in man. Mol Immunol. 2009;46(11-12):2244-8. 
Valorisation 



\section{Valorisation}

\section{Introduction}

Perioperative care in colorectal surgery has been improved by the introduction of Enhanced Recovery After Surgery (ERAS) protocols, which includes the fast start of enteral nutrition after surgery. However, despite these improvements the incidence of important complications including postoperative ileus and anastomotic leakage has remained stable.

Previous experimental and pre-clinical studies have demonstrated that enteral nutrition may attenuate surgical stress and reduce complications including postoperative ileus and anastomotic leakage. In this thesis the role of enteral nutrition in the development of complications and the surgical stress response following colorectal surgery is further investigated in a clinical setting.

\section{Social relevance}

The incidence of colorectal cancer has risen over the last years in the Netherlands. An important contributor is the development of a nationwide screening program to detect colorectal cancer as early as possible. Concomitantly, the societal burden of disease from postoperative complications is expected to rise, since postoperative complications are known to impair both short- and long-term quality of life. In addition, disease specific survival from colorectal cancer may be affected when adjuvant treatment is postponed because of complications. Therefore, there is a need to reduce postoperative complications and the results from this thesis give a direction towards therapeutic opportunities.

\section{Economic relevance}

Postoperative ileus and anastomotic leakage are common complications following colorectal surgery that can prolong length of hospital stay and strongly increase healthcare costs. Vice versa, reducing complications by means of specific interventions are likely to reduce costs. In this thesis, studies are described in which complications were significantly reduced by means of perioperative gum chewing and early start of enteral nutrition. These interventions are likely to reduce healthcare costs. Conversely, the randomized controlled trial included in this thesis investigating the effect of perioperative lipid-enriched enteral nutrition (SANICS II trial) did not show an additional effect on clinical outcomes. It is therefore unlikely to have an effect on healthcare costs in this patient group. 


\section{Target population}

The contents of this thesis are relevant for clinicians, dieticians, and researchers dedicated to improve outcomes following colorectal surgery. Specifically, the results of this thesis may help healthcare workers to gain more insight in what nutritional interventions are available to reduce postoperative ileus and other complications. In addition, this thesis may help researchers better understand the biophysiological mechanisms behind nutritional interventions, and help guide the development of successful strategies in future research.

\section{Activities and products}

A specific lipid-enriched nutritional formula was designed for the randomized controlled trial described in this thesis (SANICS II). While perioperative administration of this formula did not improve outcomes in patients undergoing colorectal surgery who were treated following ERAS protocols, its use may be further investigated in other settings. Furthermore, this thesis explores the effects of two existing enteral and parenteral formulas on several biophysiological processes. These findings may be used to optimize the composition and application of these specific nutritional interventions.

\section{Innovation}

This thesis includes the first study to investigate the use of enteral nutrition given just before, during, and directly after colorectal surgery. This is unique as current anesthesia guidelines dictate a strict period of 'nil-by-mouth' to reduce risk of aspiration. Careful design of the study resulted in a way to successfully administer perioperative enteral nutrition while minimizing the risk of aspiration by means of several precautionary measures. These measures included the use of a selfmigrating nasojejunal tube inserted the day before surgery which enabled postpyloric feeding. Safety of this innovative principle was closely monitored by measuring gastric volumes directly after intubation, strict prospective registration of complications, and frequent evaluation by an independent Data Safety and Monitoring Board. Furthermore, a specially designed, branched tube feeding system was created to successfully perform the clinical trial in double-blind manner, which strongly improved the validity of the results.

\section{Future}

A balanced surgical stress response is essential for optimal recovery following colorectal surgery. In this light, strategies to attenuate the postoperative inflammatory response may be investigated in future studies. While perioperative 
enteral nutrition did not affect clinical outcomes in patients undergoing colorectal surgery by means of ERAS protocols, it may yet be effective when postoperative inflammation and risk of postoperative ileus is greater, such as in patients undergoing multivisceral resections with hyperthermic intraperitoneal chemotherapy. Other strategies to reduce postoperative inflammation, such as electrical stimulation of the vagus nerve, are currently being investigated in a clinical setting. Furthermore, postoperative recovery may be improved by increasing functional capacity preoperatively by means of prehabilitation programs, which is currently being studied in various patient groups. 

Nederlandse samenvatting 



\section{Nederlandse samenvatting}

De incidentie van naadlekkage en postoperatieve ileus na colorectale chirurgie blijft relatief stabiel, ondanks verbeteringen in de perioperatieve zorg de afgelopen jaren. Eén van de verbeteringen die de afgelopen jaren is doorgevoerd is het snel starten van enterale voeding na de operatie, in het kader van versneld herstel (ERAS) programma's. Zowel de timing van het geven van voeding alsmede de samenstelling zouden van belang kunnen zijn bij het verminderen van complicaties. In experimentele en preklinische studies werd aangetoond dat vetrijke enterale voeding gegeven juist voor en direct na een operatie minder inflammatie en minder postoperatieve ileus geeft door activatie van de nervus vagus. In een eerdere klinische studie werd aangetoond dat de incidentie van postoperatieve ileus en naadlekkage kan worden verminderd door direct starten van enterale voeding na uitgebreide rectumchirurgie. Daarnaast liet een andere klinische studie zien dat het risico op postoperatieve ileus en naadlekkage kan worden verminderd door het geven van kauwgom (om de nervus vagus te stimuleren) juist voor en direct na een operatie. In dit proefschrift is onderzocht of enterale voeding rondom een operatie postoperatieve ileus en naadlekkage kan verminderen en welke metabole effecten het geven van vroege enterale voeding heeft.

In Hoofdstuk 2 is in bestaande literatuur systematisch onderzocht wat het effect is van enterale voeding op het ontstaan van naadlekkage na colorectale chirurgie. Het merendeel van de bestaande studies waren van matige methodologische kwaliteit, en de gebruikte definities van naadlekkage varieerden aanzienlijk. In de metaanalyse was vroeg starten van postoperatieve enterale voeding geassocieerd met een kleiner risico op naadlekkage. Echter na het excluderen van studies met risico op bias was dit gunstige effect niet langer significant. Concluderend liet deze studie zien dat er meer onderzoek van goede methodologische kwaliteit nodig is om te bepalen wat het effect van enterale voeding is op naadlekkage in een klinische setting.

In een eerdere studie van Boelens et al. werd aangetoond dat vroege enterale voeding (ten opzichte van parenteriale voeding) in patiënten die majeure rectale chirurgie ondergingen, leidde tot significant minder postoperatieve ileus en naadlekkage. ${ }^{1}$ Uit eerder onderzoek bleek dat metabole veranderingen een mogelijke verklaring zouden kunnen zijn voor dit effect. In Hoofdstuk $\mathbf{3}$ en $\mathbf{4}$ werd onderzocht of dit gunstige effect van enterale voeding een gevolg was van verschillen in plasma concentraties van klinisch relevante aminozuren, te weten glutamine, citrulline, arginine, taurine, glycine, glutaminezuur, $\mathrm{N}$-acetylcysteine, en hydroxyproline. In de enterale groep waren plasma concentraties van glutamine, arginine, en glycine postoperatief lager in vergelijking met de parenterale groep, 
terwijl de enterale groep minder complicaties had. Er werd geen verschil gezien in de overige aminozuurconcentraties, noch werd er een associatie gezien tussen plasma concentraties van aminozuren en postoperatief herstel. Deze studies toonden aan dat het gunstige effect van enterale voeding niet kon worden verklaard door verschillen in aminozuurconcentraties. In Hoofdstuk 5 werd onderzocht of het gunstige herstel in de enterale groep kon worden verklaard door een effect van voeding op postoperatieve inflammatie of insulineresistentie. Voor dit onderzoek werden markers van inflammatie (albumine en C-reactief proteïne) en van insulineresistentie (Homeostatic Model Assessment of Insulin Resistance (HOMA-IR) waarden) vergeleken tussen beide groepen. Op postoperatieve dag 1 waren plasma concentraties van albumine lager en van C-reactief proteïne hoger in de enterale groep, wat duidt op een groter inflammatoire respons. Dit kan mogelijk verklaard worden door de grotere hoeveelheid bloedverlies en langere operatieduur in de enterale groep, zoals beschreven door de auteurs in het oorspronkelijke artikel. Op postoperatieve dag 5 hadden patiënten in de parenterale groep meer caloriëen toegediend gekregen, en hadden hogere insuline concentraties en HOMA-IR scores, wat duidt op een grotere metabole ontregeling en mate van insulineresistentie in vergelijking met de enterale groep. Deze resultaten kwamen overeen met andere studies waarin werd aangetoond dat parenterale voeding vaker gepaard gaat met calorische overvoeding en metabole ontregeling, wat kan leiden tot een hogere risico op bijvoorbeeld infectieuze complicaties. Echter, de mate van metabole ontregeling was in deze studiegroep niet geassocieerd met klinische uitkomsten. Concluderend lijkt de mate van metabole ontregeling groter te zijn geweest in de parenterale groep, hoewel dit mogelijk niet van groot effect is geweest op het algemeen postoperatief herstel en dus niet verklarend is voor het betere herstel in de enterale groep.

De aanwezigheid van myopenie (i.e. verminderde skeletspiermassa) is een andere factor die mogelijk het postoperatief herstel kan vertragen door de vroege postoperatieve inflammatoire respons te beïnvloeden. In Hoofdstuk $\mathbf{6}$ werd de aanwezigheid van myopenie onderzocht in patiënten die een colorectale resectie hadden ondergaan, door de skeletspiermassa te meten op preoperatieve computertomografie-scans. Hiervoor werd data gebruikt van een eerder uitgevoerde studie, waarin patiënten waren gerandomiseerd tot perioperatief kauwgom kauwen versus placebo, en pre- en postoperatieve inflammatie markers waren gemeten. ${ }^{2}$ Patiënten met myopenie hadden postoperatief significant hogere interleukine-8 concentraties in vergelijking met patiënten zonder myopenie. Dit verschil was niet meer zichtbaar na exclusie van patiënten die preoperatief reeds verhoogde interleukine-8 concentraties hadden. Er werd geen verschil gezien in concentraties van andere inflammatie markers (C-reactief proteïne of oplosbaar tumor necrose factor receptor 1). De bevinding dat myopenie mogelijk 
geassocieerd is met een sterkere verhoging van enkele, maar niet alle postoperatieve inflammatie markers, kan dus ook te wijden zijn aan de relatief kleine studiegroep en confounders. Meer onderzoek met grotere patiëntgroepen is nodig om hier meer duidelijkheid in te verkrijgen.

In eerder experimenteel onderzoek werd aangetoond dat het risico op postoperatieve ileus en naadlekkage kan worden verminderd met behulp van enterale voeding. De samenstelling en timing waren hierbij essentieel; vetrijke voeding welke toegediend wordt vlak vóór, tijdens, en direct ná chirurgie gaf het meest gunstige effect. Dit effect van vetrijke perioperatieve enterale voeding op postoperatieve ileus en naadlekkage werd in een klinische setting verder onderzocht in een internationaal, multicenter, dubbelblind gerandomiseerd onderzoek (Hoofdstuk 7 en 8). Tweehonderdtachtig patiënten die een electieve, colorectale resectie met primaire anastomose ondergingen werden geïncludeerd. Vetrijke voeding werd op een dubbelgeblindeerde wijze toegediend middels een gesplitst, ondoorzichtig sondevoedingssysteem óf aan de patiënt via een nasojejunale sonde, óf aan een geblindeerde doos die aan het bed van de patiënt werd bevestigd. Bij alle patiënten werd de voeding 3 uur vóór de operatie gestart, en liep continu door tot 6 uur ná de operatie. In tegenstelling tot eerder pre-klinisch onderzoek werd er geen effect van vetrijke perioperatieve enterale voeding gezien op postoperatieve ileus, naadlekkage, of andere klinisch uitkomsten. Het uitblijven van een significant effect kan mogelijk verklaard worden door belangrijke verschillen tussen de huidige studie-opzet en eerdere studies. Het veelvuldig gebruik van laparoscopische chirurgie en goede compliantie aan ERAS protocollen kan mogelijk de chirurgische stress respons reeds dusdanig hebben geminimaliseerd dat een effect van vetrijke voeding niet langer meetbaar was. Aanvullend onderzoek zal hier meer duidelijkheid over moeten verschaffen.

In Hoofdstuk 9 werd een overzicht gegeven van bestaande voedingsinterventies gericht op het verminderen van postoperatieve ileus. Van belang was dat effectieve interventies uit pre-klinische studies niet werkzaam bleken in een klinische setting. Andere therapieën tegen postoperatieve ileus zoals elektrische stimulatie van de nervus vagus worden op dit moment onderzocht in klinische studies. 


\section{Referenties}

1. Boelens PG, Heesakkers FF, Luyer MD, van Barneveld KW, de Hingh IH, Nieuwenhuijzen GA, et al. Reduction of postoperative ileus by early enteral nutrition in patients undergoing major rectal surgery: prospective, randomized, controlled trial. Ann Surg. 2014;259(4):649-55.

2. van den Heijkant TC, Costes LM, van der Lee DG, Aerts B, Osinga-de Jong M, Rutten HR, et al. Randomized clinical trial of the effect of gum chewing on postoperative ileus and inflammation in colorectal surgery. Br J Surg. 2015;102(3):202-11. 
Publications 



\section{Publications}

Pattamatta M, Smeets BJJ, Evers SMAA, Peters EG, Luyer MDP, Hiligsmann M. Quality of life and costs of patients prior to colorectal surgery. Expert Rev Pharmacoecon Outcomes Res. 2019 Jun 17:1-6.

Pattamatta M, Evers SMAA, Smeets BJJ, Peters EG, Luyer MDP, Hiligsmann M. An economic evaluation of perioperative enteral nutrition in patients undergoing colorectal surgery (SANICS II study). J Med Econ. 2018 Dec 7:1-14.

Smeets BJJ, Luyer MDP. Nutritional interventions to improve recovery from postoperative ileus. Curr Opin Clin Nutr Metab Care. 2018 Sep;21(5):394-39.

Smeets BJJ, Brinkman DJ, Horsten ECJ, Langius JAE, Rutten HJT, de Jonge WJ, Luyer MDP. The Effect of Myopenia on the Inflammatory Response Early after Colorectal Surgery. Nutr Cancer. 2018 Apr;70(3):460-466.

Peters EG, Smeets BJJ, Nors J, Back CM, Funder JA, Sommer T, Laurberg S, Løve US, Leclercq WKG, Slooter GD, de Vries Reilingh TS, Wegdam JA, Nieuwenhuijzen GAP, Hiligsmann M, Buise MP, Buurman WA, de Jonge WJ, Rutten HJT, Luyer MDP. Perioperative lipid-enriched enteral nutrition versus standard care in patients undergoing elective colorectal surgery (SANICS II): a multicentre, double-blind, randomised controlled trial. Lancet Gastroenterol Hepatol. 2018 Apr;3(4):242-251.

Pattamatta M, Smeets BJJ, Evers SMAA, Rutten HJT, Luyer MDP, Hiligsmann M. Health-related quality of life and cost-effectiveness analysis of gum chewing in patients undergoing colorectal surgery: results of a randomized controlled trial. Acta Chir Belg. 2018 Jan 30:1-8.

Smeets BJJ, Peters EG, Horsten ECJ, Weijs TJ, Rutten HJT, Buurman WA, de Jonge WJ, Luyer MDP. Effect of Early vs Late Start of Oral Intake on Anastomotic Leakage Following Elective Lower Intestinal Surgery: A Systematic Review. Nutr Clin Pract. 2017 Jun 1:884533617711128.

van Barneveld KW, Smeets BJ, Heesakkers FF, Bosmans JW, Luyer MD, Wasowicz D, Bakker JA, Roos AN, Rutten HJ, Bouvy ND, Boelens PG. Beneficial Effects of Early Enteral Nutrition After Major Rectal Surgery: A Possible Role for Conditionally Essential Amino Acids? Results of a Randomized Clinical Trial. Crit Care Med. 2016 Jun;44(6):e353-61. 
Berkelmans GH, Kouwenhoven EA, Smeets BJ, Weijs TJ, Silva Corten LC, van Det MJ, Nieuwenhuijzen GA, Luyer MD. Diagnostic value of drain amylase for detecting intrathoracic leakage after esophagectomy. World J Gastroenterol. 2015 Aug 14;21(30):9118-25.

Peters EG, De Jonge WJ, Smeets BJ, Luyer MD. The contribution of mast cells to postoperative ileus in experimental and clinical studies. Neurogastroenterol Motil. 2015 Jun;27(6):743-9.

Peters EG, Smeets B, Dekkers M, Buise MD, de Jonge WJ, Slooter GD, de Reilingh TS, Wegdam JA, Nieuwenhuijzen G, Rutten H, de Hingh I, Hiligsmann M, Buurman WA, Luyer $M$. The effects of stimulation of the autonomic nervous system via perioperative nutrition on postoperative ileus and anastomotic leakage following colorectal surgery (SANICS II trial): a study protocol for a double-blind randomized controlled trial. Trials. 2015 Jan 27;16(1):20. 
Curriculum vitae 



\section{Curriculum Vitae}

Boudewijn Jacobus Joseph Smeets werd geboren te Oss (Noord-Brabant) op 15 juli 1990. Hij behaalde zijn Gymnasium diploma op het Titus Brandsma Lyceum in 2008, en ging daarna Geneeskunde studeren aan de Universiteit van Maastricht. Na het behalen van zijn artsendiploma in 2014 volgde een promotietraject bij de afdeling Chirurgie in het Catharina Ziekenhuis in Eindhoven, onder begeleiding van Misha Luyer, Harm Rutten, en Petra Boelens. Na 2,5 jaar met veel plezier als fulltime arts-onderzoeker te hebben gewerkt, startte hij in augustus 2017 als arts-assistent Chirurgie in het Catharina Ziekenhuis. Een jaar later maakte hij de overstap naar het Máxima Medisch Centrum, Veldhoven, waar hij tot op heden met veel genoegen werkt als arts-assistent Chirurgie. In zijn vrije tijd houdt hij van hockey, wielrennen, motorrijden en reizen. 
Dankwoord 



\section{Dankwoord}

Tot slot wil ik graag iedereen bedanken die direct of indirect heeft bijgedragen aan de totstandkoming van dit proefschrift. Zonder jullie hulp was me dit nooit gelukt; ik ben jullie allen ontzettend dankbaar!

Allereerst wil ik alle patiënten bedanken die hebben geparticipeerd aan het klinisch wetenschappelijk onderzoek dat in dit proefschrift wordt beschreven. Dit proefschrift is in de eerste plaats aan jullie te danken. Velen van jullie zijn vanwege verschrikkelijke ziektes geopereerd; we zullen er alles aan blijven doen om de zorg rondom darmchirurgie verder te verbeteren!

Beste Misha. Als semi-arts bood jij mij in 2014 de kans om zowel mijn klinische als wetenschappelijke stage in het Catharina ziekenhuis te komen doen. Ik had in het begin nooit gedacht dat daar uiteindelijk dit werk uit zou voortkomen! Gedurende de afgelopen jaren ben je een groot voorbeeld geweest als mijn directe begeleider in dit promotietraject, en nog steeds blijf ik veel leren van je immer kritische blik. Je stimuleert me om altijd in grote lijnen te denken, en mede door jouw gedrevenheid is mijn enthousiasme voor chirurgie en wetenschappelijk onderzoek zo gegroeid. Ik hoop de komende jaren nog veel van je te mogen leren. Bedankt voor alles!

Professor Rutten, beste Harm. Zowel in onderzoek als in de kliniek verdient u veel respect van niet alleen de promovendi en arts-assistenten, maar ook van uw directe collega chirurgen in het Catharina Ziekenhuis en daarbuiten. De afgelopen jaren heb ik mij in datzelfde groepje geschaard. Met uw ervaring, rust en relativeringsvermogen bent $u$ een voorbeeld zowel in de kliniek als bij mijn promotie. Ik wil u hartelijk danken voor alle hulp en ondersteuning, en hoop dat ik nog meer van u mag blijven leren de komende tijd.

Beste Petra, onze samenwerking begon nadat ik een presentatie namens jou mocht geven op het Nationale Voedingscongres. De aanvullende onderzoeken met data van de gerandomiseerde studie die je eerder hebt gepubliceerd bleken van grote toegevoegde waarde voor dit proefschrift. De manier van samenwerken en kopjes koffie in Breda vond ik altijd erg leuk, en je oprechte interesse in mijn klinische loopbaan waardeer ik enorm. Ontzettend bedankt voor alle begeleiding en vertrouwen!

Beste leden van mijn leescommissie en corona, te weten professor Stassen, professor Beets, professor Masclee, professor de Wilt, dr. Dekker, professor Bouvy, en dr. Slooter. Zonder uw kritische blik en vragen zou ik deze promotie niet kunnen volbrengen. Dank voor alle tijd en moeite die u hebt opgebracht! 
Beste Emmeline. Gedurende mijn tijd als semi-arts heb je me wegwijs gemaakt in de opzet en achtergrond van de SANICS II studie. Toen ik aansloot had je al veel werk verricht in bijvoorbeeld de subsidie aanvragen. Ik prijs mezelf erg gelukkig dat ik met dat geld nadien kon aanblijven als arts-onderzoeker, en met jou de SANICS II tot een succesvol einde heb kunnen brengen. De samenwerking in het uitvoeren van de studie en het schrijven van artikelen was altijd erg prettig. Bedankt voor alles, en heel veel succes met je loopbaan in de radiotherapie!

Professor de Jonghe, beste Wouter. Samen met Misha heb je aan de basis gestaan van de SANICS II trial, en daarmee tevens aan de basis van de promotie van Emmeline en die van mijzelf. Ik kon altijd rekenen op een scherpe, kritische blik als ik je een manuscript toestuurde, en met je feedback werden de stukken altijd beter. Ik wil je hartelijk danken voor alle hulp!

Graag wil ik mijn grote dank uitspreken aan alle anderen die de uitvoering van de SANICS II trial mogelijk hebben gemaakt, waaronder dr. Slooter, dr. Leclercq, dr. Wegdam, dr. De Vries Reilingh, dr. Nieuwenhuijzen, dr. De Hingh, dr. Nienhuijs, Anton, Antje, Marloes, Eelco, Claudia, Daan, Juliette, Richard, Fenne, Jitske, Maxime, Maartje, Rick, Rudaba, Reshab, en iedereen van het lab, de afdeling pathologie, de $\mathrm{OK}$, en de verpleegafdelingen. Zonder jullie hulp en ondersteuning hadden we de SANICS II studie nooit zo goed kunnen uitvoeren; jullie inzet is van ontschatbare waarde geweest. Hartelijk bedankt!

To all our Danish colleagues who helped to perform the SANICS II trial in Århus, Randers, and Viborg, including Jesper Nors, Christian Back, professor Søren Laurberg, Jonas Funder, Thorbjørn Sommer, Uffe Løve, Rikke Demming, and all others. Your efforts were of crucial importance in the success of the SANICS II trial. Thank you for all the help and hard work, and for making our stay in Denmark so pleasant! I hope this may serve as a basis from which we can continue our successful collaboration.

Beste Daan en Gijs. Meer dan 10 jaar nadat we elkaar hebben leren kennen in Maastricht, gaan jullie me nu bijstaan als paranimfen tijdens de verdediging van mijn proefschrift. Van mooie borrels met de jaarclub, tot het samen uitvoeren van wetenschappelijk onderzoek en trainen voor de Alphe d'Huzes; het is samen altijd erg gezellig, jullie vriendschap is me veel waard. Dank voor al jullie hulp in het realiseren van dit proefschrift, en dat we nog maar vele jaren plezier mogen maken!

Alle collega arts-onderzoekers van het CZE; David, Thijs, Martin, Yannick, Marijn, Koen, Dennis, Checca, Anneroos, Desley, Sandra, Eva, Laura, Poodt, Nina, en Niels. De dagen in de kelder en later de zolder konden soms lang zijn, maar waren 
dankzij jullie ook altijd erg gezellig! Samen konden we een gezonde balans houden tussen hard werken en tijdig pauze nemen waarbij de bakjes pleur altijd rijkelijk vloeiden! Dank voor jullie steun en gezelligheid!

Aan alle collega arts-assistenten in het Catharina Ziekenhuis. $\mathrm{Na}$ mijn onderzoeksjaren kon ik bij jullie mijn start maken in de kliniek. Zowel binnen als buiten het ziekenhuis maakten we altijd veel plezier op bijvoorbeeld de vrijmibo en het assistenenweekend! Het was een erg gezellige tijd en een topgroep om mee te werken in de kliniek. Dank voor alle gezelligheid en veel succes met jullie carrières!

Aan alle chirurgen in het Catharina Ziekenhuis. In 2014 begon ik mijn chirurgische carriere bij jullie als semi-arts, en ben nadien ook als arts-onderzoeker en arts-assistent in totaal ruim $4 \frac{1}{2}$ jaar gebleven. Gedurende deze periode heb ik veel van jullie geleerd en kon ik altijd rekenen op steun in de kliniek en voor het onderzoek; ik wil jullie daarom allen hartelijk danken voor de fijne samenwerking!

Aan alle arts-assistenten in het Máxima Medisch Centrum. Na mijn periode bij het CZE heb ik ook in Veldhoven een leuke groep collega's leren kennen waar ik iedere dag heel prettig mee kan samenwerken. Vooral tijdens het Chirurgenweekend hebben we erg veel gelachen! Stefan, als collega artsonderzoeker in de colorectale chirurgie kon ik altijd op je rekenen om even te sparren over het onderzoek, of als er iets moest worden nagekeken voor de SANICS II studie in Veldhoven. Dank voor al jullie hulp en gezelligheid, het ga jullie goed!

Aan alle chirurgen van het Máxima Medisch Centrum. Jullie zijn een hechte groep collega's die met elkaar garant staan voor een prettige sfeer en goede zorg. Tegelijkertijd staat de overdracht van kennis naar ons, arts-assistenten, hoog in het vaandel. Ik wil jullie ontzettend bedanken voor alles wat ik tot nu toe heb mogelijk leren en voor de fijne samenwerking.

Beste Dirk, Daan, Nick, Wouter, Rishy, en Kirolos. Met jullie heb ik een fantastische tijd gehad in het Titus Brandsma Lyceum. Het feit dat we nu nog zo kunnen lachen, bewijst hoe hecht onze vriendschap is! Beste Timster, Ballie, Leon, Soppie, Ief, Fiek, Kesler, Groot, Karrie, Rennie, en Pio; dank voor de mooie tijd die we als Sociëteitscommissie B.U.N.K.E.R. hebben gehad, en nog steeds met elkaar hebben! Beste Gijs, Daan, Bas, Rik, Erik, Tibor, Reinoud, Alexander, Tibor, Olav, Lars; mijn maten van HJC Coïtus Caelestis \#1! Dank voor alle gezelligheid en prominentie! Beste Lieke, Fons, Joost, Joris, Lotte, Louise, Maaike, Nils, Ruben en Simone; dank voor de mooie borrels in Zuid-Afrika en Nederland.

Juist door tijd vrij te blijven nemen om met jullie allemaal leuke dingen doen, blijf je als promovendus gemotiveerd om je onderzoek af te ronden en het proefschrift te 
voltooiien. Laten we dit de komende jaren dan vooral ook voortzetten, zodat we nog veel feest en plezier met elkaar kunnen maken! Proost!

Beste Marienoëlle, Walther, Roël, Dirren, en overige familie Tibosch en familie van der Doelen. Ik heb me vanaf het eerste moment zeer welkom gevoeld in jullie familie. De verjaardagen en etentjes in Berlicum zijn altijd enorm gezellig, en de bezoekjes, kaartjes, en cadeaus zijn altijd even attent. Ik prijs mezelf zeer gelukkig met zo'n fijne schoonfamilie; dank voor al jullie steun en hartelijkheid.

Lieve mam, André, Vincent en alle anderen van mijn dierbare familie. Hoe fijn het ook is om de successen en het geluk van het leven met jullie te mogen delen; het zijn juist de moeilijkere momenten waarin je het meeste aan elkaar hebt. Dankzij jullie onvoorwaardelijke liefde en steun voelde ik me gesterkt om door te gaan in die tijden dat het even tegenzat. Bedankt voor jullie hulp en ondersteuning door de jaren heen, ik houd van jullie!

Lieve pap. Helaas kun je er niet meer bij zijn om dit succes samen te vieren. Weet dat jouw doorzettingsvermogen en onvoorwaardelijke liefde voor mij altijd een grote steun is geweest. Ondanks dat je zelf een zware tijd hebt moeten doorstaan, bleef je tot aan het einde geïnteresseerd in mijn leven en welzijn. Als ik aan je denk voel ik hoe trots je zou zijn geweest. Pap, dit boek draag ik op aan jou.

Lieve Romée, jij hebt als geen ander ervaren hoe saai het kon zijn als ik thuis zat te werken om dit proefschrift uiteindelijk af te kunnen maken. De momenten waarin we wel samen leuke dingen doen, maken alles de moeite waard! Vooral tijdens onze reizen blijf ik me verbazen hoe gemakkelijk we samen kunnen genieten van mooie dingen in het leven. Ik wil je ontzettend bedanken voor je geduld en steun; zonder dat was dit werk nooit gelukt! 